\title{
DEVELOPMENT AND IMPLEMENTATION OF DISPERSION PHASE DIAGRAMS (DPDS) FOR FOUR DIFFERENT HYDROPHOBICALLY MODIFIED ETHOXYLATED URETHANE (HEUR) BASED ACRYLIC PAINT SYSTEMS
}

\author{
A Project Report \\ presented to
}

the Faculty of California Polytechnic State University,

San Luis Obispo

\begin{abstract}
In Partial Fulfillment
of the Requirements for the Degree

Master of Science in Polymers and Coatings
\end{abstract}

by

Tyler James Bell

June 2014 
(C) 2014

Tyler James Bell

ALL RIGHTS RESERVED 
COMMITTEE MEMBERSHIP

TITLE:

Development and Implementation of Dispersion Phase

Diagrams (DPDs) for Four Different Hydrophobically

Modified Ethoxylated Urethane (HEUR) Based Acrylic

Paint Systems

AUTHOR: $\quad$ Tyler James Bell

DATE SUBMITTED: June 2014

COMMITTEE CHAIR: Raymond H. Fernando, PhD

Professor of Polymers and Coatings

COMMITTEE MEMBER: Jason S. Ness, PhD

Senior Scientist of The Valspar Corporation

COMMITTEE MEMBER: Corinne Lehr, PhD

Associate Professor of Chemistry and Biochemistry 


\begin{abstract}
Development and Implementation of Dispersion Phase Diagrams (DPDs) for Four Different Hydrophobically Modified Ethoxylated Urethane (HEUR) Based Acrylic Paint Systems
\end{abstract}

Tyler James Bell

Latex polymers serve as binders in a wide range of architectural paints and coatings. A latex is an aqueous colloidal dispersion of polymer particles that when dried above the polymer's film formation temperature coalesces into a dry polymer film (Dragnevski, Routh, Murray, \& Donald, 2010). The other main components of paint include associative thickeners, surfactants, pigments and fillers with the thickener being the primary area of focus for this study.

The relatively simple system of latex, associative thickener and surfactant has been studied extensively. These studies have shown the mechanism of thickening for the associative thickener, and surfactant effects on both latex and thickener; however, there are few studies conducted for a fully-formulated system. The introduction of pigments, fillers, coalescing aids, functional amines, and other additives greatly increases the difficulty of research in this area. The addition of many additives ultimately affects the stability and physical properties of the end-product. Phase separation of the paints, also called syneresis, is a major concern of paint formulators because paints need to be as stable when left sitting in a paint-can for an extended period of time. The goal of this 
project is to essentially probe the areas of phase separation for some hydrophobically modified ethoxylated urethane (HEUR) thickened paint systems that are very similar to commercially used paint formulations. The probing of these phase separated regions includes the careful preparation of each paint sample, physical property testing, as well as new experimental development in the area of syneresis, rheology, followed by statistical analysis of data.

Dispersion phase diagrams (DPDs) were first reported by Kostansek (2003) in a simple system of HEUR thickener, surfactant, and latex. They are a plot of the three possible dispersion states for an associative thickened system. These states include bridging flocculation which occurs at low levels of HEUR in which $50 \%$ or less of the latex particle surface is covered by the associative thickener. The second state is a good dispersion, which does not show any signs of flocculation. The third state is a mode of flocculation called depletion flocculation that occurs when the particle surfaces of the system are covered mostly with surfactant. The free associative polymer in the system is excluded from the free space in between particles, and the latex particles form aggregates (Otsubo, 1995). The three dispersion phases are then plotted with wt\% HEUR on the continuous phase versus wt $\%$ surfactant on the continuous phase. The ideal end product for this project would be to use various combinations of latex, surfactant, and associative thickeners (ATs) to create multiple DPDs, which then could be used to troubleshoot formulations and samples in which flocculation is present.

Each formulation was made using a thickening package of two non-ionic HEURs: a lowshear and high-shear thickener. Surfactant additions were made after the HEUR in small incremental amounts. Each DPD would consist of one surfactant, the previously stated combination of HEURs, and an all-acrylic latex. Three different surfactants were used in the study: two non-ionic surfactants, and an anionic surfactant. The first non-ionic 
surfactant was not studied in full as the other two surfactants due to time constraints. Two different all-acrylic latexes were used which varied in the particle size. The first latex studied, Acrylic-A, has an average particle size of $105 \mathrm{~nm}$, and the second latex was Acrylic-B with $150 \mathrm{~nm}$ particle size. The $\mathrm{TiO}_{2}$ used in each DPD was surface treated and used in powder form. By the end of the project, 4 full-scale DPDs were made with the following combinations: Acrylic-A and a non-ionic surfactant, Acrylic-A and an anionic surfactant, Acrylic-B and a non-ionic surfactant, and Acrylic-B and an anionic surfactant. From these DPDs the mechanistic interactions of various components of the system could be made. The DPDs could also be used to troubleshoot problematic paints and even hypothesize new formulations. 


\section{ACKNOWLEDGMENTS}

First off, I would like to thank my advisor Dr. Raymond Fernando of Cal Poly State

University. The knowledge and expertise learned from Dr. Fernando propelled me into the person I am today. I would also like to thank him for setting up thesis work that was conducted at The Valspar Corporation. The industrial experience has been life-changing and has been essential to my both my educational and professional experience.

Second, I would like to thank Dr. Jason Ness at The Valspar Corporation. His hardworking and intelligent nature pushed me to the level needed to complete a master's degree. He challenged me to be a better scientist, and promoted skills that will be essential for me to succeed in the professional world.

Lastly, I would like to thank some Valspar folk who helped me along the way. Karl Booth and Steve Korenkiewicz were the support that made my project go. Their professional advice and guidance assisted me the entire project and I am truly grateful for their help. I would also like to thank Carrie Street for her rheometer assistance and overall positive personality. The last thanks is for the entire resin group at Valspar. Every person in the resin group made me feel right at home and created a great working environment.

Of course, none of this would have been possible without the Cal Poly Polymer's and Coatings Program. Everyone that has helped me along the way through this program has got me where I am today. 
Table of Contents

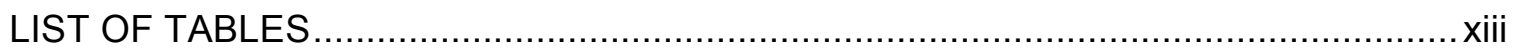

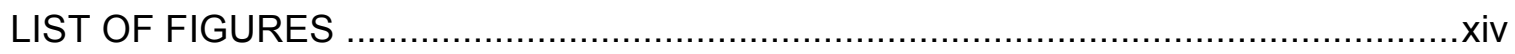

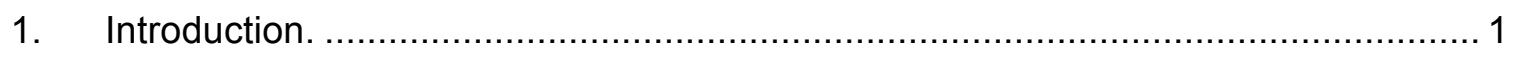

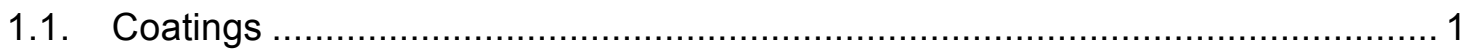

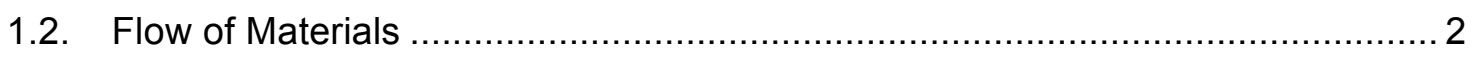

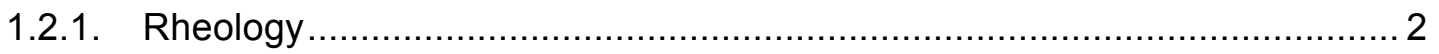

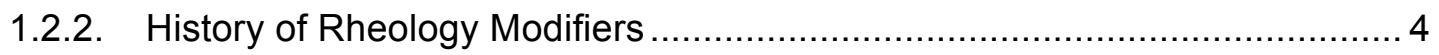

1.3. Thickeners, Surfactants, Latex, Pigments, and their Interactions. .................... 7

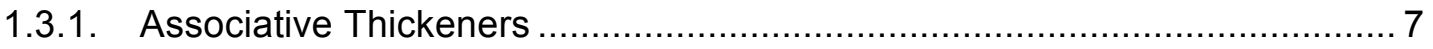

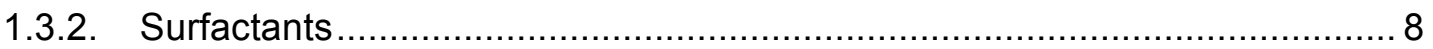

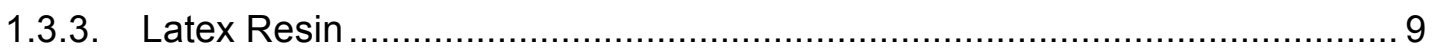

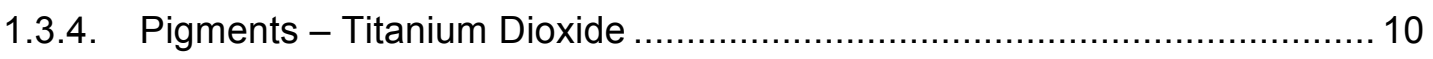

1.3.5. Interactions and Network Formation Theories ....................................... 12

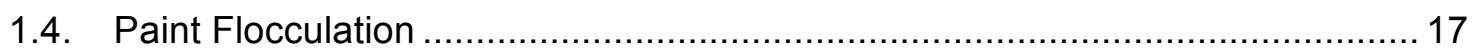

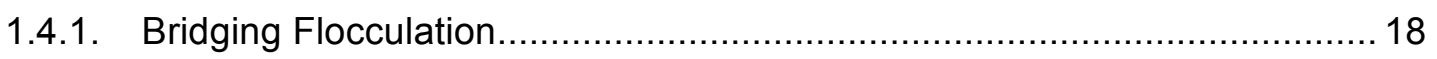

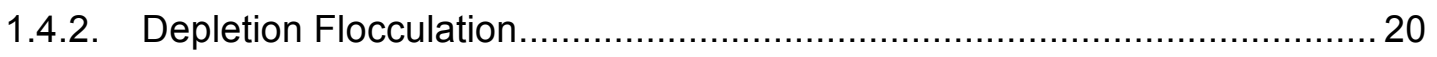

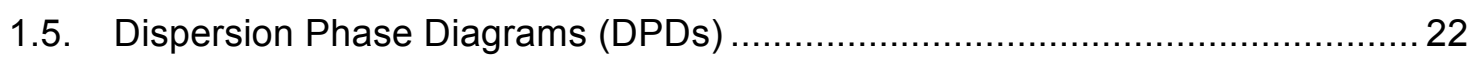

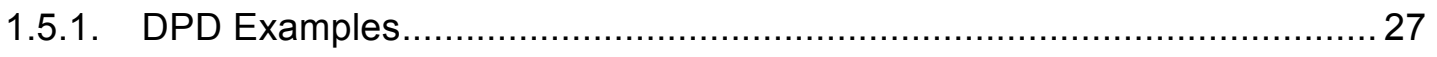

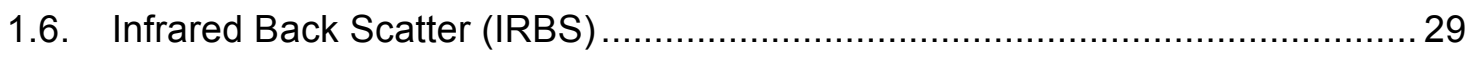

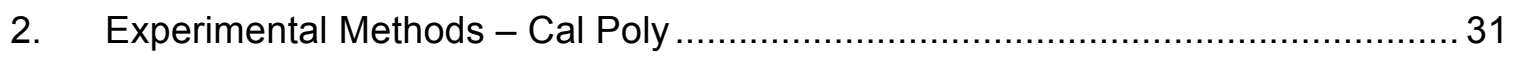

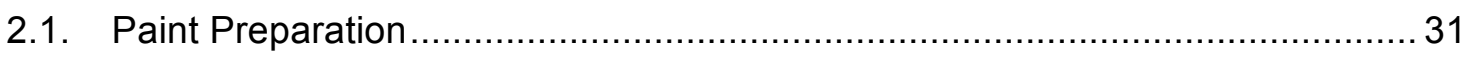

2.1.1. 166A - 0.26\% HEUR Starting Batch ...................................................... 31

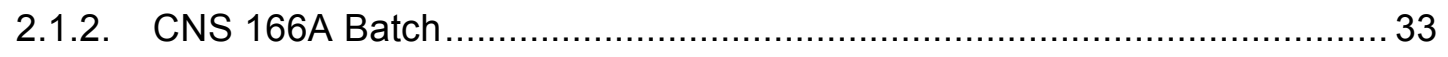

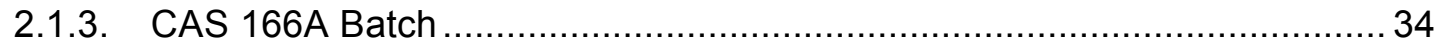

2.1.4. 167A - 1.33\% HEUR Starting Batch...................................................... 34

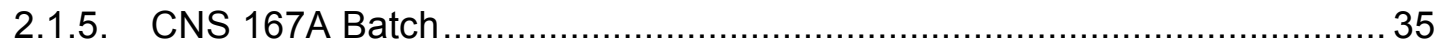

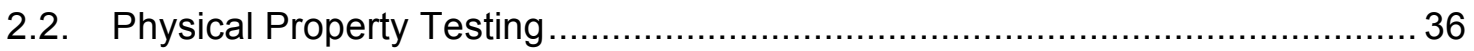




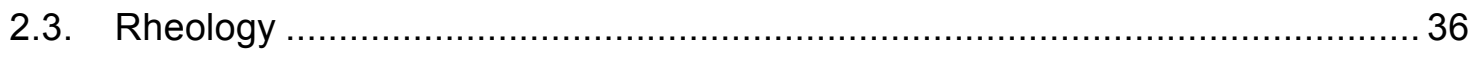

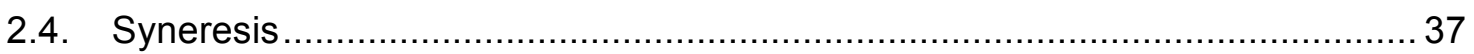

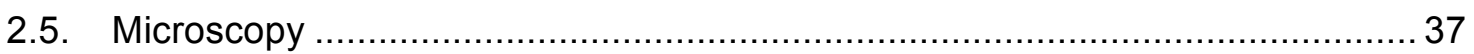

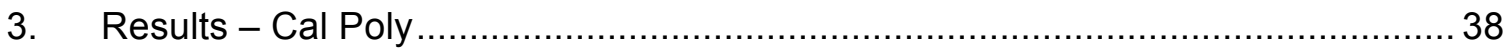

3.1. CNS 166A - Non-ionic Surfactant Additions to 0.26\% HEUR Batch.................. 38

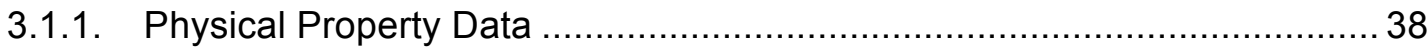

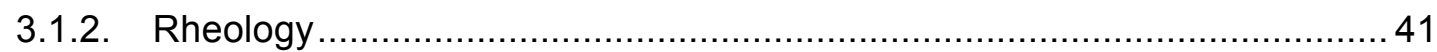

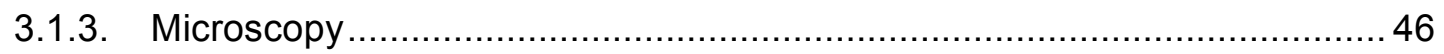

3.2. CAS 166A - Anionic Surfactant Additions to 0.26\% HEUR Batch .................... 48

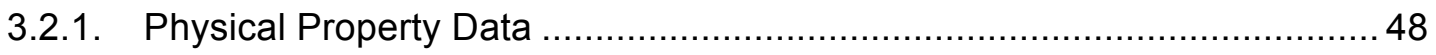

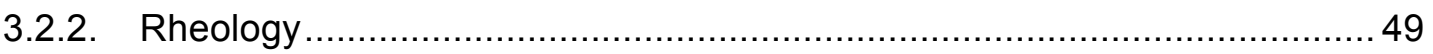

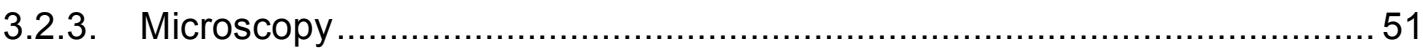

3.3. CNS 167A - Non-ionic Surfactant Additions to 1.33\% HEUR Starting Batch ... 52

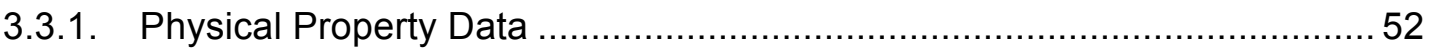

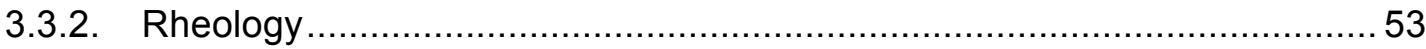

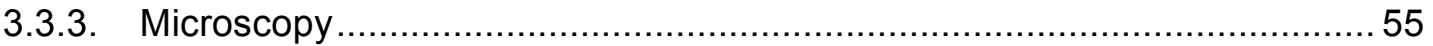

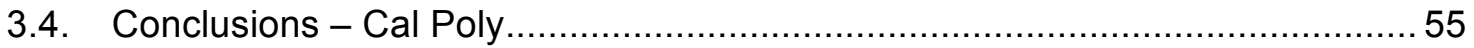

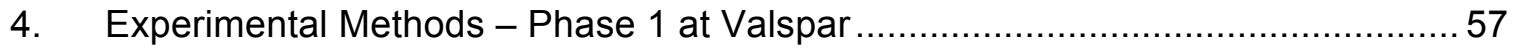

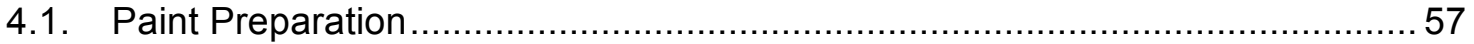

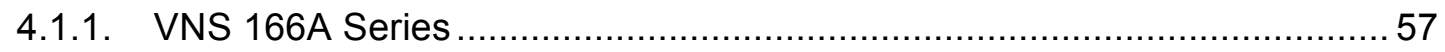

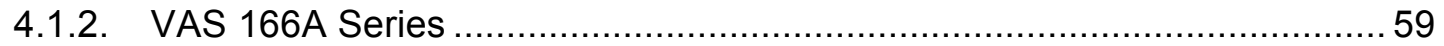

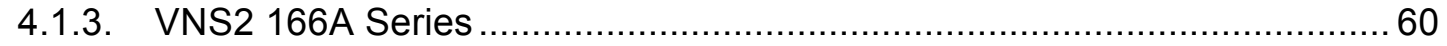

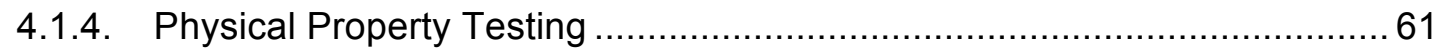

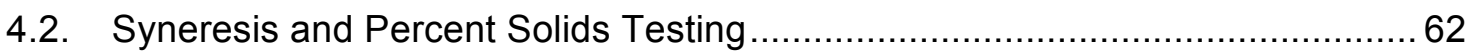

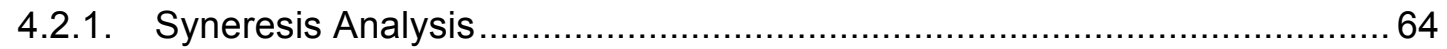

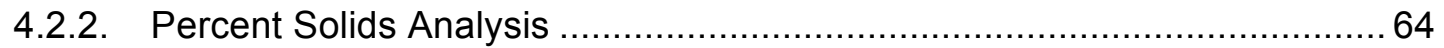

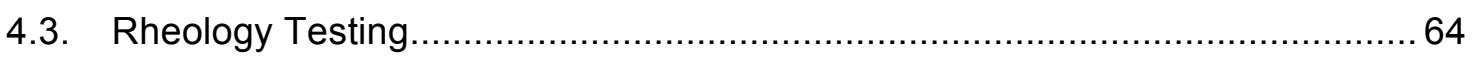

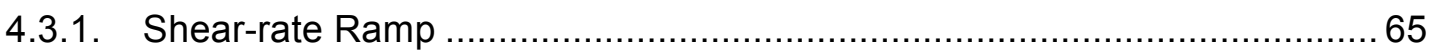

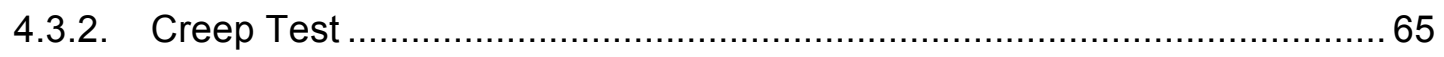

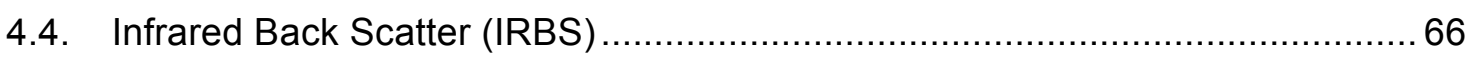

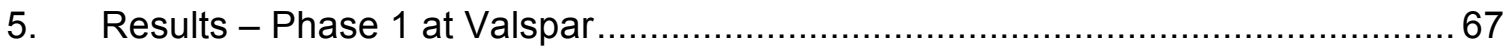




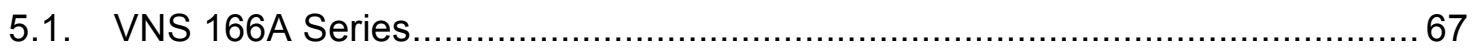

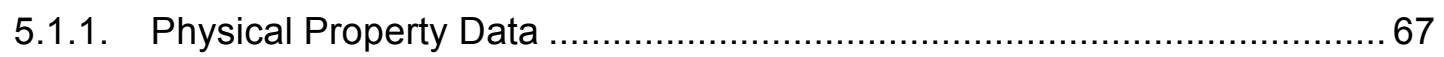

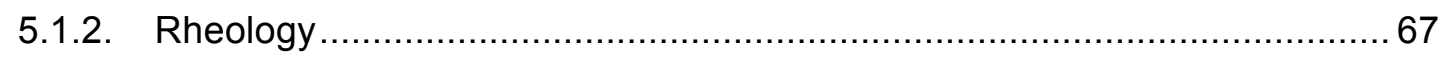

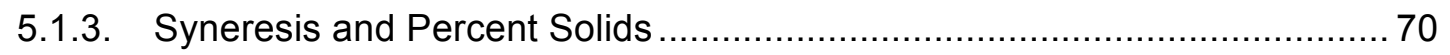

5.1.4. VNS 166A Series Flocculation Determination and DPD ......................... 71

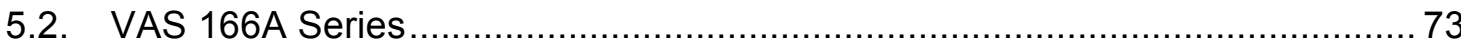

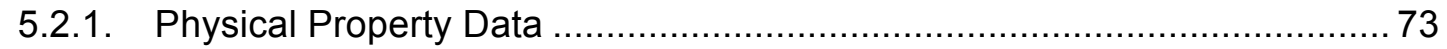

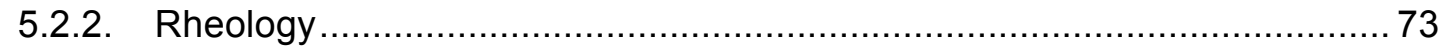

5.2.3. Syneresis and Percent Solids .................................................................. 74

5.2.4. VAS 166A Series Flocculation Determination and DPD ........................... 74

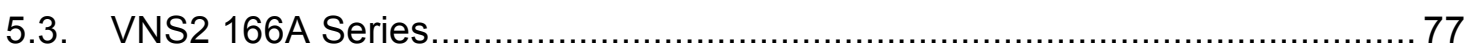

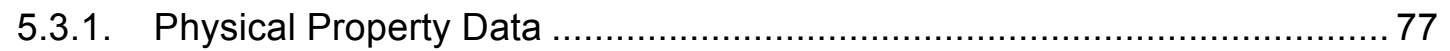

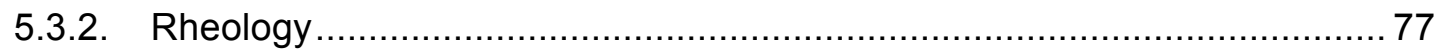

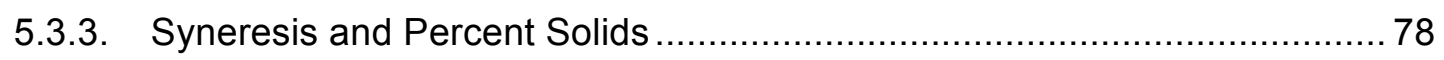

5.4. Testing Analysis - Improvements and Changes .................................. 79

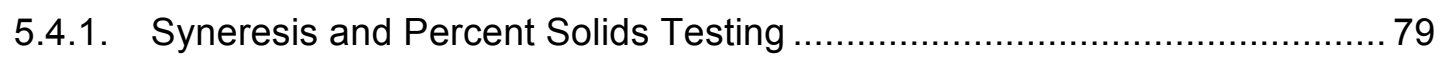

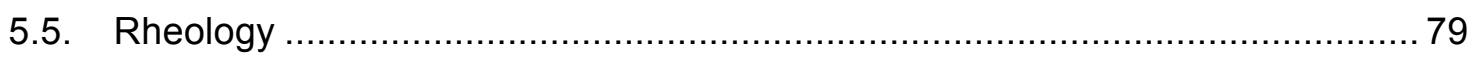

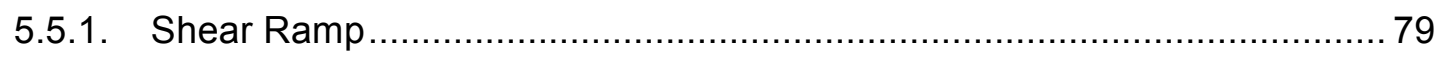

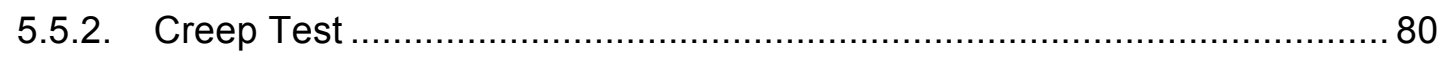

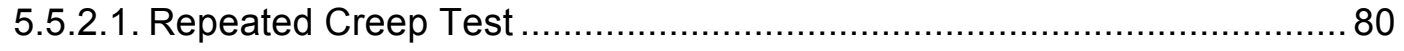

5.5.2.2. Repeated Creep Test \#2 ................................................... 81

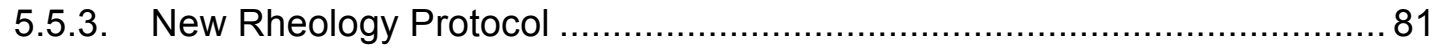

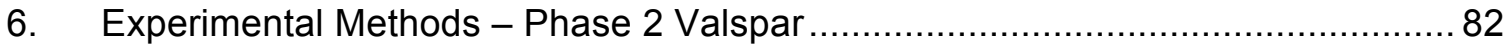

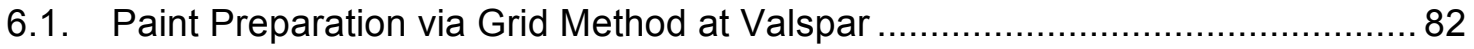

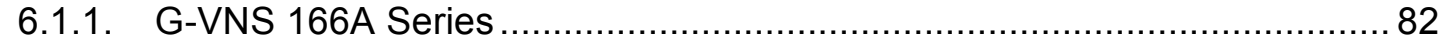

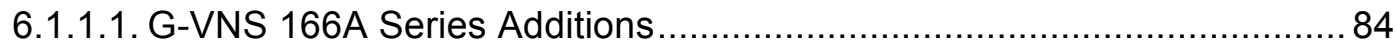

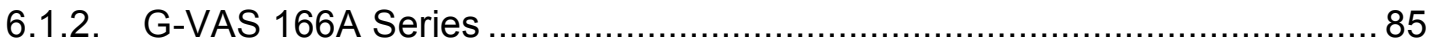

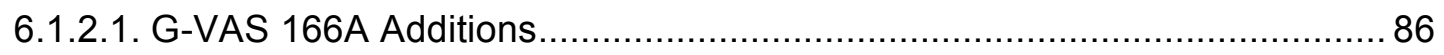

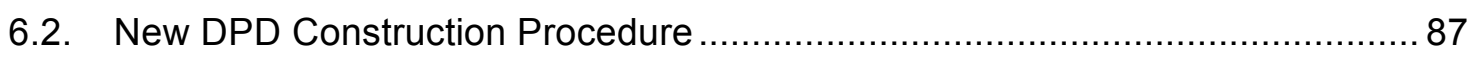

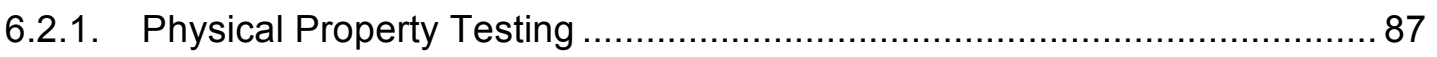

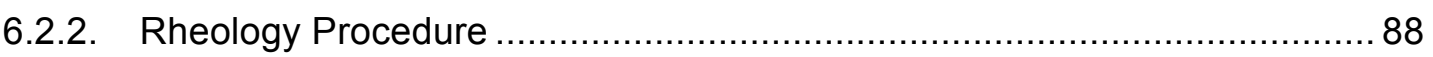




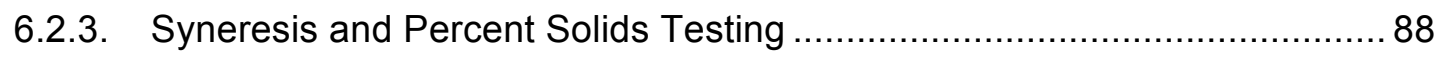

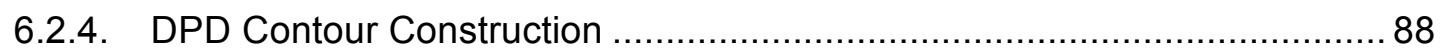

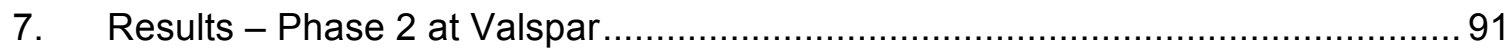

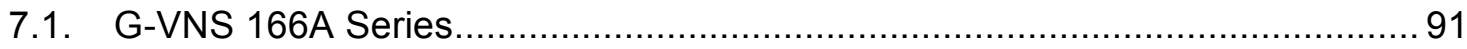

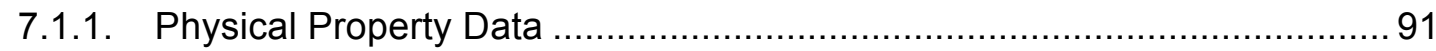

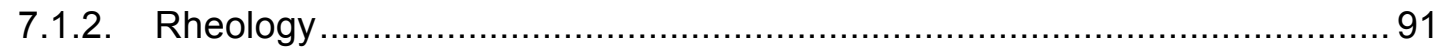

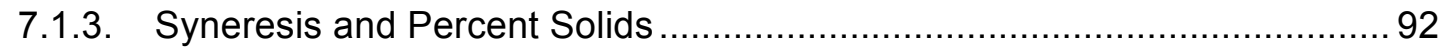

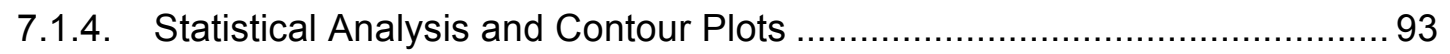

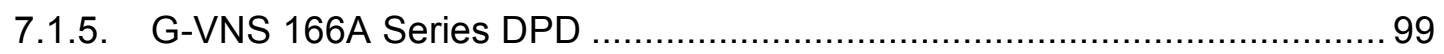

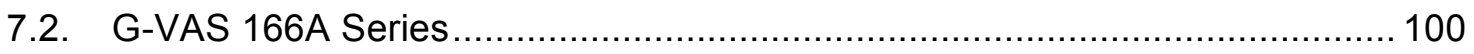

7.2.1. Physical Property Data .......................................................... 100

7.2.2. Syneresis and Percent Solids ....................................................... 100

7.2.3. Statistical Analysis and Contour Plots .......................................... 100

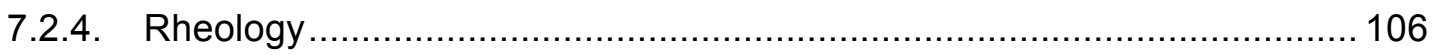

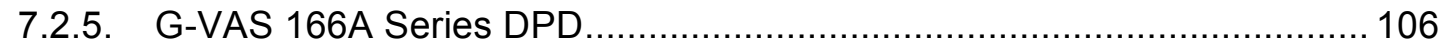

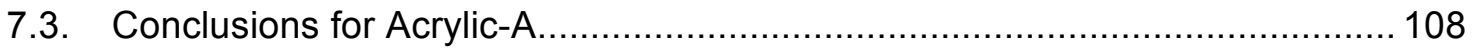

8. Experimental Methods - Phase 3 at Valspar .............................................. 109

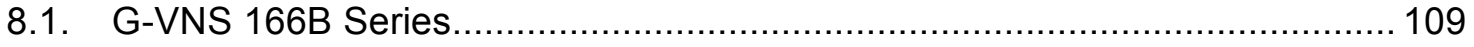

8.1.1. G-VNS 166B Series Troubleshooting ............................................ 110

8.2. G-VNS 166A Series Paint Preparation ................................................ 111

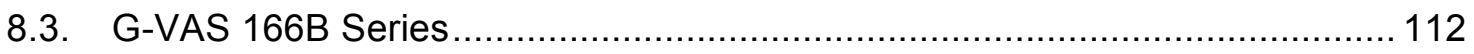

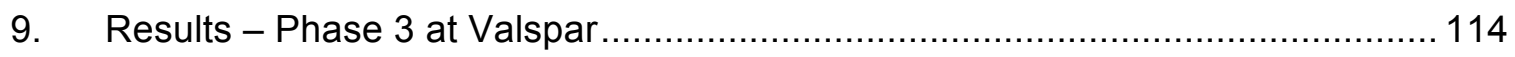

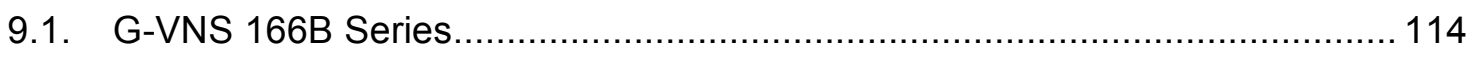

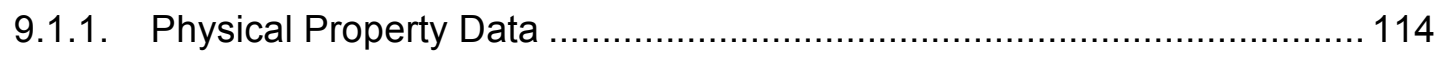

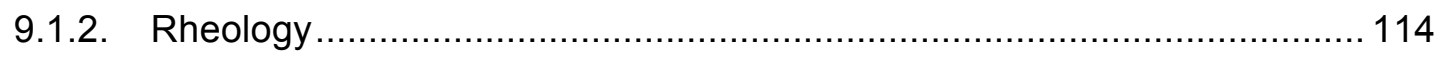

9.1.3. Syneresis and Percent Solids ......................................................... 115

9.1.4. Statistical Analysis and Contour Plots ................................................ 116

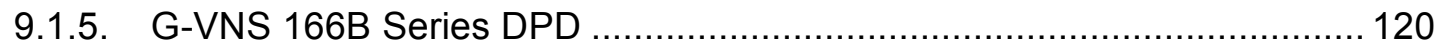

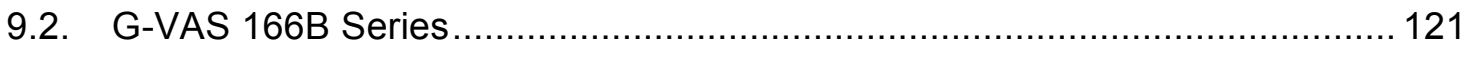

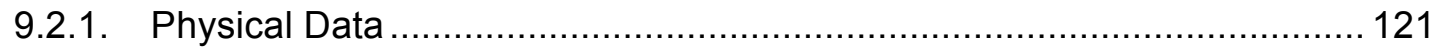

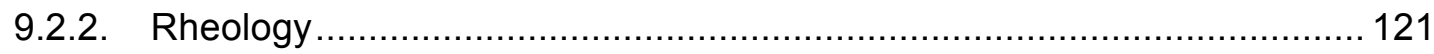




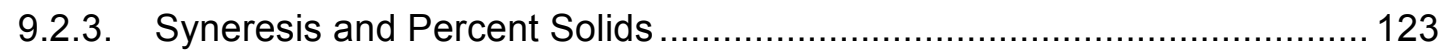

9.2.4. Statistical Analysis and Contour Plots ............................................ 123

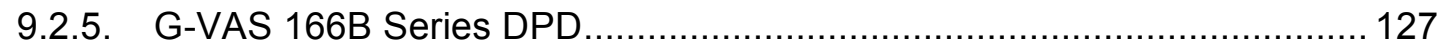

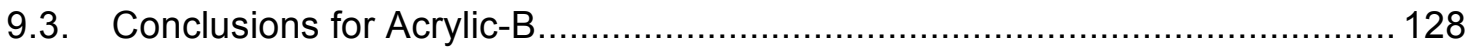

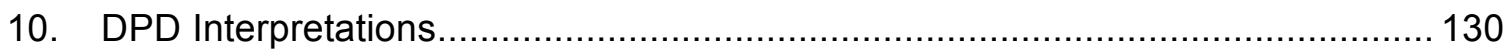

10.1. KU Contour Comparison ......................................................... 130

10.2. 60 Degree Gloss Contour Comparison ........................................... 132

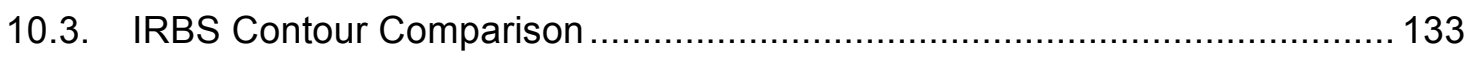

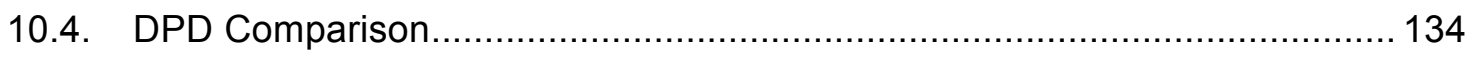

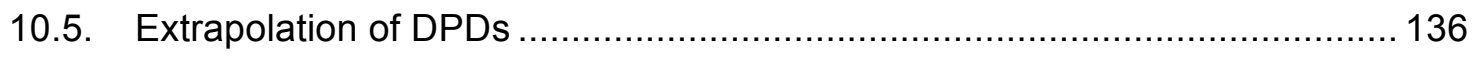

10.5.1. Change Hydrophobicity of Thickener.............................................. 136

10.5.2. Adjust Surfactant for the Latex.................................................. 137

10.5.3. Change Hydrophobicity of Surfactant .......................................... 137

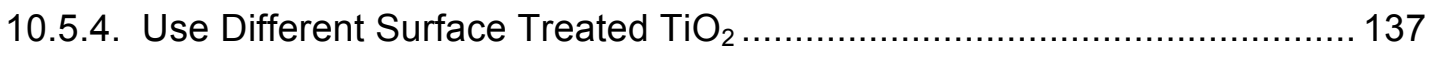

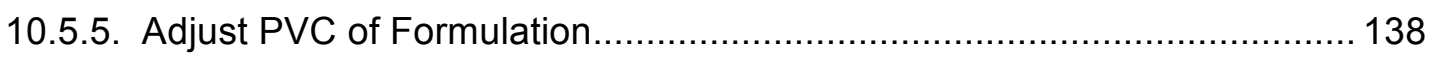

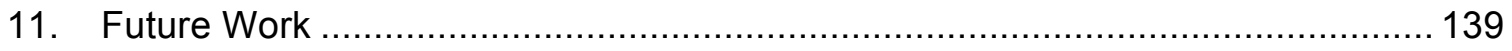

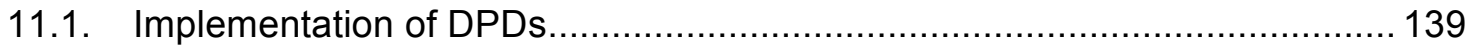

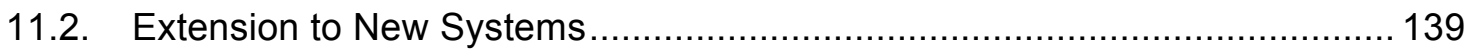

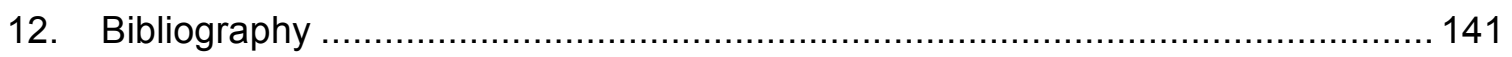

13. Appendix A: Sample, Call Names, and Wt\% HEUR and Surfactant for Each

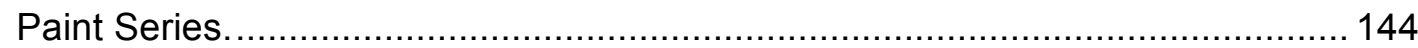

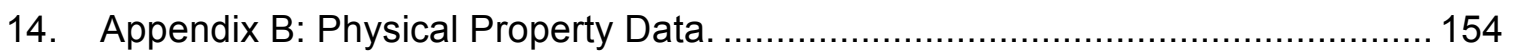

15. Appendix C: Syneresis and Percent Solids Data ........................................ 168

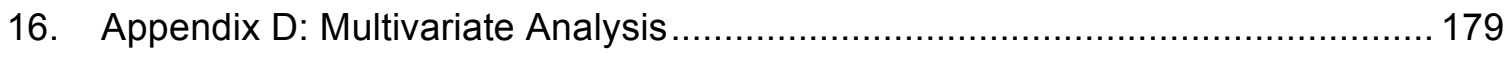




\section{LIST OF TABLES}

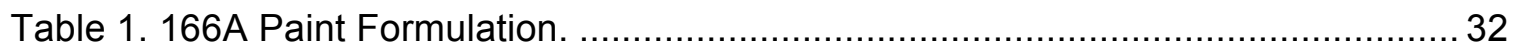

Table 2. Wt\% HEUR and surfactant for Surfactant-A additions to $166 \mathrm{~A}$. ......................... 34

Table 3. Wt\% HEUR and surfactant for the Surfactant-B additions to $166 \mathrm{~A}$. ................ 34

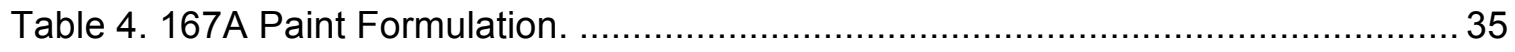

Table 5. Wt\% HEUR and surfactant additions for the Surfactant-A additions to

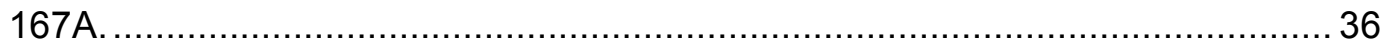

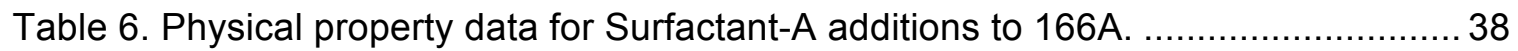

Table 7. Physical property data for anionic additions of Surfactant-B to $166 \mathrm{~A}$.............. 48

Table 8. C167A to C167E Physical Property Data. ................................................ 53 


\section{LIST OF FIGURES}

Figure 1. Shear stress vs. shear rates for different types of liquids (Wicks, Jones,

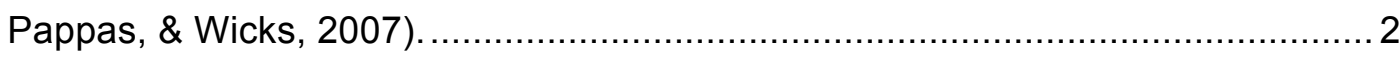

Figure 2. Plots representing four different types of creep responses. The figures are represented as such: (a) an ideal elastic solid, (b) Newtonian fluid, (c) a viscoelastic sample with cross-linking (complete recovery), and (d) a viscoelastic sample lacking complete recovery (Wicks, Jones, Pappas, \& Wicks, 2007).

Figure 3. Schematic for the different pigment and latex dispersion states.

Dispersion (a) shows a non-associative system in which the pigment (black circles) and latex (blue circles) are co-flocculated and phase separated from the thickener and continuous phase. Dispersion (b) represents a welldispersed system where both pigment and latex particles are uniformly dispersed. Dispersion (c) shows an ineffective dispersant which resulted in flocculated pigment surrounded by a well-dispersed latex. Dispersion (d) shows a different case in which well-dispersed pigment is surrounded by flocs of latex (Kostansek, 2007). 6

Figure 4. General structure of a HEUR associative thickener (Saucy, 2008). 7

Figure 5. Schematic showing the traditional theory for the formation of a transient network of a fully formulated HEUR thickened system (Münzenberg, 2011)

Figure 6. Simple schematic of the old (left) and current model (right) based on PFGNMR results for $1 \%$ HEUR and $30 \%$ latex composite. Small black dots represent hydrophobic end groups of HEUR molecules (Beshah, Izmitli, Van Dyk, Rabasco, \& Bohling, 2013). 
Figure 7. Schematic representation of the hydrodynamic volumes of low and high molecular weight thickeners that are adsorbed onto the latex surface (Saucy, 2008)

Figure 8. Bridging flocculation via a direct bridge is typical at lower level of polymer in the bridging flocculation region. 19

Figure 9. Bridging flocculation induced by inter-chain (flower micelle) associations. 19

Figure 10. TEM image showing depletion flocculation of latex with a nonassociative thickener (Saucy, 2008).

Figure 11. Simplified schematic for depletion flocculation of a thickened latex system 22

Figure 12. Idealized DPD showing the three possible regions for a simple system containing latex, thickener, and surfactant (Kostansek, 2003). 23

Figure 13. Shows microscopy pictures of three different systems: $A$ - an unthickened latex, B - low wt\% HEUR thickened latex in a bridging flocculation state, C - HEUR thickened system in a good dispersion (Kostansek 2003).

Figure 14. Shows the micrograph of a mixed sample depleting over a 20 second period. (Kostansek 2003).

Figure 15. Interparticle potential energy diagram showing a good dispersion (on the left) and a depletion flocculation sample (on the right) (Kostansek, 2003)

Figure 16. Phase diagram for a $140 \mathrm{~nm}$ BA/MMA thickened with HEUR

(Kostansek, 2003). 27

Figure 17. DPD for a $300 \mathrm{~nm}$ BA/MMA with a high concentration of surface acid (Kostansek, 2003). 
Figure 18. DPD for a $300 \mathrm{~nm}$ BA/Styrene latex thickened with HEUR (Kostansek,

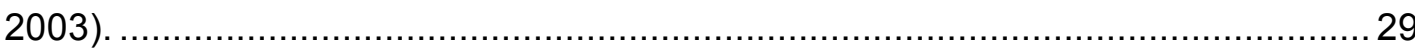

Figure 19. Syneresis tubes for CNS-1 to CNS-5 after one week of syneresis................... 39

Figure 20. Rheological data for 500 cps Newtonian oil control.................................. 42

Figure 21. Rheological data for HEC control and latex paint. .................................. 43

Figure 22. Rheological data for samples CNS-1 to CNS-5 ..................................... 44

Figure 23. Schematic showing extension of bridge with respect to CNS-1 rheology curve containing a shear-thickening region.................................................. 46

Figure 24. Microscopy pictures for samples CNS-1 to CNS-5 at 20x.......................... 47

Figure 25. Rheological data for samples CAS-1 to CAS-5 ...................................... 49

Figure 26. Syneresis tubes for CAS-1 to CAS-5 one week after samples were made. 50

Figure 27. Microscopy pictures for samples CAS-1 to CAS-5 at 20x. ............................ 52

Figure 28. Rheological data for samples CNS-6 to CNS-10 ....................................... 54

Figure 29. Microscopy pictures for samples CNS-6 to CNS-10 at 20x.........................55

Figure 30. Graph showing each sample made for the non-ionic surfactant addition of Surfactant-A and HEUR addition for the VNS 166A series. Each set of colored symbols represents a group of samples that were made from the same batch 58

Figure 31. Graph showing each sample made for the anionic surfactant addition of Surfactant-B and additions of high-shear HEUR thickener. Each set of colored symbols represents a group of samples that were made from the same $166 \mathrm{~A}$ batch. 60

Figure 32. Graph showing each sample made for the VNS2 166A series. Each set of colored symbols represents a group of samples that were made from the same 166A batch 
Figure 33. Step by step scheme for measuring percent solids of the top and bottom layer of a syneresis tube.

Figure 34. Creep results for PVP and PEO phase samples to show differences in phase separation. The PEO systems shown on top in black crosses had no recovery, where the bridging flocculation PVP systems all had noticeable relaxation (remaining three curves) (MacFarlane, Wagner, Kaler, \& Lynch, 2010) 66

Figure 35. Rheology results for the shifting of the maxima for the bridging flocculation region of the VNS 166A series.... 68

Figure 36. Rheology data for samples VNS-A9, VNS-A10, VNS-A11, VNS-A12, VNS-A13, and VNS-A15. VNS-A9 and VNS-A10 were concluded to be close to the boundary of the BF-region with all the other samples to be considered either a good dispersion or depletion flocculation sample.... 69

Figure 37. Flocculation determinations by each sample for the VNS 166A series (red squares - bridging flocculation, green triangle - good dispersion,

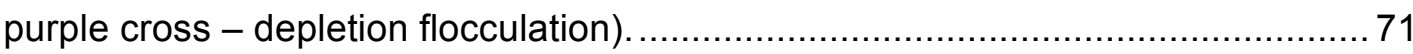

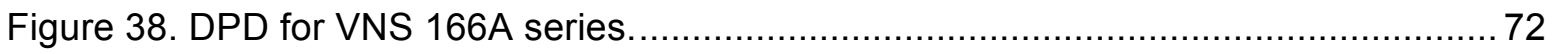

Figure 39. Rheology profiles for the VAS 166A series...................................... 74

Figure 40. VAS 166A series via flocculation type (red squares - bridging flocculation, green triangle - good dispersion, and purple crosses -

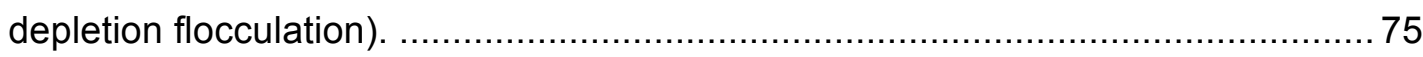

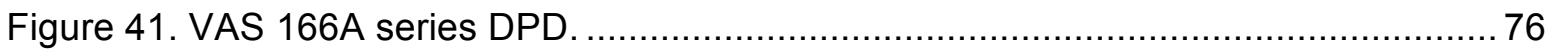

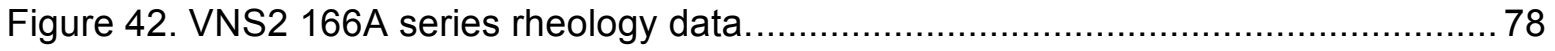

Figure 43. Graph showing the grid of samples made for the G-VNS 166A series. Each point represents and individual sample that was created within the data set. 83 
Figure 44. Initial set of additions for G-VNS 166A series are shown in blue

diamonds. 84

Figure 45. Second set of additions for G-VNS 166A series shown in blue diamonds. 85

Figure 46. Graph showing the grid approach for paint-making for the G-VAS 166A series. Each point represents an individual sample that was created within the data set. 86

Figure 47. Additional samples made to G-VAS 166A series are shown in red squares with the blue diamond's being the original samples. 87

Figure 48. Contour plot example for the DPD for Acrylic-A and Surfactant-A. ................ 89

Figure 49. Rheology results for the G-VNS 166A series. ................................... 92

Figure 50. 24 hour KU viscosity contour plot for G-VNS 166A series........................... 95

Figure 51. 60 degree gloss contour plot for G-VNS 166A series............................ 96

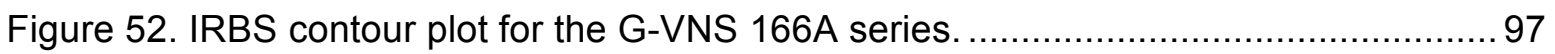

Figure 53. Conductivity contour plot for the G-VNS 166A series.............................. 98

Figure 54. DPD for G-VNS 166A series - green shows good dispersion, bridging flocculation in blue, and depletion flocculation in red. The system consists of Acrylic-A (105 nm), the non-ionic Surfactant-A, and a low- and high-

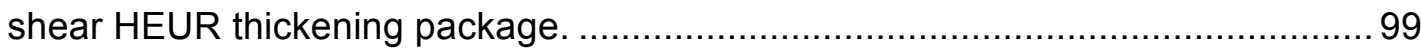

Figure 55. Contour plot for $24 \mathrm{hr}$ KU viscosity for the G-VAS 166A series..................... 101

Figure 56. Contour plot for 60 degree gloss for the G-VAS 166A series....................... 102

Figure 57. Contour plot for conductivity for the G-VAS 166A series............................ 104

Figure 58. Contour plot for IRBS for the G-VAS 166A series. ...................................... 105

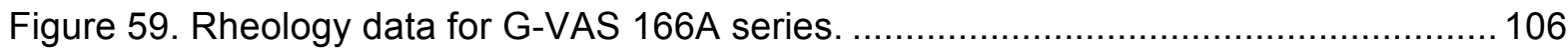

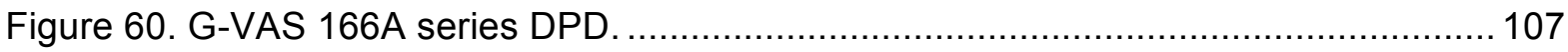

Figure 61. Addition matrix for the G-VNS 166B series. ......................................... 110 
Figure 62. Paint samples made for the G-VNS 166B series.................................. 112

Figure 63. Paint samples for the G-VAS 166B series......................................... 113

Figure 64 . Rheology data for the G-VNS 166B series. ....................................... 115

Figure 65. Contour plot for $24 \mathrm{KU}$ viscosities for the G-VNS 166B series. ..................... 117

Figure 66. Contour plot for 60 degree gloss for the G-VNS 166B series...................... 118

Figure 67. IRBS contour plot for the G-VNS 166B series...................................... 119

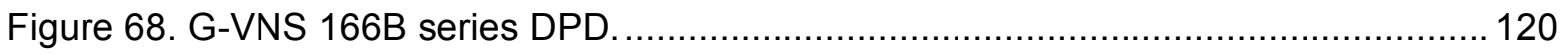

Figure 69. Rheology results for the G-VAS 166B series....................................... 121

Figure 70. Shear ramp results for samples G-VAS-B11 and G-VNS-B11 .................... 122

Figure 71. 24 hour KU contour plot for the G-VAS 166B series. ................................... 124

Figure 72. 60 degree contour plot for the G-VAS 166B series. ................................. 125

Figure 73. Conductivity contour plot for the G-VAS 166B series................................ 126

Figure 74. IRBS contour plot for the G-VAS 166B series....................................... 127

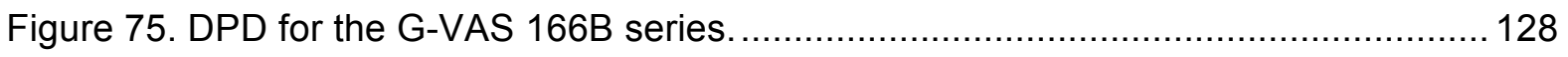

Figure 76. 24 hour KU contour plots for G-VNS 166A series (top left), G-VAS 166A series (top right), G-VNS 166B series (bottom left), and G-VAS 166B series (bottom right). 131

Figure 77. 60 degree gloss contour plots for G-VNS 166A series (top left), G-VAS 166A series (top right), G-VNS 166B series (bottom left), and G-VAS 166B series (bottom right). 132

Figure 78. IRBS contour plots for the G-VNS 166A series (top left), G-VAS 166A series (top right), G-VNS 166B series (bottom left), and G-VAS 166B series (bottom right). The values of IRBS are shown on the right with all contours using the same numbering scheme. 133 
Figure 79. DPD contour plots for the G-VNS 166A series (top left), G-VAS 166A series (top right), G-VNS 166B series (bottom left), and G-VAS 166B series (bottom right). 
1. Introduction.

\subsection{Coatings}

Coatings are all around us. There are coatings on the walls, refrigerator, cabinets, furniture, wires, circuits, and inside television sets. Outside there are coatings on the house, car, buildings, fences, and street signs (Wicks, Jones, Pappas, \& Wicks, 2007). The coatings industry is a well-developed field, but still is very promising with many challenges, career opportunities, and innovation. Some of these innovations include the reduction of emissions for air pollutants, reducing energy requirements, and protecting metals from corrosion (Wicks, Jones, Pappas, \& Wicks, 2007).

Coatings are typically described by their appearance and function. Coatings can appear clear, pigmented, metallic, or glossy, and some functions are corrosion protection, abrasion protection, skid resistant, decorative, or photosensitive (Wicks, Jones, Pappas, \& Wicks, 2007). Coatings are distinguished as organic or inorganic, but overlap for both are possible. The global consumption of coatings as of 2012 was worth nearly 120 billion dollars (Kusumgar, Nerlfi, \& Growney, 2013).

Architectural coatings, which include paints and varnishes, are used to decorate and protect buildings. Product coatings, which are often called industrial coatings or finishes, are applied in factories on commercial products such as automobiles, appliances, aircraft, furniture, metal cans, chewing gum wrappers and more (Wicks, Jones, Pappas, \& Wicks, 2007). Special purpose coatings are industrial coatings that are applied outside a factory, and also include a few other miscellaneous coatings. The three main reasons 
coatings are used are decoration, protection, or for some certain functionality (Wicks, Jones, Pappas, \& Wicks, 2007).

\subsection{Flow of Materials}

\subsubsection{Rheology}

Rheology is defined as the study of flow and deformation and includes every aspect of flow behavior: aeronautics, hydraulics, fluid dynamics, and solid mechanics (Macosko, 1994). Flow properties for coatings are important for the proper application and appearance of films. Rheology in practice is typically restricted to the study of fundamental relations between force and deformation in materials. The types of possible flows of various liquids are shown in Figure 1 (Wicks, Jones, Pappas, \& Wicks, 2007).

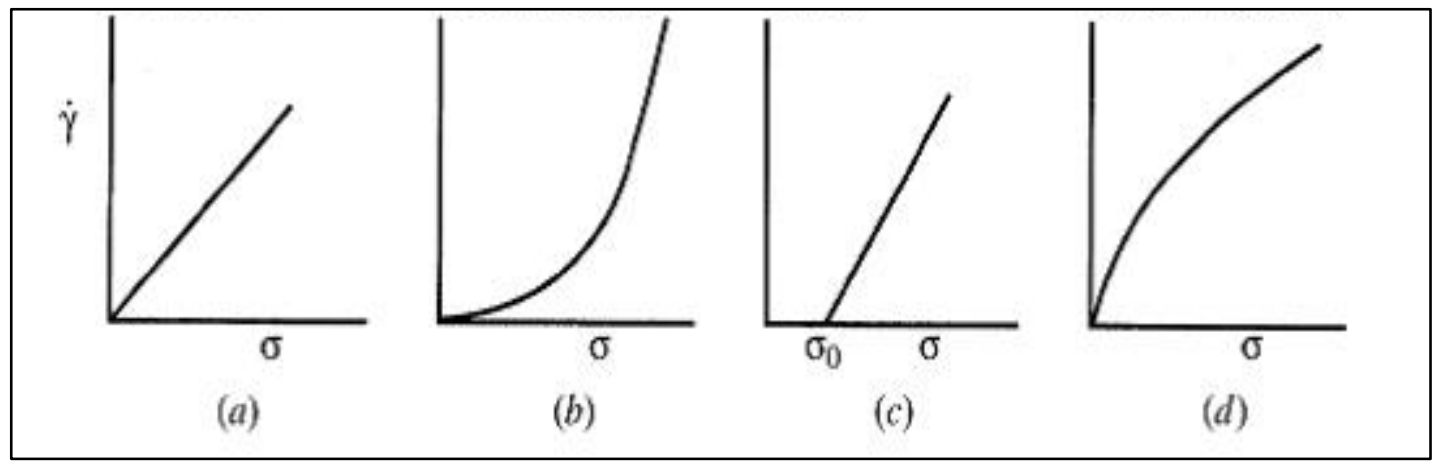

Figure 1. Shear stress vs. shear rates for different types of liquids (Wicks, Jones, Pappas, \& Wicks, 2007).

When the ratio of shear stress to shear rate is constant, liquids are considered to be Newtonian, and the viscosity is independent of shear rate (shown in Figure 1a). Newtonian flow is typical of liquids of small molecules, and some solutions of oligomeric resins can also be approximately Newtonian in flow (Wicks, Jones, Pappas, \& Wicks, 2007). Many liquids are non-Newtonian which exhibit a decrease in viscosity with an increase in shear rate; this behavior is called shear thinning (shown in Figure 1b). The 
other case of a liquid showing an increase in viscosity with shear rate is called shear thickening (shown in Figure 1d). The last case, to be called plastic flow, occurs when no detectable flow occurs until a minimum shear stress is reached (shown in Figure 1c) (Wicks, Jones, Pappas, \& Wicks, 2007). These descriptions of liquid flow can also be used for other systems such as pigment and resin dispersions.

Stress-strain analysis is another measurement applicable to many plastics and coatings. A common stress-strain test that is run is called the creep test in which a constant stress is applied with the resulting strain being measured. Another test is stress relaxation where a stress is monitored under a constant strain. An ideal elastic material undergoes instantaneous strain with an applied stress, shown in Figure 2a. The response for a Newtonian fluid is shown in Figure $2 b$ where a linear increase of strain takes place with time. Two cases for a viscoelastic sample are shown in which strain is observed to increase overtime. The resulting responses of a full relaxation and a partial relaxation are shown in Figure 2c and Figure 2d, respectively (Wicks, Jones, Pappas, \& Wicks, 2007). 


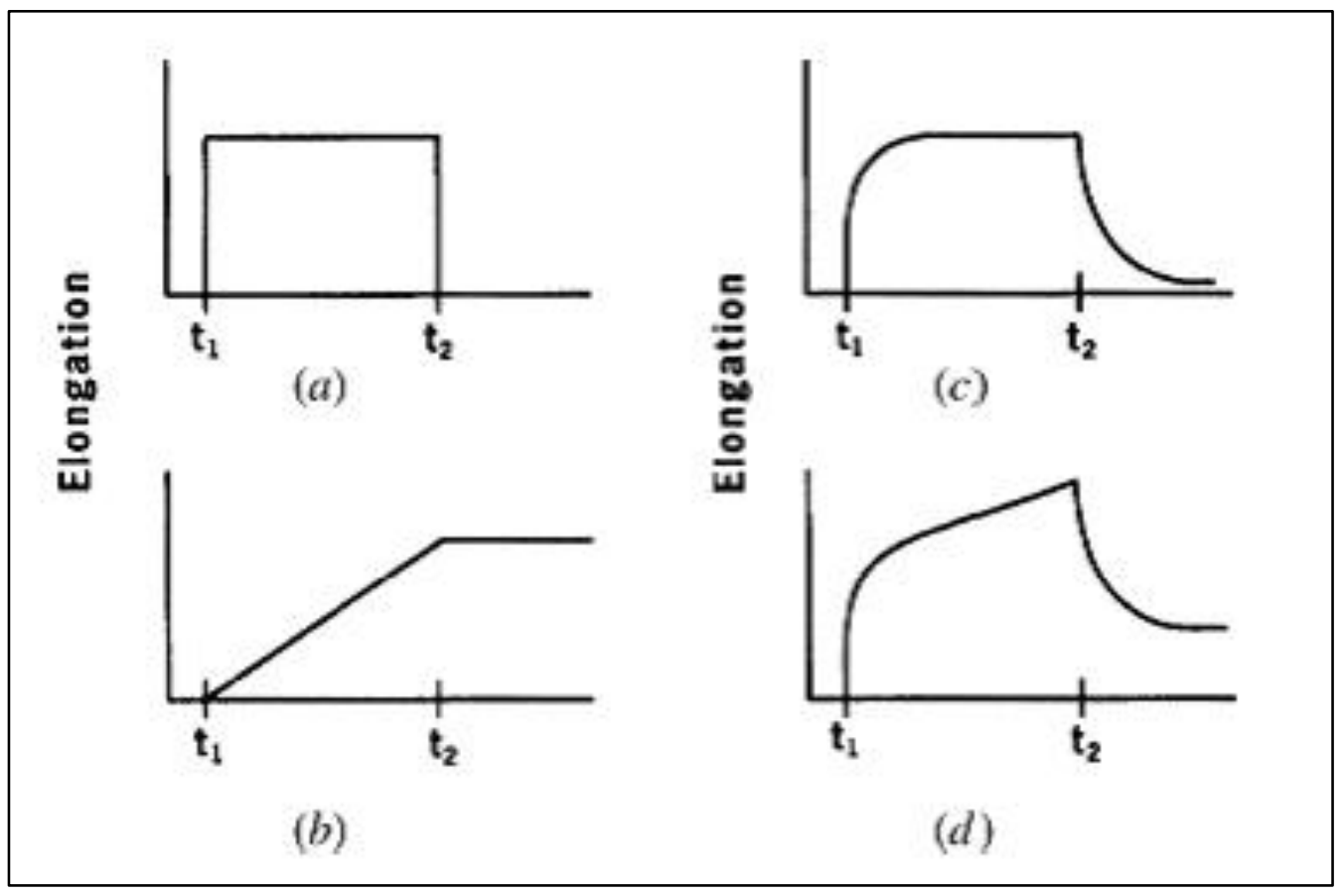

Figure 2. Plots representing four different types of creep responses. The figures are represented as such: (a) an ideal elastic solid, (b) Newtonian fluid, (c) a viscoelastic sample with cross-linking (complete recovery), and (d) a viscoelastic sample lacking complete recovery (Wicks, Jones, Pappas, \& Wicks, 2007).

\subsubsection{History of Rheology Modifiers}

The success of a many different commercial products and industrial processes depend on meeting specific flow requirements. Some of these products and processes include: architectural and industrial coatings, molded plastics, adhesives, personal care products and cosmetics, inks, cement, drilling muds, ceramic slips, solder pastes, and medicines. Rheology modifiers have been used for many years in these fields to provide ideal viscosity behavior, and are essential for the functioning of paints and coatings. Traditionally, hydroxyethyl cellulose (HEC) has been used as a nonionic, water-soluble polymer derived from cellulose to adjust the rheology of paints. HEC thickeners are low cost and can be produced by natural resources; however, they typically yield paints with 
poor leveling, reduction of gloss, roller spatter, water sensitivity, bio-degradability, and syneresis or phase separation (Eley, 2005). These traditional (non-associative) thickeners do not adsorb onto latex or pigment particles in a system. This leads to a particle distribution shown in Figure 3a, in which the thickener separates from pigment and latex particles (Kostansek, 2007).

Associative thickeners (ATs) were introduced into the coatings industry in the 1970s as rheology modifiers without many of the disadvantages of traditional non-associative thickeners. The use of ATs required much attention to be drawn to the reformulation of paints due to the complicated interactions that were introduced. Traditionally, HEC and alkali-swellable emulsions (ASE) thicken primarily by their high molecular weights and particle flocculation characteristics. ATs perform much differently in that they have many interactions with latex particles, pigments, fillers, and surfactants (Kostansek, 2003). These interactions can lead to good particle dispersion, which provides superior rheological, optical, and barrier properties. Many types of ATs are available in the market today, and all are moderately low molecular weight, hydrophilic polymers with two or more long chain non-polar hydrocarbon groups along the backbone. Non-ionic associative thickeners include hydrophobically modified ethoxylated urethanes (HEUR), hydrophobically modified aminoplast ethers (HEAT), and hydrophobically modified cellulose derivatives. One example of an anionic associative thickener available today is the hydrophobically modified alkali-swellable emulsions (HASE) (Herrick \& Fernando, 2013). For formulated systems ATs can provide good in-can appearance, thickening efficiency, spatter resistance, excellent flow and leveling, hiding, uniform film formation, and gloss development (Wicks, Jones, Pappas, \& Wicks, 2007). In contrast to traditional thickeners, a much more uniform distribution can be attained with associative thickeners with the proper understanding and selection of latex parameters, dispersant type, and surfactant. The idealized dispersion that can result is shown in Figure 3b, in which both 
the latex and pigment are uniformly dispersed (Kostansek, 2007). If improper combinations of latex and pigment with thickener, surfactant, and dispersant are used, other forms of dispersion can be observed such as poor pigment dispersion with good latex dispersion as shown in Figure 3c, or good pigment dispersion and poor latex dispersion as shown in Figure 3d (Kostansek, 2007).

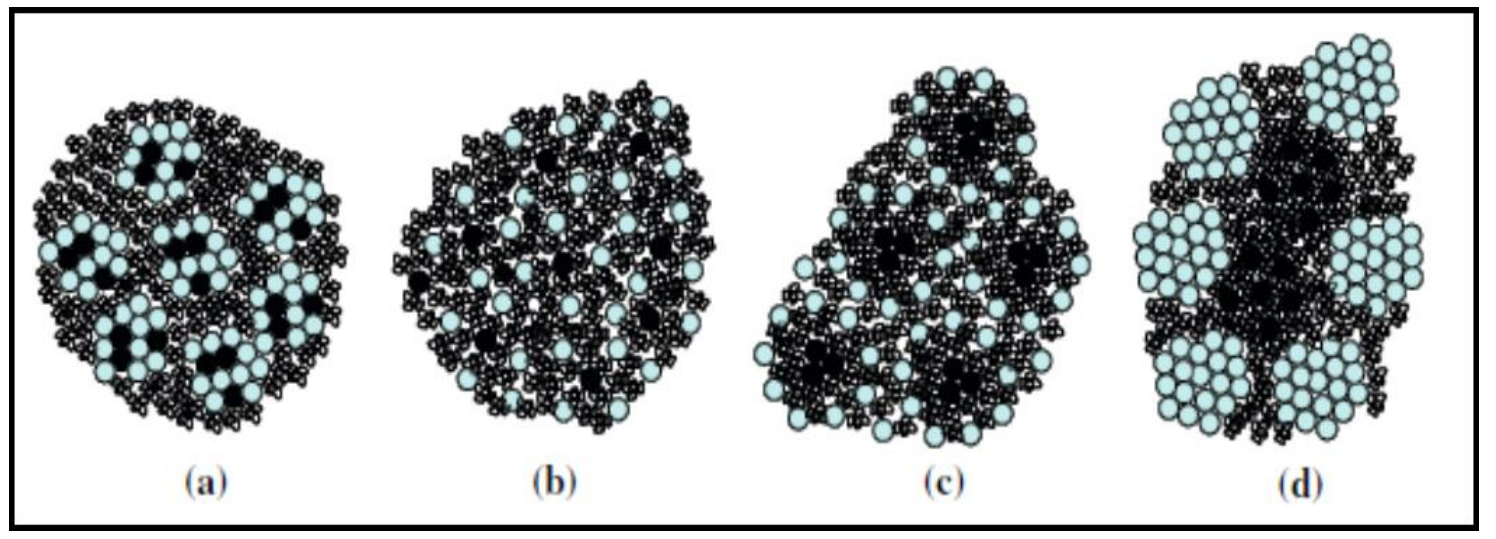

Figure 3. Schematic for the different pigment and latex dispersion states. Dispersion (a) shows a non-associative system in which the pigment (black circles) and latex (blue circles) are co-flocculated and phase separated from the thickener and continuous phase. Dispersion (b) represents a well-dispersed system where both pigment and latex particles are uniformly dispersed. Dispersion (c) shows an ineffective dispersant which resulted in flocculated pigment surrounded by a well-dispersed latex. Dispersion (d) shows a different case in which well-dispersed pigment is surrounded by flocs of latex (Kostansek, 2007).

Many studies have presented mechanisms of the associations of associative thickeners; however, they are typically not applicable to paint formulations due to the complexity of the formulations compared to the simple system in the studies. These studies use high concentrations of thickeners in aqueous solution, wherein for real coatings formulations the amounts of thickeners are much lower and have many other significant interactions 
that affect the mechanisms of the associative thickeners (Chen, Wetzel, Ma, \& Glass, 1997).

1.3. Thickeners, Surfactants, Latex, Pigments, and their Interactions.

\subsubsection{Associative Thickeners}

Associative thickeners contain a water-soluble polymer backbone with at least two hydrophobic groups. For the benefit of this study, the focus will remain primarily on HEUR associative thickened systems. The general structure for a HEUR composition is shown in Figure 4 (Saucy, 2008).

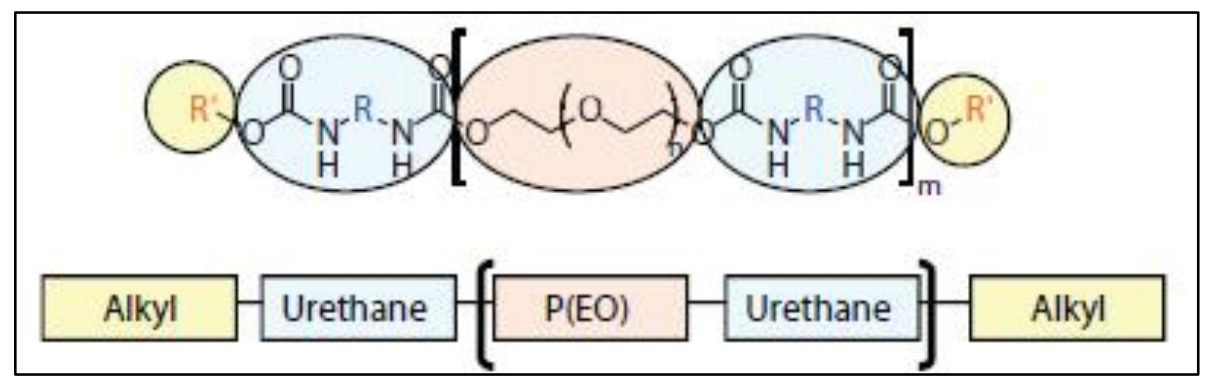

Figure 4. General structure of a HEUR associative thickener (Saucy, 2008).

HEUR thickeners adsorb onto a latex surface through hydrophobic interactions between the latex surface and the hydrophobes of the surfactant or thickener (Chen, Wetzel, Ma, \& Glass, 1997). HEUR thickeners have been used in the paint and coatings industry for over 30 years, and the rheology of these systems has been studied extensively in both solution and formulated paint systems. These non-ionic associative thickeners are made from water-soluble poly(ethylene oxide) (PEO) backbone with internal, terminal, and even pendant hydrophobes. The PEO and other components are linked with urethane groups via isocyanate chemistry (Beshah, Izmitli, Van Dyk, Rabasco, \& Bohling, 2013). HEURs are typically synthesized commercially via a step-growth polymerization of 
excess diisocyanate with oxyethylene diol (PEO) of around 6,000 to 8,000 molecular weight (Glass, 2001).

\subsubsection{Surfactants}

Surfactants of different types and quantities are present for most architectural latex coatings. Even before the discovery of associated thickeners, surfactants were utilized for the stabilization of the bulk-dispersed phase (latex, and pigment), wetting of substrates, development of colorant strength, among many others applications (Mahli, Steffenhagen, Xing, \& Glass, 2003). In fully formulated coatings systems, surfactants do not function by themselves; instead, there are competitive and synergistic mechanisms that influence the system as a whole. For surfactants in water, aggregation occurs primarily as a result of the hydrogen bonding of water molecules with other water molecules and a small interaction of hydrophobes from the surfactant (Mahli, Steffenhagen, Xing, \& Glass, 2003). These aggregates will then form micelles above a critical micelle concentration $(\mathrm{CMC})$ in a structure that is specifically related to the individual surfactant molecule. This behavior of micelle formation can have a large influence on the viscosity and physical properties of coatings thickened with associative thickeners (Mahli, Steffenhagen, Xing, \& Glass, 2003).

In this study, three different surfactants were studied: two different non-ionic surfactants of varying hydrophobicity called Surfactant-A (NS-1) and non-ionic Surfactant-B (NS-2) and one anionic surfactant called anionic Surfactant-C (AS-1).

Non-ionic surfactants are typically classified by the Hydrophile-Lipophile Balance (HLB). This numerical system is essentially a ratio of the amount of hydrophilic to lipophilic (oilloving) groups in the molecule that is derived directly from the structure of the surfactant (Lin, 1972). In other words, the higher the HLB value for the non-ionic surfactant 
translates to a larger attraction to water with (0 representing a totally hydrophobic entity and 20 for a completely hydrophillic). The literature HLB values for Surfactant-A and Surfactant-C are 17.6 and 13.4 respectively.

Surfactants can provide nucleation sites to facilitate the hydrophobes from two different associative thickeners to build the viscosifying mechanism at low HEUR levels (Mahli, Steffenhagen, Xing, \& Glass, 2003). Surfactants, similar to HEUR, will adsorb onto latex surfaces via hydrophobic interactions between the latex surface and hydrophobes of surfactant. The surfactant will compete with HEUR thickeners for adsorption sites onto latex particles, and the more hydrophobic the surfactant is the more competitive it will be for adsorption onto latex (Chen, Wetzel, Ma, \& Glass, 1997).

\subsubsection{Latex Resin}

Latex is defined as a dispersion of polymer particles in water. Most latexes are synthesized via a free radical chain-growth polymerization where the monomers are emulsified in water, leading to the name of an emulsion polymerization. The molecular weight (MW) of polymers synthesized via this method are typically of high MW $(1,000,000$ or more is common) (Wicks, Jones, Pappas, \& Wicks, 2007). Emulsion polymerization is carried out in water with monomer, surfactant, and an initiator. For the scope of this project, the focus of the latexes will be acrylic resins. Surfactants are very important in controlling the particle size and particle size distribution of latexes, and acrylic resins are the primary binder for most industrial coatings with their best attributes being photo-stability and resistance to hydrolysis (Wicks, Jones, Pappas, \& Wicks, 2007).

There are two mechanisms to describe the stabilization of latex dispersions by surfactants. The first is by charge repulsion in which the particle surface has an excess 
of one electrostatic charge (typically negative). For example, a latex is stabilized by an anionic surfactant adsorbed onto the surface of the latex with the surfactant polymers orienting themselves with the hydrophobic hydrocarbon tails in the polymer and the hydrophilic head groups on the outer shell interacting with water (Wicks, Jones, Pappas, \& Wicks, 2007). This results in the surface of the latex particle covered by anions causing electrostatic repulsion between latex particles, which affects the stability of the latex dispersion. The second mechanism is by repulsion of the outer layers of the latex particle. This repulsion is commonly referred to as steric, entropic, and osmotic repulsion. This occurs when the hydrophilic particles on the surface of the latex adsorb water and the surface swells. When the surface swells to a large enough thickness to keep the particles from approaches each other, this is called steric repulsion (Wicks, Jones, Pappas, \& Wicks, 2007). An example for entropic repulsion is when a non-ionic surfactant anchors onto the latex particle via a hydrophobic interaction, and the hydrophilic portion extends into the water phase in many different conformations. As particles come closer together, the long hydrophilic regions are compressed and lower the amount of conformations possible in the system, which leads to a loss in entropy. This resistance to the decrease in entropy leads to entropic repulsion (Wicks, Jones, Pappas, \& Wicks, 2007). Some literature refers to the reduction of the amount of water in the compressed layer for the entropic repulsion mechanism as osmotic repulsion. This loss of water creates an osmotic pressure which is called osmotic repulsion (Wicks, Jones, Pappas, \& Wicks, 2007).

\subsubsection{Pigments - Titanium Dioxide}

Pigments are fine and insoluble particle materials used in coatings for the following reasons: color, hiding power, change application properties, and reduce cost. The particle size of the pigment affects color strength, transparency or opacity, exterior 
durability, solvent resistance, and other properties (Wicks, Jones, Pappas, \& Wicks, 2007). The processing of pigments typically involves precipitation from water, and the actual process used dictates particle size. Many pigments are also surface treated during the manufacturing process, and the pigment is precipitated, filtered and delivered to the consumer in a dry powder of aggregates (Wicks, Jones, Pappas, \& Wicks, 2007). The two most common forms that titanium dioxide $\left(\mathrm{TiO}_{2}\right)$ comes in are rutile and anatase. Rutile is the more commonly used providing about $20 \%$ greater hiding power than anatase (Wicks, Jones, Pappas, \& Wicks, 2007). Many manufacturing techniques also include surface treatment of the pigments. The most common surface treatments are silica, alumina, and also a variety of other metal oxides. Typical surface treatments for rutile $\mathrm{TiO}_{2}$ is about $6 \mathrm{wt} \%$ silica and $4 \mathrm{wt} \%$ alumina. An ideal surface treatment would form a continuous shell on the pigment to prevent contact between $\mathrm{TiO}_{2}$ and binder. The surface treatments improve dispersibility of the $\mathrm{TiO}_{2}$, which reduces the amount of $\mathrm{TiO}_{2}$ needed in a formulation. The variety of $\mathrm{TiO}_{2}$ pigments offered differs for each manufacturer. As a result, formulators need to be aware of the different types to enhance coating performance and save money (Wicks, Jones, Pappas, \& Wicks, 2007).

The $\mathrm{TiO}_{2}$ used in this study was a surface treated. Such treatments are primarily carried out using aluminum compounds, but other treatments include silicon, zirconium and manganese compounds as well as some organic treatments. These treatments are performed to improve certain pigment properties. The coatings process of the pigment involves a deposition of matter onto the surface of the pigment particles (Reck \& Seymour, 2003). Silica is added in order to aid the dispersion in aqueous systems as well as improve durability. Zirconium also improves durability, and alumina helps with the dispersion and dispersion stability (Reck \& Seymour, 2003). The treatment substances are also insoluble under normal conditions, and strong acids or bases are needed to 
dissolve them. Small quantities of organic substances are also added to almost all pigments in order to improve the wettability.

\subsubsection{Interactions and Network Formation Theories}

The modeling of latex systems is not trivial as a result of the many possible variations that can be present. For stability purposes, most latex resins are synthesized with oligomeric acids or polymer fragments grafted to their surfaces. These surface modifications along with latex particle size dictate the amount of surfactant and associative thickener that can be adsorbed. Another issue for studies on latex is that they are synthesized in various median particle sizes and particle size distributions, and are commonly blended to make bi- and multimodal particle size distributions (Chen, Wetzel, Ma, \& Glass, 1997). All of these issues must be accounted for when attempting to define the interactions between the latex, surfactant, and thickener. The complications are increased with pigmented systems, which create another variable in the interaction scheme for a given formulation. One traditionally accepted viscosifying mechanism for a fully formulated system is show in Figure 5 (Münzenberg, 2011). 


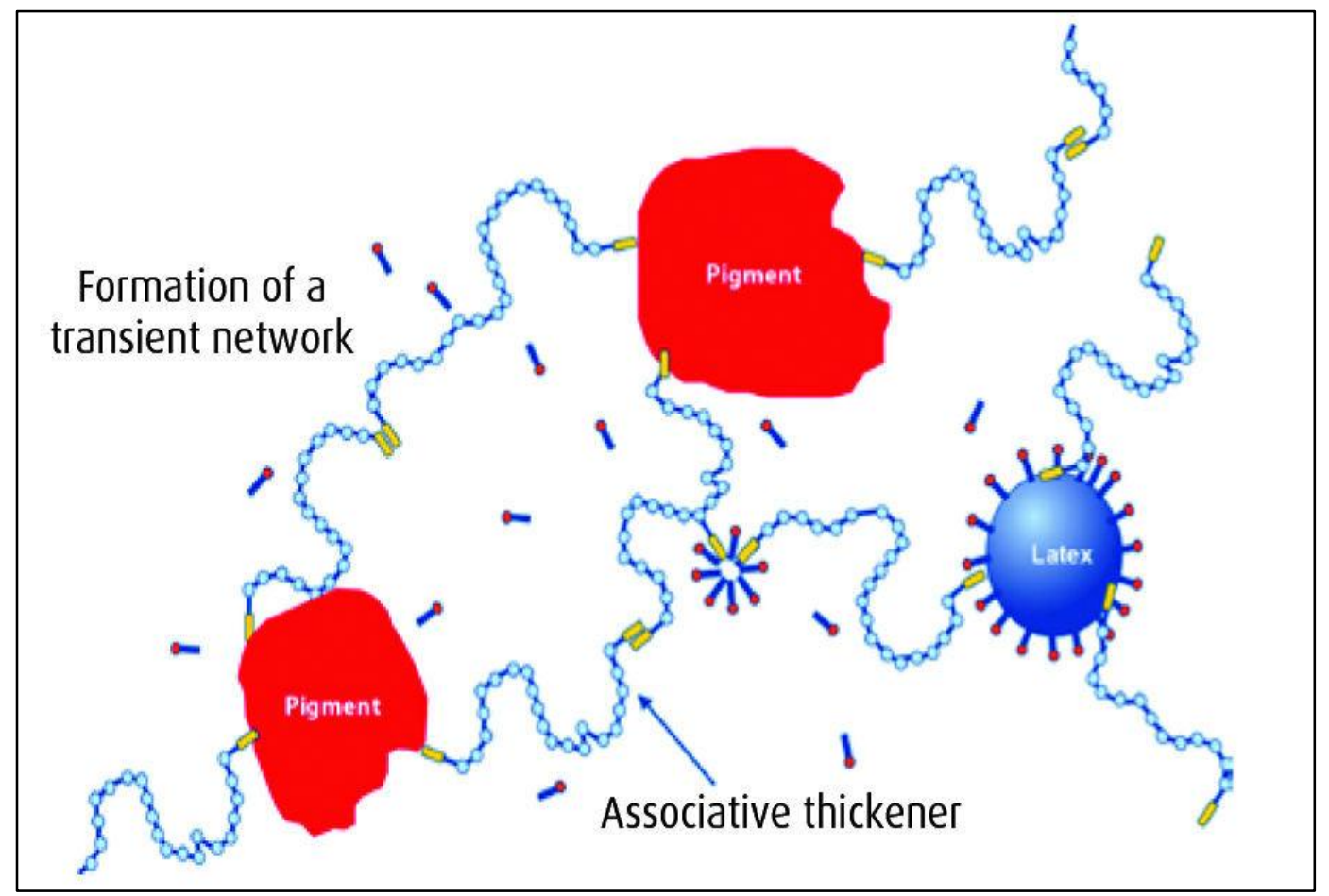

Figure 5. Schematic showing the traditional theory for the formation of a transient network of a fully formulated HEUR thickened system (Münzenberg, 2011).

The adsorption of HEUR polymers onto latex surfaces through hydrophobic end groups, with the PEO portion forming a thin shell is understood and recognized; however, the effects of component contributions of core-shell hydrodynamic volume, particle aggregation, viscous drag on aggregated particles, and HEUR transient network on a given system's rheology is unclear (Beshah, Izmitli, Van Dyk, Rabasco, \& Bohling, 2013). Early research proposed a transient network, shown in Figure 5, in which HEUR polymers form flower-like micelles which coexists with latex. In this model, some of the network nodes were believed to be occupied by latex particles and the HEUR bridges formed the transient network (Beshah, Izmitli, Van Dyk, Rabasco, \& Bohling, 2013). Most studies of the transient network are based on centrifugation to separate supernatant from the latex particle as a method to quantify the amount of HEUR in the aqueous phase. A drawback to this method is that there is other evidence that has 
shown centrifugation to disrupt the weakly bound hydrophobes resulting in inaccurate detection of free HEUR in the aqueous phase (Beshah, Izmitli, Van Dyk, Rabasco, \& Bohling, 2013). A newer technique developed by Beshah et al. utilized an in situ method to detect the free HEUR in the aqueous phase as a way to circumvent the perturbation of whichever networks are present in the system. This test included a PFGNMR of a neat system of HEUR, latex, and water which counteracted the idea of the formation of flower-like micelle formation of HEUR. A simple cartoon representation of this referenced work is shown in Figure 6 (Beshah, Izmitli, Van Dyk, Rabasco, \& Bohling, 2013).

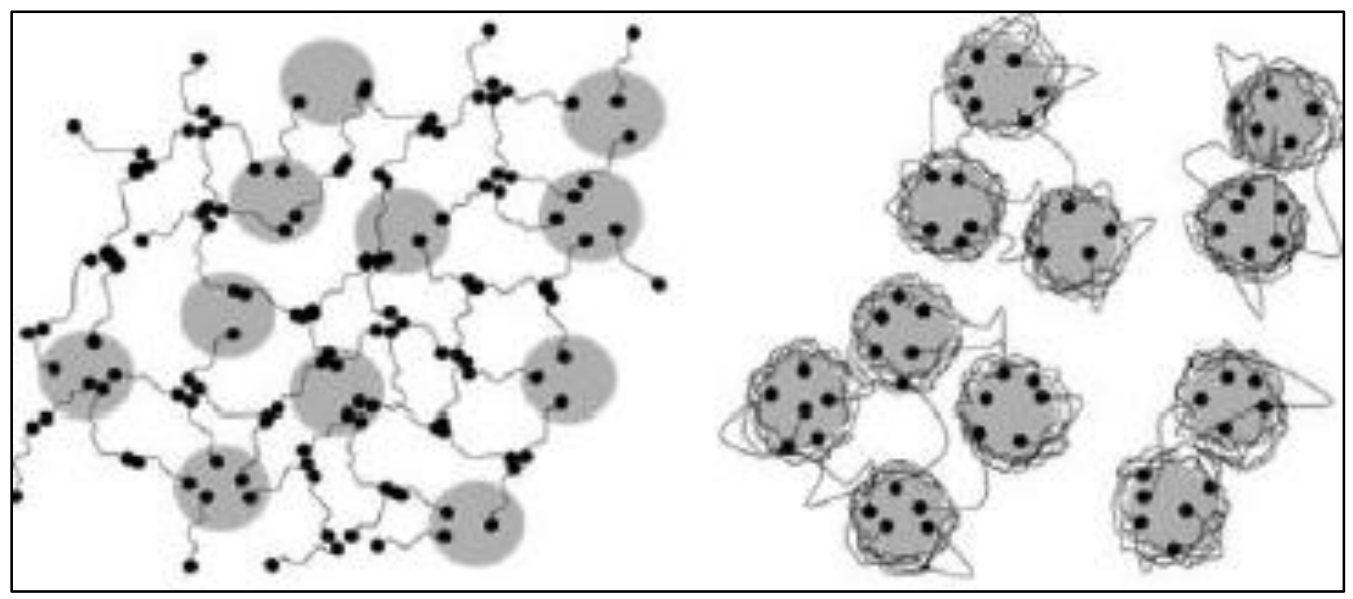

Figure 6. Simple schematic of the old (left) and current model (right) based on PFGNMR results for $1 \%$ HEUR and $30 \%$ latex composite. Small black dots represent hydrophobic end groups of HEUR molecules (Beshah, Izmitli, Van Dyk, Rabasco, \& Bohling, 2013).

This test was conducted in a $1 \%$ HEUR and $30 \%$ latex composite which is a typical representation of commercial paints and coatings. The study concluded that at this level of HEUR and latex there was no flower-like micelles typical of the formation of a transient network shown on the left side of Figure 6 . The study does mention that at higher levels of HEUR that flower-like and transient networks may arise, but the scope of this study was at the levels close to that of typical commercial use (Saucy, 2008). This 
mechanism was proven for a simple system of latex, thickener, and water so the application to a fully formulated system may be different. The formation of a transient network with interactions of HEUR to HEUR via the hydrophobic ends has been shown not to exist in an aqueous system; however, this has not yet been proved for a fully formulated system.

Both models of the formation of networks for a HEUR thickened system are an attempt to define the viscosifying mechanisms present. Each model has limitations, and for this project report the latter model presented by Beshah et al. in 2013 will be considered more accurate.

The nature of the weak van der Waals type hydrophobe-hydrophobe interactions creates an adsorption-desorption exchange of the hydrophobe groups of the HEUR molecules and latex particles. As a result, the stronger the interaction between the hydrophobes of HEUR and hydrophobic latex surfaces, the lower the exchange rate and thus the lifetime of the hydrophobe in the aqueous phase. This means that exchanges in this given system are mainly between loop to loop, loop to direct bridge, and perhaps direct bridge to direct bridge (Beshah, Izmitli, Van Dyk, Rabasco, \& Bohling, 2013). Formation of bridges loops, and chain transport between surfaces have been studied and are dependent on HEUR hydrophobes, concentrations, hydrophobicity, particle size, and others (Dewalt, Gao, \& Ou-Yang, 1996).

Another interaction that must be considered is hydrophobic interactions introduced via surfactants in a system. The hydrophobes from surfactants compete for adsorption sites on the latex surface, and in the process the surfactant displaces associative thickener from the surface (Saucy, 2008). The addition of surfactants will first initiate an increase in viscosity at low thickener concentrations. As the surfactant concentration is increased, 
the viscosity increase will reach a maximum and the show a decrease in viscosity. The decrease in viscosity with an increase in surfactant concentration is typically observed above the CMC of the surfactant (Glass, 2001). The use of colorants in paints, which contain high levels of surfactants, has been an issue resulting in viscosity loss. Much research has been dedicated to develop a rheology modifier with improved viscosity stability with the additions of surfactant. One newer rheology modifier technology has been developed which reduces the viscosity loss upon tinting. The improved viscosity stability is achieved essentially through a new viscosity-building mechanism (Saucy, 2008). Two classifications that are commonly used for associative thickeners are highshear viscosity builder (also called an ICI builder) and mid-shear viscosity builder (also called $\mathrm{KU}$ builder). $\mathrm{KU}$, which is called a Krebs Unit, is a viscosity measurement most widely used in architectural paints with typical KU values ranging from 90-100 (Wicks, Jones, Pappas, \& Wicks, 2007). The ICI builder is typically used in higher amounts than the $\mathrm{KU}$ builder, and has a higher molecular weight than the $\mathrm{KU}$ builder as well. The difference in molecular weights, shown in Figure 7, leads to the two thickeners occupying varying volumes of space when adsorbed to the latex. This difference in occupied space hinders access to the lower-molecular weight KU builder, and essentially inactivates a fraction of the thickening polymers of the system. When surfactants are added, displacement of thickener will occur for both the high- and midshear builders, but some compensation will be provided through the now activated midshear thickeners that were not previously participating in network building. In addition, the displaced polymer chains can participate in building an extended linked network that was not accessible before addition of surfactant (Saucy, 2008). 


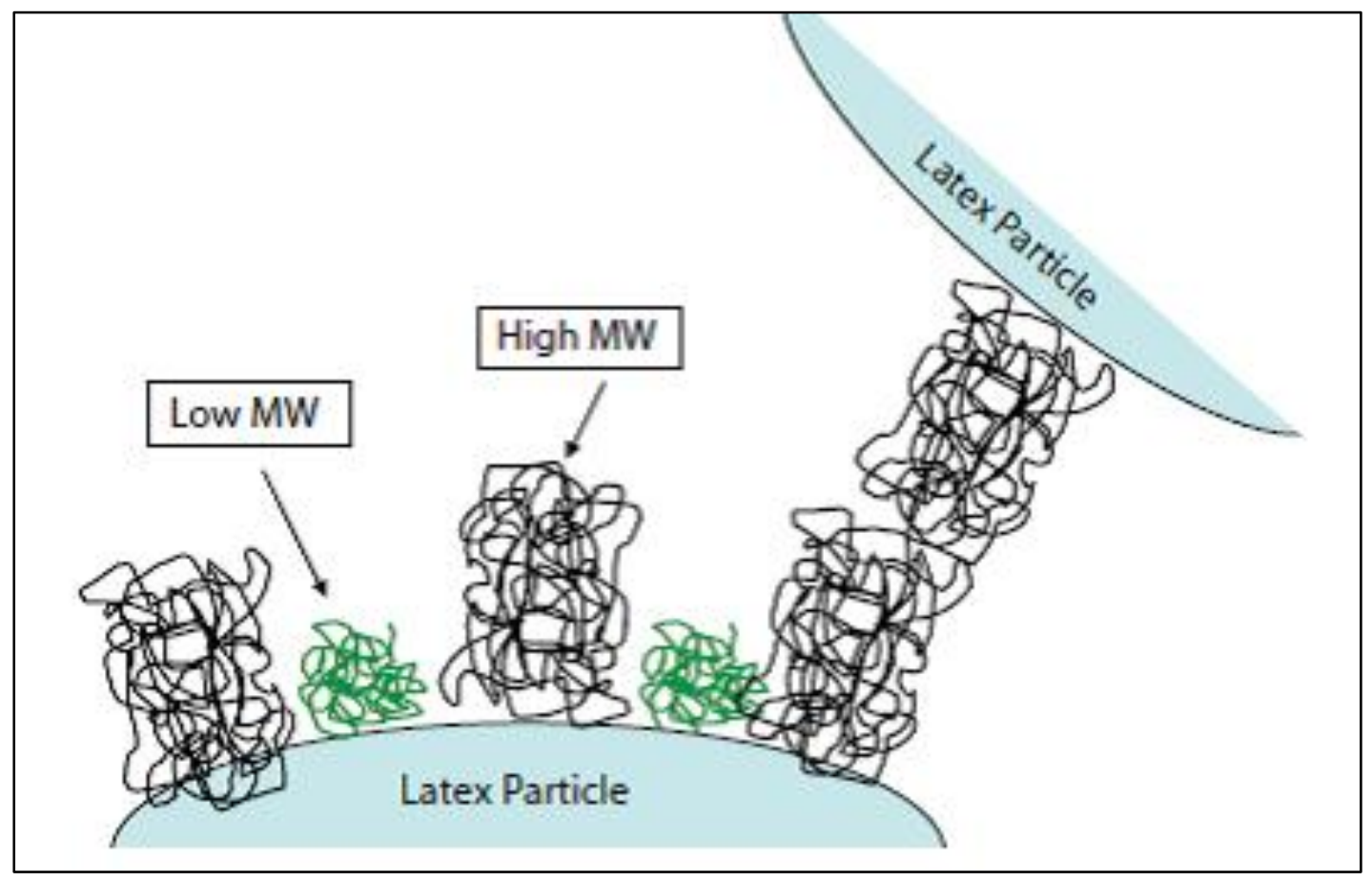

Figure 7. Schematic representation of the hydrodynamic volumes of low and high molecular weight thickeners that are adsorbed onto the latex surface (Saucy, 2008).

\subsection{Paint Flocculation}

The state of dispersion of colloidal particle systems used in paint have been studied for years in an attempt to control their stability. The stability of paints usually refers to the state of phase separation or flocculation that the paint is in. Three types of stability are typically discussed for a dispersion of particle in a solution. The first which occurs at low levels of thickener levels is called bridging flocculation. The second form at high levels of thickener or surfactant is called depletion flocculation. The third dispersion state is a good dispersion in which no flocculation is present (Olsson, Joabsson, \& Piculell, 2005). The states of flocculation are a result of the many interactions present in the paint system. 


\subsubsection{Bridging Flocculation}

Bridging flocculation occurs at low concentrations of polymer in a colloidal dispersion in which a single polymer chain adsorbs on two or more particles and binds them together (Horigome \& Otsubo, 2002). The associating polymers can also create bridges through cross-linking of several chains connected by the intermolecular cross-linking of the polymer, shown in Figure 8 (Horigome \& Otsubo, 2002). Flocculation by this method takes place only when the polymer chain is long enough to reach both particles (single stranded or cross-linking of a multiple polymers), and where the surface coverage by the adsorbed polymer is low. When the adsorption is reversible and the affinity of the polymer to the particle surface is weak, the polymer bridges are constantly forming, breaking, and then re-forming again under no shear (Otsubo, 1999). When bridging flocculation is induced with associative polymers end-capped with hydrophobic groups two different bridging flocculation mechanisms can be present. Two mechanisms of bridging flocculation were proposed in a study using sedimentation experiments to measure the surface separation of particles in a colloidal system. The first, shown in Figure 8 , is called direct bridging flocculation, which occurs at very low coverage of polymer on latex. This conclusion was made as a result of a high storage modulus and short separation of particles. The second, Figure 9, is a schematic representation of polymer bridging flocculation that occurs at relatively higher polymer concentrations while still contained in the bridging flocculation region. This was confirmed with an increase in particle distance of the colloidal system as well as a decrease in elastic modulus. These suspensions are highly elastic even at strains in the nonlinear viscoelastic region. Otsubo added that these particles are connected by longer and flexible bridges that are not as rigid as a direct bridging flocculation (Horigome \& Otsubo, 2002). Otsubo was able to show long-range bridging flocculation via HEUR to HEUR interactions (called flower micelles) for a simple system. This flower micelle interactions 
of HEUR thickener was proved not be present in the work done by Beshah et al. which was previously discussed.

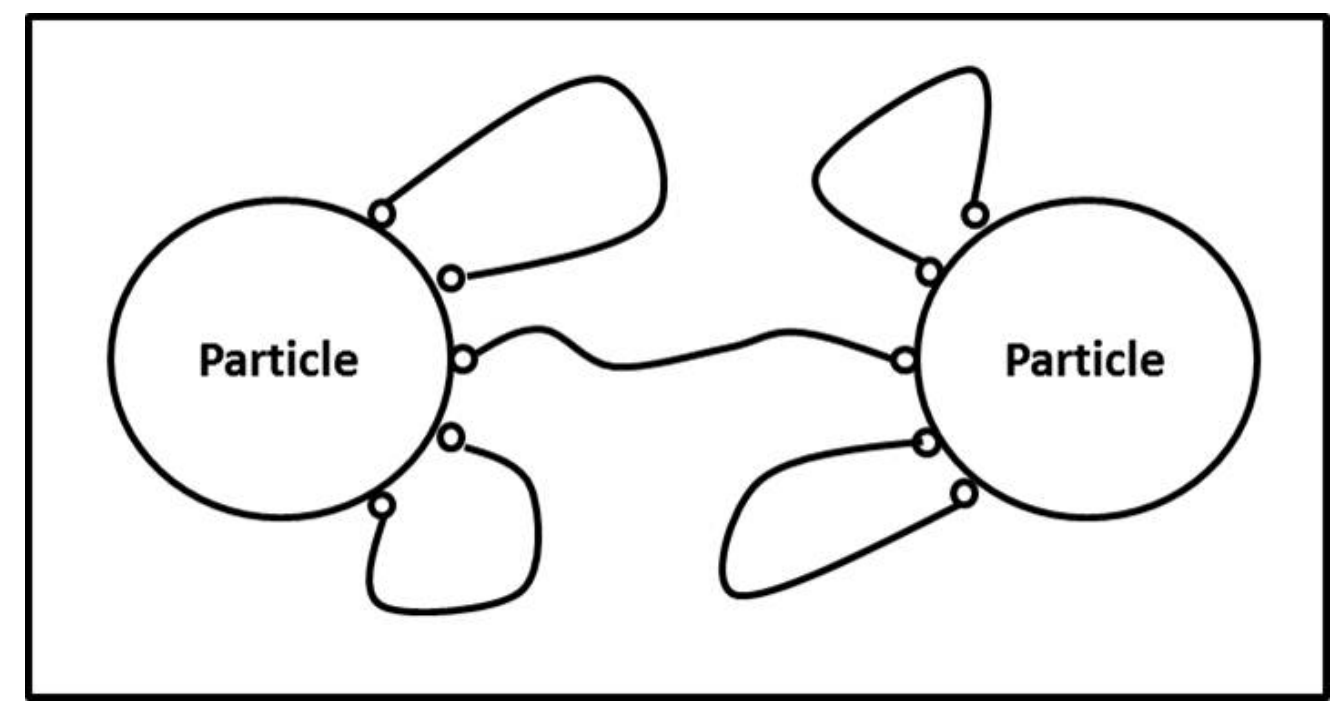

Figure 8. Bridging flocculation via a direct bridge is typical at lower level of polymer in the bridging flocculation region.

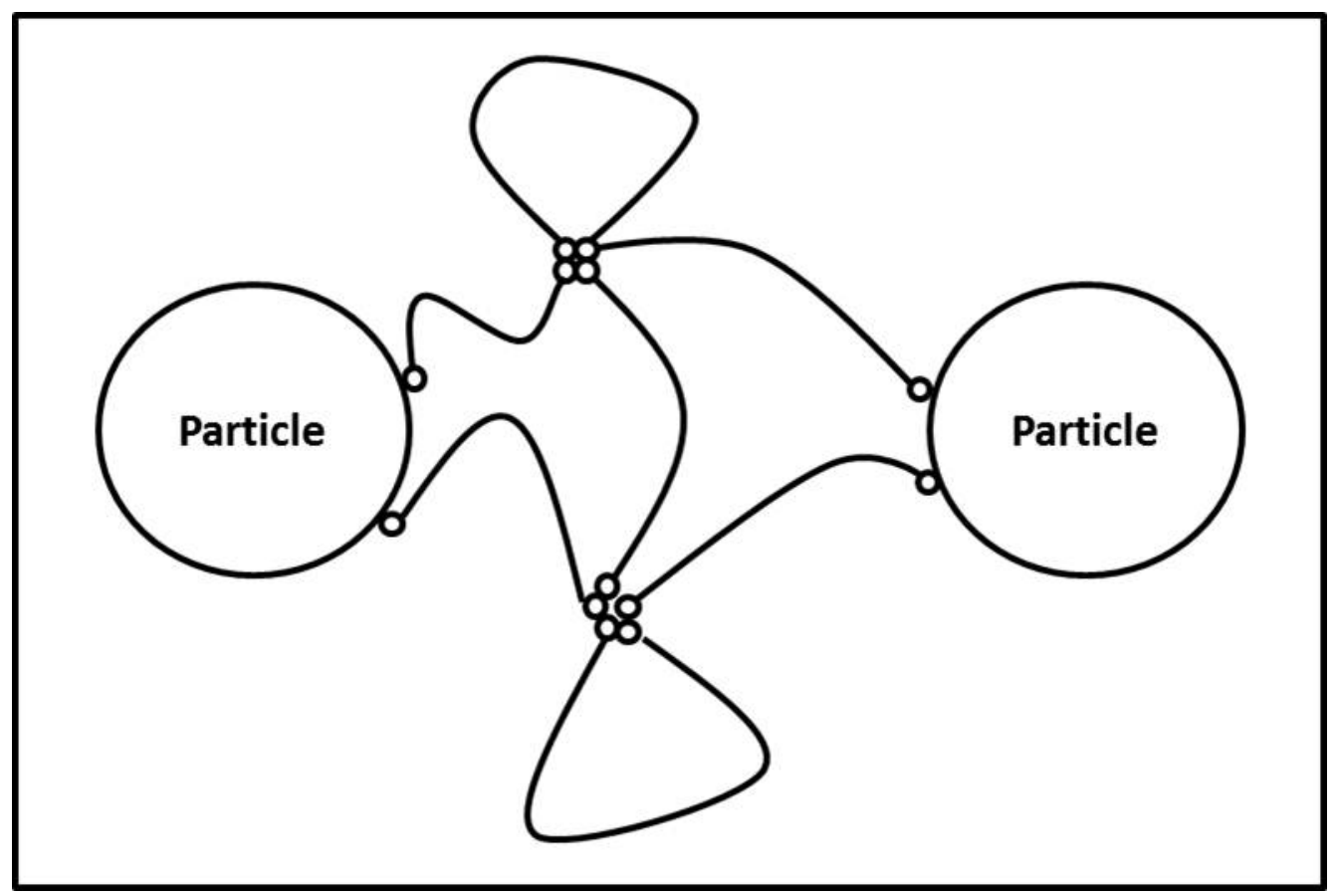

Figure 9. Bridging flocculation induced by inter-chain (flower micelle) associations. 
The addition of surfactant to a HEUR thickened system affects the formation of bridges in the system. As discussed previously, the surfactant competes with thickener for adsorption to latex and pigment. Bridging flocculation can be eliminated by adding additional associative thickener, surfactant, or both to the system (Kostansek, 2003). When discussing the flow of the system the addition of surfactants have the following affects: the viscosity is increased at very small levels of surfactant, at intermediate concentrations the viscosity decreases as thickener desorbs from the particles in the system, at high levels the system can enter a depletion flocculation region where the flow becomes shear thinning (Otsubo, 1995).

\subsubsection{Depletion Flocculation}

Depletion flocculation can occur at relatively high concentrations of polymer when the associative interactions for the particle surfaces are weak. The flocculation mechanism is similar to that of a traditional thickener such as HEC, which do not actually interact with particles in the system (Horigome \& Otsubo, 2002). Typically, depletion flocculation is the most observed type of separation, and is very common for traditional systems (Kostansek, 2006). A transmission electron micrograph (TEM) of a neat latex and latex with non-associative thickener (depletion flocculation system) is shown in Figure 10 (Saucy, 2008). 


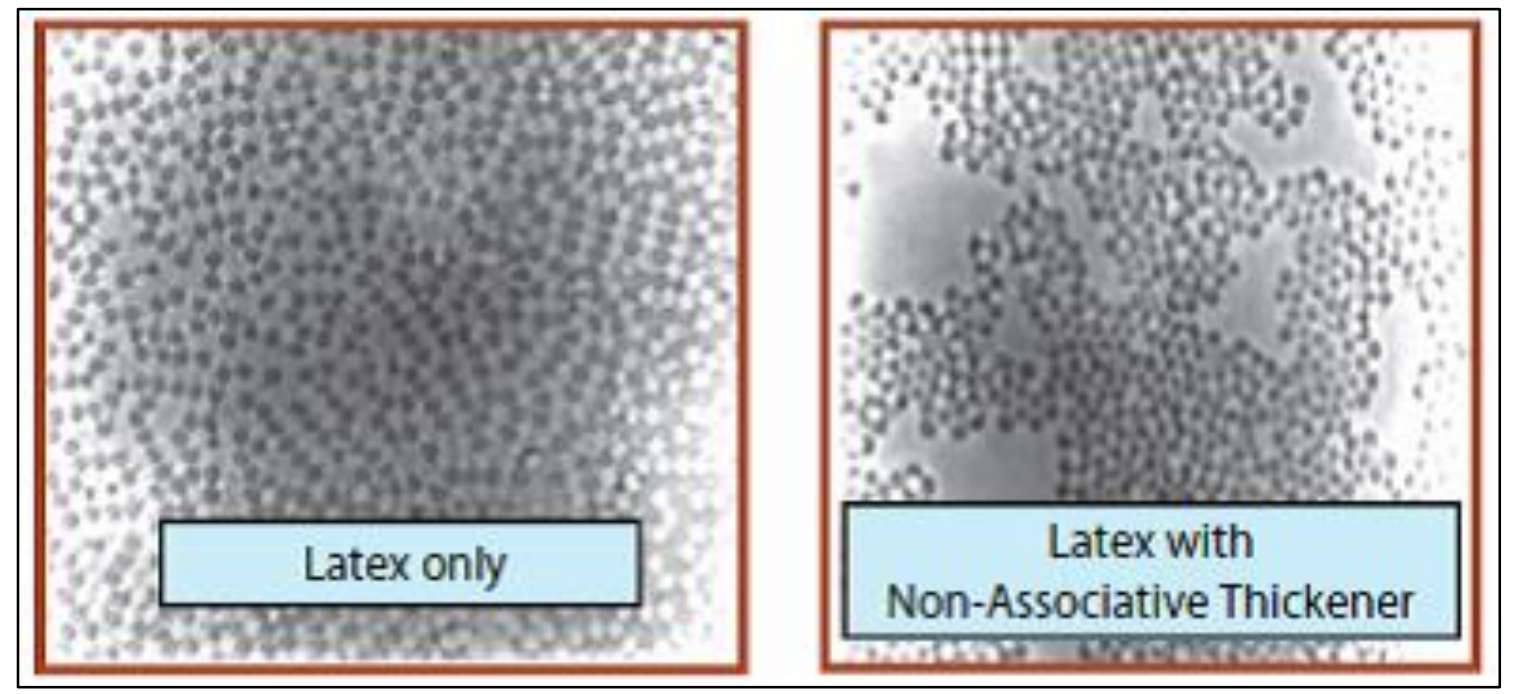

Figure 10. TEM image showing depletion flocculation of latex with a non-associative thickener (Saucy, 2008).

Depletion flocculation can also be introduced via surfactant additions to a HEUR thickened system. As discussed in a previous section, the surfactant competes for adsorption to particle surfaces with associative thickener. When the particle surfaces of the system are covered mostly with surfactant, the system can enter a depletion flocculation state with the lack of polymer adsorption. The free polymer in the system is excluded from the free space in between particles, which creates an attractive force between the particles proportional to the osmotic pressure of the polymer solution, a simple schematic is shown in Figure 11. When the volume concentration of the free polymer exceeds a certain limiting value, depletion flocculation is observed (Otsubo, 1995). Depletion flocculation is dependent on the particle volume solids, thickener molecular size, and concentration (Kostansek, 2003). 


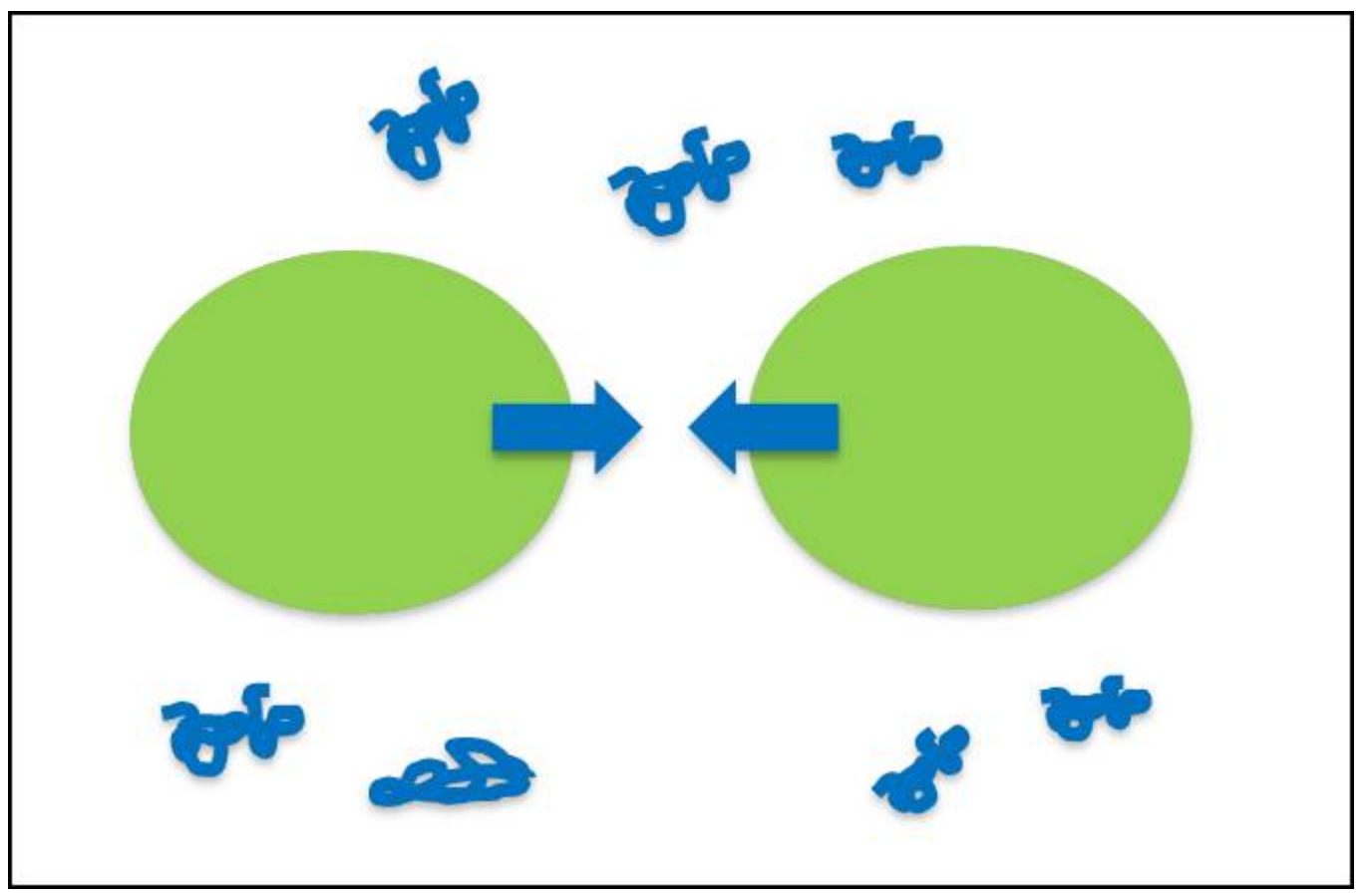

Figure 11. Simplified schematic for depletion flocculation of a thickened latex system.

\subsection{Dispersion Phase Diagrams (DPDs)}

As a method to visualize the flocculation regions for a given system, Kostansek developed experimental techniques to generate phase diagrams for a simple system containing latex, surfactant, and associative polymer (Kostansek, 2003). The ideal DPD that Kostansek developed is shown in Figure 12. 


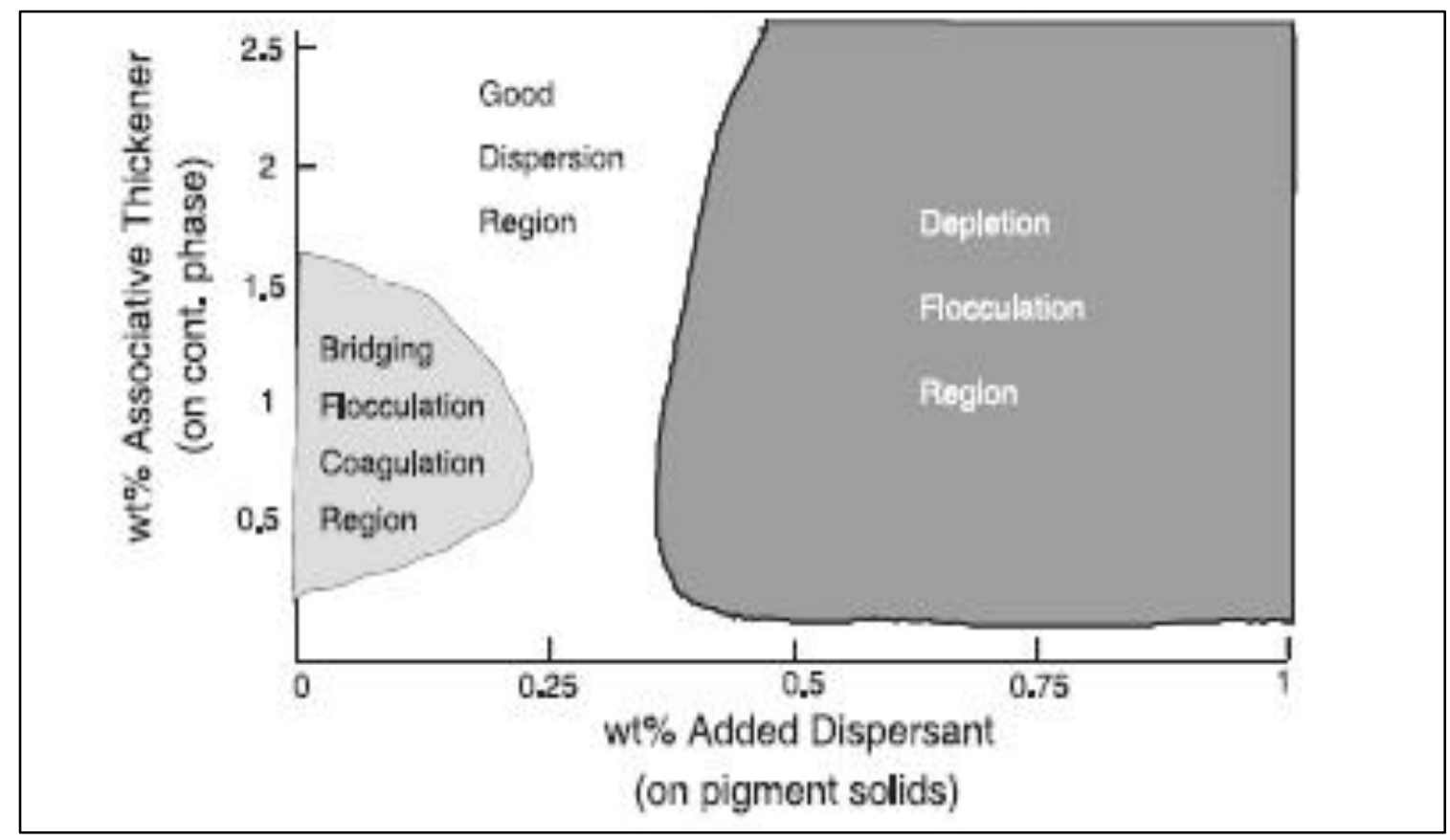

Figure 12. Idealized DPD showing the three possible regions for a simple system containing latex, thickener, and surfactant (Kostansek, 2003).

Kostansek used DPDs to illustrate the effect of latex particle size, composition, cosolvent, and electrolyte on dispersion. The testing method used relied heavily upon microscopic examination of samples in which flocculation was observable. Some microscopy showing a bridging flocculation system is shown in Figure 13 (Kostansek, 2003). 


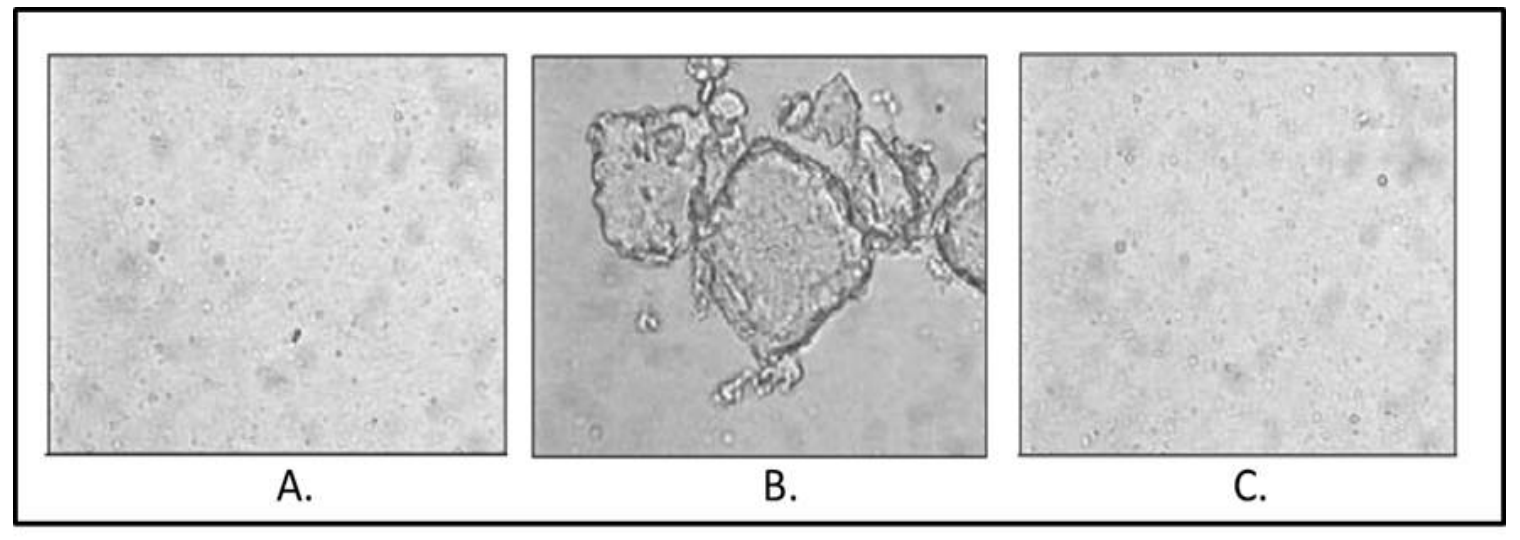

Figure 13. Shows microscopy pictures of three different systems: A - an unthickened latex, B - low wt\% HEUR thickened latex in a bridging flocculation state, C - HEUR thickened system in a good dispersion (Kostansek 2003).

This test was very conclusive for a simple system to be able to see individual flocs of bridges forming, and being able to compare this to both an unthickened and good dispersion state. Kostansek was able to visually see depletion flocculation under the microscope as well. This was achieved by mixing the sample and placing it on the microscope immediately, shown in Figure 14 (Kostansek, 2003). Depletion flocculation occurs overtime and this method allowed for the flocculation to be observed over a certain time frame. The figure clearly shows depletion flocs forming very quickly, which confirms what kind of flocculation is present in this sample. 


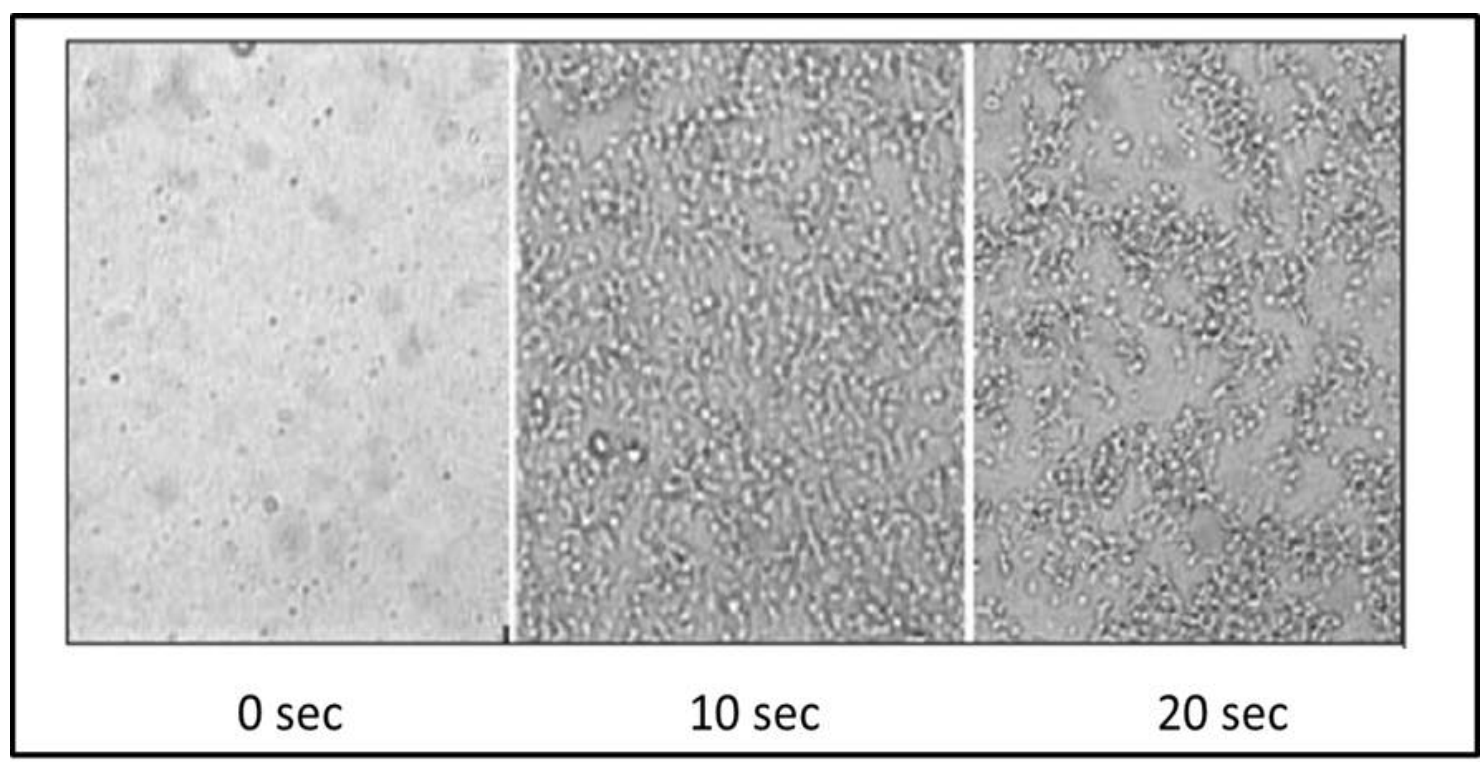

Figure 14. Shows the micrograph of a mixed sample depleting over a 20 second period. (Kostansek 2003).

Kostansek confirmed each of the flocculated samples further by either diluting a depletion flocculation sample into a good dispersion, or adding associative thickener or surfactant to a bridging flocculation sample until a good dispersion was observed. This testing method followed the theory that a transition from a bridging flocculation to good dispersion to depletion flocculation system should be observable for these systems (Kostansek, 2003).

The depletion flocculation and good dispersion system can be expressed via particle potential energy to show why the flocculation is occurring from an energetic standpoint (Kostansek, 2007). The energy diagrams for the two systems are shown in Figure 15. 

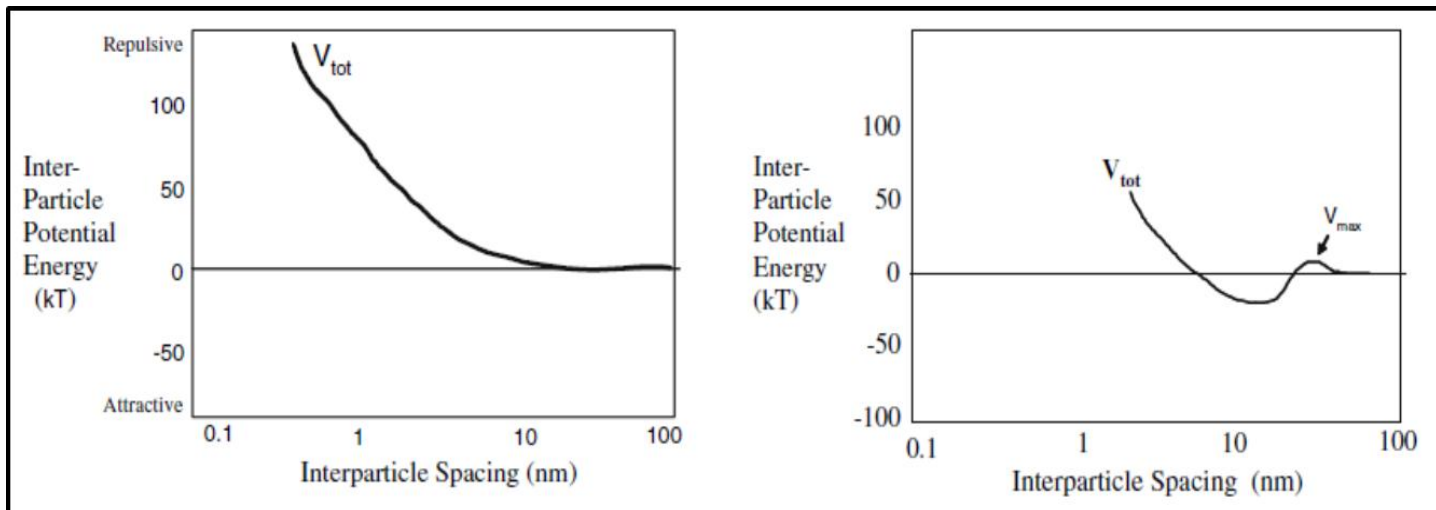

Figure 15. Interparticle potential energy diagram showing a good dispersion (on the left) and a depletion flocculation sample (on the right) (Kostansek, 2003).

The state of dispersion is dictated by the attractive and repulsive forces present in the coating. This state can be represented in a simple form of interparticle potential shown in Equation 1.

$$
V_{t o t}=V_{e l e c}+V_{v d w}+V_{d e p l}
$$

\section{Equation 1}

Velec represents the repulsive energy, $V v d w$ is the attractive energy due to Van der Waals forces, and Vdepl is the depletion energy as a result of the osmotic forces generated by non-adsorbing polymers and various particles in suspension (Kostansek, 2007). This simplified state of interparticle potential energy will help understand why separation is occurring. In Figure 15, the good dispersion sample shows that as the particles approach each other they only experience an increase in repulsive energy. The potential energy diagram for the depletion flocculation sample shows a well where attractive forces dominate which causes the particles to flocculate. There is an energy barrier present to put the depletion flocculation samples into a good dispersion, which 
explains why depletion flocculation is a time-dependent process which was observed by microscopy in Figure 14 (Kostansek, 2007).

\subsubsection{DPD Examples}

The work by Kostansek created multiple simple DPDs composed of various combinations of latex, thickener, and surfactant. The latexes that were studied were allacrylic latex, and styrene-acrylic latexes of various particle sizes. An example of a 140 $\mathrm{nm}$ BA/MMA Latex and sodium dodecyl sulfate (SDS) surfactant is shown in Figure 16 (Kostansek, 2003).

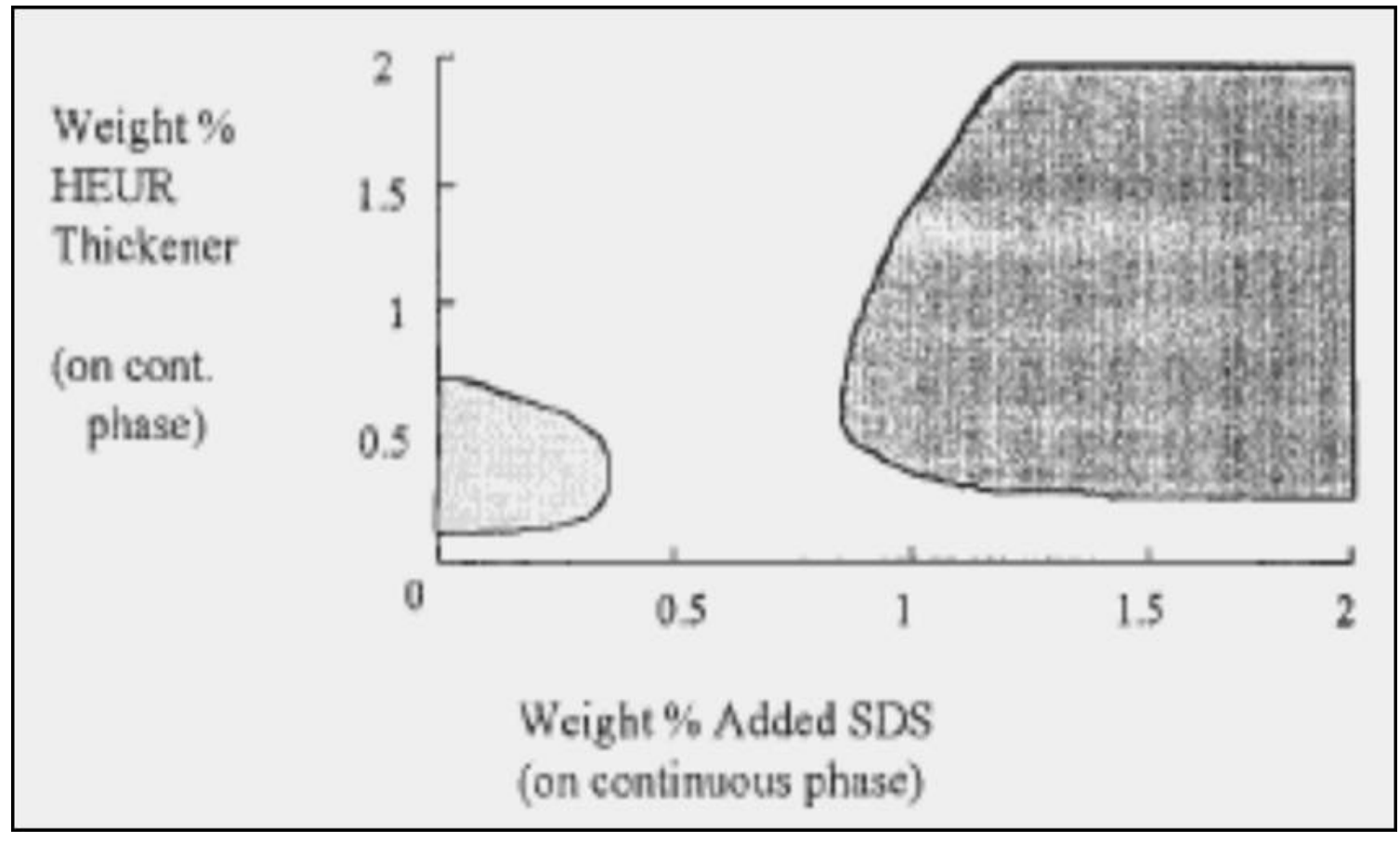

Figure 16. Phase diagram for a $140 \mathrm{~nm}$ BA/MMA thickened with HEUR (Kostansek, 2003).

The phase diagram shows that the smaller particle size latex, which has more surface area, leads to a large region of good dispersion. This is due to the surface area of the latex allowing for more adsorption sites of which the HEUR and SDS to interact with 
(Kostansek, 2003). Another aspect that was studied was the hydrophobicity of the latex surface on the flocculation regions. A larger particle size latex of $300 \mathrm{~nm} B A / M M A$ is shown in Figure 17 (Kostansek, 2003).

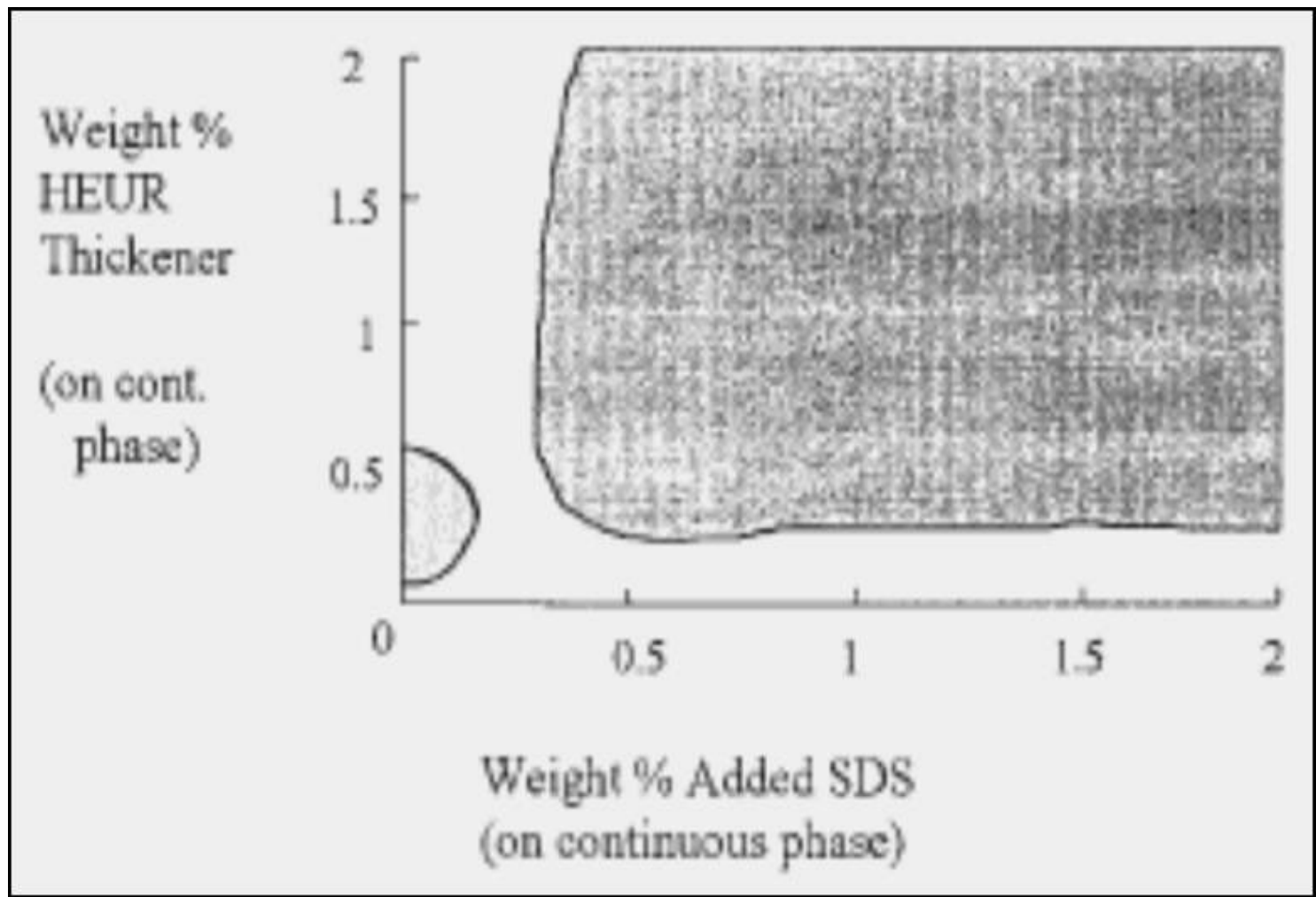

Figure 17. DPD for a $300 \mathrm{~nm}$ BA/MMA with a high concentration of surface acid (Kostansek, 2003).

The larger particle size of the latex, shown in Figure 17, significantly reduces the areas of which hydrophobes can adsorb and as a result the good dispersion region for this system is smaller (Kostansek, 2003). The other case of a more hydrophobic latex surface was also studied. When the latex surface is more hydrophobic the interactions of the surface with HEUR molecules is increased. A similar DPD is shown with a $300 \mathrm{~nm}$ BA/Styrene with the Styrene creating a more hydrophobic latex is shown in Figure 18 
(Kostansek, 2003). As a result of the increased hydrophobicity, the bridging flocculation and good dispersion regions are larger than the similar sized latex in Figure 17.

\section{Weight $\%$ \\ HEUR \\ Thickener}

(on cont.
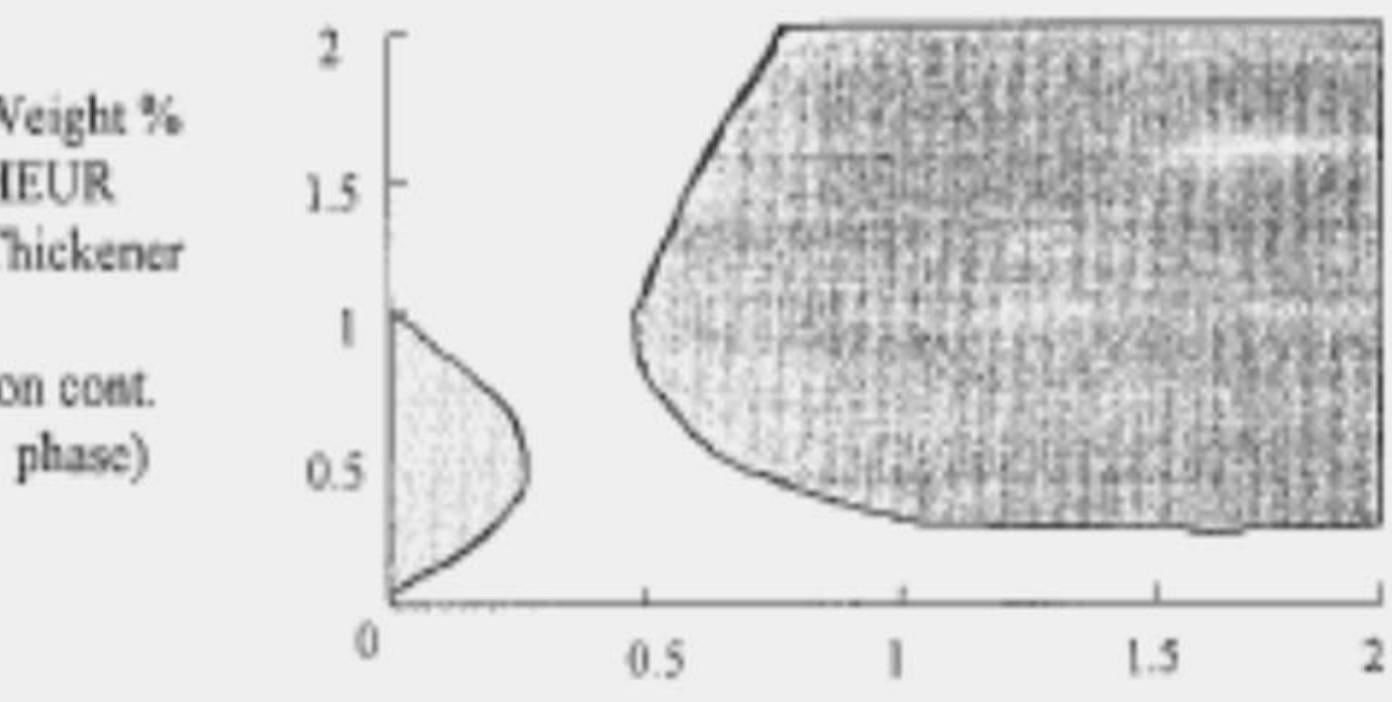

Weight $\%$ Added SDS

(on continuous phase)

Figure 18. DPD for a $300 \mathrm{~nm}$ BA/Styrene latex thickened with HEUR (Kostansek, 2003).

\subsection{Infrared Back Scatter (IRBS)}

The degree of pigment dispersion is of upmost importance since it affects both the optical and rheological properties of a fully formulated paint system. Typically, the degree of pigment dispersion is quantified using a quick and simple fineness of grind test; however, the test is non-quantitative and is limited to particles of 10 micrometers or more (Hall, Bordeleau, \& Rowland, 1988). The state of a dispersion is fundamentally accepted as the pigment particle size distribution within a certain medium. Many techniques have been used to measure the degree of pigment dispersion for coatings: sedimentation techniques, chromatography, electron microscopy, light scattering methods, contact microradiography, rub out test, and color strength (Hall, Bordeleau, \& 
Rowland, 1988). One technique has been shown to accurately describe the pigment flocculation in dry and wet paint films. The technique is based on the idea that the scattering efficiency of electromagnetic radiation by spherical particles is a function of the diameter of the particle with respect to the wavelength of radiation. This concept was utilized to quantify pigment flocculation in a dry paint film via IRBS. The study conducted by Balfour and Hird involved measuring the amount of IR radiation at $2500 \mathrm{~nm}$ that was back-scattered by a paint film at a given film thickness (Rutherford \& Simpson, 1985). The resulting measurement of IR backscatter is related to the amount of $\mathrm{TiO}_{2}$ flocculation present in the dry sample. The contribution of scattering by well-dispersed particles is very small and the scattering is mostly due to the aggregates and flocculates for a system (Balfour \& Hird, 1975). This technique called a flocculation gradient technique is essentially a quantification of the amount of radiation backscattered to a paint film as a function of wavelength, and can be used as a direct measuring tool for the amount of $\mathrm{TiO}_{2}$ aggregation for a dry paint film (Hall, Bordeleau, \& Rowland, 1988). 


\section{Experimental Methods - Cal Poly}

The first portion of this work was conducted at Cal Poly with funding from The Valspar Corporation. The work started at Cal Poly and was conducted for three months. The project was completed the following six months at The Valspar Corporation labs in Minneapolis.

\subsection{Paint Preparation}

\subsubsection{A - 0.26\% HEUR Starting Batch}

All materials were commercially available products and simplified paint formulations were also provided by The Valspar Corporation. The paints were made using a Series 2000 Premier Mill Corp laboratory disperser with a high-shear dispersion blade at Cal Poly State Chemistry Labs. The theoretical wt\% solids for this formulation is 44.77 , with a pigment volume concentration (PVC) of 21.77. The first latex studied was Acrylic-A which has a $105 \mathrm{~nm}$ particle size all-acrylic latex. The A of the 166A description means the paint is made using Acrylic-A. 
Table 1. 166A Paint Formulation.

\begin{tabular}{|ccc|}
\hline Material Name & \multicolumn{1}{c|}{ Amount $(\mathrm{g})$} \\
\hline & LETDOWN & \\
\hline Acrylic-A & & 44.762 \\
Defoamer & 0.097 \\
\hline & GRIND & \\
\hline Water & 6.296 \\
Dispersant & 0.487 \\
Co-Dispersant & 0.195 \\
Defoamer & 0.097 \\
Dry TiO ${ }_{2}$ & 21.894 \\
Microbicide & 0.162 \\
Coalescent Aid & 0.487 \\
Water & 7.327 \\
\hline Water & \\
\hline ADD TO LETDOWN & 14.012 \\
High Shear Thickener & 0 \\
Low-Shear Thickener & 0.584 \\
Water & 3.6 \\
\hline Total Weight & 100 \\
\hline
\end{tabular}

The grind was made first with a high-shear grind blade for 20 minutes. After 20 minutes, co-solvent and water were added and mixed at lower speed for an additional 5 minutes. The letdown was added to the mixing grind at lower speed and mixed for 2 minutes before thickener was added. The low-shear HEUR thickener was added and mixed at speed to maintain a vortex without dragging air bubbles into the system for 20 minutes. The batch containing $0.26 \%$ on the continuous (water) phase of low-shear HEUR thickener was immediately split into quarts of $514.5 \mathrm{~g}$ each of which surfactant additions were made. 


\subsubsection{CNS 166A Batch}

The first surfactant additions to be tested was the non-ionic Surfactant-A. The surfactant was added to $514.5 \mathrm{~g}$ of the $0.26 \%$ low-shear HEUR thickener batch previously described. The starting HEUR batch is called $166 \mathrm{~A}$ and will be used in the naming scheme for each individual sample. Each surfactant addition was made at medium speed with the same high-shear grind blade and allowed to mix for an additional 20 minutes. The samples made with the wt\% HEUR and wt\% surfactant with respect to the continuous (water) phase are listed in Table 2. For the remainder of this study, all wt\% HEUR and wt\% surfactant will be with respect to the continuous (water) phase. An example of the naming scheme of samples used in Table 2 is X166Y-AAAA-BBBB-CCC where $X$ is the location the paint was made ( $C$ for Cal Poly and $V$ for Valspar), 166 represents the $0.26 \%$ low-shear HEUR thickened starting batch, $\mathrm{Y}$ is for the latex used in the formulation ( $A$ for Acrylic-A and $B$ for Acrylic-B), AAAA is a numerical representation of the amount of total wt\% HEUR in the sample (multiplied by 1000), BBBB represents the wt\% surfactant in the sample (multiplied by 1000), and CCC represents the type of surfactant used (405 for Surfactant-A, 411 for Surfactant-B, and 100 for Surfactant-C). For ease of analysis the samples will be called by the call names shown. For example, for CNS-1 the C represents the sample was made at Cal Poly, and the NS represents the non-ionic Surfactant-A was used, and 1 is for the number of the sample in the set. All the paints that were made at Cal Poly used the same Acrylic-A latex. 
Table 2. Wt\% HEUR and surfactant for Surfactant-A additions to $166 \mathrm{~A}$.

\begin{tabular}{|c|c|c|c|}
\hline Sample & Call Name & Wt\% HEUR & Wt\% Surfactant \\
\hline C166A-0260-0000-405 & CNS-1 & 0.26 & 0.00 \\
\hline C166A-0260-0290-405 & CNS-2 & 0.26 & 0.29 \\
\hline C166A-0260-0580-405 & CNS-3 & 0.26 & 0.58 \\
\hline C166A-0260-0870-405 & CNS-4 & 0.26 & 0.87 \\
\hline C166A-0260-1160-405 & CNS-5 & 0.26 & 1.16 \\
\hline
\end{tabular}

\subsubsection{CAS 166A Batch}

The second surfactant additions to be tested were the anionic Surfactant-B. The surfactant was added to $514.5 \mathrm{~g}$ of the $166 \mathrm{~A}$ (0.26\% low-shear HEUR thickener) batch previously described, and the naming scheme is the same as well with CCC represented by 411 for the Surfactant-B. The additions made are listed in Table 3.

Table 3. Wt\% HEUR and surfactant for the Surfactant-B additions to 166A.

\begin{tabular}{|c|c|c|c|}
\hline Sample & Call Name & \% HEUR & \% Surfactant \\
\hline C166A-0026-0000-411 & CAS-1 & 0.26 & 0.00 \\
\hline C166A-0026-0029-411 & CAS-2 & 0.26 & 0.29 \\
\hline C166A-0026-0058-411 & CAS-3 & 0.26 & 0.58 \\
\hline C166A-0026-0087-411 & CAS-4 & 0.26 & 0.87 \\
\hline C166A-0026-0116-411 & CAS-5 & 0.26 & 1.16 \\
\hline
\end{tabular}

\subsection{4. $167 \mathrm{~A}-1.33 \%$ HEUR Starting Batch}

The next step in the DPD making process was to make samples containing higher levels of HEUR into which surfactant additions would be made. The 167A batch is very similar 
to $166 \mathrm{~A}$, with the exception of $1.07 \%$ increase in HEUR using the high-shear HEUR thickener. The same amount of low-shear HEUR thickener is contained in 167A and 166A. The formulation followed is shown in Table 4.

Table 4. 167A Paint Formulation.

\begin{tabular}{|c|c|}
\hline Material Name & Amount $(\mathrm{g})$ \\
\hline \multicolumn{2}{|c|}{ LETDOWN } \\
\hline Acrylic-A & 44.762 \\
\hline Defoamer & 0.097 \\
\hline \multicolumn{2}{|c|}{ GRIND } \\
\hline Water & 6.288 \\
\hline Dispersant & 0.486 \\
\hline Co-Dispersant & 0.194 \\
\hline Defoamer & 0.097 \\
\hline Dry $\mathrm{TiO}_{2}$ & 21.867 \\
\hline Microbicide & 0.162 \\
\hline Coalescent Aid & 0.486 \\
\hline Water & 7.318 \\
\hline \multicolumn{2}{|c|}{ ADD TO LETDOWN } \\
\hline Water & 11.205 \\
\hline High Shear Thickener & 2.916 \\
\hline Low-Shear Thickener & 0.583 \\
\hline Water & 3.6 \\
\hline Total Weight & 100 \\
\hline
\end{tabular}

The same paint making parameters were followed as $166 \mathrm{~A}$ with the exception of after each HEUR addition the paint was mixed at a speed to create vortex for 20 minutes. Each addition of HEUR was made separately and had individual mix times to ensure equilibrium was reached before the next HEUR was added.

\subsubsection{CNS 167A Batch}

Additions of surfactant were made to the higher wt\% HEUR batch of $167 \mathrm{~A}$. The surfactant used was Surfactant-A and the additions made are listed with the same 
naming scheme previously used in Table 5 . The call name list was continued from the CNS list previously made since the same latex and surfactant were used, and the only difference was the amount of HEUR used in the formulation.

Table 5. Wt\% HEUR and surfactant additions for the Surfactant-A additions to 167A.

\begin{tabular}{|c|c|c|c|}
\hline Sample & Call Name & Wt\% HEUR & Wt\% Surfactant \\
\hline C167A-0133-0000-405 & CNS-6 & 1.33 & 0.00 \\
\hline C167A-0133-0029-405 & CNS-7 & 1.33 & 0.29 \\
\hline C167A-0133-0058-405 & CNS-8 & 1.33 & 0.58 \\
\hline C167A-0133-0087-405 & CNS-9 & 1.33 & 0.87 \\
\hline C167A-0133-0116-405 & CNS-10 & 1.33 & 1.16 \\
\hline
\end{tabular}

Each sample was made following the same methods as $166 \mathrm{~A}$ samples in which the surfactant was added then mixed at medium speed for 20 minutes.

\subsection{Physical Property Testing}

Drawdowns were made immediately after the preparation of the paints with a 3 mil BYK drawdown bar. Gloss and contrast ratio $(C R)$ were measured from the drawdowns after the sample had dried overnight. The gloss was measured with a BYK microgloss meter and CR with a Datacolor Mercury colorimeter. Initial and 24 hour KU viscosities were measured using a Brooksfield Viscometer.

\subsection{Rheology}

The rheometer used for Cal Poly work was a Discovery HR-2 Hybrid Rheometer. The initial testing conducted at Cal Poly consisted of a shear rate ramp 0.1 to $1000 \mathrm{~s}^{-1}$ with a 
$5 \%$ torque consistency tolerance and maximum equilibrium time of 90 seconds. The viscosity profiles were presented in viscosity versus shear rate plots.

\subsection{Syneresis}

Syneresis tubes were set up immediately after surfactant was added and mixed for 20 minutes. Each sample was added to a $15 \mathrm{~mL}$ screw-topped glass tube and allowed to remain undisturbed for a one-week duration. The amount of separation was measured with a ruler in millimeters.

\subsection{Microscopy}

Digital micrographs were taken using a Leica DM2500P light microscope. Each slide was prepared by placing a small drop of paint on the slide with a glass cover on top without any further agitation. 


\section{Results - Cal Poly}

\subsection{CNS 166A - Non-ionic Surfactant Additions to $0.26 \%$ HEUR Batch}

\subsubsection{Physical Property Data}

The initial step in the analysis was performing overnight $(\mathrm{o} / \mathrm{n}) \mathrm{KU}$ viscosity, gloss, contrast ratio $(\mathrm{CR})$, and syneresis measurements. The data was collected for the samples made at Cal Poly, which was compared to a set of data previously obtained at Valspar earlier. Both sets of data, Valspar and Cal Poly, are shown in Table 6. The syneresis setup for the five samples is shown in Figure 19.

Table 6. Physical property data for Surfactant-A additions to 166A.

\begin{tabular}{|c|c|c|c|c|c|c|c|c|c|c|c|}
\hline \multirow{2}{*}{ Sample } & \multirow{2}{*}{$\begin{array}{l}\text { Call } \\
\text { Name }\end{array}$} & \multirow{2}{*}{$\begin{array}{c}\% \\
\text { HEUR }\end{array}$} & \multirow{2}{*}{$\begin{array}{l}\% \\
\text { Surf }\end{array}$} & \multicolumn{2}{|c|}{ Contrast Ratio } & \multicolumn{2}{|c|}{ 60' Gloss } & \multicolumn{2}{|c|}{$\begin{array}{l}\text { Overnight KU } \\
\text { Viscosity }\end{array}$} & \multicolumn{2}{|c|}{ Syneresis } \\
\hline & & & & Valspar & $\begin{array}{l}\text { Cal } \\
\text { Poly }\end{array}$ & Valspar & $\begin{array}{l}\text { Cal } \\
\text { Poly }\end{array}$ & Valspar & $\begin{array}{l}\text { Cal } \\
\text { Poly }\end{array}$ & Valspar & $\begin{array}{l}\text { Cal } \\
\text { Poly }\end{array}$ \\
\hline $\begin{array}{c}\text { C166A- } \\
0260- \\
0000- \\
405\end{array}$ & $\begin{array}{c}\text { CNS- } \\
1\end{array}$ & 0.26 & 0.00 & 97.53 & 96.97 & 33.80 & 19.30 & 108.0 & 110.2 & 13 & 8 \\
\hline $\begin{array}{c}\text { C166A- } \\
0260- \\
0290- \\
405\end{array}$ & $\begin{array}{c}\text { CNS- } \\
2\end{array}$ & 0.26 & 0.29 & 97.74 & 98.14 & 48.50 & 21.80 & 107.6 & 111.9 & 19 & 10 \\
\hline $\begin{array}{c}\text { C166A- } \\
0260- \\
0580- \\
405\end{array}$ & $\begin{array}{c}\text { CNS- } \\
3\end{array}$ & 0.26 & 0.58 & 97.42 & 97.90 & 59.00 & 25.50 & 104.0 & 112.6 & 21 & 8 \\
\hline $\begin{array}{c}\text { C166A- } \\
0260- \\
0870- \\
405\end{array}$ & $\begin{array}{c}\text { CNS- } \\
4\end{array}$ & 0.26 & 0.87 & 95.77 & 97.45 & 60.10 & 36.60 & 95.6 & 109.1 & 15 & 19 \\
\hline $\begin{array}{c}\text { C166A- } \\
0260- \\
1160- \\
405\end{array}$ & $\begin{array}{l}\text { CNS- } \\
5\end{array}$ & 0.26 & 1.16 & 96.00 & 95.35 & 63.10 & 34.00 & 87.5 & 106.4 & 0 & 10 \\
\hline
\end{tabular}


The drawdowns for CR measurements were made at Cal Poly 7 days after mixing, and the Valspar samples were made 1 day after mixing. The physical property testing for the Cal Poly work was essential in learning the processes of which the testing methods could be improved upon. For ease of analysis, the sample names will be called by call names.

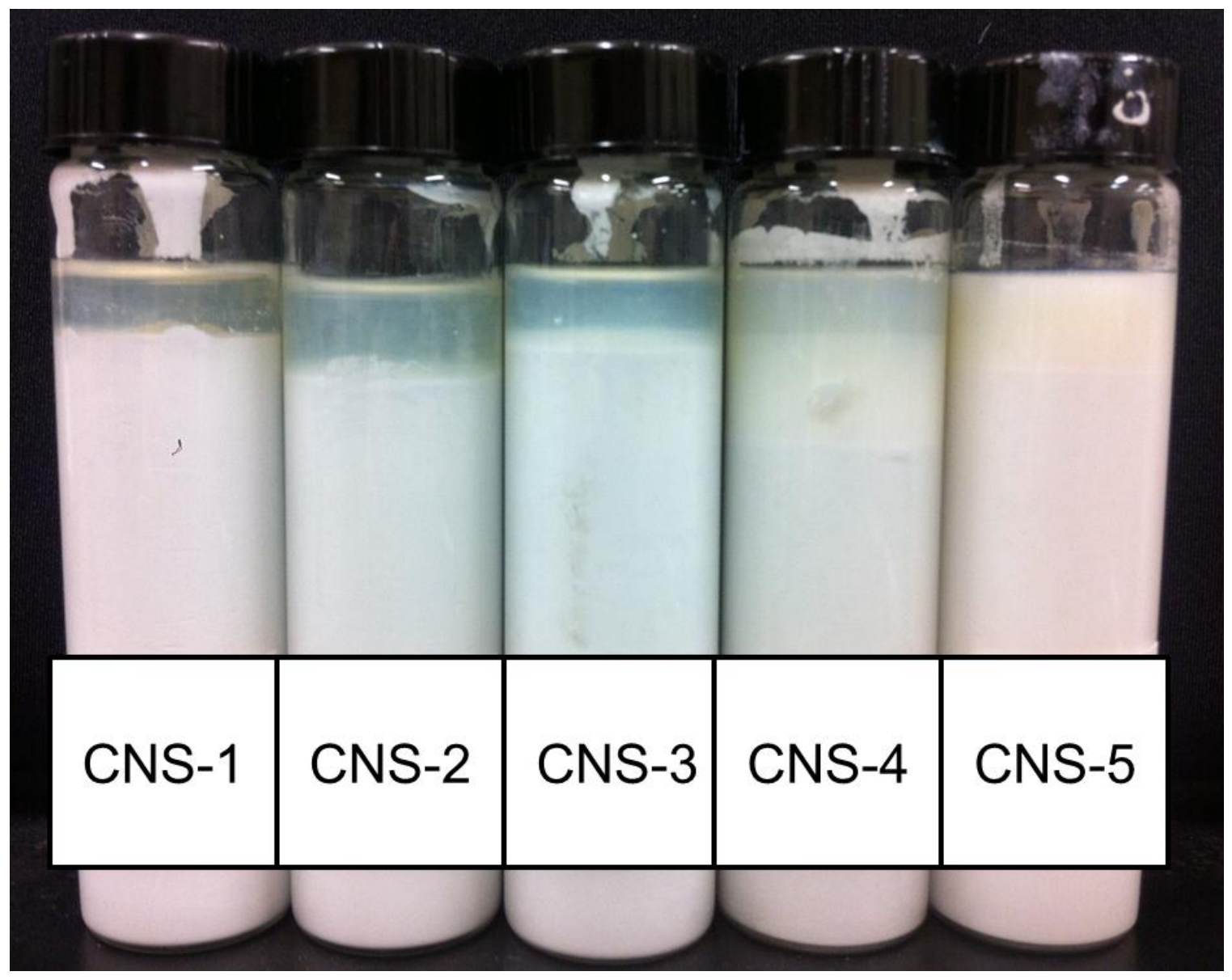

Figure 19. Syneresis tubes for CNS-1 to CNS-5 after one week of syneresis.

There were some initial concerns in comparing the paint samples made at Cal Poly to those made at Valspar. Table 6 shows four analysis columns with Valspar's results on the left and Cal Poly's results on the right. First, there are some clear discrepancies in 
CR results. CNS-1 to CNS-3 appear to be relatively close in values, but when comparing CNS-4 and CNS-5 there are some differences that must be noted. The CR for CNS-4 for Valspar is about 2 units smaller than Cal Poly, and the CR difference for CNS-4 and CNS-5 for Valspar stays relatively unchanged whereas the Cal Poly sample has a large drop. Next, the gloss was examined and an increasing trend was observed for both Valspar and Cal Poly samples, except for CNS-5 for Cal Poly which had a loss in gloss. There are large differences in the actual gloss values; however, this could be accounted for by the fact that the measurements were made after 24 hours since mixing for Valspar and 7 days for Cal Poly. Some of these differences in actual values may be accounted for by the time duration. Another explanation is also due to the difference of high-speed mixer used for Valspar and Cal Poly. The timing of mixing was the same on both sides; however, the shear rate could have been a variation. The overnight $\mathrm{KU}$ measurements were examined next. Valspar followed a decreasing trend, whereas Cal Poly had a slight increase for CNS-1 to CNS-3, followed by a slight decrease. The largest difference in KU between Cal Poly and Valspar was seen in CNS-4 and CNS-5, which had a large drop in viscosity for Valspar, with Cal Poly only showing a slight drop. The last column compared the syneresis test results. The height of syneresis measured was from the line of separation to the top of the sample. The glaring difference again is in CNS-5 with the Valspar sample having no separation, and Cal Poly sample having $10 \mathrm{~mm}$ of separation.

After careful analysis and comparison of the two sets of results there is clearly some discrepancies between the paint made at Valspar and Cal Poly. Each paint was made following the same formulation, so the differences must be due to the time the paint was allowed to remain undisturbed before testing, the mixer used, and possibly human error when preparing the paints. Nonetheless, the outliers appear to be CNS-4 and CNS-5 for the comparison of the two sets. This initial testing at Cal Poly was to become familiar 
with making and analyzing the paints. The inability to recreate the exact samples as had previously been done at Valspar is due to the differences in the preparation procedure between the two labs. The major differences include the separation of the grind and letdowns as well as using the appropriate blades for each. This alone could account for the major differences in physical data, so this data was not used in the construction of any DPDs.

\subsubsection{Rheology}

Shear-rate experiments were performed on the rheometer with the parameters previously listed in the experimental section. Two controls were run initially - a $500 \mathrm{cp}$ Newtonian oil, and a HEC-thickened latex paint, and the results are shown in Figure 20, and Figure 21, respectively. Rheology data for samples CNS-1 to CNS-5 are shown in Figure 22. 


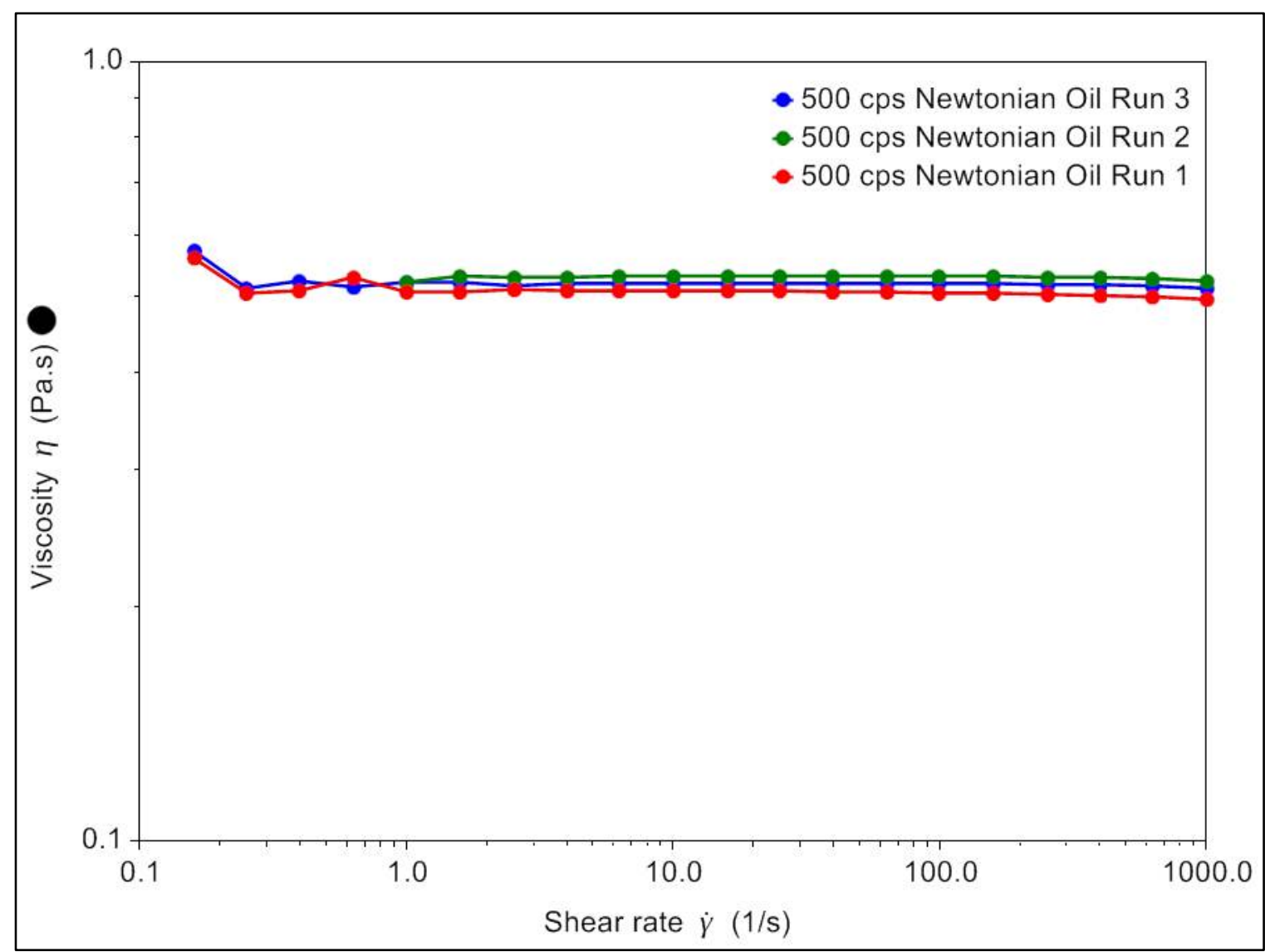

Figure 20. Rheological data for 500 cps Newtonian oil control. 


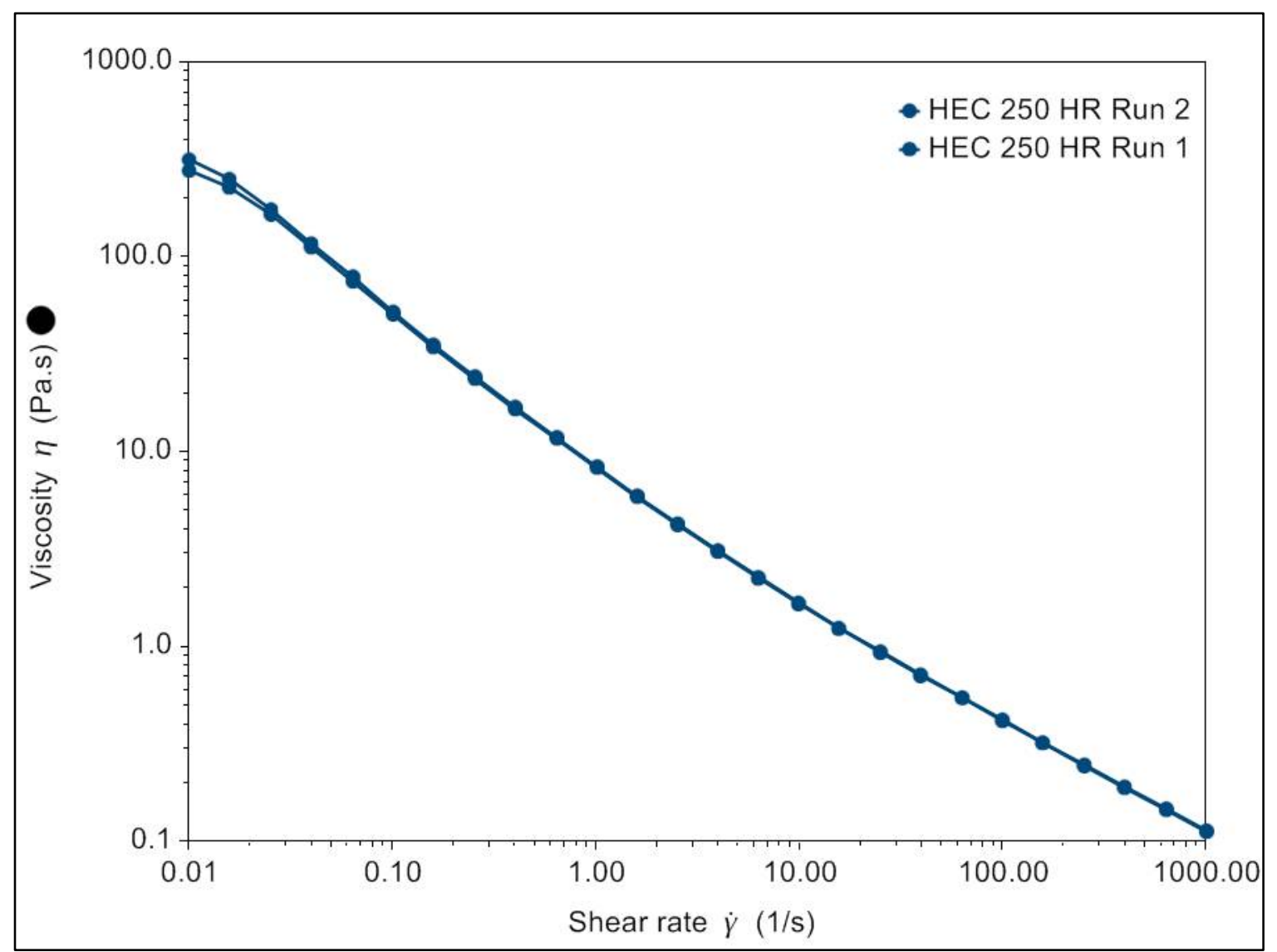

Figure 21. Rheological data for HEC control and latex paint.

For the two controls, the results are as expected. The Newtonian sample shows Newtonian-like behavior over the entire range of shear-rates. The HEC thickened sample shows shear-thinning behavior for the entire graph which is expected of a depletion-flocculated sample. 


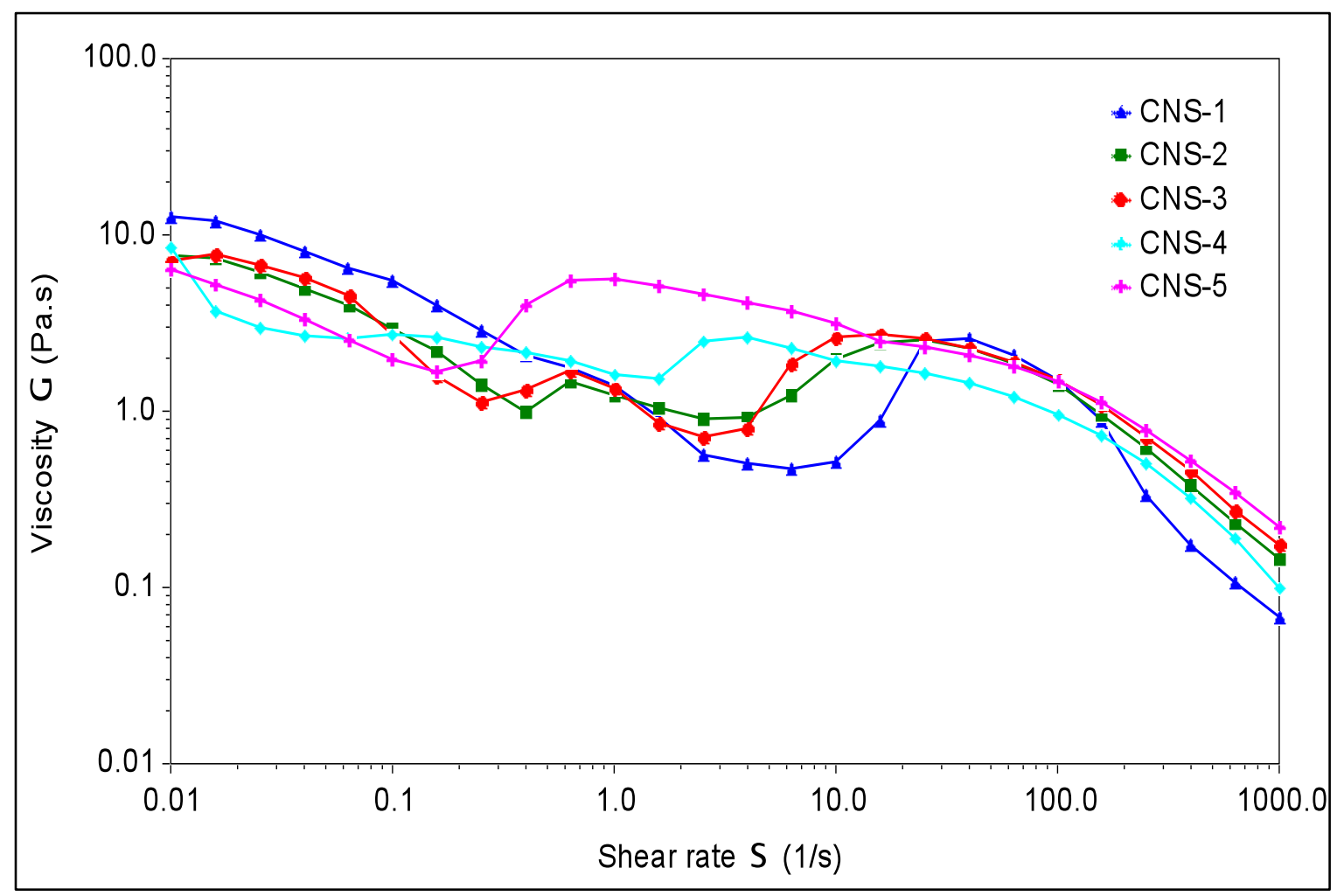

Figure 22. Rheological data for samples CNS-1 to CNS-5.

The rheological data for this system followed a general trend of shear-thinning at the low shear end rate followed by a shear-thickening portion at medium shear-rates. At higher shear-rates, the rheological curves showed a shear-thinning region. As the nonionic surfactant concentration is increased from CNS-1 to CNS-5, a shift in the maxima of the shear-thickening region can be observed. The shift becomes much more profound at higher levels of surfactant, as the surfactant is shifting equilibriums between thickener, latex particles, and pigment in the system. Looking at the rheology data, the region between 100 to $1000 \mathrm{~s}^{-1}$ shows a trend of increasing viscosity with surfactant. The flow behavior of colloidal systems depends on the type of flocculation mechanisms present, which are dictated by the conformation of polymer chains. One of the most important factors to control the rheology of these systems containing an associative polymer is the affinity between the polymer chains and particle surface (Otsubo, 1995). Due to the 
nature of the bridging of two particles by a flexible polymer coil, elastic and deformable flocs can be made in suspensions flocculated by reversible bridging. When the dispersion is placed under shear the bridges are subjected to rapid extension which can lead to high resistance to flow from the restoring forces present in the adsorbed bridges. The extended bridges can result in high resistance to flow if the adsorption to the particle is stronger than the applied shear. This results in the viscosity vs. shear rate graph becoming shear thickening at intermediate shear rates, which was observed for samples CNS-1 to CNS-5 (Otsubo, 1999).

Otsubo accounts for the shear-thickening flow primarily from the extension of the bridges. When higher shear is applied the bridges are extended until they finally desorb from the particle which is represented in a simple schematic in Figure 23, by the shearthinning portion at higher shear rates. In the schematic, CNS-1 is used as an example to show the extension of the bridge with its relation to the position on the viscosity profile. The bridge is extended until it finally desorbs from the particle and the thickening mechanism is lost (shown with a sharp shear-thinning portion at high-shear rate). Since desorption occurs at a constant force, the system shows plastic flow at high shear rates (Otsubo, 1999). The shear-rate ramp up test will be used in further testing of bridging flocculation in paint samples. 


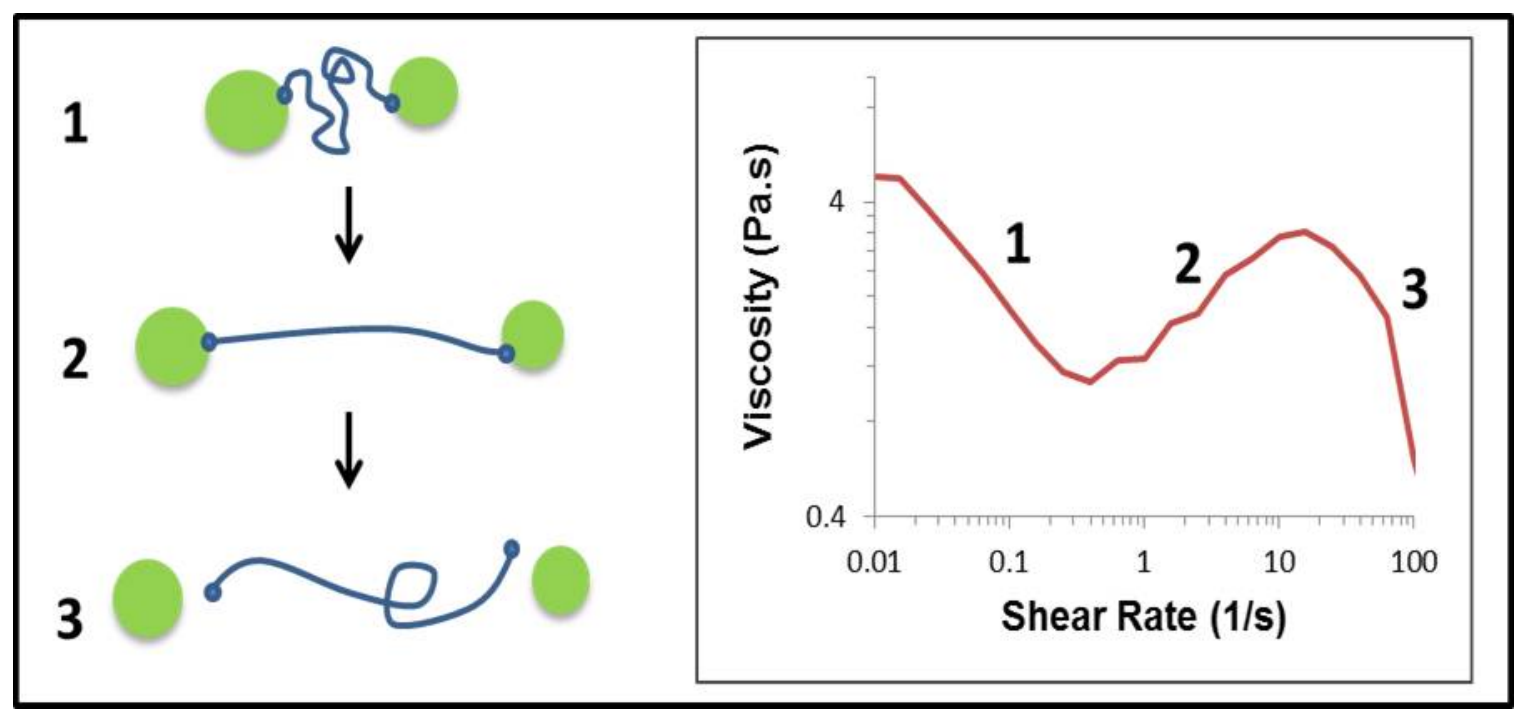

Figure 23. Schematic showing extension of bridge with respect to CNS-1 rheology curve containing a shear-thickening region.

\subsubsection{Microscopy}

Microscopy was used as an attempt to examine different forms of flocculation that may be occurring. The pictures are shown in Figure 24. 


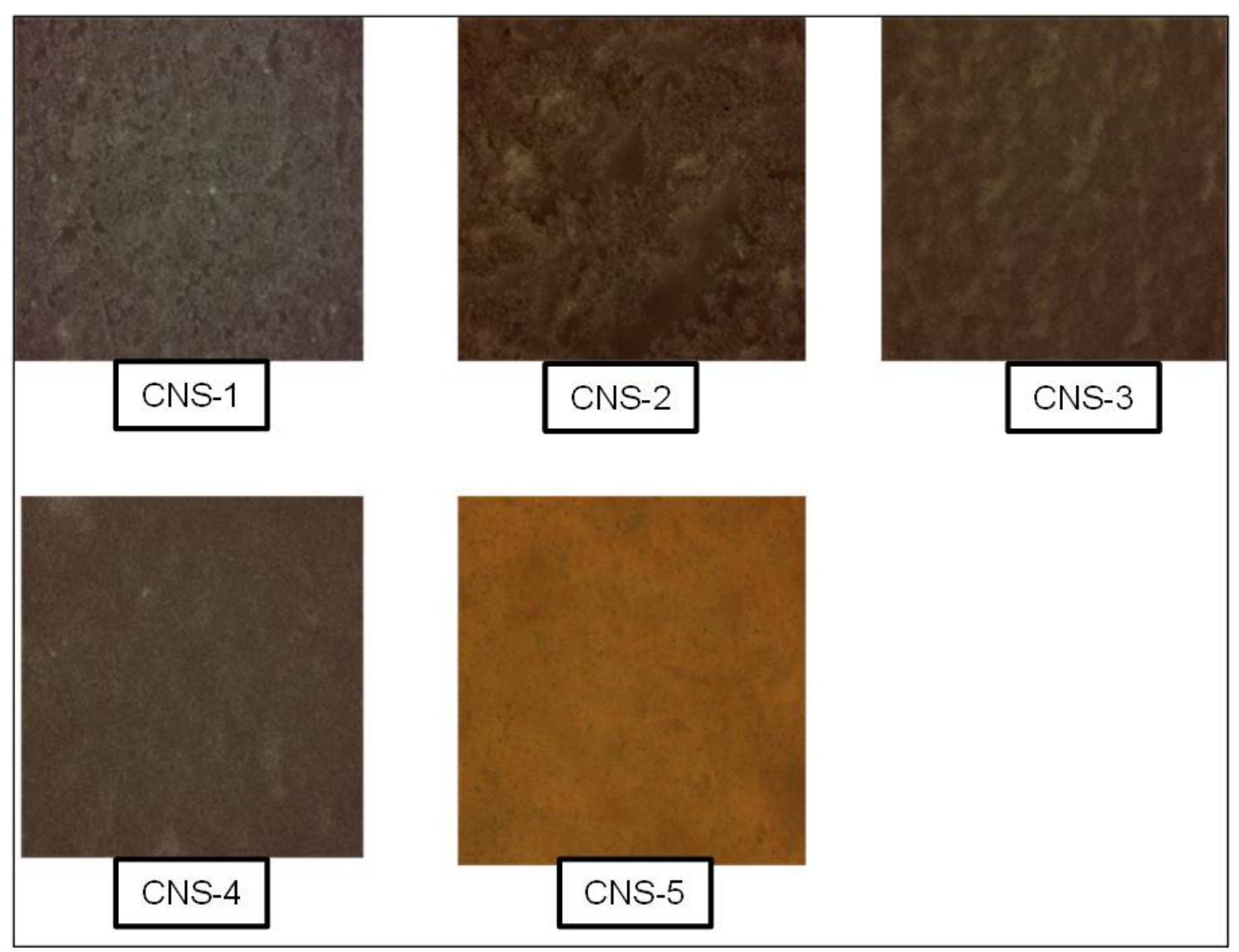

Figure 24. Microscopy pictures for samples CNS-1 to CNS-5 at 20x.

For samples CNS-1 - CNS-3 there is some noticeable channels in the samples, whereas CNS-4 and CNS-5 appear to have no similar characteristic channels. These observations match up with the type of syneresis observed. CNS-1 to CNS-3 had clear separations and CNS-4 and CNS-5 had opaque separations. The only conclusions that can be made are that there are clearly some observable separations for CNS-1 to CNS3, but not for CNS-4 and CNS-5. The use of microscopy for further analysis was not conducted due to the unavailability of a high power microscope. 


\subsection{CAS $166 \mathrm{~A}$ - Anionic Surfactant Additions to $0.26 \%$ HEUR Batch}

\subsubsection{Physical Property Data}

The physical property data for the anionic additions are shown in Table 7.

Table 7. Physical property data for anionic additions of Surfactant-B to $166 \mathrm{~A}$.

\begin{tabular}{|c|c|c|c|c|c|c|c|c|c|c|c|}
\hline \multirow{2}{*}{ Sample } & \multirow{2}{*}{$\begin{array}{c}\text { Call } \\
\text { Name }\end{array}$} & \multirow{2}{*}{$\begin{array}{c}\% \\
\text { HEUR }\end{array}$} & \multirow{2}{*}{$\begin{array}{c}\% \\
\text { Surf }\end{array}$} & \multicolumn{2}{|c|}{ Contrast Ratio } & \multicolumn{2}{|c|}{ 60' Gloss } & \multicolumn{2}{|c|}{$\begin{array}{l}\text { Overnight KU } \\
\text { Viscosity }\end{array}$} & \multicolumn{2}{|c|}{ Syneresis } \\
\hline & & & & Valspar & $\begin{array}{c}\text { Cal } \\
\text { Poly }\end{array}$ & Valspar & $\begin{array}{c}\text { Cal } \\
\text { Poly }\end{array}$ & Valspar & $\begin{array}{c}\text { Cal } \\
\text { Poly }\end{array}$ & Valspar & $\begin{array}{l}\text { Cal } \\
\text { Poly }\end{array}$ \\
\hline $\begin{array}{c}\text { C166A- } \\
0260- \\
0000- \\
411\end{array}$ & $\begin{array}{c}\text { CAS- } \\
1\end{array}$ & 0.26 & 0.00 & 97.53 & 96.98 & 33.80 & 19.20 & 108.0 & 109.0 & 13 & 7 \\
\hline $\begin{array}{c}\text { C166A- } \\
0260- \\
0290- \\
411\end{array}$ & $\begin{array}{c}\text { CAS- } \\
2\end{array}$ & 0.26 & 0.29 & 98.01 & 97.39 & 62.10 & 42.30 & 110.7 & 115.1 & 22 & 17 \\
\hline $\begin{array}{c}\text { C166A- } \\
0260- \\
0580- \\
411\end{array}$ & $\begin{array}{c}\text { CAS- } \\
3\end{array}$ & 0.26 & 0.58 & 97.15 & 98.22 & 64.50 & 62.20 & 92.2 & 105.2 & 7 & 20 \\
\hline $\begin{array}{c}\text { C166A- } \\
0260- \\
0870- \\
411\end{array}$ & $\begin{array}{c}\text { CAS- } \\
4\end{array}$ & 0.26 & 0.87 & 96.85 & 95.49 & 61.40 & 60.80 & 64.3 & 78.0 & 4 & 0 \\
\hline $\begin{array}{c}\text { C166A- } \\
0260- \\
1160- \\
411\end{array}$ & $\begin{array}{c}\text { CAS- } \\
5\end{array}$ & 0.26 & 1.16 & 96.10 & 93.84 & 63.50 & 63.00 & 55.0 & 58.9 & 1 & 0 \\
\hline
\end{tabular}

The drawdowns for CR measurements were made at Cal Poly 7 days after mixing, and the Valspar samples were made 1 day after mixing. The physical property testing for the Cal Poly work was simply to learn the processes of which the testing methods would be improved upon. 


\subsubsection{Rheology}

Rheology data for the paint samples with the anionic surfactant additions are shown in Figure 25. For simplicity of referencing samples within this document the samples will be called by the call names shown in Table 7.

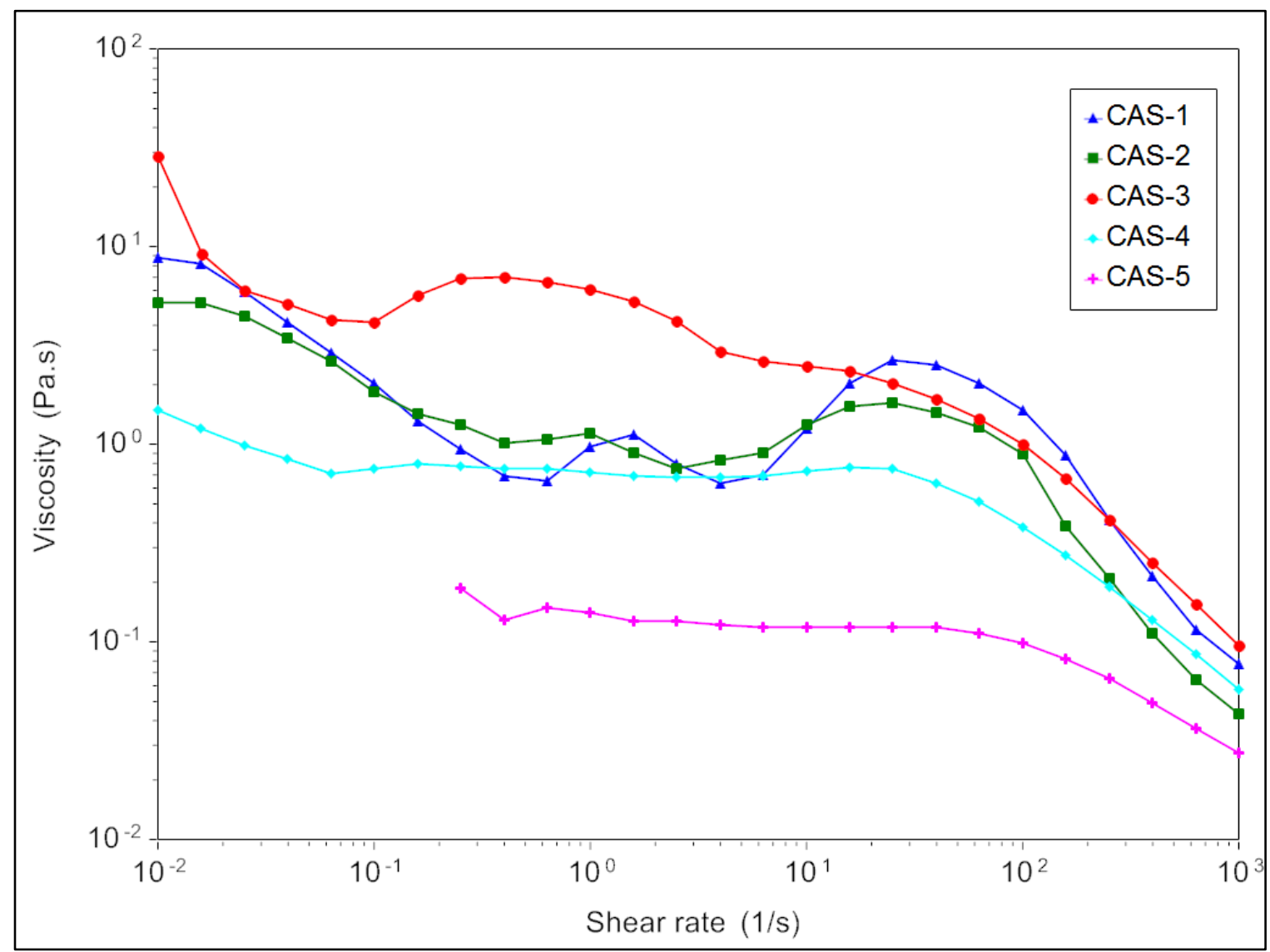

Figure 25. Rheological data for samples CAS-1 to CAS-5.

With the addition of an anionic surfactant, the maxima again shifted to the left until samples $\mathrm{H}$ and I showed large drops in viscosity and did not have any maxima. The torque sensitivity of the rheometer for CAS- 5 did not extend into shear rates below 0.10 $\mathrm{s}^{-1}$ as a result of the very low viscosity of the sample. CAS-1 to CAS-3 follow the same pattern as seen in with the non-ionic surfactant, but the samples of CAS-4 and CAS-5 did not show any syneresis and did not have maxima. The prior evidence presented 
along with the work by Otsubo points towards the shifting of the maxima resulting from the bridging flocculation present. For samples CAS-4 and CAS-5 a good dispersion was maintained over the week period; however, there was a large viscosity drop. The surfactant could be stabilizing the system but at the cost of disrupting the viscosifying mechanism of the HEUR associative thickener. The syneresis tubes for this sample set are shown in Figure 26. The test showed CAS-1 and CAS-2 having clear colored separations, and CAS-3 having an opaque separation. Samples CAS-4 and CAS-5 had no visible separation.

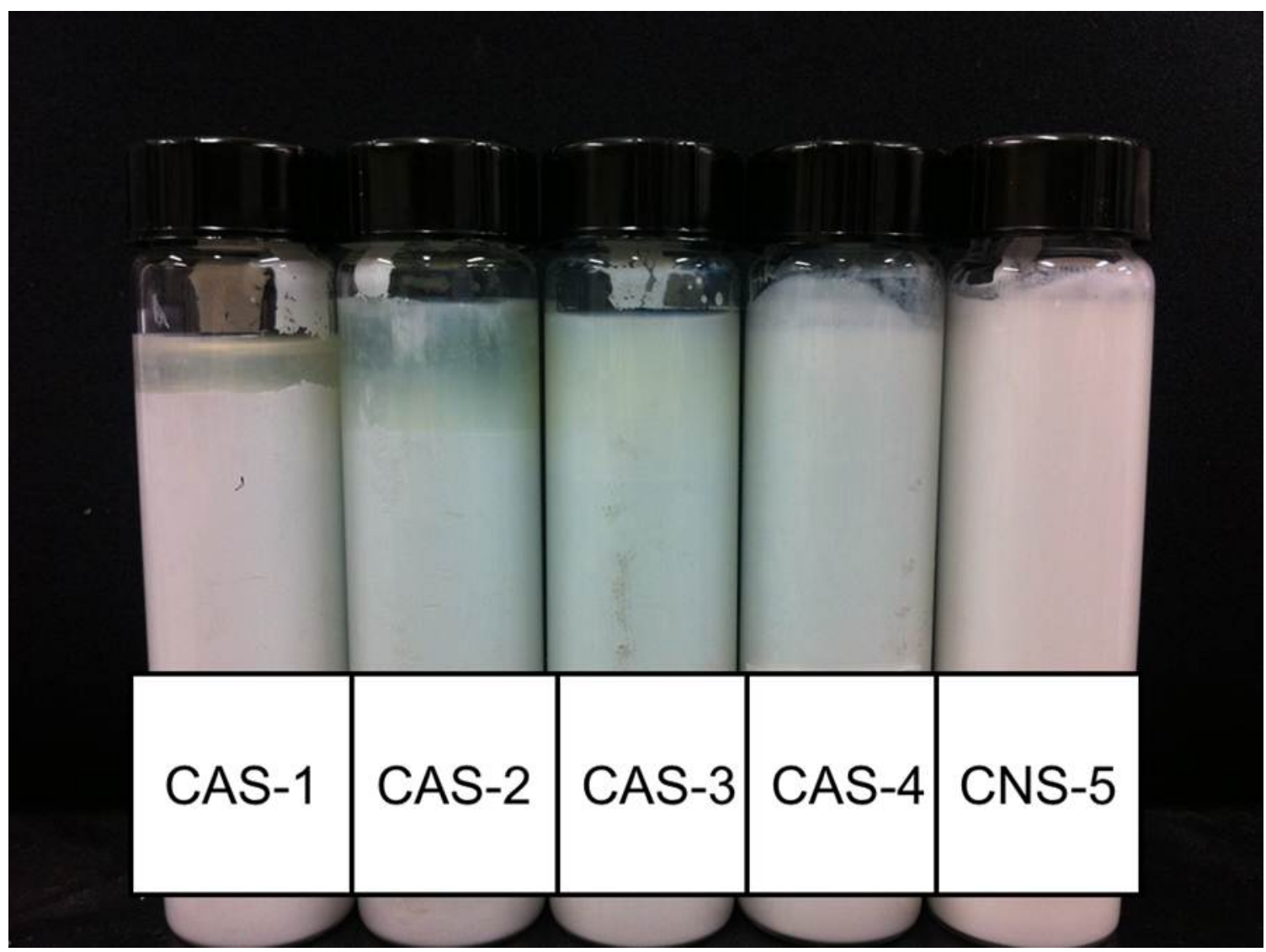

Figure 26. Syneresis tubes for CAS-1 to CAS-5 one week after samples were made.

The surfactants have been shown to interact with the associative polymer, pigment, and latex in a given system. One study using SDS, which has a sulfate anion head group 
similar to Surfactant-B, showed that the SDS was effective at destroying the viscosifying mechanisms of a HEUR thickened system (Kostansek, 2007). The same results were observed using Surfactant-B as for SDS in Kostansek's work, in which the surfactant significantly shrank the bridging flocculation region and the bridging phenomena was not observed at lower surfactant concentrations. The samples lacking this bridging flocculation region were concluded to be either a good dispersion or depletion flocculation sample.

\subsubsection{Microscopy}

Microscopy was run for samples CAS-1 to CAS-5 shown in Figure 27 . Here the separation is only seen for CAS-1 and CAS-2. Again these were the only two samples that had a clear separation, whereas CAS-3 had an opaque separation and CAS-4 and CAS-5 had no separation. In this case, there is no noticeable difference between CAS-3 with an opaque separation and CAS-4 and CAS- 5 without separation. For these current results, no solid conclusions can be made except that there are clear observable channels for the samples with a top clear colored separation layer. 


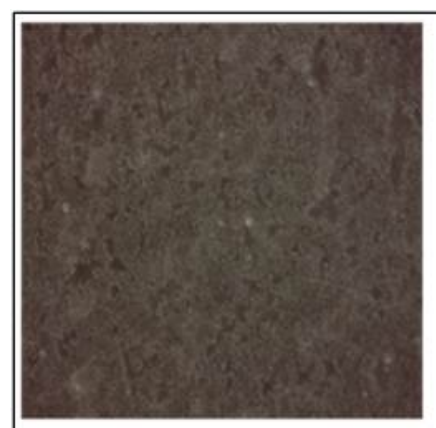

CAS-1

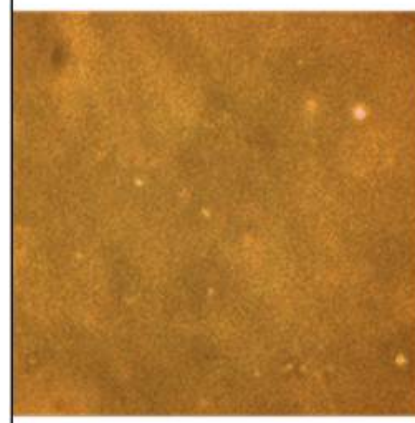

CAS-4

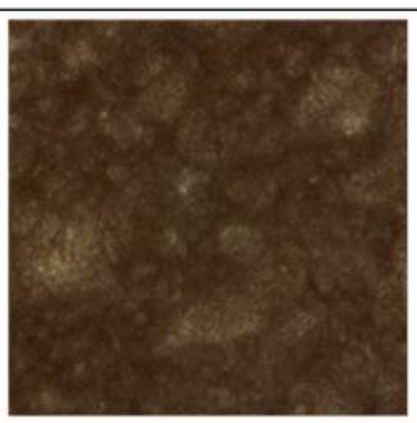

CAS-2 CAS-3

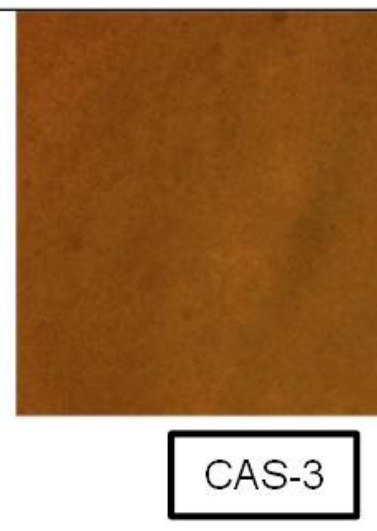

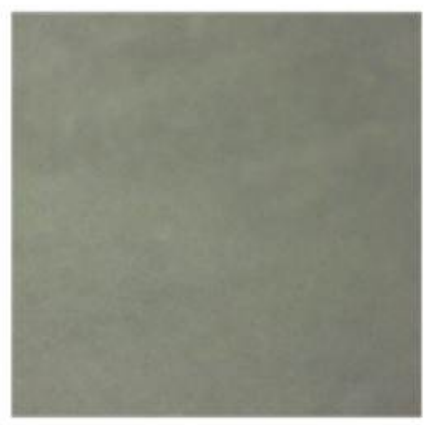

CAS-5

Figure 27. Microscopy pictures for samples CAS-1 to CAS-5 at 20x.

3.3. CNS 167A - Non-ionic Surfactant Additions to $1.33 \%$ HEUR Starting Batch

\subsubsection{Physical Property Data}

For ease of analysis of the data, the sample names and call names will be used interchangeably. The physical property data for CNS-6 to CNS-10 was collected using the same methods as the 166 series at Cal Poly, and is shown in Table 8. 
Table 8. C167A to C167E Physical Property Data.

\begin{tabular}{|c|c|c|c|c|c|c|c|}
\hline Sample & $\begin{array}{c}\% \\
\text { HEUR }\end{array}$ & $\begin{array}{c}\% \\
\text { SURF }\end{array}$ & $\begin{array}{c}3 \text { mil } \\
\text { CR }\end{array}$ & $\begin{array}{c}60^{\circ} \\
\text { Gloss }\end{array}$ & $\begin{array}{c}\text { o/n KU } \\
\text { Visc }\end{array}$ & $\begin{array}{c}\text { Syneresis } \\
(\mathrm{mm})\end{array}$ & $\begin{array}{c}\text { Color of } \\
\text { Separation }\end{array}$ \\
\hline CNS-6 & 1.33 & 0.00 & 97.73 & 61.70 & 104.3 & 0 & no separation \\
\hline CNS-7 & 1.33 & 0.29 & 97.84 & 63.00 & 101.3 & 0 & no separation \\
\hline CNS-8 & 1.33 & 0.58 & 97.70 & 63.80 & 97.4 & 0 & no separation \\
\hline CNS-9 & 1.33 & 0.87 & 97.91 & 63.40 & 93.3 & 0 & no separation \\
\hline CNS-10 & 1.33 & 1.16 & 97.53 & 61.80 & 88.6 & 0 & no separation \\
\hline
\end{tabular}

Each sample for the CNS 167A series showed no separation in the syneresis experiments. The drawdowns that were measured showed high values of gloss which is typical of a sample with a good dispersion. These samples were expected to be good dispersions and the data reflected the predictions. The addition of surfactant caused a drop in KU viscosity as seen in the CNS 166A data set. For a non-ionic surfactant, the maxima in viscosity generally occurs at higher concentrations than the CMC of the surfactant (Glass, 2001). If this is true, the first addition of surfactant would appear to be above the CMC of the surfactant and thus cause the drop in the viscosity. The viscosity drop is dependent upon the HEUR used, latex size, and hydrophobicity of both thickener and surfactant, so the viscosity drop seen for this system could be different than the systems used for the study by Glass.

\subsubsection{Rheology}

The 167 data set contained samples CNS-6 to CNS-10 with increasing amounts of nonionic surfactant. The samples had 2 different HUER thickeners and yielded samples with excellent dispersions. The rheological profiles are shown in Figure 28. 


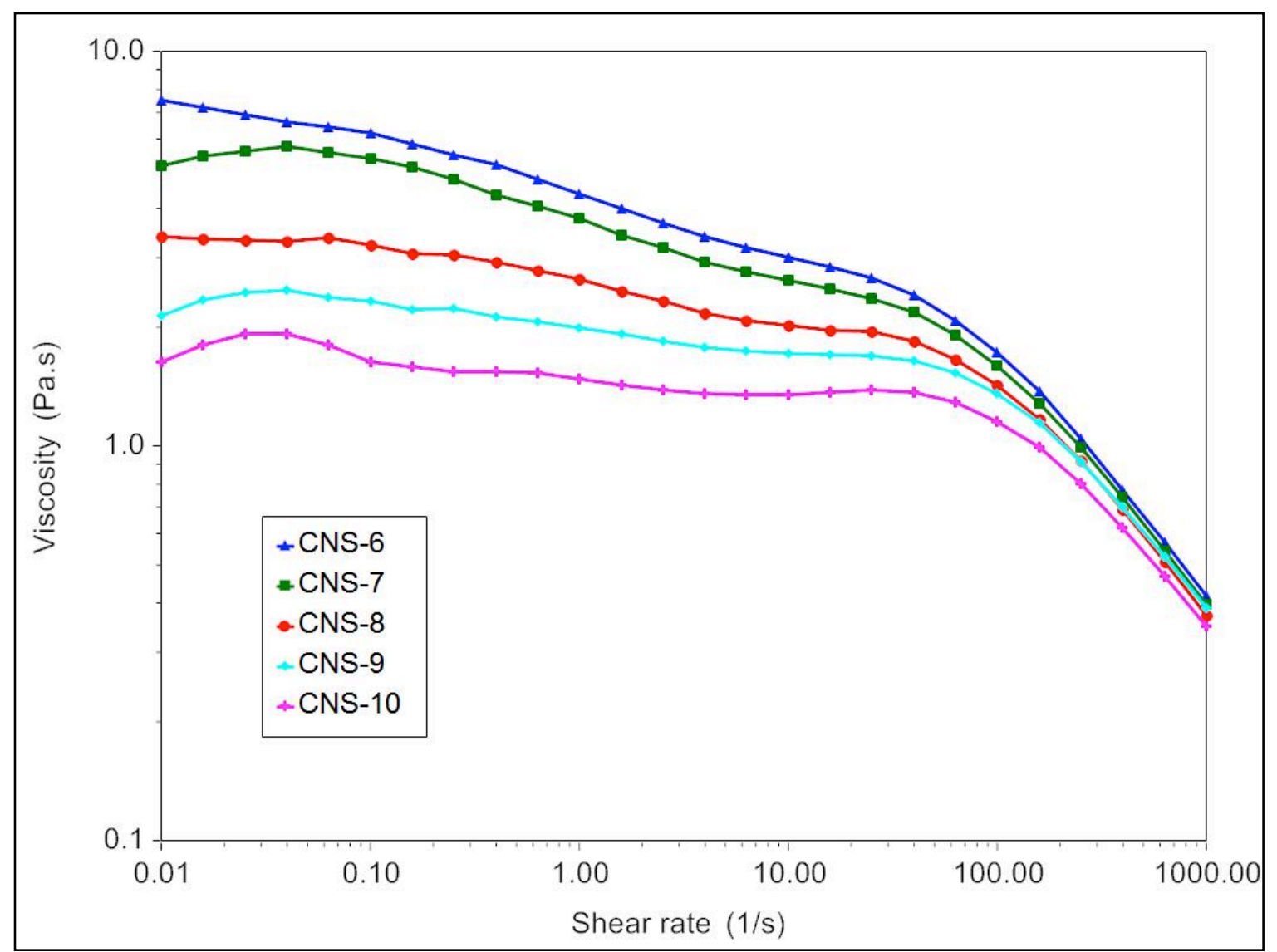

Figure 28. Rheological data for samples CNS-6 to CNS-10.

The rheology data showed a decrease in viscosity with an increase in surfactant concentrations at lower shear rate. At higher shear rates above $100 \mathrm{~s}^{-1}$, the viscosity differences became much smaller for the samples. The samples followed Newtonian like behaviors below $100 \mathrm{~s}^{-1}$ then showed shear thinning behavior above $100 \mathrm{~s}^{-1}$. The higher HEUR levels created good dispersion samples; however, the surfactant additions did cause drops in viscosity as previously observed. Most likely, the surfactant is disrupting the HEUR thickening molecules by desorbing some of the associating polymer from the latex surface; however, the much higher amount of HEUR is still promoting a well dispersed system. 


\subsubsection{Microscopy}

Microscopy was also conducted for samples CNS-6 to CNS-10 and is shown in Figure 29.

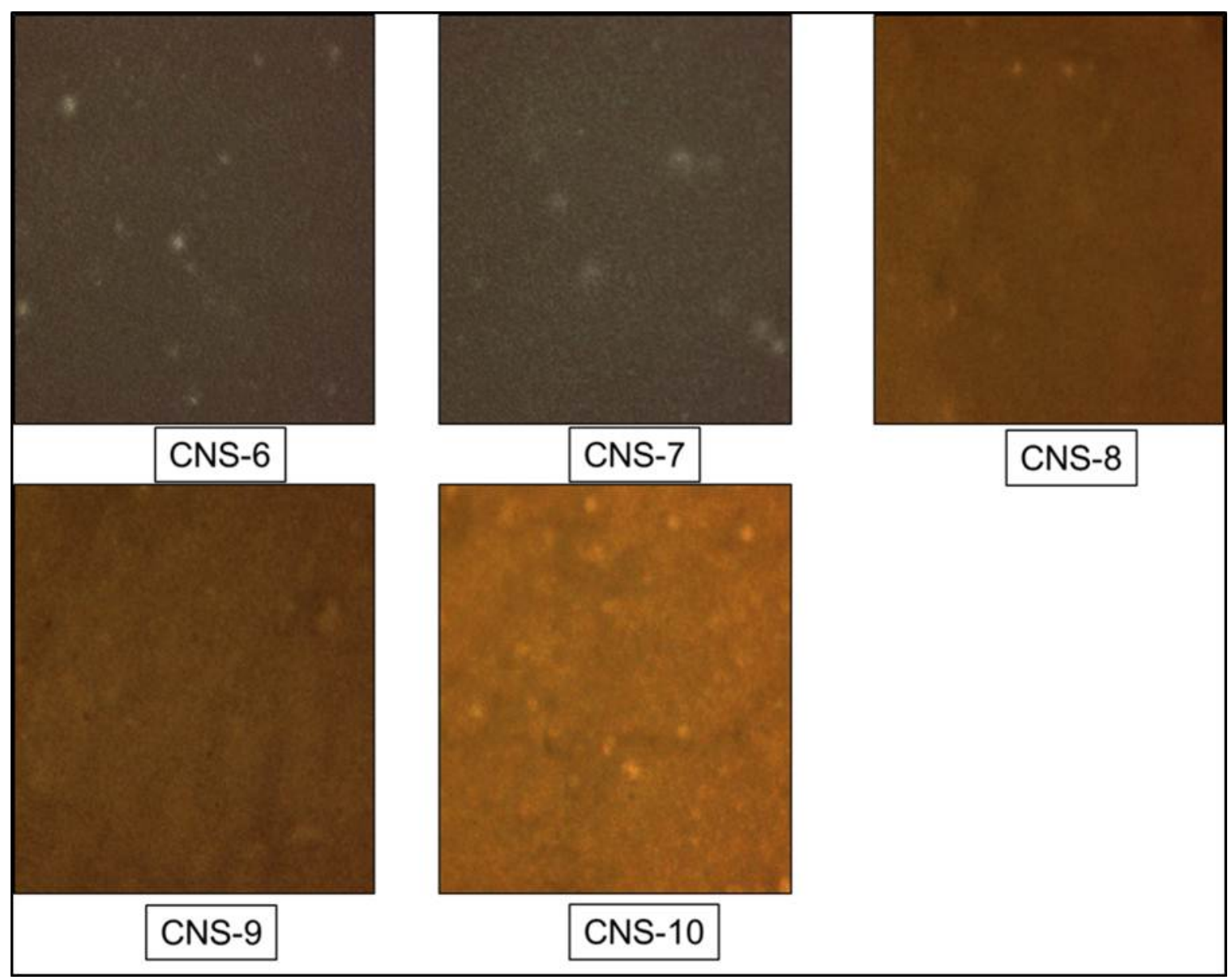

Figure 29. Microscopy pictures for samples CNS-6 to CNS-10 at 20x.

The only noticeable trend again is the changing of a darker brown or black color to an orange color with increasing surfactant.

\subsection{Conclusions - Cal Poly}

All work conducted at Cal Poly was an initial learning step to become familiar with synthetic processes and techniques that would be used further at Valspar to construct 
DPDs. Physical property, rheology, microscopy, and percent solids data were collected for Cal Poly samples; however, this data was not used in the construction of DPDs. Instead, this data was used as a starting point to which the rest of the project was conducted. Rheology was found to be the most conclusive test for determining if bridging flocculation is present in a paint sample, which shows a distinct shear-thickening region at medium to high shear rates. Physical property data would still be collected going forward. 


\section{Experimental Methods - Phase 1 at Valspar}

\subsection{Paint Preparation}

The 166A formulation, shown in Table 1, was used as the starting point to which additions of surfactant and HEUR were made. All the same components were used in the paint as discussed in the experimental section for the Cal Poly work. The paint making process was slightly different than that at Cal Poly, in which the grind was made using a high-shear grind blade, and the letdown using a low-shear letdown blade. The pigment grind was performed at very high-shear for 20 minutes before being added to the mixing letdown. The base level of low-shear HEUR thickener was added with and mixed for 20 minutes at a speed to maintain a vortex without dragging in air bubbles to the paint. The base batch was then split into smaller cans in which additions of the highshear HEUR thickener and surfactant were made. HEUR additions were always made first, mixed for 20 minutes, and then followed with the desired surfactant additions. After the surfactant addition, the mixture was mixed for an additional 20 minutes.

\subsubsection{VNS 166A Series}

The first series of additions made was called the VNS 166A series. The $V$ represents that the paints were made at Valspar. The NS represents the non-ionic Surfactant-A, 166 means the additions were made to the 166 starting batch with $0.26 \%$ low-shear HEUR thickener, and the A represents Acrylic-A binder latex is used in the formulation. The sample sets that were prepared are shown in Figure 30, where each point on the graph represents an individual sample made on the DPD. There were 5 different batches synthesized for the VNS 166A series, represented in Figure 30 by different symbols and colors. The corresponding wt $\%$ HEUR and wt\% surfactant for the additions for the non- 
ionic DPD are shown in Appendix A. The naming scheme for the VNS series is the same as the NS series. The scheme is $\mathrm{X} 166 \mathrm{Y}-\mathrm{AAAA}-\mathrm{BBBB}-\mathrm{CCC}$ where $\mathrm{X}$ represents where the paint was made ( $\mathrm{C}$ for Cal Poly and $\mathrm{V}$ for Valspar), 166 represents $0.26 \%$ low-shear HEUR thickener used in the starting batch, $Y$ is for which acrylic was used in the formulation (A for Acrylic-A or B for Acrylic-B), AAAA is a numerical representation of the amount of total wt\% HEUR in the sample (multiplied by 1000), BBBB represents the wt $\%$ surfactant in the sample (multiplied by 1000), and CCC represents the type of surfactant used (405 for Surfactant-A, 411 for Surfactant-B, and 100 for Surfactant-C). Call names were made for each corresponding sample, and one example for a call name is VNS-A1, which was made at Valspar for $\mathrm{V}$, NS for Surfactant-A, A for Acrylic-A and 1 for the first sample of the set.

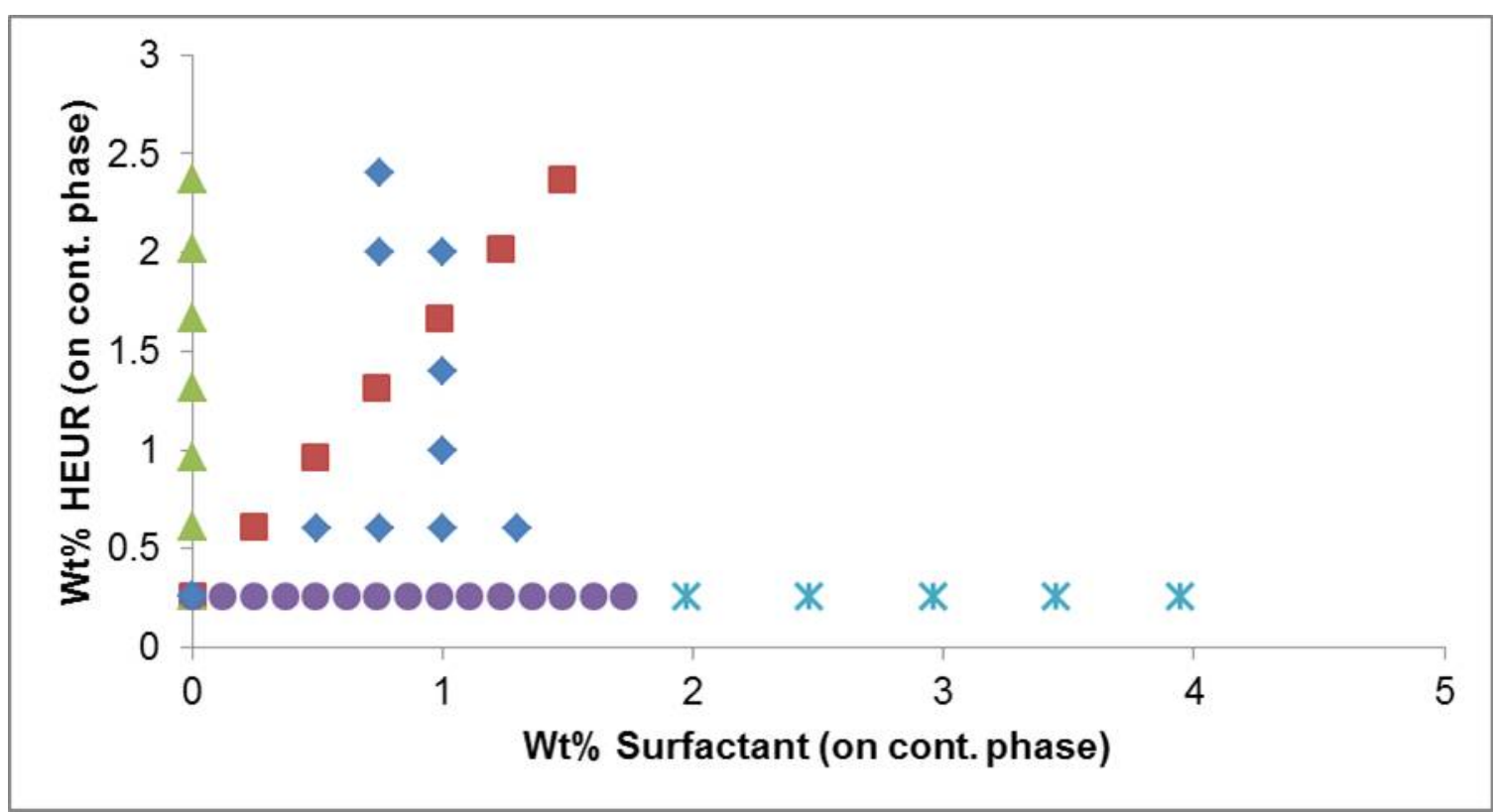

Figure 30. Graph showing each sample made for the non-ionic surfactant addition of Surfactant-A and HEUR addition for the VNS 166A series. Each set of colored symbols represents a group of samples that were made from the same batch. 
The batch making process was improved and modified with more work at Valspar. The initial work done for the VNS 166A series was the first series on which improvements and changes were made going forward. The development of the experimental procedures is described in the results section for the VNS 166A series.

\subsubsection{VAS 166A Series}

The second series consisted of anionic additions of Surfactant-B and were called the VAS $166 \mathrm{~A}$ series. The $\mathrm{V}$ represents that the paint was made at Valspar and AS represents the anionic Surfactant-B. The 166 means the additions were made to the 166 starting batch containing $0.26 \%$ low-shear HEUR thickener, and the A is for ACRLYIC-A. The samples were made the same as described for the VNS $166 \mathrm{~A}$ series, and the sample set that was prepared are shown in Figure 31. The corresponding wt\% HEUR and surfactant for the VAS 166A series are shown in Appendix A. The naming scheme is the same as the VNS series except for the 411 tag at the end of the name for SurfactantB. 


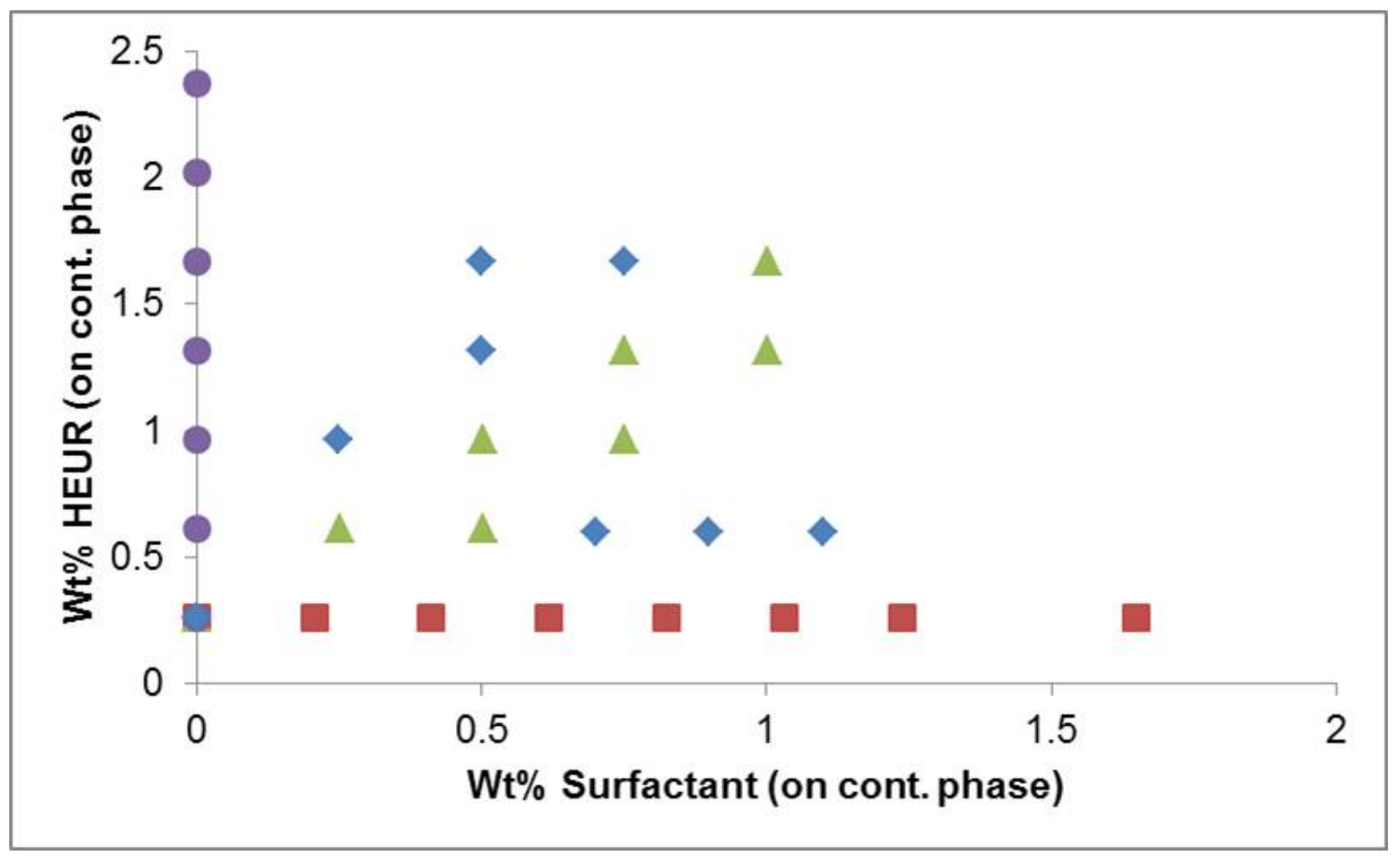

Figure 31. Graph showing each sample made for the anionic surfactant addition of Surfactant-B and additions of high-shear HEUR thickener. Each set of colored symbols represents a group of samples that were made from the same 166A batch.

Similar to the VNS $166 \mathrm{~A}$ series, the development and changing of the experimental procedure will be described in the results section.

\subsubsection{VNS2 166A Series}

The third series consisted of non-ionic additions of Surfactant- $C$, from the Dow Chemical Company. The $\mathrm{V}$ represents the paints were made at Valspar. The NS2 represents the non-ionic Surfactant-C, 166 means the additions were made to the 166 starting batch with $0.26 \%$ of low-shear HEUR thickener, and A if for Acrylic-A in the formulation. The sample set that was made is shown in Figure 32, where each point on the graph 
represents an individual sample made on the DPD. The sample name, call name, and corresponding wt\% HEUR and surfactant for the additions for the non-ionic DPD are shown in Appendix A. The naming scheme is the same as used before with X166YAAAA-BBBB-CCC except for the CCC tag represented by 100 for Surfactant-C.

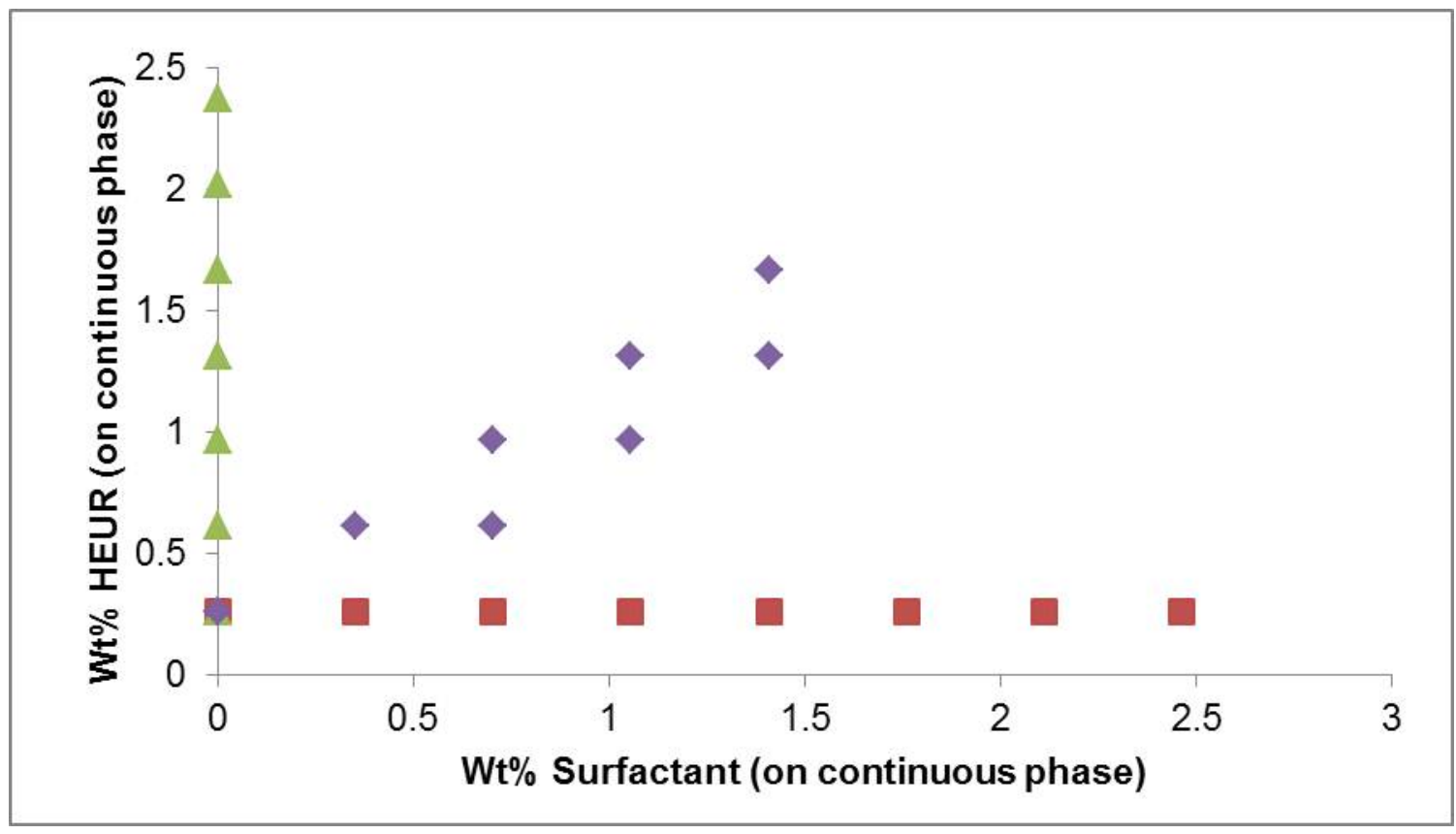

Figure 32. Graph showing each sample made for the VNS2 166A series. Each set of colored symbols represents a group of samples that were made from the same $166 \mathrm{~A}$ batch.

The VNS2 166A series followed the same experimental techniques as VNS and VAS series. This series was not developed further due to time constraint, but the conclusions for this system are listed in the results section.

\subsubsection{Physical Property Testing}

The physical properties of each paint sample were measured similarly to the testing at Cal Poly. The physical properties were used as a way to confirm flocculation types, as well as checkpoints to verify paints meet certain specifications. When the most effective 
paint making process was developed, statistical analysis of the physical properties was conducted. The test that was performed as soon as the paint had been made was initial $\mathrm{KU}$ viscosity with a Brooksfield Viscometer; 3 mil drawdowns were made on $B Y K$ drawdown paper with a BYK drawdown bar. The following day, the 24 hour $K U$ measurement was made and analysis was performed on the drawdowns: 20,60 , and 85 degree gloss using a BYK Glossmeter, and CR using a DataColor SE 600 Plus-CT. The drawdowns were also analyzed for IRBS in which flocculation gradients were calculated for each paint sample.

\subsection{Syneresis and Percent Solids Testing}

Syneresis testing was started for each sample immediately after additions of HEUR and surfactant by transferring the sample into a syneresis tube. Initial testing at Valspar was similar to that at Cal Poly in which $15 \mathrm{~mL}$ plastic tubes instead of glass were used. The testing was changed to use $150 \mathrm{~mL}$ glass jars for ease of visually assessing separation, and also for improving percent solids analysis which will be discussed next. The VNS and VAS sample sets used $15 \mathrm{~mL}$ tubes, and the use of $150 \mathrm{~mL}$ jar was started for the VNS2 166A sample set. Percent solids measurements were made using a Mettler Toledo HB45-5 Halogen Moisture Analyzer. The top layer was measured first by carefully pipetting off some of the top layer sample, without disturbing the bottom layer. A distance of 8 to $10 \mathrm{~mm}$ was typically needed to run a percent solids test at Valspar which required 0.6 to 1 gram of sample. The top layer was then decanted before running percent solids on the bottom layer. A simple schematic is shown in Figure 33. 


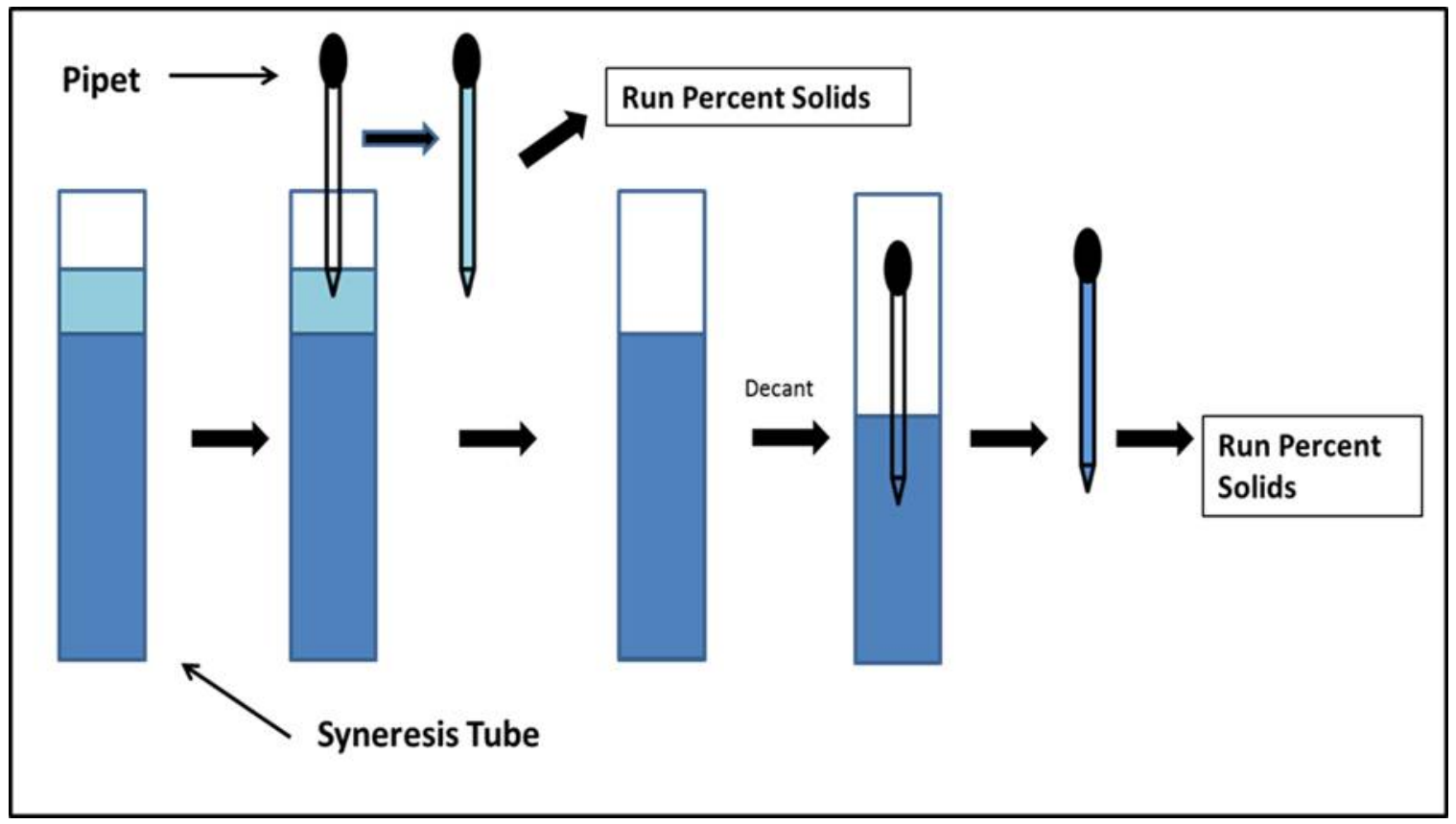

Figure 33. Step by step scheme for measuring percent solids of the top and bottom layer of a syneresis tube.

This test was limited when using the $15 \mathrm{~mL}$ tubes which required a minimum separation of the sample for a measurement. For separations below the $10 \mathrm{~mm}$ threshold, the top layer consisted of a mixture of the top and bottom layer since there was not enough sample on the top layer to run the test. This issue was improved by using $150 \mathrm{~mL}$ glass jars instead of tubes. The glass jars provided a larger distance of separation for a given sample and the top layer could be samples even at very small separation distances. This larger amount of top layer was also easier to sample, and could be run more than once. The same sampling method was followed as with the smaller $15 \mathrm{~mL}$ tubes; however, the results were more accurate and representative of the true value of percent solids for each layer. 


\subsubsection{Syneresis Analysis}

Syneresis, as previously mentioned was measured as the distance of separation for a given sample. In addition to the distance, the color of separation was also noted. At low levels of HEUR (where a transition from bridging flocculation to good dispersion to depletion flocculation is observed), the distance started large, then decreased as the good dispersion region was approached, essentially reaching zero separation. When the depletion flocculation region was entered the distances slowly increased with increase in surfactant. At higher levels of HEUR, the ability to observe a transition from good dispersion into a depletion flocculation region was needed to conclude a transition was present from good dispersion to depletion flocculation.

\subsubsection{Percent Solids Analysis}

The two values of percent solids were measured for each sample for a top and bottom layer representation. Trends were observed to help conclude which type of flocculation was occurring. This technique was used hand-in-hand with syneresis and was a helpful tool in making a conclusion on which type of separation was present.

\subsection{Rheology Testing}

The same rheology testing that was conducted at Cal Poly was followed at Valspar. The rheometer used at Valspar was a TA Instruments AR-G2 Rheometer. The use of the rheometer was progressed much further in an attempt to fully determine flocculation behavior in each sample. The technique was found to be very efficient at showing bridging flocculation in a sample; however, other tests were unable to show a good dispersion from a depletion flocculation sample. The following sections discuss the experimental development on the rheometer and the conclusions made from each test are listed in the results section. 


\subsubsection{Shear-rate Ramp}

The shear-rate ramp technique was the same as previously discussed for the work at Cal Poly. The bridging flocculation region was observed in the same way with a distinct shear-thickening portion followed by shear-thinning at higher shear rates.

\subsubsection{Creep Test}

Creep test, which is a common stress-strain test where a constant stress is applied and the resulting strain is measured, was attempted as a faster method for determining a bridging flocculation sample from a good dispersion or depletion flocculation sample. The creep test should have the same results as the shear ramp test; however, the testing time would be less than 5 minutes compared to the 30 minute test needed for the shear ramp. Creep testing was performed on samples for the VAS 166A series and VNS2 166A series. The initial creep tests consisted of a preshear of $5 \mathrm{~s}^{-1}$ for 30 seconds, followed by a stress hold step of $0.1 \mathrm{~Pa}$ for 60 seconds, followed by 180 seconds of relaxation of which the strain was measured. The creep tests were the starting point of which much time was invested into investigating the ability for the rheometer to test for bridging, depletion flocculation, and a good dispersion.

The starting point at which the creep tests were developed was testing done by Macfarlane et al. The hypothesis used was samples separated by bridging flocculation should show an elastic recovery that will not be present in samples separated by depletion flocculation. The testing was conducted on poly(vinyl pyrolidone (PVP) and poly(ethylene oxide) (PEO) and the creep results are shown in Figure 34 (MacFarlane, Wagner, Kaler, \& Lynch, 2010). 


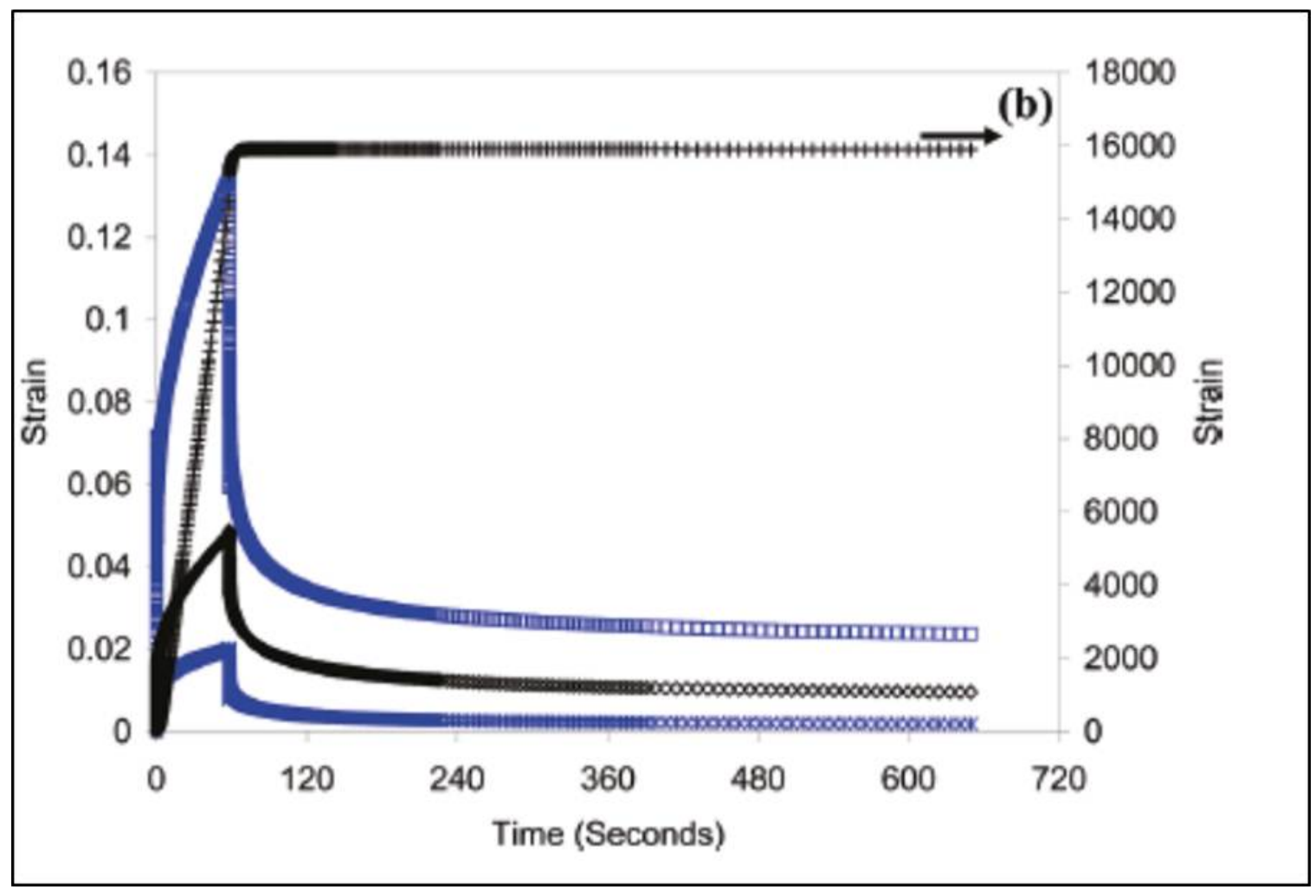

Figure 34. Creep results for PVP and PEO phase samples to show differences in phase separation. The PEO systems shown on top in black crosses had no recovery, where the bridging flocculation PVP systems all had noticeable relaxation (remaining three curves) (MacFarlane, Wagner, Kaler, \& Lynch, 2010).

The creep tests clearly show relaxation for bridging flocculation samples, and no relaxation for a depletion flocculation flocculated sample (black crosses). This system was different than the ones studied in this project, but the test has some similarities. The results are discussed in the subsequent results section for rheology.

\subsection{Infrared Back Scatter (IRBS)}

IRBS was performed using a spectrophotometer. 


\section{Results - Phase 1 at Valspar}

\subsection{VNS 166A Series}

\subsubsection{Physical Property Data}

Physical property data was collected for all the data sets made for the VNS 166A series and is shown in Appendix B. Due to the nature of the paint preparation process for the VNS $166 \mathrm{~A}$ series, the physical property data was not very reproducible from batch to batch. The variation from batch to batch could have been a result of a few possible variables: shear rate and time, slight variations of added components, equilibrium time, temperature, and humidity. This issue will be revisited after a more advanced paint preparation technique developed in this study allows for better analysis of the physical properties for a data set. The flocculation conclusions for each sample were not based upon physical property data, but rather the syneresis, percent solids, and rheological data. The physical property data would prove to be much more useful when the preparation of the paints was altered.

\subsubsection{Rheology}

Shear ramp measurements were performed for the first set of samples made for the VNS 166A series. The shifting of maxima was observed for samples VNS-A1, VNS-A3, VNS-A5, VNS-A7, and VNS-A9 are shown in Figure 35. 


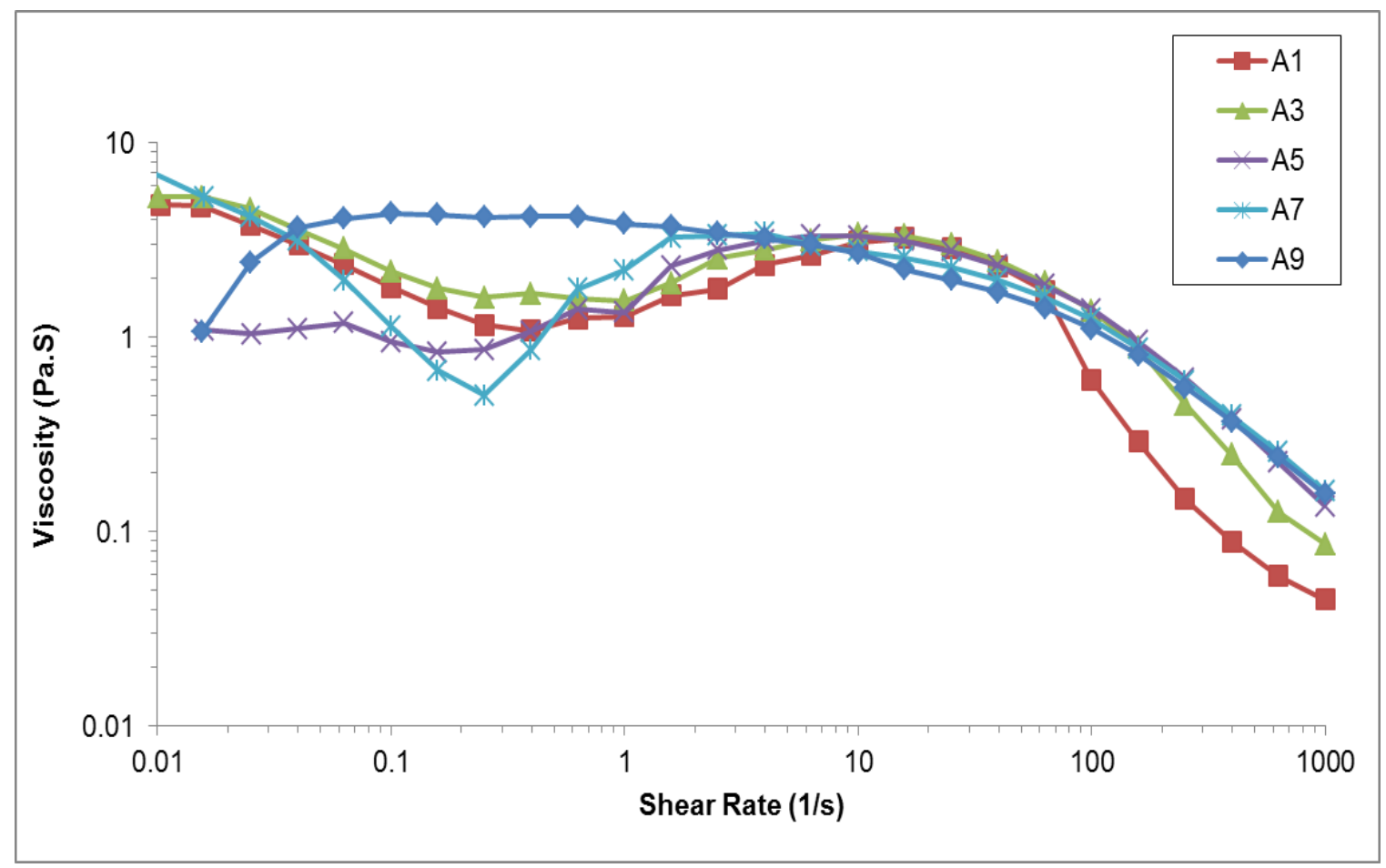

Figure 35. Rheology results for the shifting of the maxima for the bridging flocculation region of the VNS 166A series.

As seen before with the rheology work at Cal Poly, a unique portion of shear-thickening region is present for bridging flocculation samples. The reasoning for the shearthickening region is explained in the Cal Poly results section in which the elongated bridge produces a high resistance to flow causing an increase in viscosity. The shifting of the maxima does relate very closely with the observations made with the syneresis and percent solids data. This gives more credibility for the shear ramp test being able to accurately test for bridging flocculation in a sample. The next set of samples that will be analyzed is samples around the end of the bridging flocculated region and into the good dispersion/depletion flocculation region, shown in Figure 36. 


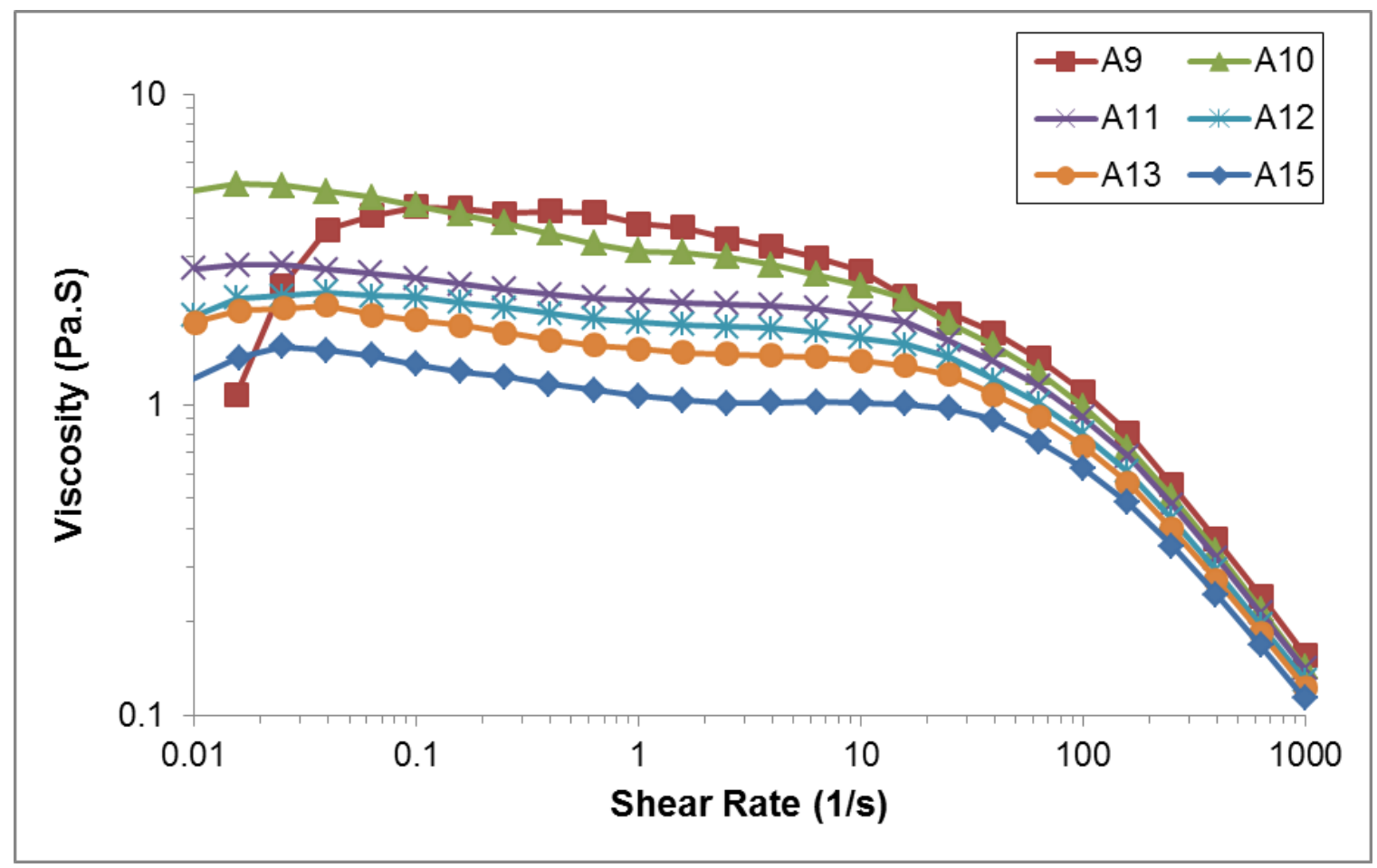

Figure 36. Rheology data for samples VNS-A9, VNS-A10, VNS-A11, VNS-A12, VNSA13, and VNS-A15. VNS-A9 and VNS-A10 were concluded to be close to the boundary of the BF-region with all the other samples to be considered either a good dispersion or depletion flocculation sample.

The rheology data shown in Figure 36 shows a clearly bridging flocculation sample shown in orange for VNS-A9, and VNS-A10 which appears to have a higher-shifted viscosity curve than the next samples in the sequence. The conclusion made for this data is that VNS-A9 is in the bridging flocculated region and VNS-A10 is on the boundary of BF and good dispersion. The rheology testing has been shown to be very conclusive at showing samples in or near the bridging flocculation region. All other samples in the set can only be concluded to be either a good dispersion or depletion flocculation. Samples that show a clear shear-thickening region are very easily concluded to be bridging flocculation, and samples that have curves shifted to high viscosity, with some irregular shaping compared to good dispersion/depletion 
flocculation samples are concluded to be on the bridging flocculation boundary. The nature of these fully formulated systems has made transitions from the three regions of the DPD a gradual change with samples that appear to have a mixture of bridging flocculation and good dispersion, or good dispersion and depletion flocculation aspects to them. For these samples that appear to be in the boundary, a full conclusion cannot be made as to which region the sample belongs to, but rather that the sample is located in a gradual change from boundary to boundary.

\subsubsection{Syneresis and Percent Solids}

The syneresis and percent solids data was collected for the VNS $166 \mathrm{~A}$ series, and is shown in Appendix C. The syneresis and percent solids were the conclusive tests to determine which form of flocculation is present. At low levels of HEUR, the ability to visually observe a transition from a separated sample, to a non-separated sample, and again to a separated sample for incremental increases of the wt $\%$ of surfactant gives a strong conclusion that a transition had been made from a bridging flocculation to good dispersion to depletion flocculation regions. At higher levels of HEUR (above the bridging flocculation region), the ability to visually see a transition from a non-phaseseparated sample to a phase-separated sample was the strongest evidence to show a transition from a good dispersion into a depletion flocculation region was attained. The visual observations were tied in with the percent solid testing of both layers as verification that separation was present. Initial flocculation determinations were made for each sample. These flocculation determinations were heavily based upon rheology confirmations for the bridging flocculation region, and syneresis and percent solids for the remaining regions. 


\subsubsection{VNS 166A Series Flocculation Determination and DPD}

Conclusions were made for each flocculation region and are shown in Figure 37, in which each sample is plotted by the flocculation determination made. The resulting DPD for the first VNS 166A series was drawn in by hand to best represent each region as a result of all the methods of testing, shown in Figure 38.

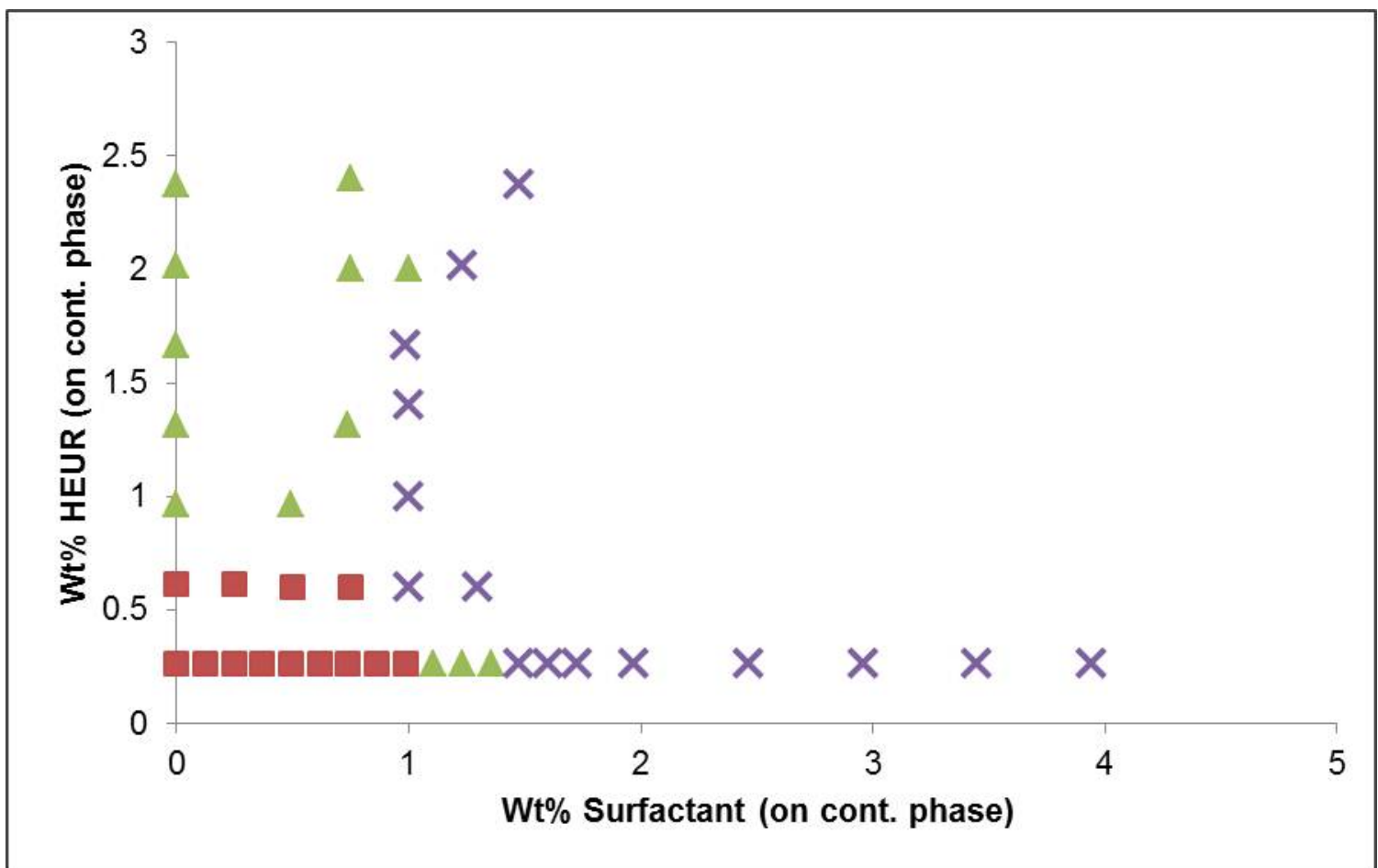

Figure 37. Flocculation determinations by each sample for the VNS $166 \mathrm{~A}$ series (red squares - bridging flocculation, green triangle - good dispersion, purple cross depletion flocculation). 


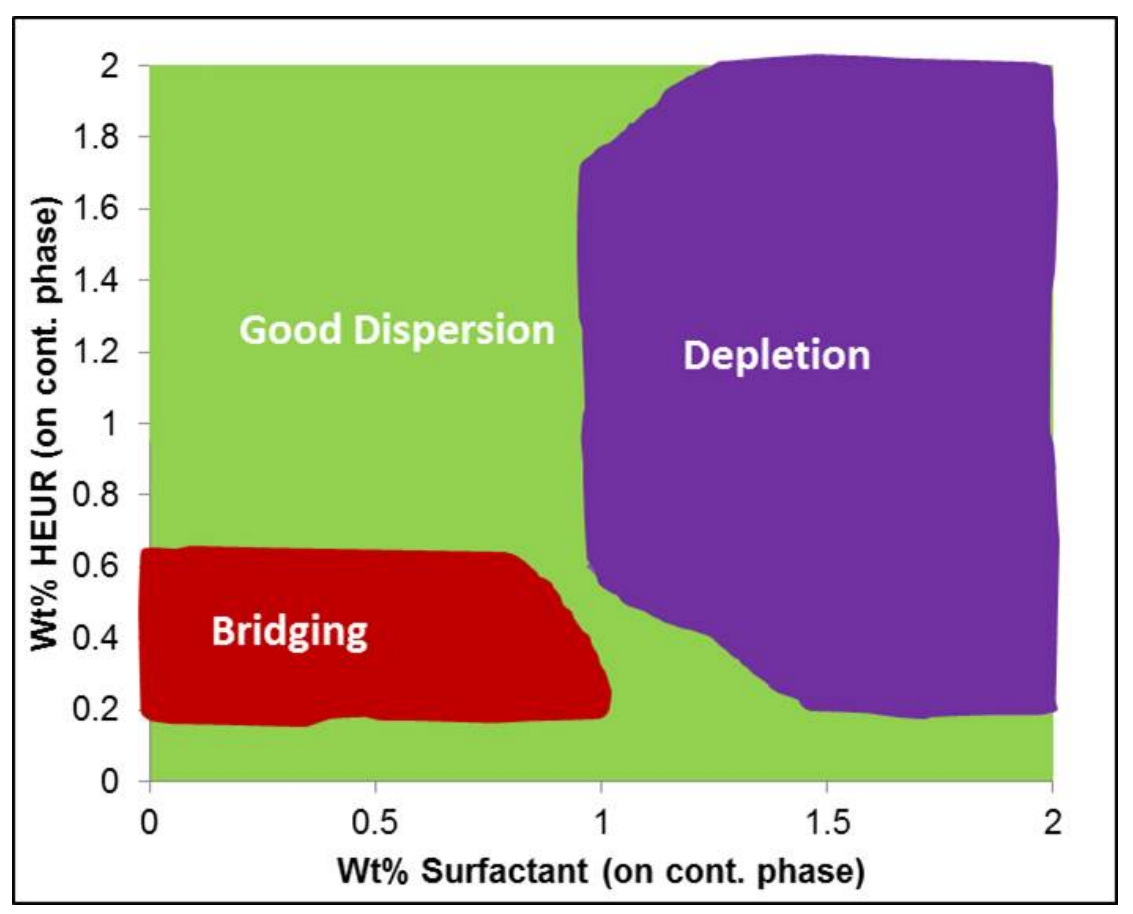

Figure 38. DPD for VNS 166A series.

The first attempt in making the DPD for the VNS 166A series was to lay the foundation of which the experimental techniques could be improved. The methods of testing were still to be improved to make higher resolution DPDs. Most of the variation occurred from batch to batch, in that 4 to 5 different sets of paints were made to represent the DPD. All paint samples were not prepared under the same parameters and this issue was corrected with improved paint making techniques which will be discussed later. The first DPD helped prioritize which tests were the most effective and ineffective. Rheology testing was found to be very conclusive in showing the bridging flocculation region, and the syneresis and percent solids tests showed separation and separation type for all the samples in the DPD. The physical properties were not very reproducible from batch to batch, but this again will be revisited with improved experimental techniques.

Even with a fairly low resolution DPD, some conclusions can be made. The good dispersion region appears to be above $0.8 \%$ HEUR and below $1 \%$ surfactant. This 
region should be sought for making well-dispersed paints with these components. Also, there is clearly a competition for adsorption to the particles in the system by the thickener and surfactant for the ranges of wt\% surfactant and HEUR thickener for the DPD. This is clear because there is an observable transition occurring from bridging flocculation to good dispersion to depletion flocculation which can be interpreted by the changing of thickening mechanisms in the system with additions of HEUR and surfactant. At higher levels of HEUR the transition is seen from good dispersion to depletion flocculation. There is good evidence of desorption of the HEUR polymers from the particles in the system by the formation of a separated phase with the addition of surfactant.

\subsection{VAS $166 \mathrm{~A}$ Series}

The VAS 166A series was constructed in a similar manner to the VNS 166A series, with the only differences being the weight percent of HEUR and surfactant added. The additions were similar and were contained in the sample space of 0 to $2.0 \mathrm{wt} \%$ HEUR and surfactant.

\subsubsection{Physical Property Data}

The physical property data that was collected for the VAS $166 \mathrm{~A}$ series is shown in Appendix B. The same conclusions for the VNS 166A series physical property data were made for the VAS 166A series. The data would be found to be more useful with a different paint preparation technique and will be revisited.

\subsubsection{Rheology}

The shear ramp profiles for the VAS 166A series are shown in Figure 39. 


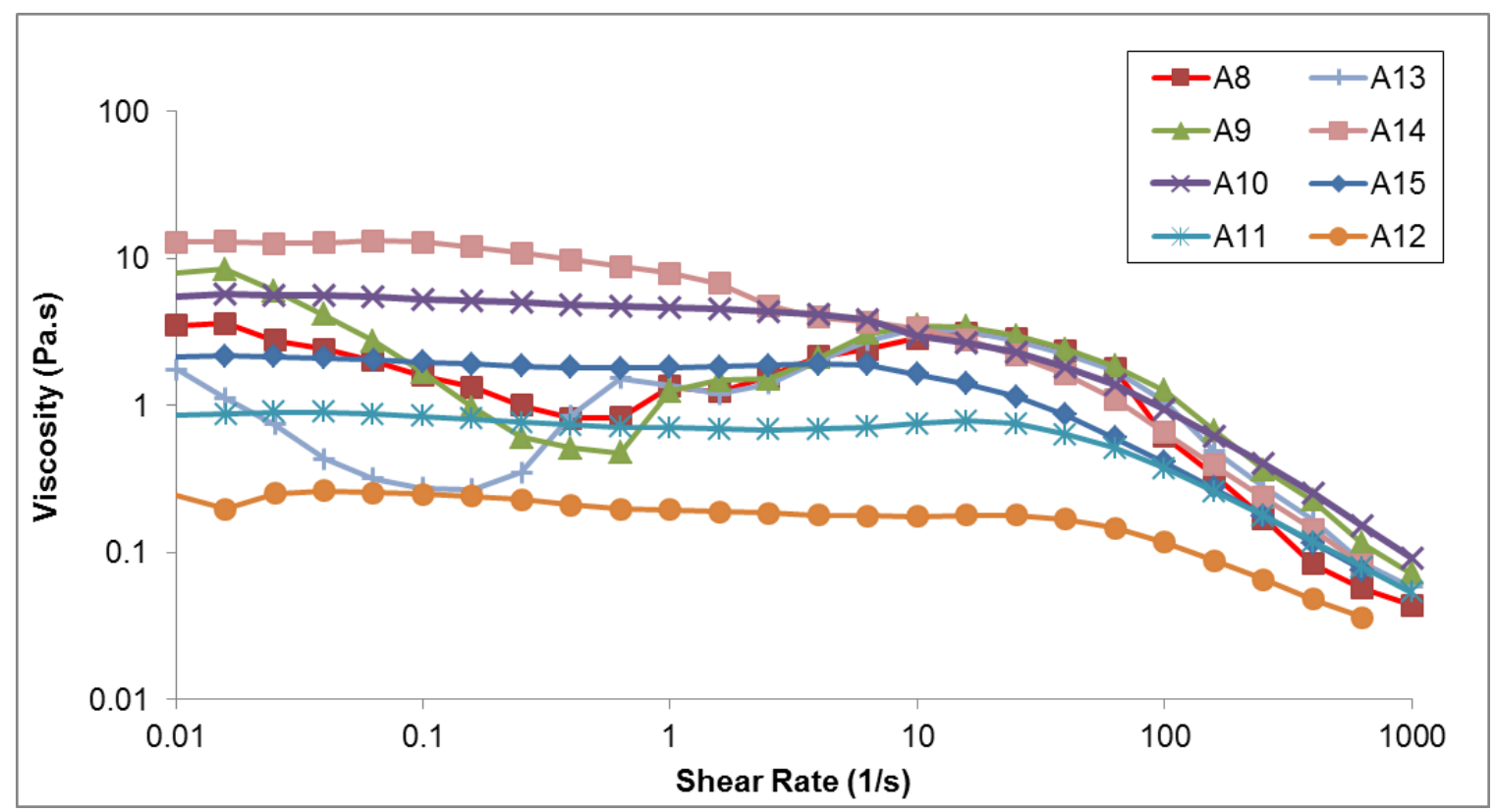

Figure 39. Rheology profiles for the VAS 166A series.

The rheology results above confirmed the bridging flocculation region for the following VAS 166 A series samples: $8,13,9$, and 14 . Sample VAS-A10 was considered to be in the boundary of the bridging flocculation and good dispersion region. These conclusions were made in the same fashion as for the VNS 166A series in constructing an anionic DPD.

\subsubsection{Syneresis and Percent Solids}

The syneresis and percent solids data was collected and analyzed in the same way as the VNS 166A series. The syneresis and percent solids data for the VAS 166A series is shown in Appendix C.

\subsubsection{VAS 166A Series Flocculation Determination and DPD}

Conclusions were made for each flocculation region and are shown in Figure 40, in which each sample is plotted by the flocculation determination made. The resulting DPD for the VAS 166A series was drawn in by hand to best represent each region as a result of all the methods of testing, shown in Figure 41. 


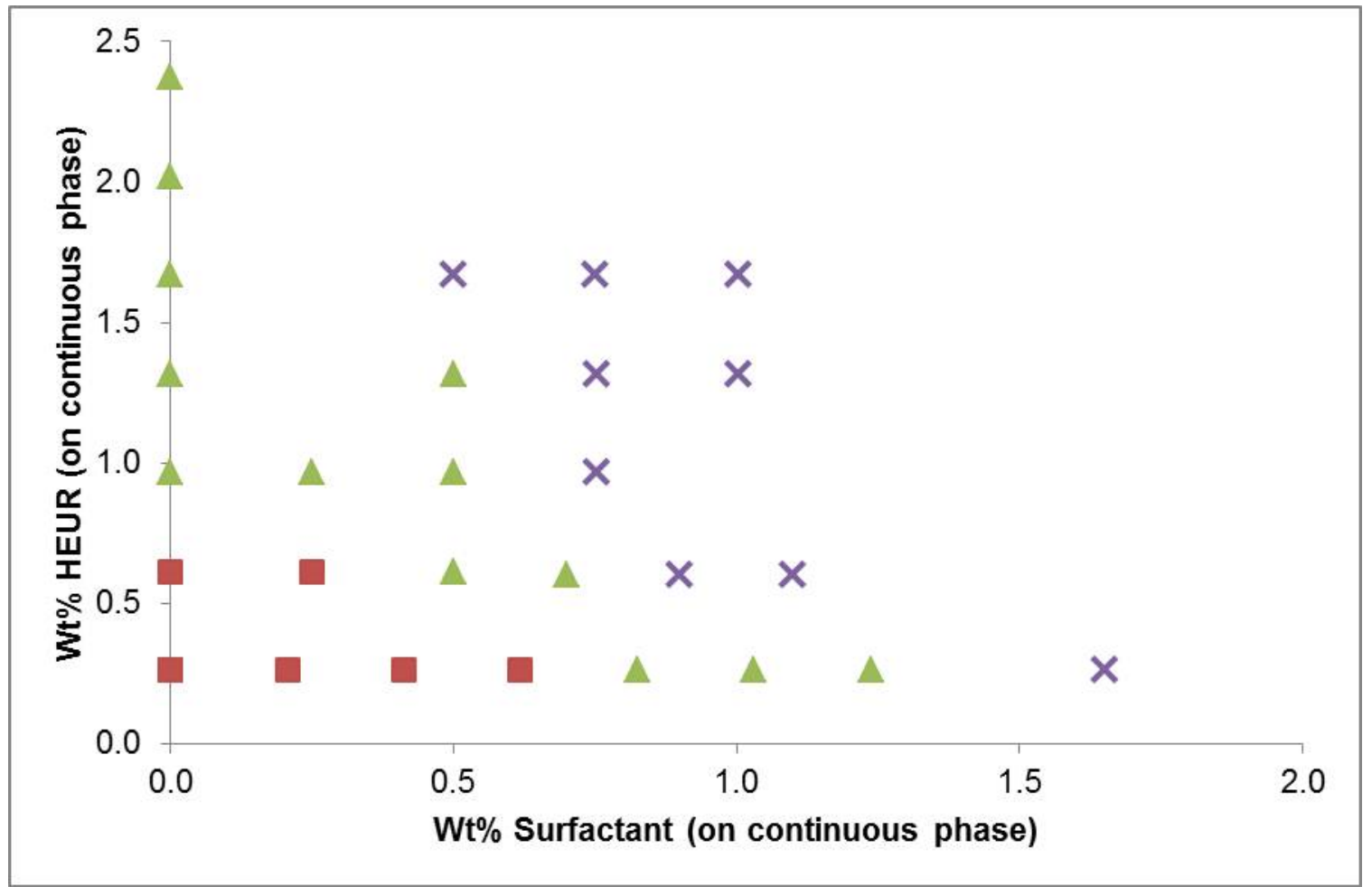

Figure 40. VAS 166A series via flocculation type (red squares - bridging flocculation, green triangle - good dispersion, and purple crosses - depletion flocculation). 


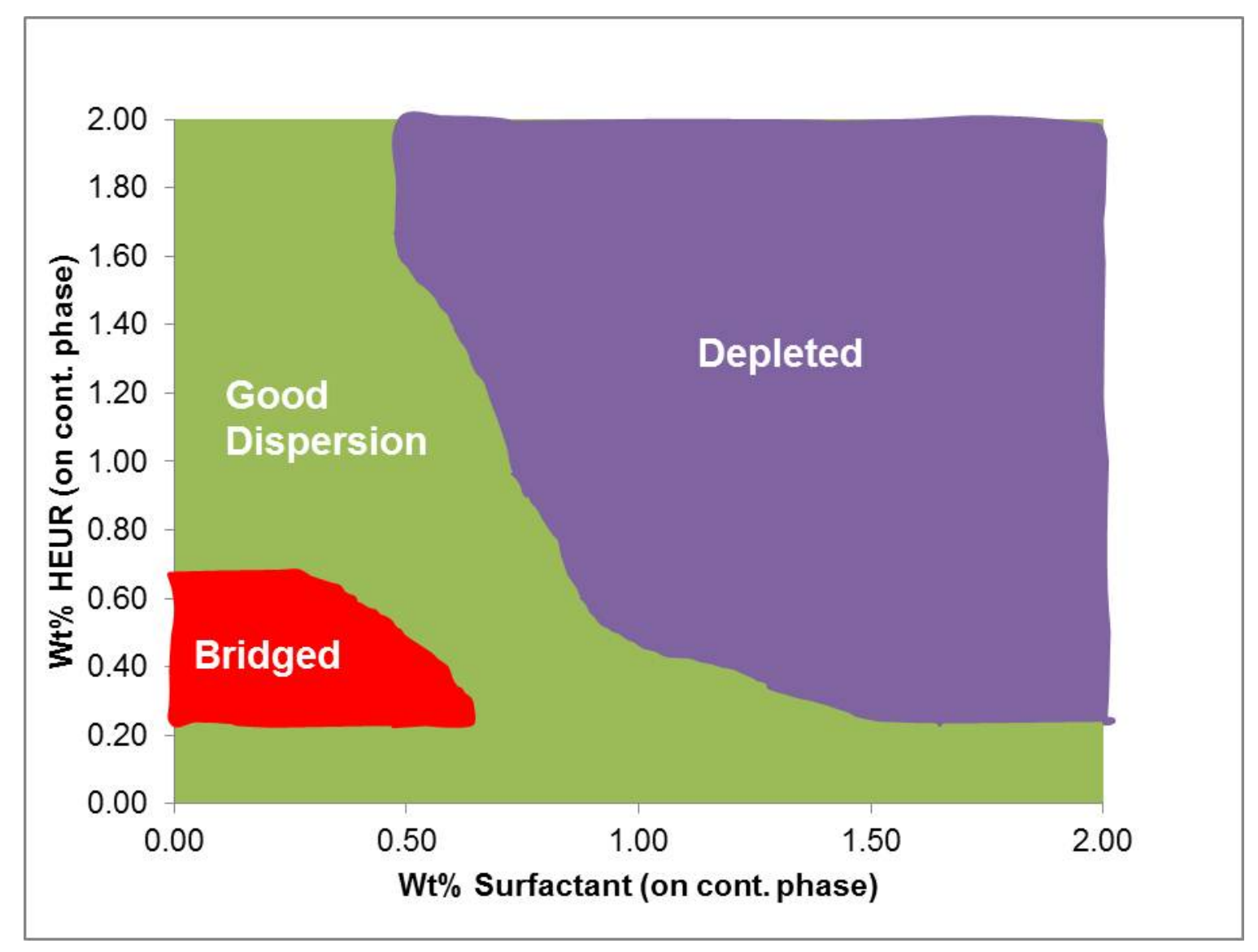

Figure 41. VAS 166A series DPD.

As for the VNS 166A series, the same caution must be taken with these first DPDs. The resolution of the first two DPDs is fairly poor and the regions are not well defined. This will be improved upon with different paint preparation techniques and testing. Some observations can be made for this DPD: the good dispersion region shrank a bit while the depletion flocculation region increased in size. The anionic surfactant should compete more efficiently for the latex surface than the non-ionic surfactant resulting in a smaller bridging flocculation region and depletion flocculation at lower surfactant concentration. The good dispersion region is located above $1 \%$ HEUR and less than $0.6 \%$ surfactant to ensure a good dispersion region is securely found. Other regions 
close to these numbers could yield samples of good dispersion; however, the safest zone is deep within the good dispersion region to ensure a good sample will be made.

\subsection{VNS2 166A Series}

The VNS2 166A series was made using Surfactant-C with the same HEUR and latex as the VNS 166A and VAS 166A series. The NS2 166A series was not completed fully when more efficient and conclusive techniques were developed. After the development, the focus of the new techniques was to first remake the VNS 166A and VAS 166A series. The VNS2 166A series DPD was not able to be made in the time frame of the project.

\subsubsection{Physical Property Data}

Physical property data was collected for the VNS2 166A series, shown in Appendix B. The physical property data collected was very similar to the VNS $166 \mathrm{~A}$ series. The further analysis into this system was put on hold due to time constraints.

\subsubsection{Rheology}

Rheology was conducted for VNS2 166A series in the same manner as previous series. The collected shear ramps for the series are shown in Figure 42. 


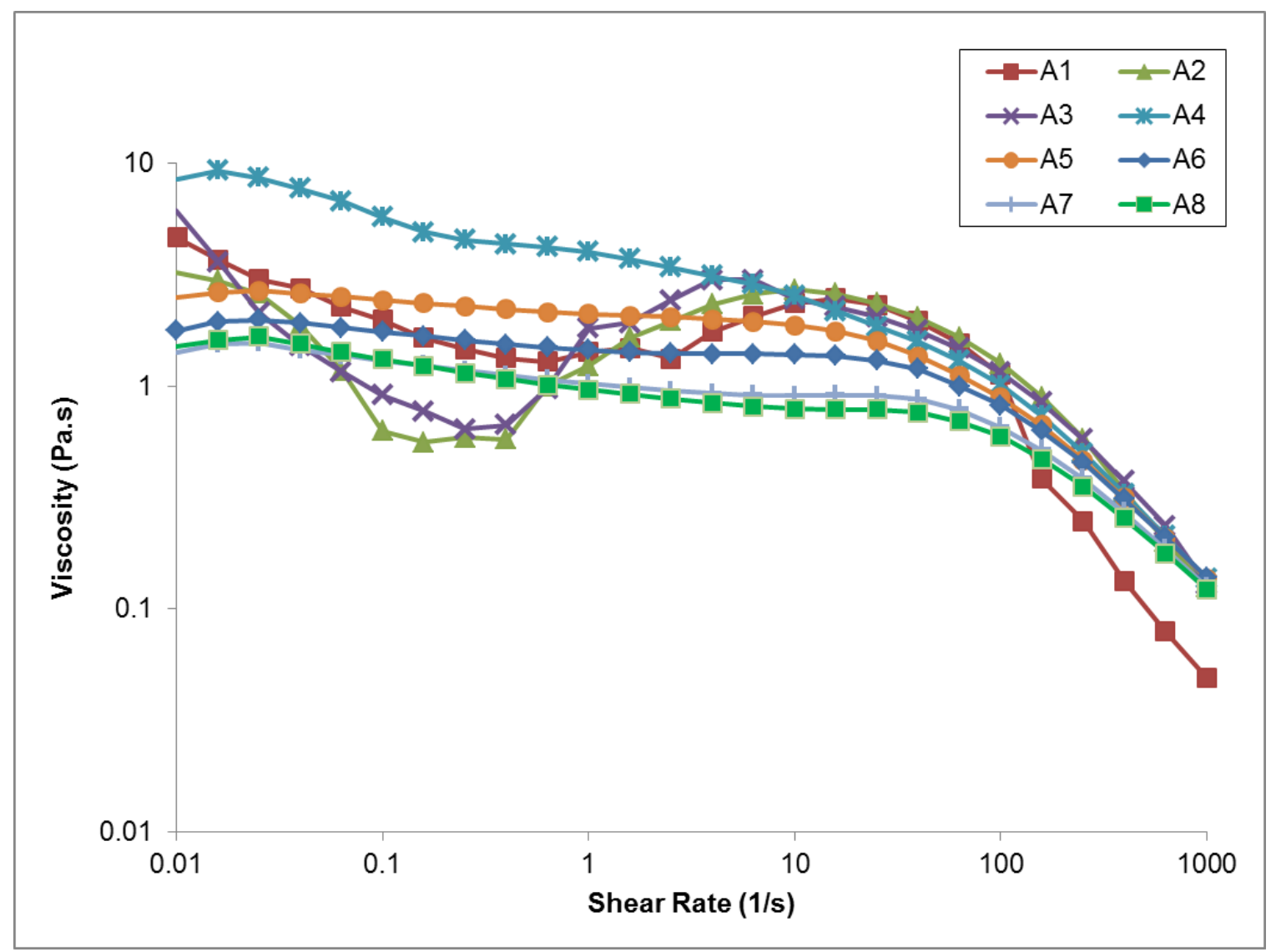

Figure 42. VNS2 166A series rheology data.

The rheology results showed bridging flocculation conclusions for the following samples for the VNS2 166A series: 1, 2, 3, and 4. The remaining samples were considered to be good dispersion or depletion flocculation samples.

\subsubsection{Syneresis and Percent Solids}

The VNS2 166A series was the first data set in which $150 \mathrm{~mL}$ glass jars were used instead of $15 \mathrm{~mL}$ centrifuge tubes. The advantages of using glass jars were that separations were more easily identified visually, and each layer of separation had more volume which made the percent solids testing of the layers more accurate. The syneresis and percent solids data is shown in Appendix C. The conclusions of the 
syneresis and percent solids were not used to make a DPD, but confirmed that the new method of performing the syneresis is superior to the $15 \mathrm{~mL}$ tubes.

\subsection{Testing Analysis - Improvements and Changes}

\subsubsection{Syneresis and Percent Solids Testing}

The initial testing of syneresis and percent solids had some issues. The first issue was the ability to visually observe a separation by the eye in the smaller plastic tubes was difficult. For a pigmented system the separations were not always easily identified, and separation needed to be confirmed with percent solids testing of the layers. The second issue with the percent solids testing is that the separation in the small $15 \mathrm{~mL}$ tubes did not always have enough sample to run the percent solids of the top layer.

In order to correct these issues with the syneresis and percent solids a larger test tube or container was needed. The best possible replacement was $150 \mathrm{~mL}$ glass jars with a screw-top cap. The glass jars were easier to see through which helped the identification of separation in the sample, and the volumes of the layers were much larger. Each layer was large enough to run percent solids at least once by itself, and for larger separations the test could be run multiple times for better representation of the data. The new protocol allowed for easier identification of separation and more accurate measurements of percent solids for the layers present.

\subsection{Rheology}

\subsubsection{Shear Ramp}

Through the first two phases of testing, at Cal Poly and Valspar, the shear ramp has been found to be the most useful test for determining bridging flocculation. The ability to easily probe samples for bridging flocculation in a 30 minute period has been very useful 
and going forward will be used in this way. Going forward, the new testing method will be to test samples starting at the lowest HEUR and surfactant levels, and run shear ramps until the bridging flocculation region is no longer observed. This initial rheology testing is very efficient at plotting out the bridging flocculation region of the DPD.

\subsubsection{Creep Test}

The creep test was conducted extensively as a way to test for a bridging flocculation system in less time, and also was attempted to determine a depletion flocculation versus a good dispersion sample. The testing was found to be inconclusive for the tested systems and the results will be followed in a step-by-step manner in which the testing was conducted. The test results were negative, but still some notable conclusions could be made. The first step of the creep sequence was to shear the sample on the rheometer at $5 \mathrm{~s}^{-1}$ for 30 seconds followed by a creep step of $0.1 \mathrm{~Pa}$ for 30 seconds, which was then finished with a relaxation observation for 100 seconds. The initial creep tests were run on samples made for the VNS2 166A series and some VAS 166A series. The data showed some relaxation for bridging flocculation samples, which was absent from good dispersion and depletion flocculation samples; however, the data was not reproducible.

\subsubsection{Repeated Creep Test}

The initial creep test was followed by a similar test in which repetitions were made. The samples were pre-mixed the same as the last tests followed by a pre-shear of $1.0 \mathrm{~s}^{-1} \mathrm{for}$ 60 seconds. The creep portion followed next with $0.1 \mathrm{~Pa}$ for 60 seconds, and finished with a relaxation step for 200 seconds. The measurement was then run again on the same sample without placing a new sample on the rheometer. The pre-shear of $1.0 \mathrm{~s}^{-1}$ was used because a lower shear-rate for the pre-shear was shown to have slightly better reproducibility. 


\subsubsection{Repeated Creep Test \#2}

The repeated creep test was slightly modified in an attempt to show better reproducibility. The new testing parameters had an increase in the applied stress for the creep test. The pre-mixing of the sample was the same then followed by a pre-shear of $1.0 \mathrm{~s}^{-1}$ for 60 seconds. The creep portion was next at $0.1 \mathrm{~Pa}$ for 60 seconds with a relaxation of 200 seconds at the end. The test was ran again at a creep of 1.0 and $10 \mathrm{~Pa}$ for 60 seconds. The test was conducted for a bridging and depletion flocculation sample. The relaxation region was observed to increase with an increase in strain on the sample. This is as expected since the bridging flocculation region should be extended to a larger degree with relation to an increase in strain, and exhibit an increase in the relaxation portion of the bridges. This data was compared with a depletion flocculation sample to see if more conclusions can be made. The depletion flocculation sample was run in a similar manner as above; however, four different strain inputs were used. The depletion flocculation sample showed very irregular results at all four strains, and was concluded to be not reproducible.

\subsubsection{New Rheology Protocol}

The extensive investigation into the rheology of the different flocculation types was found to be mostly inconclusive. The only test that has been shown to be conclusive was the shear ramp test, in which the bridging flocculation region for a system can be mapped out. Going forward this will be used as a main technique for determining bridging flocculation in samples. The testing procedure will include running shear ramps on samples starting at the lowest HEUR level, and then moving left to right with increasing surfactant until the bridging flocculation aspect is not observed. The next level of HEUR is tested in the same fashion, and is repeated until the bridging flocculation region is no longer observed. 


\section{Experimental Methods - Phase 2 Valspar}

\subsection{Paint Preparation via Grid Method at Valspar}

Through the first phase of testing, some conclusions had been made on the way to test the paints for flocculation. The next major change in the experimental development was to change the method in which the paints were made. The reason for this is to improve the resolution of the constructed DPDs. The new approach to making the samples in the DPD space was to make a 5 by 5 grid of 25 samples. All the samples would be made from the same batch and the weight percent's of HEUR and surfactant would be evenly spaced throughout the grid to give a more uniform representation of the sample space of each DPD.

The paint-making process for the first two grids involved making one large paint batch of which additions of HEUR and surfactant were made. The HEUR batches were made first and the surfactant additions were performed next. The paints were made using the same 166 formulation containing $0.26 \%$ low-shear HEUR thickener, and additions of HEUR were made using the high-shear HEUR thickener.

\subsubsection{G-VNS 166A Series}

The first grid that was made was for the non-ionic Surfactant-A, Acrylic-A, and the same HEUR thickening package consisting of a low- and high-shear HEUR thickener. The general naming schemes are the same except with G-VNS, with the G representing the samples were made in a grid. The grid with all the theoretical additions made is shown in Figure 43. The corresponding theoretical and actual weight percent of HEUR and surfactant is shown in Appendix A. The actual weight percent of the additions is slightly 
different than the targeted weight percent because the additions of surfactant and HEUR is limited by the pouring of viscous materials to a precise number. The exact naming scheme is the same as used for the prior VNS series except for an added G. The scheme is $\mathrm{G}-\mathrm{X} 166 \mathrm{Y}-\mathrm{AAAA}-\mathrm{BBBB}-\mathrm{CCC}$ where $\mathrm{X}$ represents where the paint was made (C for Cal Poly and V for Valspar), 166 represents that $0.26 \%$ low-shear HEUR thickener, $\mathrm{Y}$ is for which acrylic was used in the formulation (A for $105 \mathrm{~nm}$ Acrylic-A and $B$ for $150 \mathrm{~nm}$ Acrylic-B), AAAA is a numerical representation of the amount of total wt $\%$ HEUR in the sample (multiplied by 1000), BBBB represents the wt\% surfactant in the sample (multiplied by 1000), and CCC represents the type of surfactant used (405 for Surfactant-A, 411 for Surfactant-B, and 100 for Surfactant-C). Call names were made for each corresponding sample. One example for a call name is G-VNS-A1: G means the samples were made as part of the grid, $V$ means the sample was made at Valspar, NS for Surfactant-A, A for Acrylic-A and 1 for the first sample of the set.

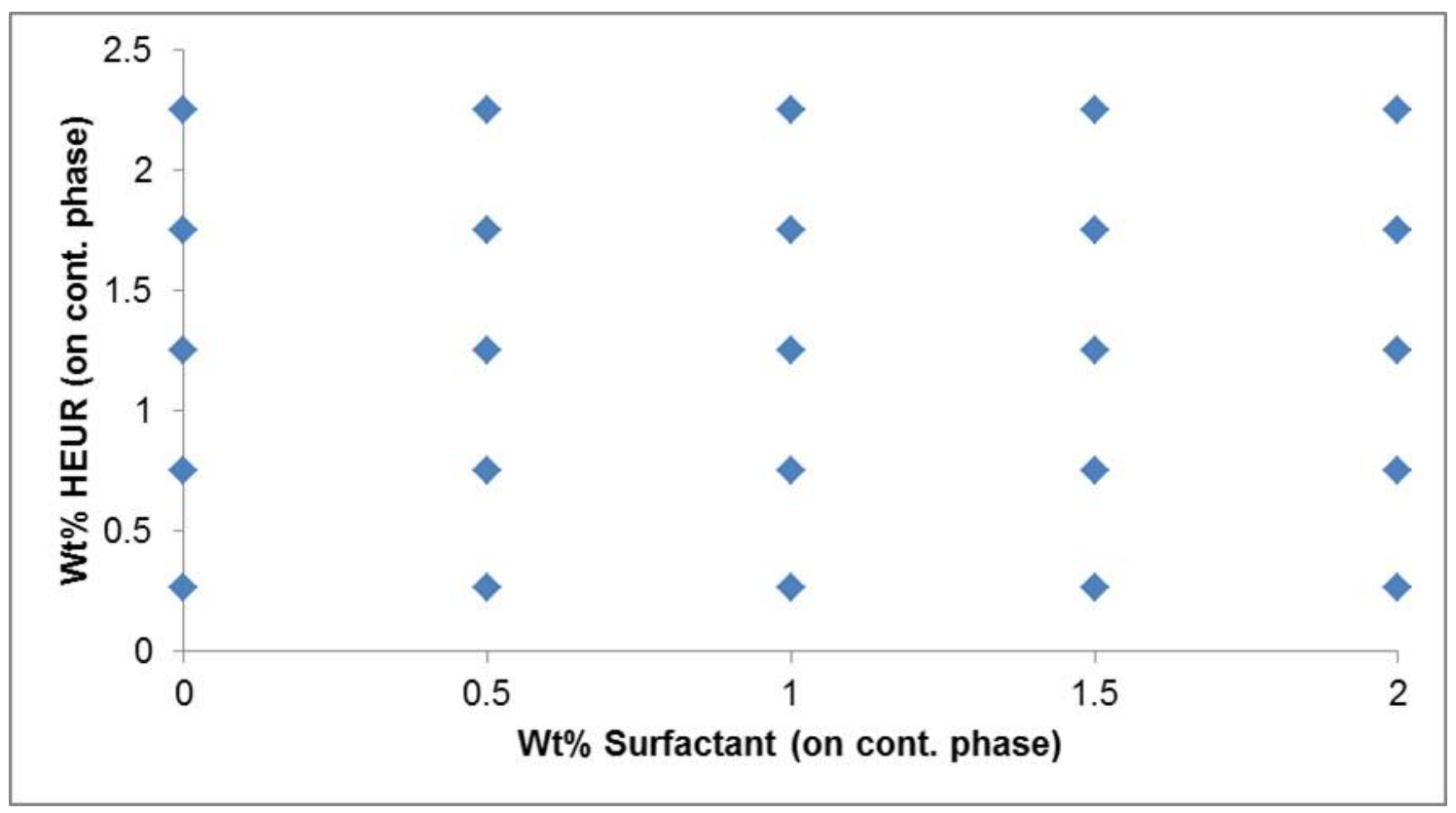

Figure 43. Graph showing the grid of samples made for the G-VNS 166A series. Each point represents and individual sample that was created within the data set. 


\subsubsection{G-VNS 166A Series Additions}

Additional samples were made for the G-VNS 166A series where boundary positions were in question. The initial and second sets of additions are shown in Figure 44, and Figure 45, respectively. The initial additions were made using excess paint from the original HEUR batches for the G-VNS 166A series. The issue with these samples was that the starting HEUR batches had been sitting for 5 days. The resulting samples showed irregular flocculation which may have been irreversible bridging flocculation in the starting batches that caused these irregular results. The second set of additions, shown in Figure 45, were made with the same preparation procedures as the original grid.

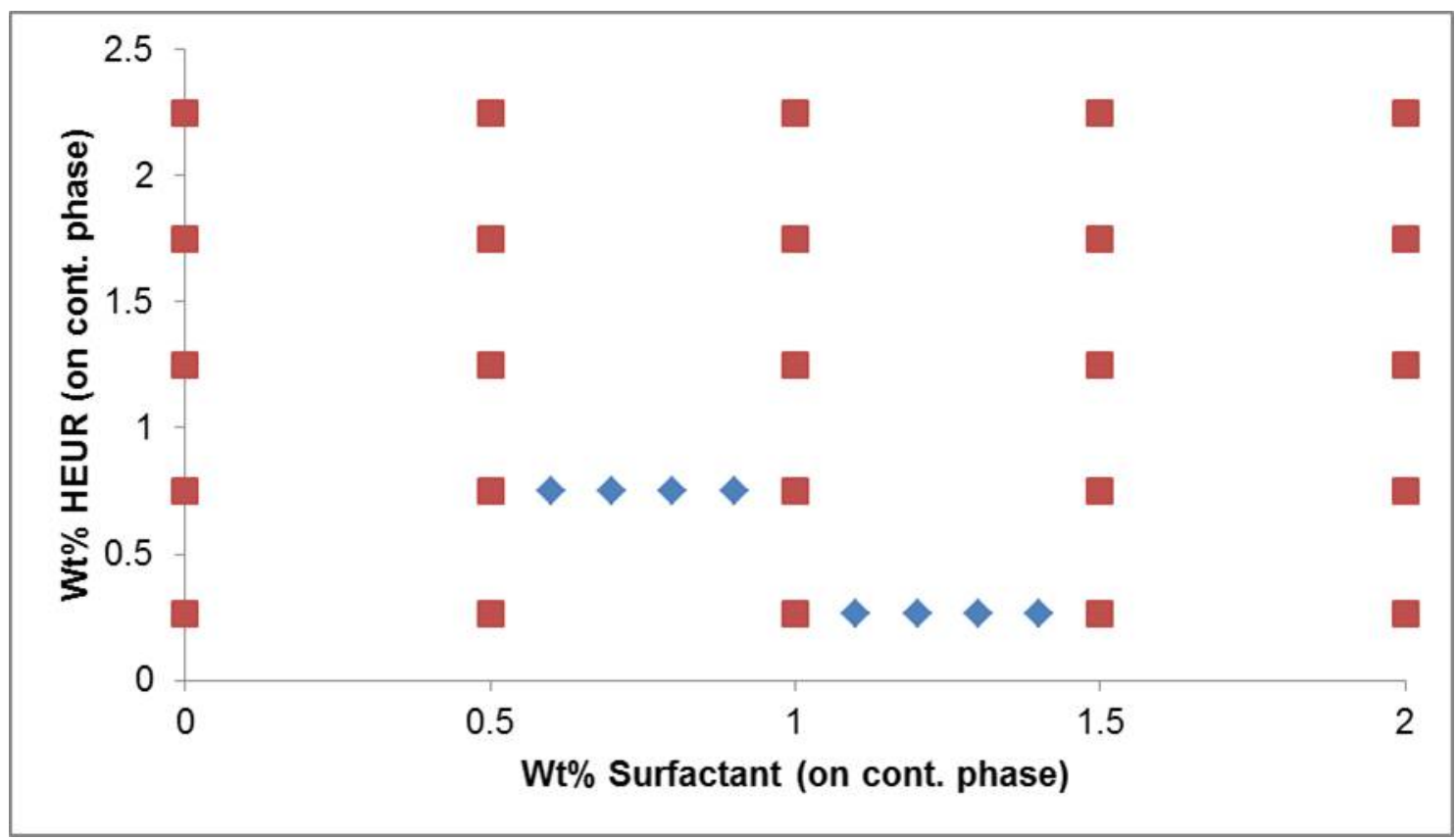

Figure 44. Initial set of additions for G-VNS 166A series are shown in blue diamonds. 


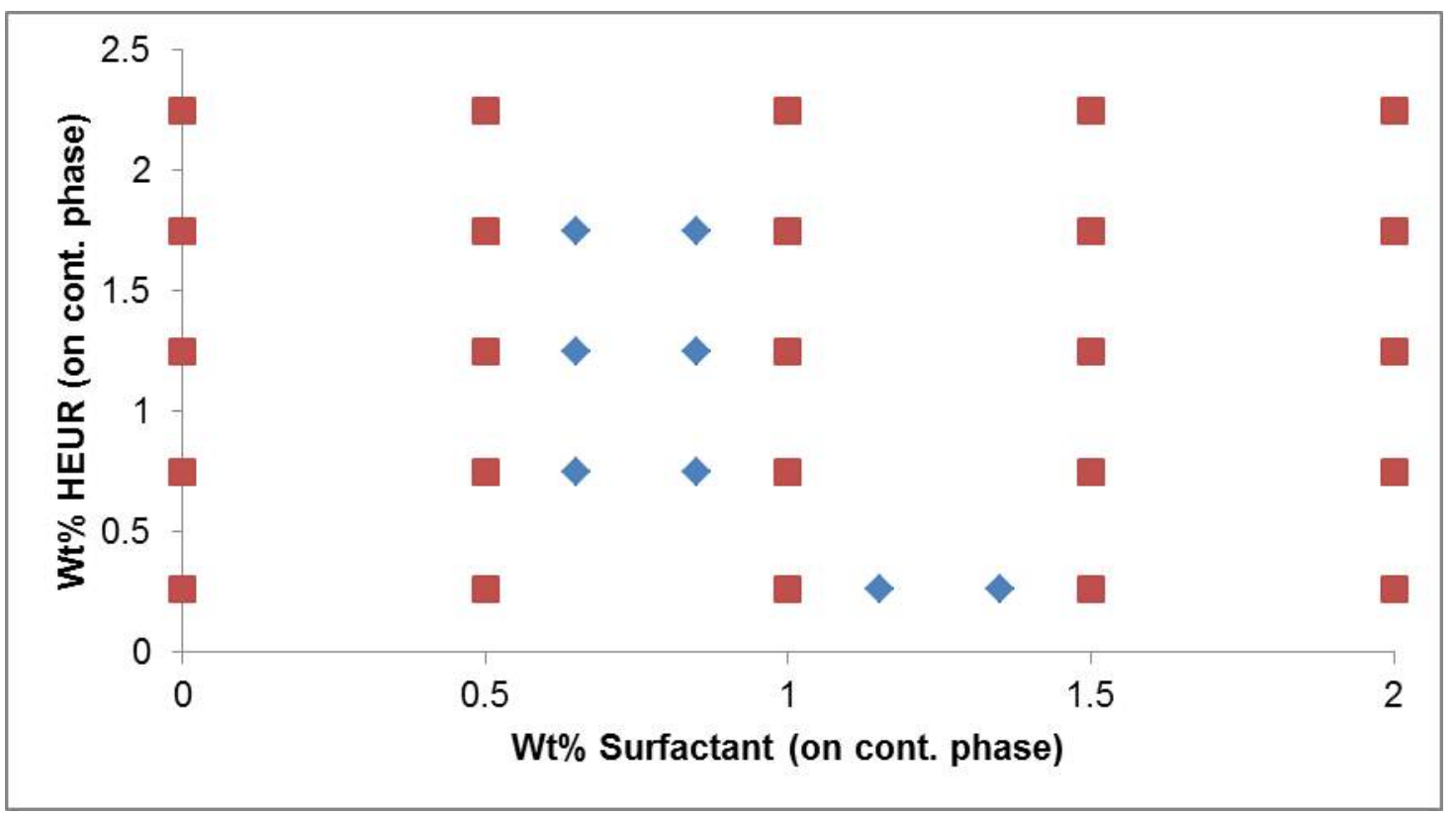

Figure 45. Second set of additions for G-VNS 166A series shown in blue diamonds.

The additions were spread out to cover more space for the second set of additions. The ability to make surfactant additions smaller than performed is limited by the ability to add the highly viscous materials in small incremental amounts.

\subsubsection{G-VAS 166A Series}

The second grid that was made was for the anionic Surfactant-B, Acrylic-A Latex, and the low- and high-shear HEUR thickening package. The sample set is called the G-VAS 166A series and all the theoretical additions are shown in Figure 46. The G-VAS 166A series was made in the exact same fashion as the G-VNS $166 \mathrm{~A}$ series. The naming scheme is the same as used for the prior G-VNS $166 \mathrm{~A}$ series. The scheme is G-X166YAAAA-BBBB-CCC where $X$ represents where the paint was made $(\mathrm{C}$ for Cal Poly and $\mathrm{V}$ for Valspar), 166 represents $0.26 \%$ of low-shear HEUR thickener, $Y$ is for which acrylic was used in the formulation (A for Acrylic-A and B for Acrylic-B), AAAA is a numerical representation of the amount of total wt\% HEUR in the sample (multiplied by 1000), BBBB represents the wt\% surfactant in the sample (multiplied by 1000), and CCC 
represents the type of surfactant used (405 for Surfactant-A, 411 for Surfactant-B, and 100 for Surfactant-C). Call names were made for each corresponding sample. One example for a call name is G-VAS-A1: $G$ means the samples were made in a grid fashion, $V$ means the sample was made at Valspar, NS for Surfactant-A, A for Acrylic-A and 1 for the first sample of the set. The corresponding weight percent of HEUR and surfactant for the G-VAS 166A series is shown in Appendix A.

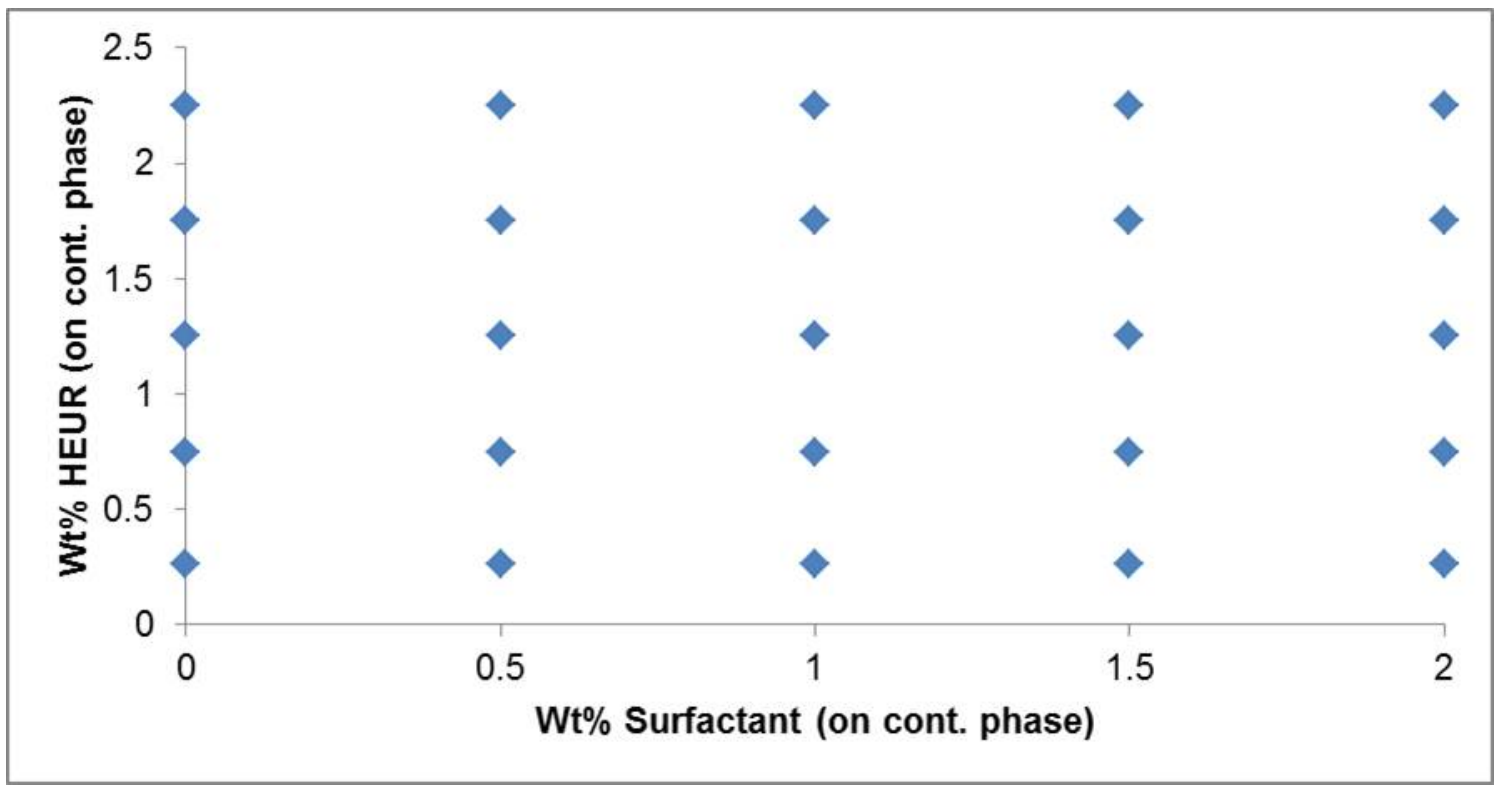

Figure 46. Graph showing the grid approach for paint-making for the G-VAS 166A series. Each point represents an individual sample that was created within the data set.

For the weight percent surfactant values, most values are within the rounding error of the scale; however, there are some values that are slightly different. Adjustments of the wt\% surfactant values were made for more accurate analysis of the DPD.

\subsubsection{G-VAS 166A Additions}

Additional samples were made in a separate batch for regions close to the flocculation boundaries. The additions are shown in Figure 47, in an easy graphical appearance where the red squares are additions and the blue diamonds are the original samples. 


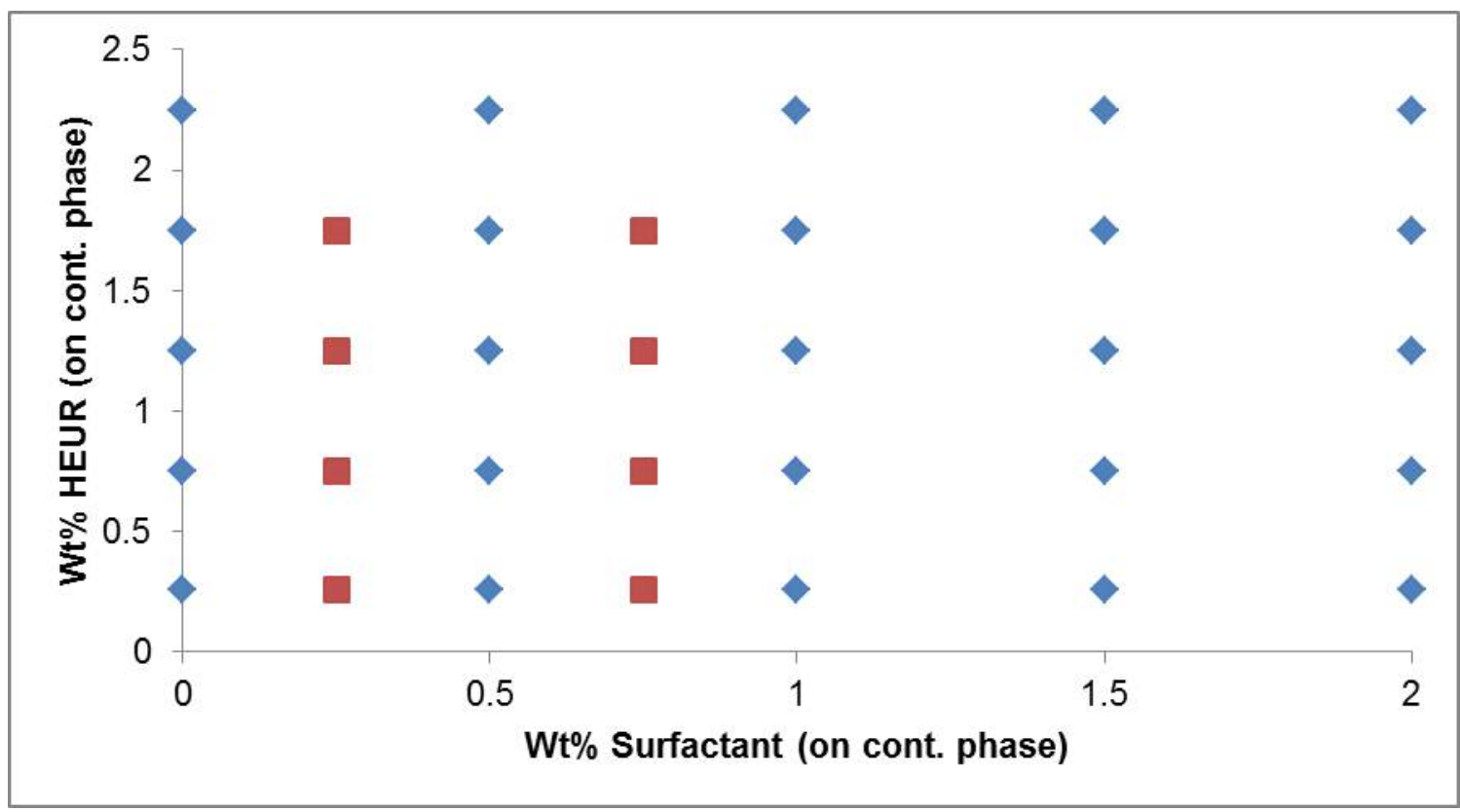

Figure 47. Additional samples made to G-VAS 166A series are shown in red squares with the blue diamond's being the original samples.

\subsection{New DPD Construction Procedure}

The DPDs were made following a revised process of which the most essential and efficient tests were utilized. The new procedures followed were a result of the work done in phase 1 which was previously discussed. The new listed procedure is a detailed stepby-step process which is followed to ultimately construct a DPD via the grid method.

\subsubsection{Physical Property Testing}

The physical property testing procedure was refined down to the most informative properties for the construction of DPD. After the paint has been prepared via the new grid method, each sample is analyzed for initial KU viscosity. After the $\mathrm{KU}$ is measured, 3 mil drawdowns are performed. Each sample is mixed by hand before the $\mathrm{KU}$ measurement and drawdowns. After 24 hours has passed, the $\mathrm{KU}$ is measured again for the 24 hour $\mathrm{KU}$ value, and the drawdowns are analyzed for 20,60 , and 85 gloss. The 
panels are then tested for IRBS to quantify the $\mathrm{TiO}_{2}$ flocculation present. The physical property data was also plotted in contour plots in with wt\% HEUR on the $y$-axis, wt $\%$ surfactant on the x-axis, and the desired physical property on the z-axis. The construction of contour plots for the physical properties allowed for observation of trends for the given system of latex and surfactant. The contour plots were made using the JMP Statistical Software.

\subsubsection{Rheology Procedure}

The rheology procedure that was found to be the most effective was shear-rate ramps described in the Phase 1 Valspar methods section. The rheology test starts with the paint sample at the lowest HEUR level and moves sequentially left to right with increasing surfactant until the bridging flocculation region is no longer observed. The next highest wt\% of HEUR is tested in the same way, and this process is repeated until the next starting level of HEUR does not show any signs of bridging flocculation. The rheology analysis should be conducted within 2 days of the synthesis of the paint samples.

\subsubsection{Syneresis and Percent Solids Testing}

The syneresis test setup that was the most accurate and efficient was to use $150 \mathrm{~mL}$ glass jars. Each sample is immediately loaded into the glass jars upon preparation of the paints, and allowed to sit undisturbed for 7 days. After the elapsed time, the separation is measured and percent solids were tested as described in the Phase 1 Valspar methods section.

\subsubsection{DPD Contour Construction}

All the tests described have lead up to the construction of full-scale DPDs for each system. The DPD is made in the same contour plot form as described for the physical 
property section above. The contour is constructed in the JMP statistical software by simply assigning a value of -1 for a bridging flocculation sample, 0 for a good dispersion, and 1 for a depletion flocculation sample. In some cases, the assigning of a depletion flocculation number was not always clear due to the nature of the systems being studied. The transition between flocculation regions is a gradual process and in some cases tests exhibit signs that the sample is in the transition boundary of a region. For these cases, a value of -0.5 would be assigned for a sample designated in the bridging flocculation to good dispersion transition, and a value of 0.5 for a sample in the good dispersion to depletion flocculation transition. The values were entered into JMP statistical software and a contour plot was constructed for each DPD. An example is shown in Figure 48 which is the first DPD for Acrylic-A and non-ionic Surfactant-A.

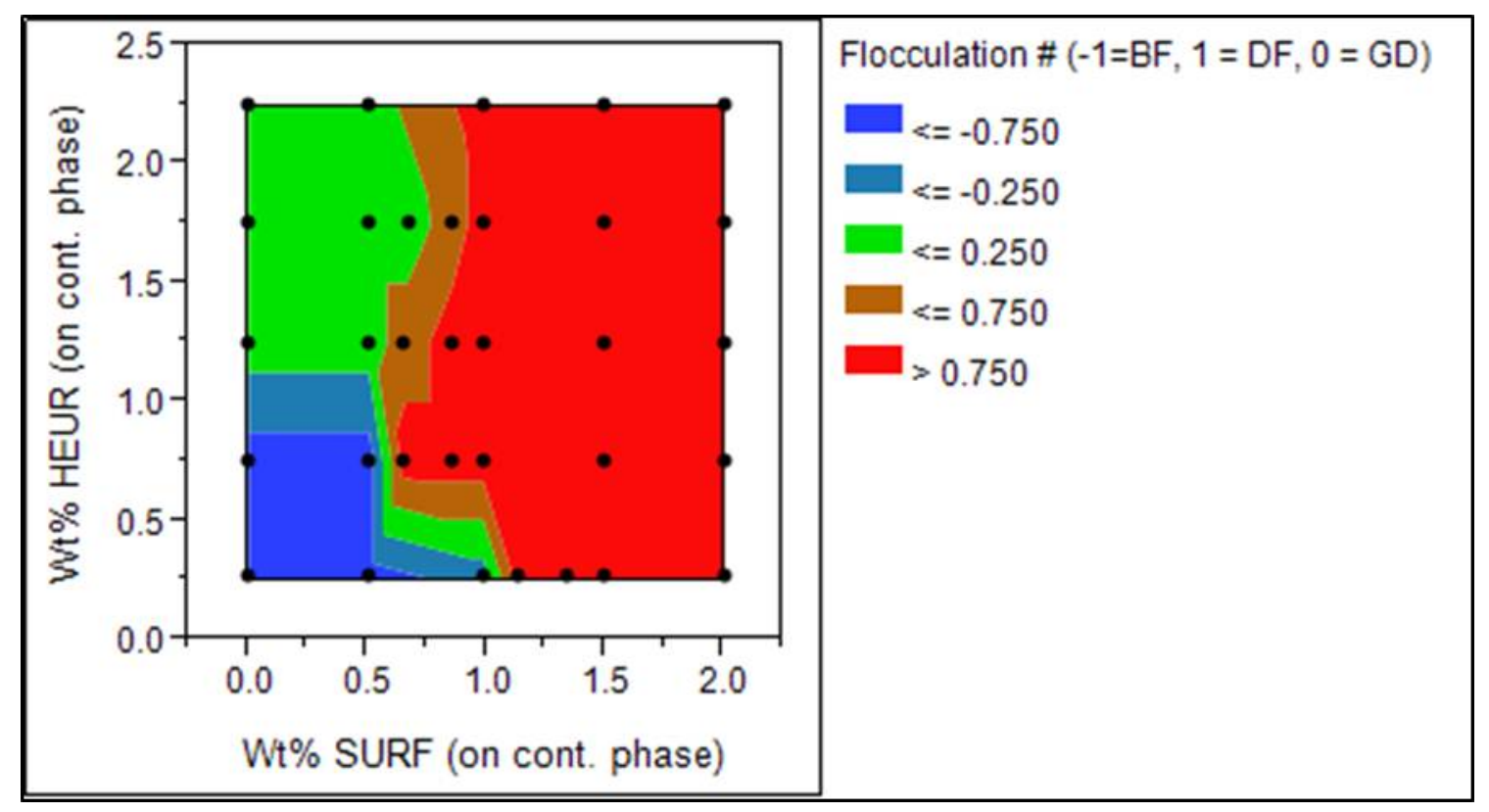

Figure 48. Contour plot example for the DPD for Acrylic-A and Surfactant-A.

This method is quite simple and effective at showing the transitions between regions. The gradual transition is important to show in the DPDs because they are present in the individual samples in the grid. The numbering scheme reflects the hypothetical transition 
between a bridging flocculated, to good dispersion, to a depletion flocculated sample, and this should be the most accurate representation of the flocculated regions.

An example for a bridging flocculation and good dispersion boundary conclusion is that the sample shows a rheology curve with elevated viscosity at lower shear rates similar to other bridging flocculation samples; however, the sample does not have a distinct region of shear-thickening. The sample is then verified to be in the boundary of bridging flocculation and good dispersion with a visible separation present in the syneresis sample. The sample does not have a rheological bridging flocculation conclusion but shows phase separation, which leads to the conclusion of -0.5 for a sample in the bridging flocculation and good dispersion boundary.

An example for a good dispersion and depletion flocculation boundary conclusion is as follows. The sample has been observed to not contain any bridging flocculation characteristics by rheology, and no visible phase separation is seen in the syneresis jars. The deciding factor for a boundary sample is that the percent solids of the top layer of the sample is much lower than the expected value. For a full conclusion of good dispersion, there must be no bridging flocculation from rheology, no visible separation present, and the percent solids of the top layer must be close to the expected value. Any factor that is lacking leads to a boundary conclusion of good dispersion and depletion flocculation. This method captures the gradual transition and is the most applicable way to represent DPDs with the current testing methods. 
7. Results - Phase 2 at Valspar

\subsection{G-VNS 166A Series}

\subsubsection{Physical Property Data}

Physical properties were collected and examined over the entire data set, shown in Appendix B. The data is more easily analyzed through outputs of contour plots, which will be shown in a subsequent section in the results. The ability to identify trends in the physical properties for the G-VNS 166A series are overwhelming by simply looking at the data. Statistical analysis was used to identify the most important testing parameters for determining DPDs. Contour plots will also be constructed to help visually recognize trends that are present in the data.

\subsubsection{Rheology}

Rheology testing was used for the G-VNS 166A series with the new testing procedure as discussed in the previous experimental section. The results for rheology for the G-VNS 166A series are shown in Figure 49. 


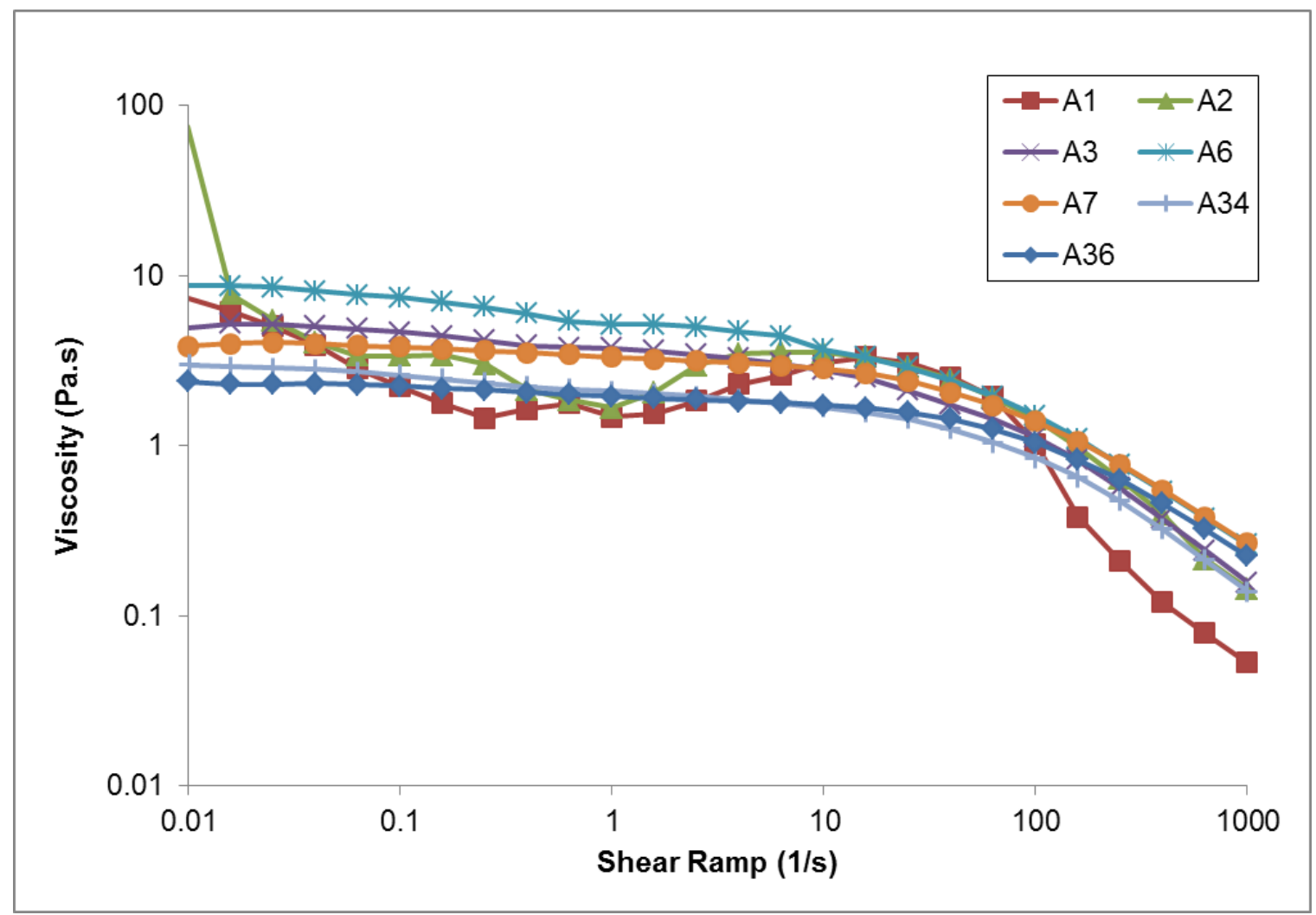

Figure 49. Rheology results for the G-VNS 166A series.

The rheology results showed a bridging flocculation confirmation for samples 1, 2 and 6 . Samples 3 and 7 were concluded to be on the boundary of the bridging flocculation region due to the shifting of their curves to higher viscosities than seen for the rheology profiles of good dispersion and depletion flocculation samples, and there was no distinct shear-thickening region.

\subsubsection{Syneresis and Percent Solids}

The syneresis and percent solids data for the G-VNS 166A series is shown in Appendix C. The $G$ will be left off of sample referencing in the following analysis. For samples VNS-11 to VNS-25, identification of the different flocculation types present is apparent. For each set of HEUR levels for the mentioned sample set, there is a clear transition 
from a good dispersion sample to a depletion flocculation sample. For one set, as an example, the VNS-11 to VNS-15 data set will be analyzed. The amount of HEUR is constant for all samples in this set and the surfactant is sequentially increased from VNS-11 to VNS-15. VNS-11 has no visible separation and a top layer percent solids of $42 \%$, which is close to the expected value of $44 \%$ for the formulation. VNS-12 has no visible separation, but has a top layer percent solids of $39 \%$. This concludes that VNS12 is still a good dispersion but the depletion flocculation region is likely being approached. The next sample in the data set is VNS-13 and separation was observed with a drop in percent solids of the top layer to $36 \%$. This concludes that the depletion flocculation region was entered at VNS-13, and VNS-14 and VNS-15 are concluded to be samples located further in the depletion flocculation region. This is confirmed with increase in the separation for VNS-14 and VNS-15 and also similar percent solids levels for the top layer. Samples VNS-16 to VNS-20 and VNS-21 to VNS-25 were analyzed in the same fashion and had similar conclusions. For samples at lower HEUR levels when a transition from a bridging flocculation sample to a depletion flocculation sample is present, the syneresis and percent solids data was used with the rheology data and physical property data to make flocculation conclusions. The rheology data discussed previously confirmed bridging flocculation for samples VNS-1, 2 and 6, and samples 3 and 7 were concluded to be on the bridging flocculation boundary. The remaining samples that had separation present, and did not have bridging flocculation determinations from rheology were concluded to be depletion flocculated.

\subsubsection{Statistical Analysis and Contour Plots}

Statistical analysis in the form of multivariate analysis was used to weigh the significance of the data collected for constructing a DPD. The analysis describes the linear relation of each variable of the data set with relation to one another. As in most statistical 
techniques, many confounding variables must be accounted for with conclusions based upon the outputs. The main assumption is that the data is bivariate normally distributed, and each variable is correlated with one another with a $95 \%$ bivariate normal density ellipse (JMP 10 Modeling and Multivariate Methods, 2012). This initial multivariate test was simply a starting test of which contour plots would be made in response. The multivariate analysis was conducted with JMP statistical analysis software and is shown in Appendix D.

From the multivariate analysis some initial analysis can be made. The $\mathrm{KU}$ viscosity is highly correlated with the amount of surfactant in the system. As discussed previously, the surfactant can desorb the thickener from particles in the system, so the addition of surfactant should have a strong correlation with changes in the viscosity. The IRBS value which is a strong indicator of $\mathrm{TiO}_{2}$ flocculation is most highly correlated with the $w t \%$ HEUR and the 20 degree gloss of the system. The 20 degree gloss, which is a measurement of the dispersion of the system, should be correlated with the IRBS because they essentially make the same conclusion. The reasoning for the HEUR correlation is not as clear, but a hypothesis can be made. The amount of HEUR should be related of how well-dispersed particles of the system are, and as a result should be correlated with IRBS. The prediction of the flocculation number is most correlated with the $\%$ surfactant and $\mathrm{KU}$ viscosity. The \% surfactant and $\mathrm{KU}$ viscosity are essentially the same correlations and the surfactant correlation will be the only variable analyzed. The addition of surfactant disturbs the network of the system, and the flocculation type should be highly correlated with this change in network formation.

Contour plots were constructed to examine trends that may be present in the physical property data for a system. The contours that were constructed were all constructed with wt $\%$ HEUR on the continuous phase on the $y$-axis, wt $\%$ surfactant on the continuous 
phase on the x-axis, and the represented physical property on the z-axis. The physical properties that were analyzed were 24 hour KU viscosity, 60 degree gloss, IRBS, and conductivity shown in Figure 50, Figure 51, Figure 52, and Figure 53 respectively.

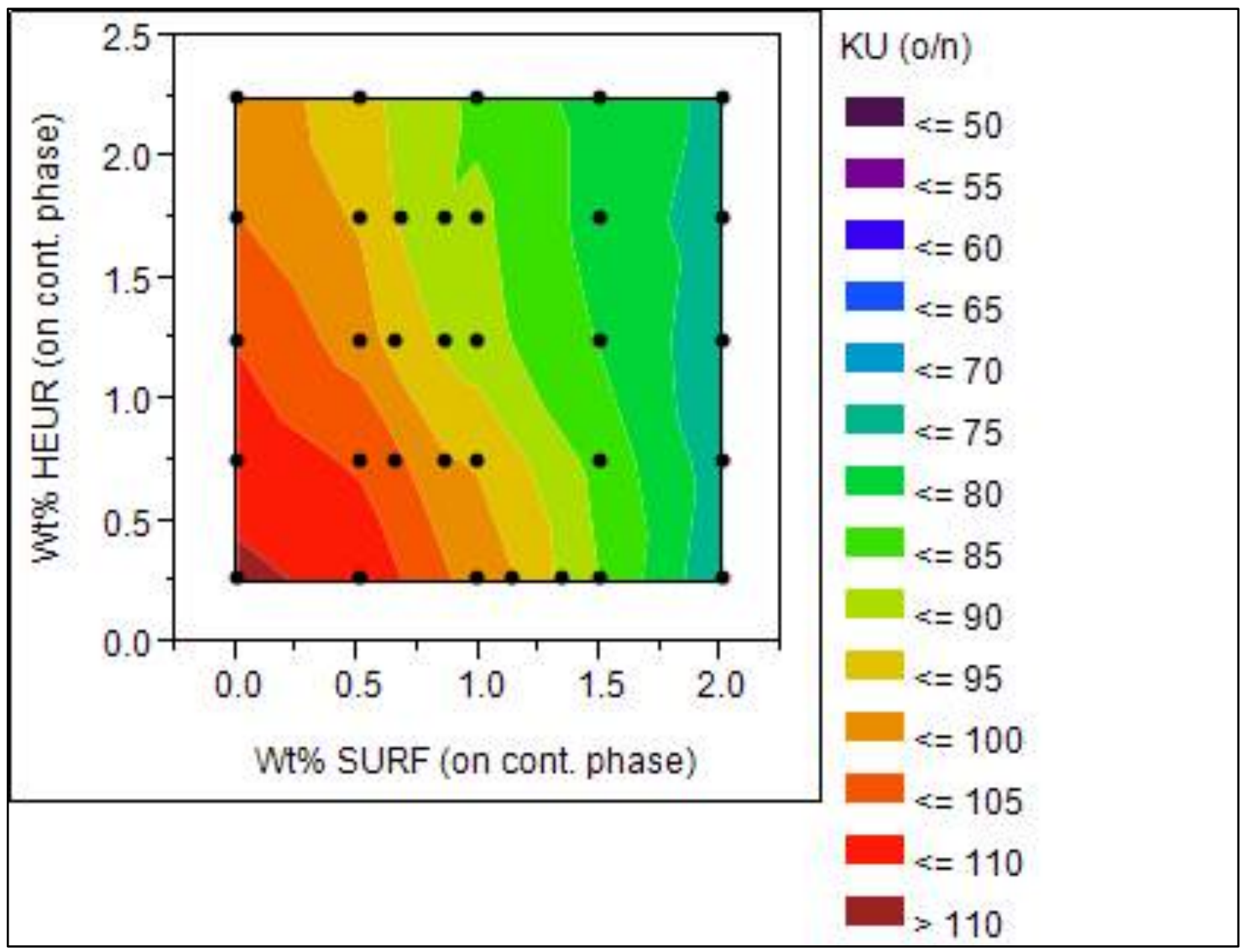

Figure 50. 24 hour KU viscosity contour plot for G-VNS 166A series.

The 24 hour $\mathrm{KU}$ plot shows that at lower levels of non-ionic surfactant, the $\mathrm{KU}$ is influenced equally by changes in both HEUR and surfactant. As a reminder, a typical KU is around $90-100 \mathrm{KU}$. As higher levels of surfactant are reached $(>1 \%)$ the contours shift to vertical contours with changes in surfactant. This means that at higher levels of surfactant, the system is overwhelmed with surfactant and any KU changes are directly in response to the increase surfactant in the system. 


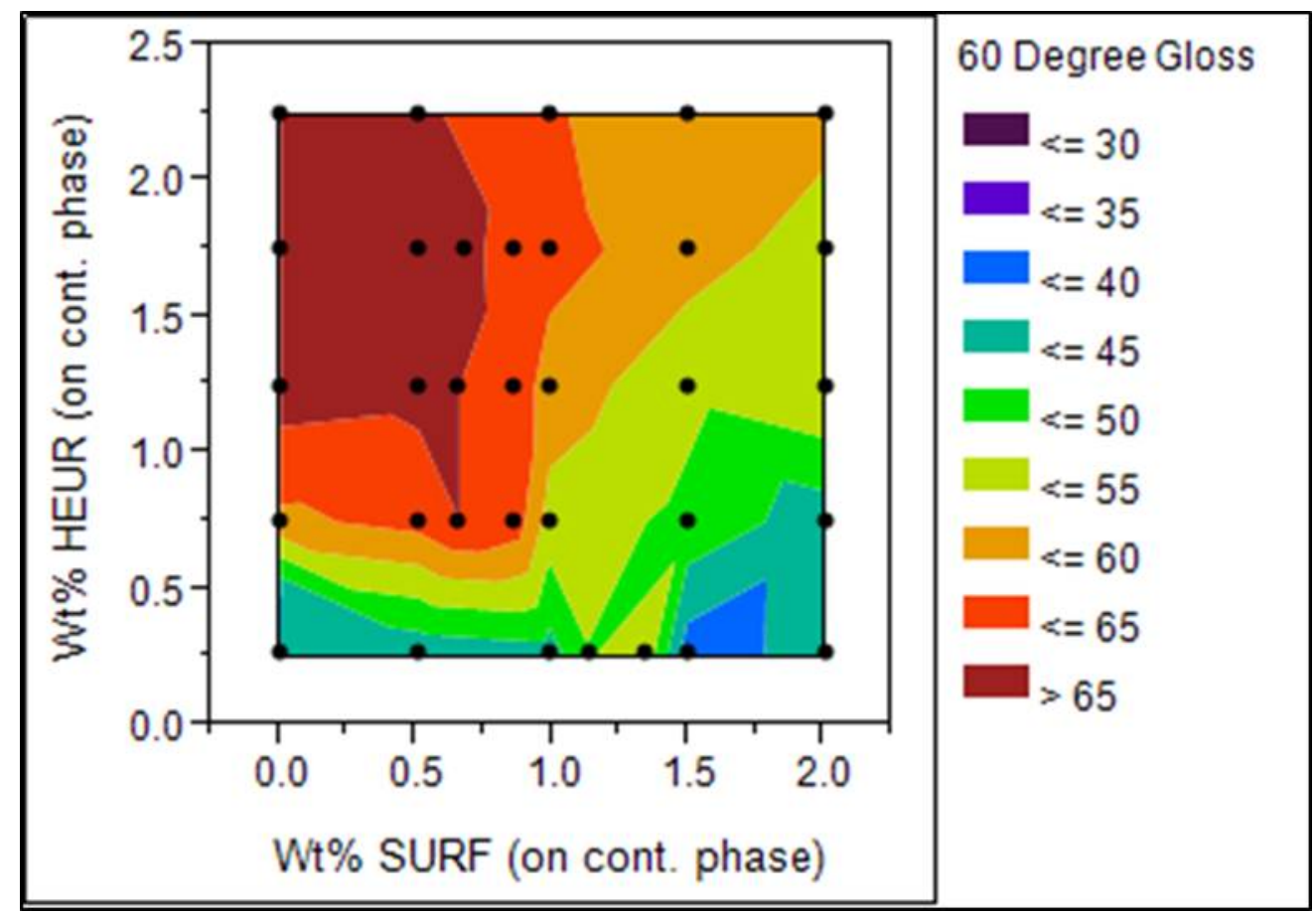

Figure 51. 60 degree gloss contour plot for G-VNS 166A series.

For this system, the gloss values are highest below $1 \%$ surfactant, and above $1 \%$ surfactant. The dark red region of $>65$ gloss matches up with the good dispersion region of the finalized DPD, which will be discussed shortly. This graph shows that for this system the gloss is a strong indicator that a sample is not flocculated, and to insure that the sample is not flocculated a minimum 60 degree gloss value should be at least 65 . 


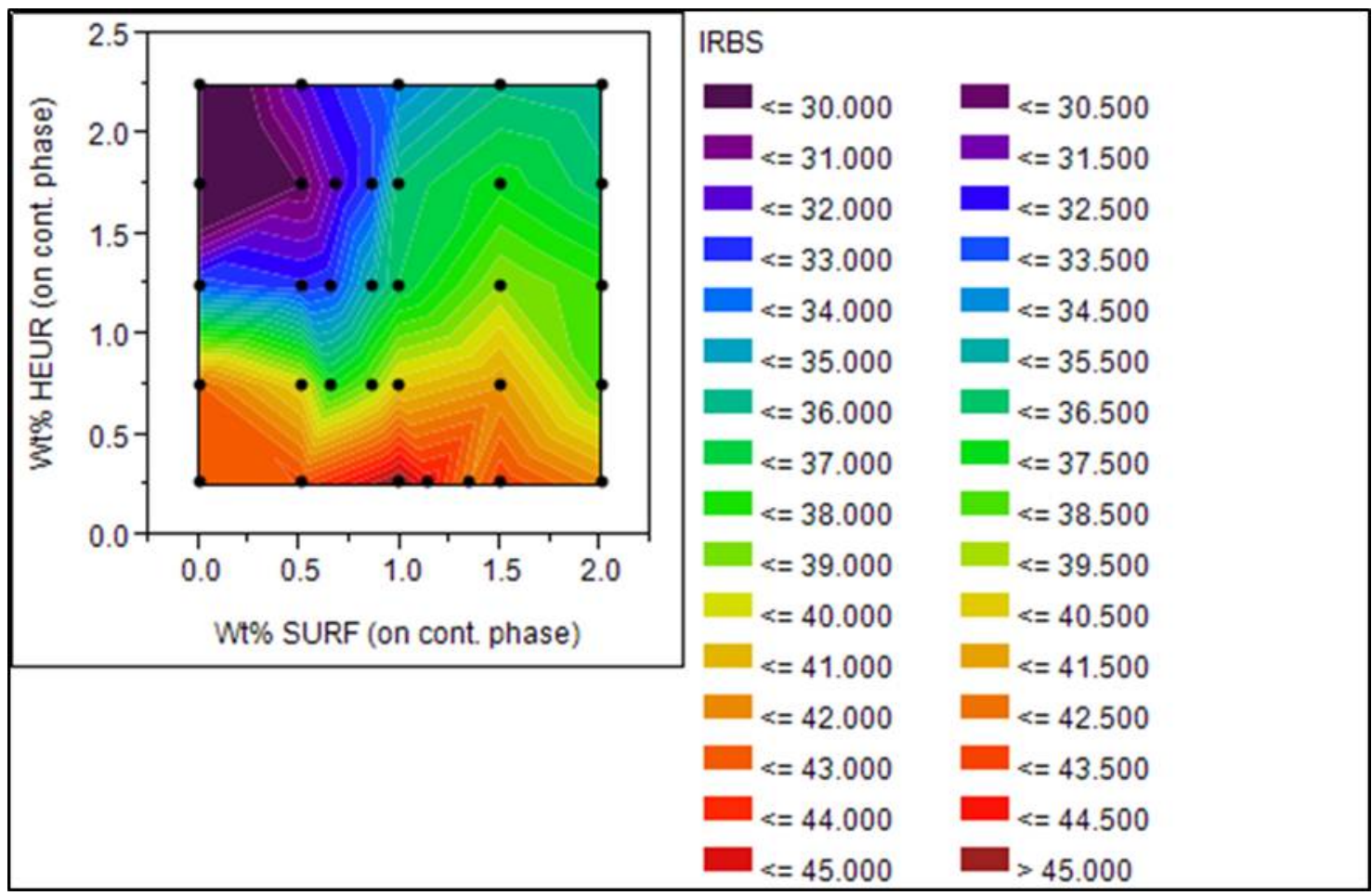

Figure 52. IRBS contour plot for the G-VNS 166A series.

IRBS which is a measurement of the $\mathrm{TiO}_{2}$ flocculation for a dry paint sample will have lower values of IRBS for well-dispersed $\mathrm{TiO}_{2}$. The quantification of the $\mathrm{TiO}_{2}$ aggregation is displayed as a flocculation gradient with 30 or less having the lowest value, which concludes that the $\mathrm{TiO}_{2}$ shows the least amount of aggregation in this region. As the flocculation gradient increases, the $\mathrm{TiO}_{2}$ aggregations are increasing and values above 37 for this system translate to a flocculated system. If the $\mathrm{TiO}_{2}$ is showing IRBS values typical of a good dispersion, the overall state of the dispersion should be good. The idea behind this is that if at a certain level of HEUR and surfactant the $\mathrm{TiO}_{2}$ is stabilized, then the latex should be stabilized as well since the interactions of HEUR and surfactant with $\mathrm{TiO}_{2}$ and latex should be related for the system. This region of good dispersion shown with the IRBS contour plot was also confirmed with the other testing methods for the system, and matches with the good dispersion region of the finalized DPD. The IRBS 
technique has not been useful in determining a bridging from a depletion flocculation system, but rather as a tool to show the good dispersion region for this given system. The IRBS technique was observed as a strong test in that the testing can be conducted once the paint film is dried and does not require a week of total testing that is needed for syneresis and percent solids testing. The last note about this testing method is that it is a comparative method in which the flocculation gradient is a tool for comparing samples of a given set. The IRBS cannot be simply run on a single sample for flocculation determination. Instead, the IRBS can be used for all the samples in a given DPD space to show areas of the lowest flocculation gradient.

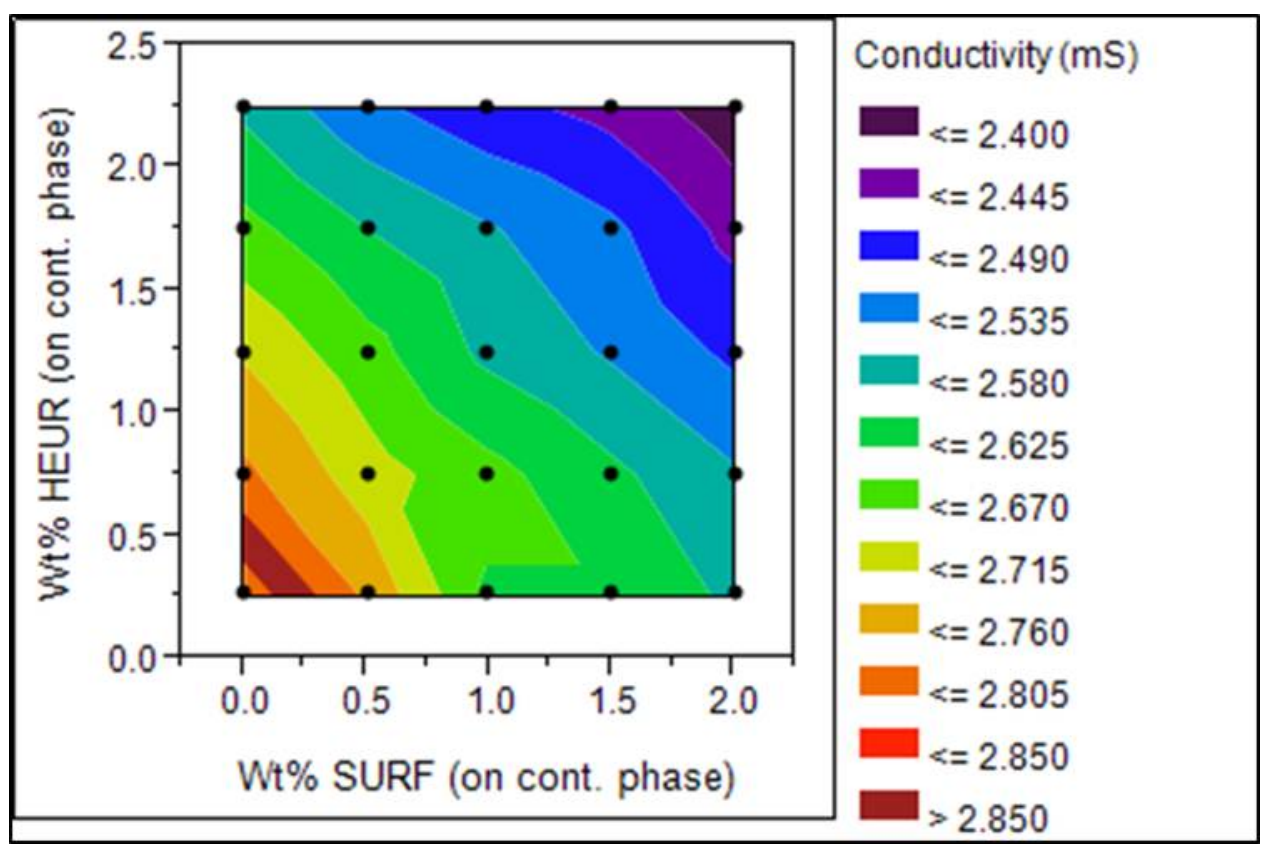

Figure 53. Conductivity contour plot for the G-VNS 166A series.

The conductivity results showed a negative linear correlation with respect to changes in both HEUR and surfactant. The addition of a non-ionic surfactant is not introducing any ionic characteristics into the system, and thus addition of the surfactant should not increase the conductivity of the system. The surfactant addition could possibly suppress 
any ionic particles in the system (most likely pigment particles), and any additions of surfactants should cause a slight decrease in the conductivity of the system.

\subsubsection{G-VNS 166A Series DPD}

The dispersion phase diagram was constructed using the technique described in the Phase 2 Valspar experimental section. To review, a value of $-1,0$, and 1 were assigned to the different flocculation sections with -1 being bridging flocculation, 0 for good dispersion, and 1 for a depletion flocculation sample. For samples that were concluded to be located in the boundary position of a transition between flocculation regions, a value of 0.5 or -0.5 were assigned accordingly. The DPD for the G-VNS 166A series is shown in Figure 54.

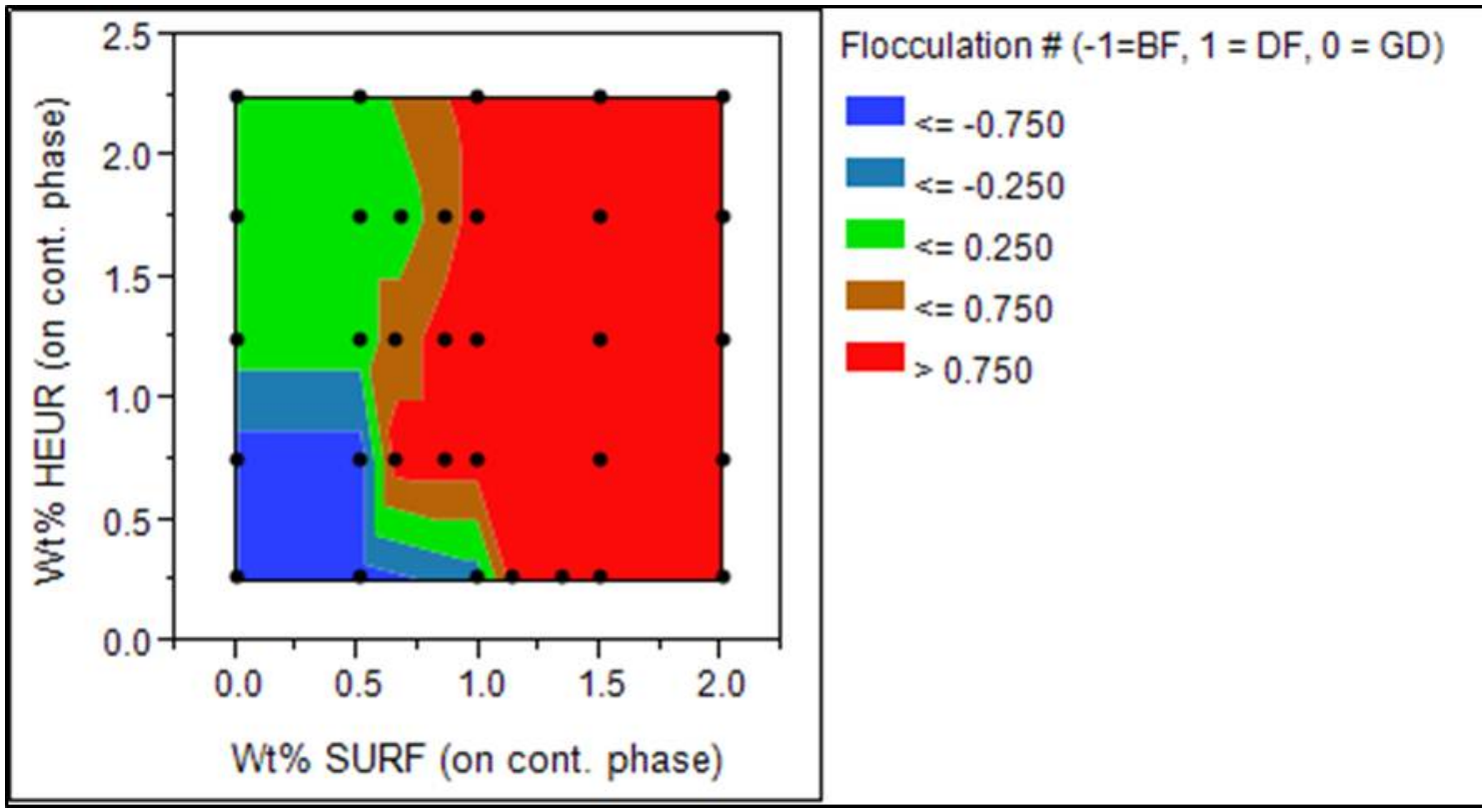

Figure 54. DPD for G-VNS 166A series - green shows good dispersion, bridging flocculation in blue, and depletion flocculation in red. The system consists of Acrylic-A (105 nm), the non-ionic Surfactant-A, and a low- and high-shear HEUR thickening package. 
The flocculation regions are clearly defined in Figure 54, with the good dispersion shown in green, bridging flocculation in blue, and depletion flocculation in red. The macroscopic separation showed in the DPD is a result of the dominant interactions for the system, and the transition between boundaries was found to be gradual. The good dispersion region begins slightly above $1 \%$ HEUR, and less than $0.75 \%$ surfactant. This region will be compared to the results for an anionic surfactant to visually describe which interactions dictate the shifting of flocculation regions for each system.

\subsection{G-VAS 166A Series}

\subsubsection{Physical Property Data}

The physical property data for the G-VAS 166A series is shown in Appendix B. The physical properties were analyzed via the same method as the G-VNS 166A series in which statistical analysis and contour plots are used.

\subsubsection{Syneresis and Percent Solids}

The syneresis and percent solids data for the G-VAS 166A series is shown in Appendix C. The syneresis and percent solids were analyzed in the same fashion as the G-VNS 166A series. The ability to observe separations, the percent solids of the top layer, with correlation to the rheology and physical data were used to determine the flocculation type of each sample.

\subsubsection{Statistical Analysis and Contour Plots}

Multivariate analysis was conducted for the G-VAS 166A series, shown in Appendix D, with the same parameters as G-VNS $166 \mathrm{~A}$ series. The only highly correlated value is the amount of surfactant in the system with the 24 hour $\mathrm{KU}$. The anionic surfactant disrupts the thickening mechanism of the system more efficiently than the non-ionic, so this 
should be expected that additions of surfactant dictate the change in viscosity for the system. The contour plots for G-VAS $166 \mathrm{~A}$ series were made similarly to G-VNS 166A series. The plot for $24 \mathrm{hr} \mathrm{KU}$ is shown in Figure 55.

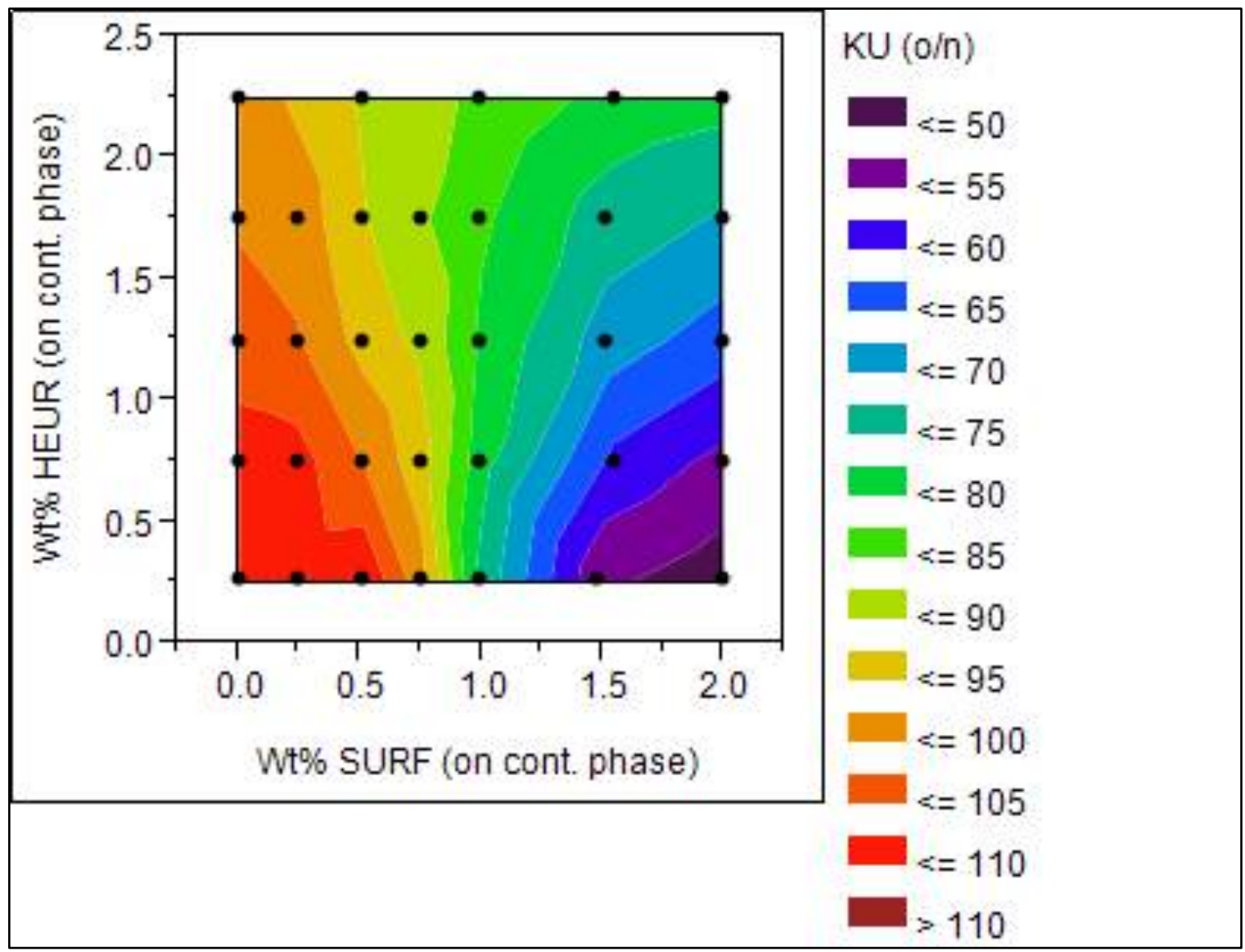

Figure 55. Contour plot for $24 \mathrm{hr}$ KU viscosity for the G-VAS 166A series.

The 24 hour KU viscosity contour plot was different than for the non-ionic surfactant. At low levels of HEUR, the viscosity of the system is affected by both surfactant and HEUR changes. At higher levels of HEUR, the changes in KU are observed to be dictated by changes in surfactant. The conclusion can be made that at lower levels of HEUR, the anionic surfactant is quickly displacing the low amounts of adsorbed HEUR in the system causing drastic changes in KU (Saucy, 2008). At higher levels of HEUR, there is more HEUR in the system to resist changes in the KU as the surfactant desorbs HEUR 
from particles in the system. The possible desorption mechanism is observed to be strongest for example at $2 \%$ thickener level, which a change from 100 to $80 \mathrm{KU}$ was observed, whereas at $0.26 \%$ HEUR there is a shift from 100 to $50 \mathrm{KU}$. At low levels of HEUR, and high levels of surfactant there is a significant difference between the nonionic and anionic contours for Acrylic-A. The anionic grid contour shows a huge drop in viscosity, which can be explained by the nature of the anionic surfactant compared to the non-ionic. Due to the anionic charge present on the surfactant, the number of molecules needed to create micelles greatly decreases (Mahli, Steffenhagen, Xing, \& Glass, 2003). The formation of micelles at lower surfactant concentration could be the reason why a huge viscosity drop is present that was not observed for the non-ionic.

The 60 degree gloss value was measured for each sample in the G-VAS 166A series, and the contour plot is shown in Figure 56.

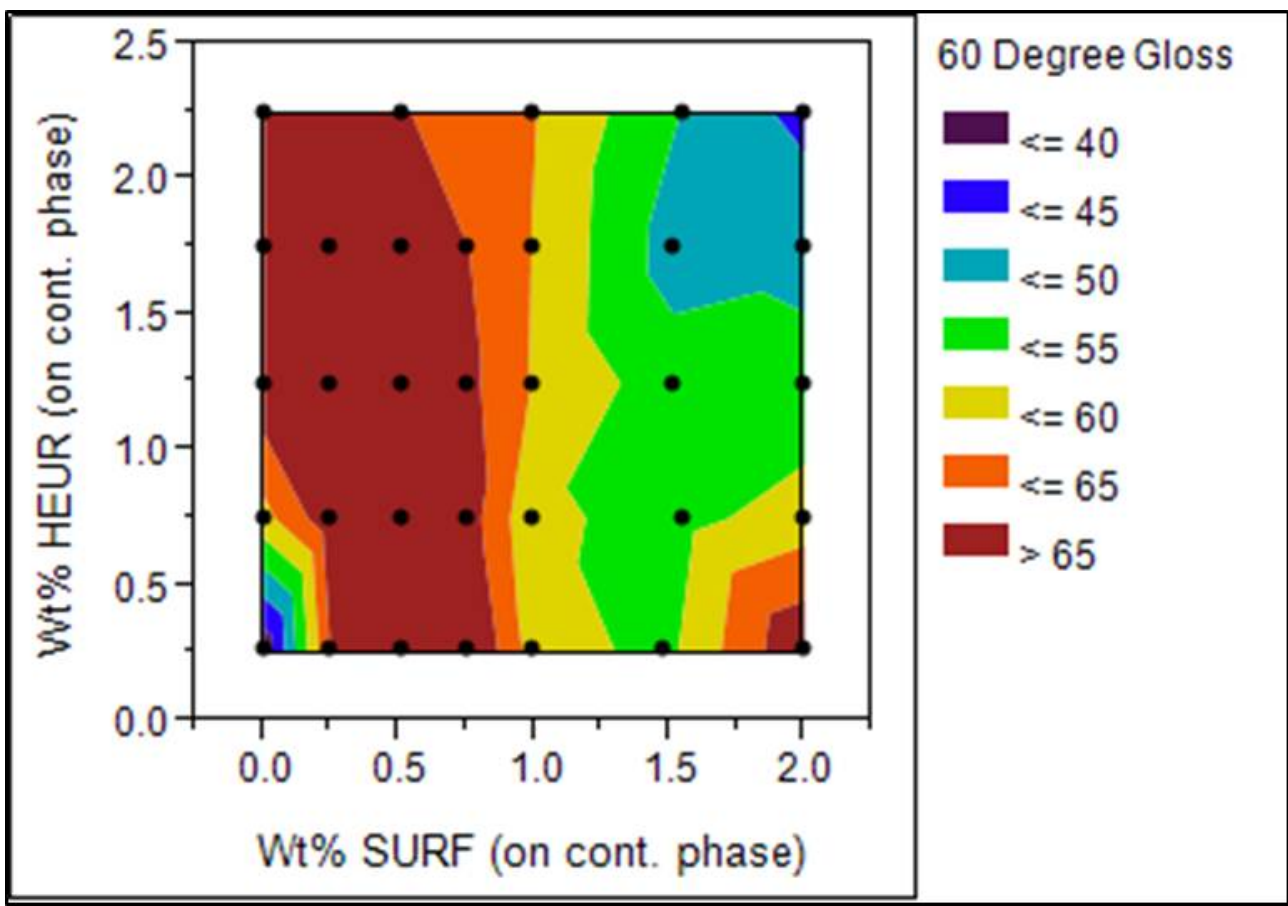

Figure 56. Contour plot for 60 degree gloss for the G-VAS 166 A series. 
Gloss is typically a good indicator of the degree of dispersion for a formulation with high gloss values translating to well dispersed system. This system showed high gloss values for almost all samples below $1 \%$ surfactant, and even had high gloss values for samples below $1 \%$ HEUR levels. Typical formulations for commercial paints are below $1 \%$ surfactant, so this region of high gloss should be expected. This study involved HEUR content (90 to $100 \mathrm{KU}$ range is most common) and surfactant levels out of the scope of typical formulations, and some irregularities of gloss were shown at high levels of HEUR and surfactant. These regions are deep into depletion flocculation regions and abnormal values for gloss are not surprising.

When comparing the 60 degree results for the G-VAS 166A series with the G-VNS 166A series there is one large difference. The G-VAS $166 \mathrm{~A}$ series has a region below $1 \%$ surfactant of high gloss values, and the G-VNS 166A series has the same region; however, the high gloss value is also dependent on the amount of HEUR in the system. The G-VNS 166A series high gloss values match closely with the good dispersion region for the DPD. The high gloss values at low HEUR levels for the anionic system could be as a result of the anionic surfactant because the only differences between the two systems studied thus far is the surfactant used. One possible reason for the high gloss for the G-VAS 166A series is that the anionic surfactant is stabilizing particles in the system better during the pre-mixing of the sample for drawdowns. The anionic surfactant in the system can be promoting a pseudo pigment dispersion state and cause a higher gloss values. Each sample is mixed by hand until the sample appears to be a good dispersion macroscopically. The non-ionic and anionic surfactants may be affected differently by this premixing which could be the reason why the high gloss values are represented more accurately with the non-ionic system. The non-ionic system gloss 
values are more representative for a good dispersion region than the anionic system which clearly has high gloss values for bridging flocculation samples in the DPD.

The conductivity for the G-VAS 166A series contour plot is shown in Figure 57.

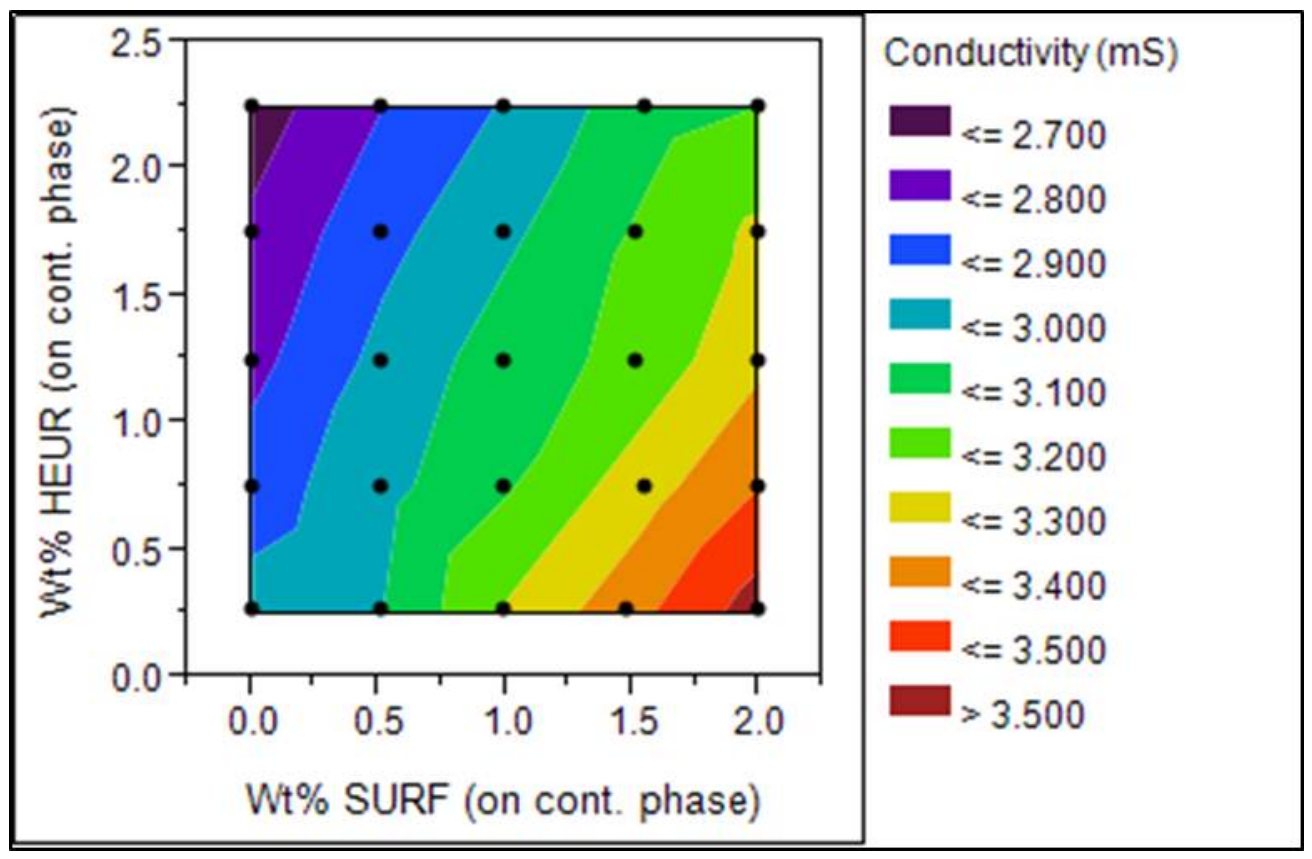

Figure 57. Contour plot for conductivity for the G-VAS 166A series.

The contour plot for conductivity for increases in wt $\%$ of anionic surfactant is linearly related with respect to additions of surfactant and HEUR. The addition of the anionic surfactant in its ammonium salt form introduces more ions into the system, and conductivity should increase in response. The results for the anionic surfactant reflect the increase in ions with an increase in conductivity.

The contour plot for the IRBS for the G-VAS 166A series is shown in Figure 58. 


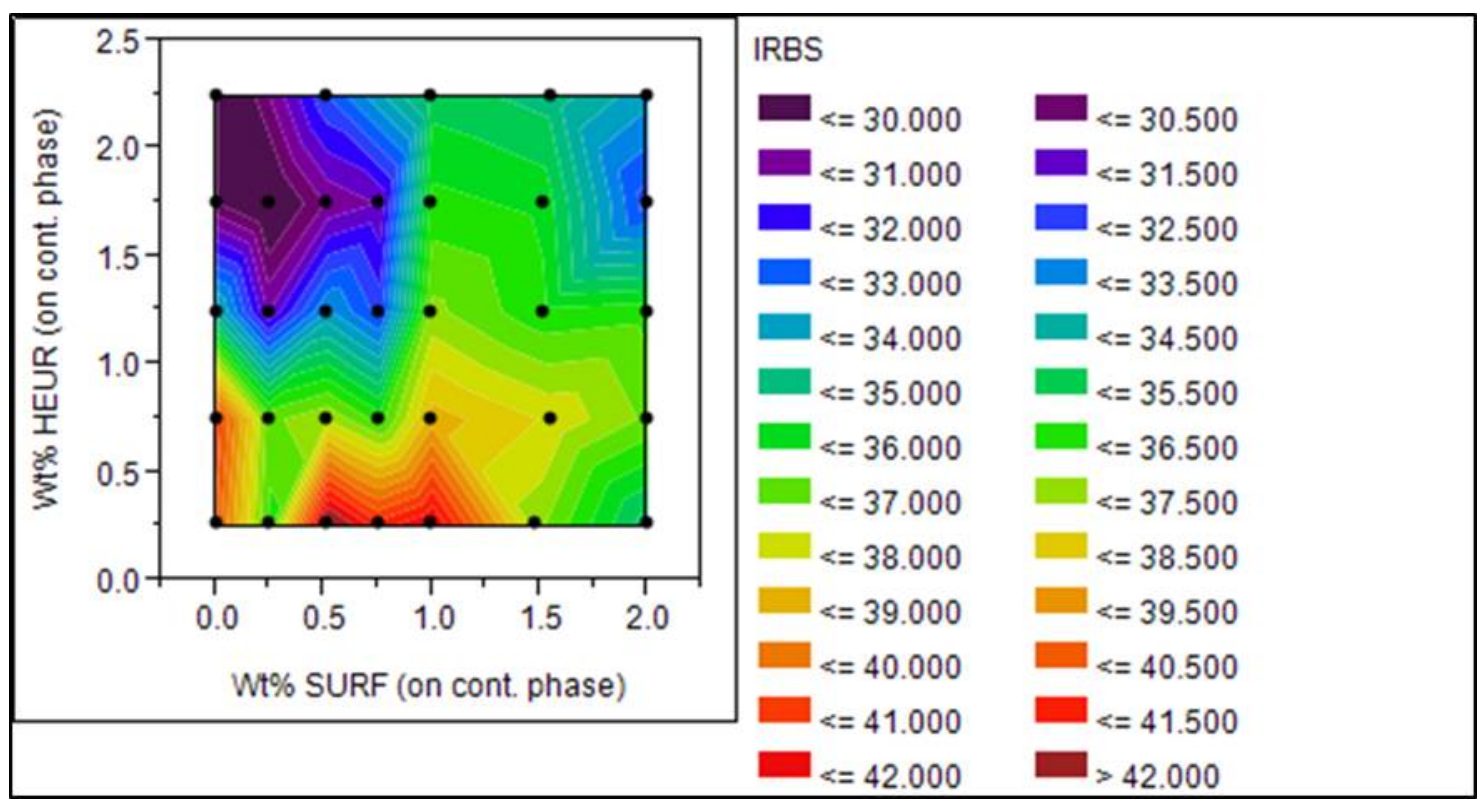

Figure 58. Contour plot for IRBS for the G-VAS 166A series.

The contour plot for the IRBS for the G-VNS 166A series will be referenced for comparison and is shown in Figure 52. As previously discussed, the lower the flocculation gradient for IRBS the better the dispersion for $\mathrm{TiO}_{2}$. First, the IRBS region of less than 30 for the flocculation gradient for the more well-dispersed $\mathrm{TiO}_{2}$ region is slightly smaller for the G-VAS 166 A series. The region at low IRBS values $(<33)$ is also smaller, which should be expected for this system in which the anionic surfactant is expected to displace thickener molecules more efficiently, and thus increases the size of the depletion flocculation region. The transition from the good dispersion region to the depletion flocculation region at higher HEUR levels should occur at lower surfactant values. This can be seen in the green region for the IRBS contour of the G-VAS 166A series, which is shifted to just below $1 \%$ surfactant. This region did not start until just above $1 \%$ surfactant addition for the G-VNS 166A series. The expectations are reflected 
in the IRBS for these 2 systems with the Acrylic-A latex, which gives credibility to the IRBS test in showing the good dispersion region for these systems.

\subsubsection{Rheology}

Rheology was conducted for G-VAS 166A series in the same way G-VNS 166A series, shown in Figure 59. The rheology results confirmed bridging flocculation regions for GVAS samples: $1,26,2,6$, and 28.

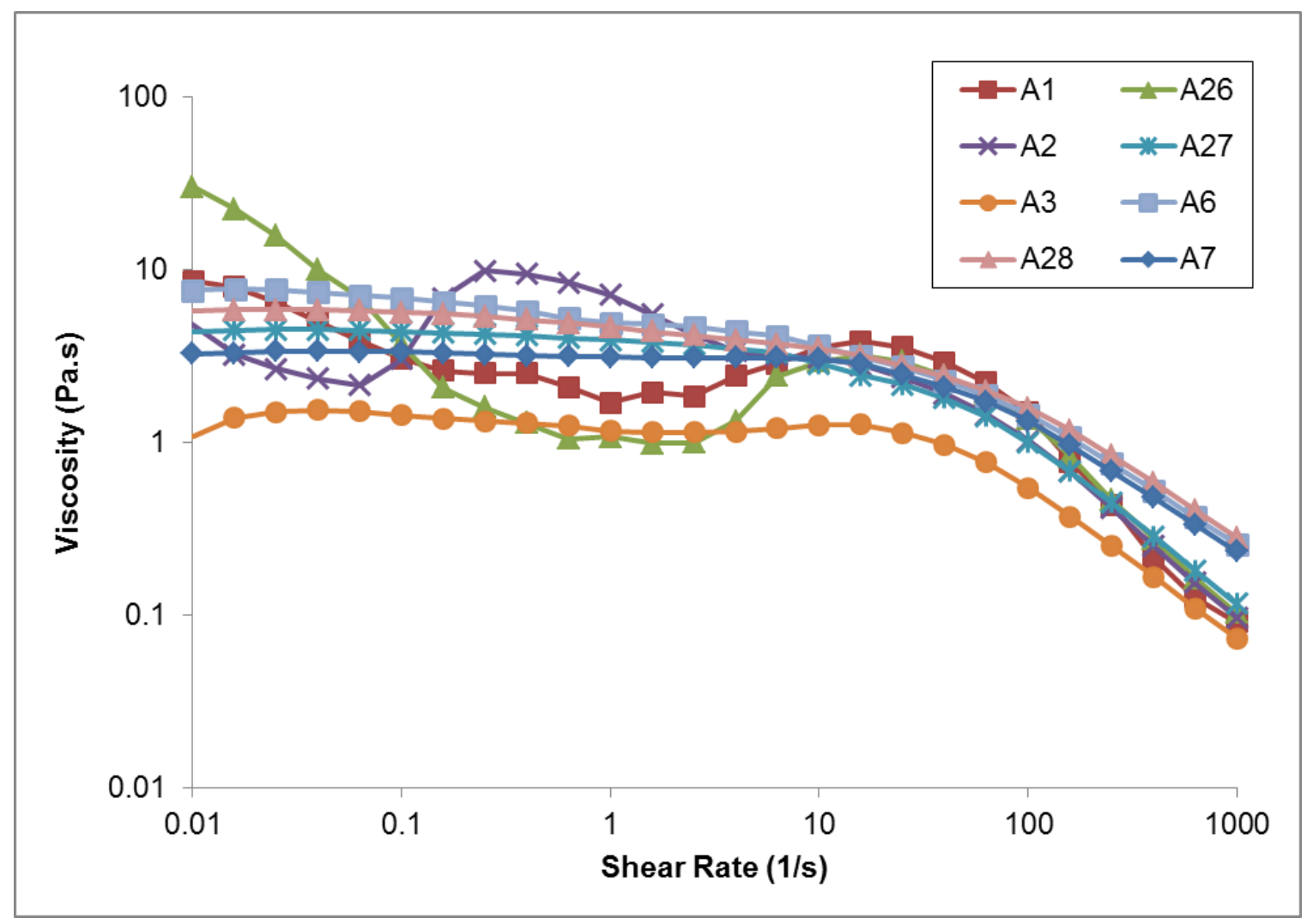

Figure 59. Rheology data for G-VAS 166A series.

\subsubsection{G-VAS 166A Series DPD}

The DPD for the G-VAS 166A series was constructed in the same fashion as the G-VNS 166A series. The DPD for the G-VAS 166A series is shown in Figure 60. 


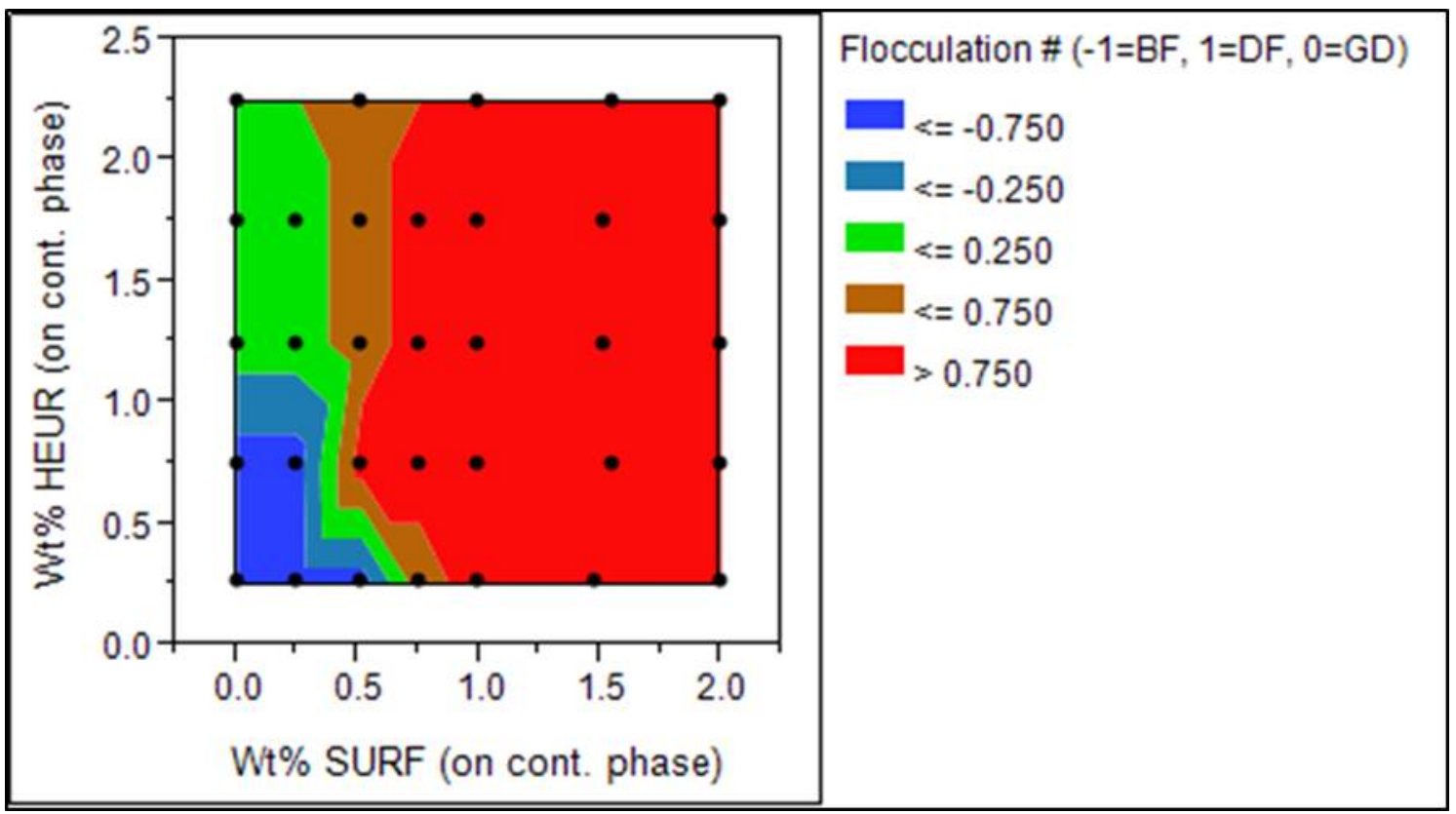

Figure 60. G-VAS 166A series DPD.

The G-VAS 166A series DPD showed some distinct differences from that of the G-VNS 166A series DPD. First, the good dispersion region was much smaller and the depletion flocculation region larger. This is as expected since the anionic surfactant was observed to disrupt the thickening mechanism of the system (loss of KU viscosity) at much lower levels of surfactant. One possible hypothesis for this occurring is that the anionic surfactant has a higher affinity for adsorption on particle surfaces in the system compared to a non-ionic surfactant, thus displacing the HEUR thickener at lower levels of surfactant. The second observation is that the bridging flocculation region has also become smaller. This again could be a result of the anionic surfactant having a higher affinity for the latex particles and as a result displacing thickener particles more efficiently. The bridges are being removed at lower levels of surfactant and a depletion flocculation region is being approached quicker. The small area of good dispersion below $1 \%$ HEUR is not an actual observed region of good dispersion, rather this region is present due to the method of which the DPDs were created. The DPD approach relies 
on the fact that there must be a transition from bridging flocculation to good dispersion to depletion flocculation, and the region below $1 \%$ HEUR is strictly a theoretical good dispersion zone. The transition from bridging to depletion flocculation is too small to make a good paint in this region. From this DPD some conclusions can be made for this combination of thickener, surfactant, latex, and pigment; the HEUR level must be above $1 \%$ HEUR, and less than $0.5 \%$ surfactant on the continuous phase. This region matches up relatively well with the IRBS contour plot, which confirms the legitimacy of the IRBS test for showing good dispersion from phase separation for this system.

\subsection{Conclusions for Acrylic-A}

Two different contour plots were constructed using the grid method and the latex AcrylicA. The same HEUR thickening package was used for both systems which is typical of commercial use in paints. Two DPDs were constructed for additions of non-ionic Surfactant-A and the anionic Surfactant-B. The final DPDs clearly show a larger region of good dispersion for the G-VNS 166A series. The small particle size latex of Acrylic-A (105 nm) has a large surface area and should be able to accommodate most of the adsorbed species in the system; however, both of the surfactants are clearly desorbing thickener from the surfaces shown by the formation of depletion flocculation regions and viscosity loss. At higher levels of surfactant, the loss in viscosity could be related to the actual desorption of thickener molecules from the particles in the system. There are some possible mechanisms by which the desorbed thickener interacts with the system: form micelles with other thickeners, form mixed micelles with free thickener and surfactant, self-aggregation, and others. This area of research is not very well known and a better understanding of these systems will be needed before further conclusions can be made on the mechanisms of the desorbed associative thickening polymer. 


\section{Experimental Methods - Phase 3 at Valspar}

The third phase at Valspar included using the new and effective grid technique to make DPDs for a different size latex. The ability to extend the developed experimental techniques to a different latex is an important goal of the project. The new latex studied was an all-acrylic latex similar to VSR 1050 and will be called Acrylic-B. The particle size of $150.9 \mathrm{~nm}$ was measured using a Mircrotrac Nanotrac 150 particle size analyzer. The percent solids was also measured to be $47.50 \%$ compared to the Acrylic-B of $48-50 \%$ solids. The paint formulation used was $166 \mathrm{~A}$ and the components used in the formulation were the same as the prior work except for using Acrylic-B in place of Acrylic-A.

\subsection{G-VNS 166B Series}

The G-VNS 166B series was made in the exact same manner as the G-VNS 166A series except with the different latex signified by the B in 166B. The G-VNS 166B series system consists of Acrylic-B, Surfactant-A, and the low- and high-shear thickening package previously described. The additions for the G-VNS $166 \mathrm{~B}$ series are shown in Figure 61. 


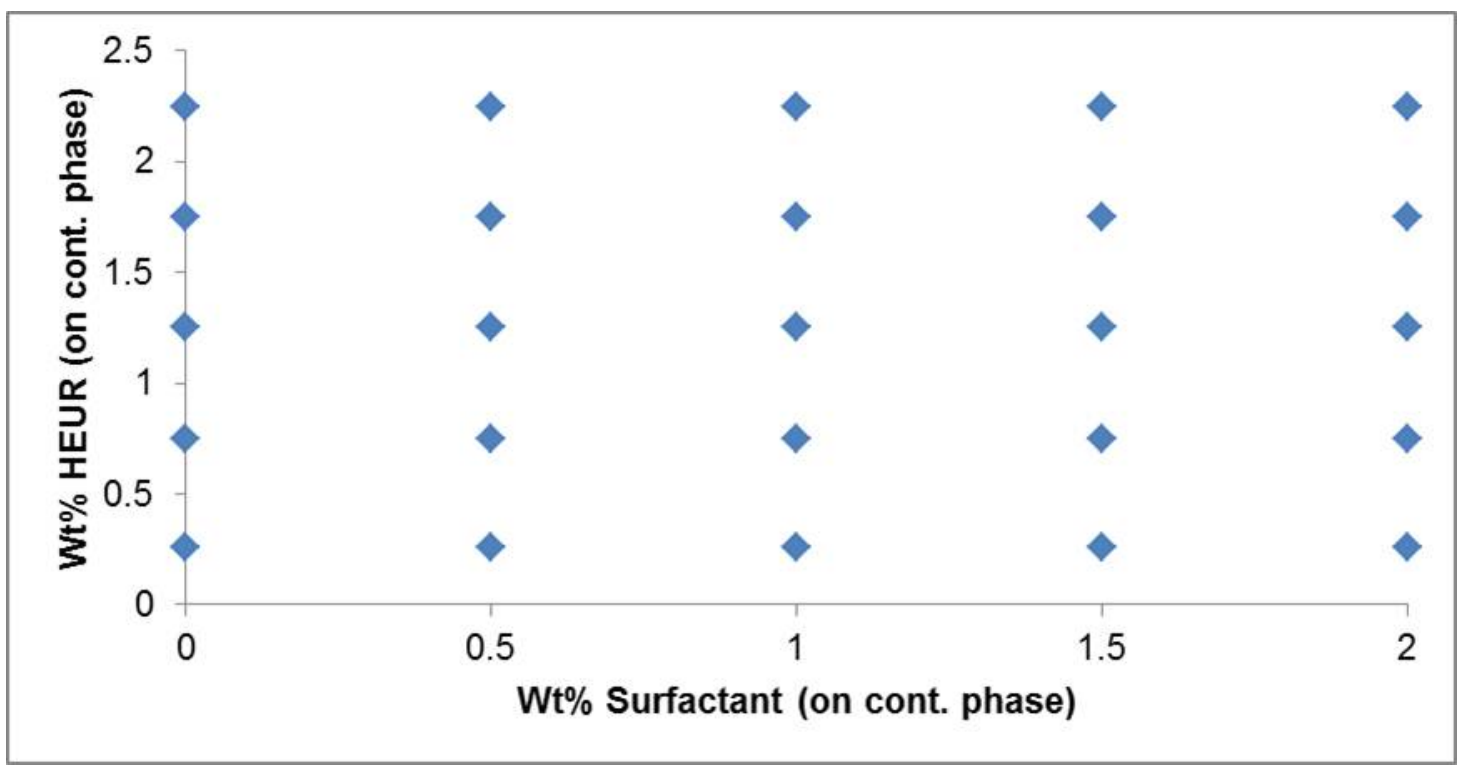

Figure 61. Addition matrix for the G-VNS 166B series.

There were some initial issues with the samples for the G-VNS $166 \mathrm{~B}$ series. When preparing 3 mil drawdowns significant cratering was present in samples at higher surfactant and HEUR levels. Before proceeding with analysis of the G-VNS 166B series, the formulation would need to be adjusted to prevent cratering.

\subsubsection{G-VNS 166B Series Troubleshooting}

The first attempt to correct cratering in the paint samples was to simply increase the amount of low-shear HEUR thickener until the KU viscosities of the samples were bumped up to at least $90 \mathrm{KU}$. The paint samples were synthesized in the same exact manner as prior samples. The first test was a quick test in which 4 samples were made with a wt $\%$ increase of $0.26 \%$ to $0.39 \%$ of low-shear HEUR thickener in the starting 166 batch. The resulting drawdowns had a decreased amount of cratering, but the cratering was still present.

Issues of flow of materials are often caused by surface tension differences. Cratering results from material flow from a region of lower surface tension to one of higher surface 
tension in an attempt to reduce the surface tension of the system (Hansen \& Pierce, 1974). This typically results in craters, and to further troubleshoot this issue the amount of defoamer was changed. Acrylic-B has some defoamer in the latex formulation, in which the Acrylic-A does not have any defoamer. The new troubleshooting batch used minimal amounts of defoamer as well as an increase in the $\mathrm{KU}$ builder, and the resulting drawdowns showed no signs of cratering. The new formulation was scaled up to create a grid DPD.

\subsection{G-VNS 166A Series Paint Preparation}

The amount of low-shear HEUR thickener used in the starting batch of 166 was adjusted from $0.26 \%$ to $0.39 \%$, and the amount of high-shear HEUR thickener is lower for the remaining batches to compensate for the additional low-shear thickener. The additions for the entire grid are shown in Figure 62, and the wt\% of HEUR and surfactant on the continuous phase are shown in Appendix A. The naming scheme was the same as for the G-VNS 166A series except using a B to represent ACRLYLIC B. The naming scheme is as follows: G-X166Y-AAAA-BBBB-CCC where $\mathrm{X}$ represents where the paint was made ( $\mathrm{C}$ for $\mathrm{Cal}$ Poly and $\mathrm{V}$ for Valspar), 166 represents $0.26 \%$ of low-shear thickener used, $\mathrm{Y}$ is for which acrylic was used in the formulation ( $A$ for Acrylic-A and $B$ for Acrylic-B), AAAA is a numerical representation of the amount of total wt $\%$ HEUR in the sample (multiplied by 1000), BBBB represents the wt\% surfactant in the sample (multiplied by 1000), and CCC represents the type of surfactant used (405 for Surfactant-A, 411 for Surfactant-B, and 100 for Surfactant-C). Call names were made for each corresponding sample. One example for a call name is G-VNS-B1: the G means the samples were made in a grid pattern, the $\mathrm{V}$ for being made at Valspar, NS for Surfactant-A, B for using the latex Acrylic-B, and 1 for the first sample of the set. The 
samples were made the same as for previous grids except for the differences in the formulation to fix cratering. The initial drawdowns showed no signs of cratering.

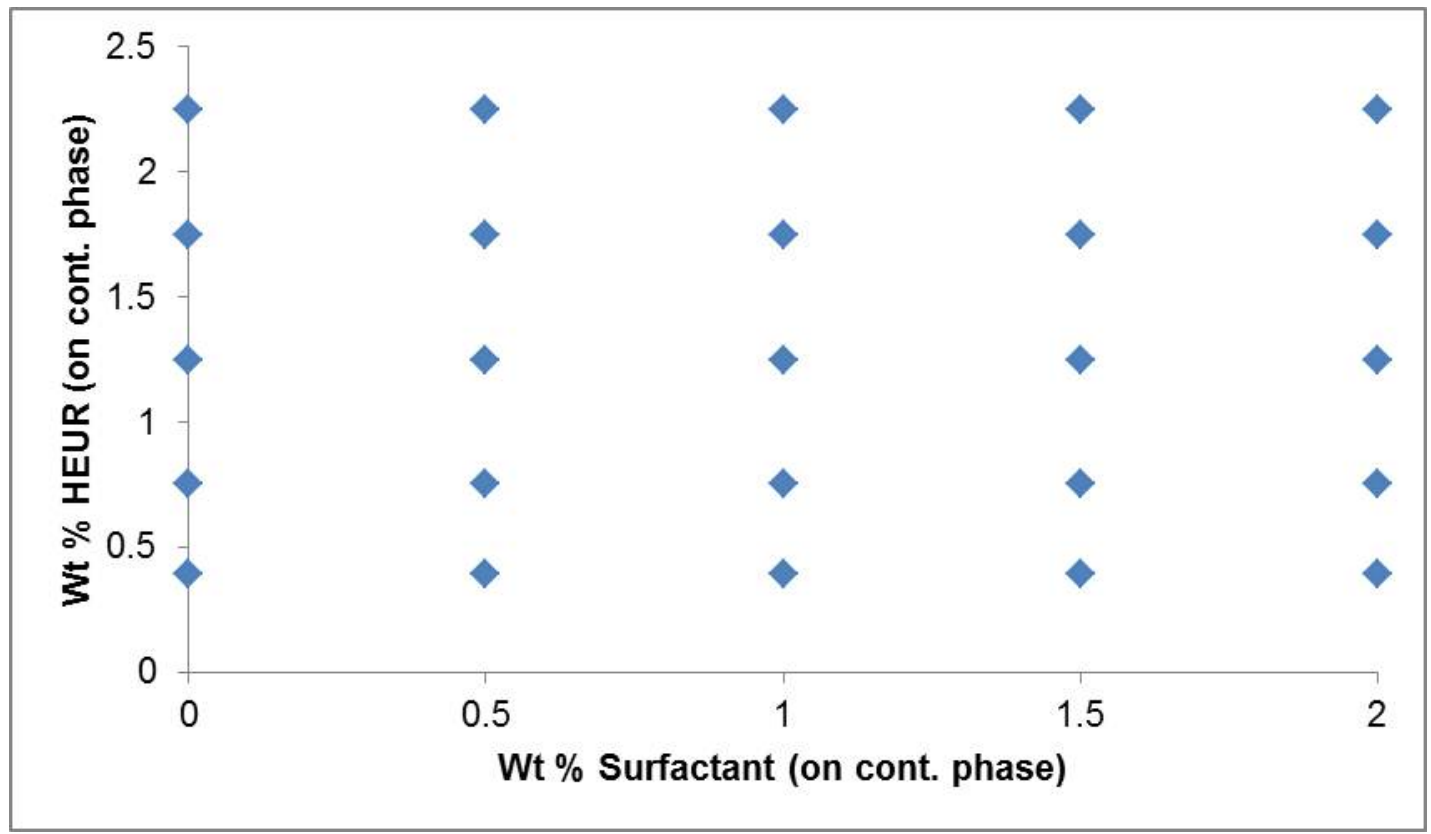

Figure 62. Paint samples made for the G-VNS 166B series.

\subsection{G-VAS 166B Series}

The G-VAS 166B series was made in the exact same manner as the G-VNS 166B series except with the anionic Surfactant-B. Also, the maximum wt\% surfactant added for the DPD was only 1.2 since the anionic surfactant disrupted the thickening mechanism at a much lower wt $\%$. The paint samples prepared for the G-VAS 166B series are shown in Figure 63. The naming scheme was the same as for the G-VNS 166B series. The naming scheme is as follows: G-X166Y-AAAA-BBBB-CCC where $\mathrm{X}$ represents where the paint was made ( $C$ for Cal Poly and $V$ for Valspar), 166 represents $0.26 \%$ of low-shear HEUR thickener, $Y$ is for which acrylic was used in the formulation (A for Acrylic-A and B for Acrylic-B), AAAA is a numerical representation of the amount of total wt\% HEUR in the sample (multiplied by 1000), BBBB represents the wt\% 
surfactant in the sample (multiplied by 1000), and CCC represents the type of surfactant used (405 for Surfactant-A, 411 for Surfactant-B, and 100 for Surfactant-C). Call names were made for each corresponding sample. One example for a call name is G-VAS-B1: the $G$ means the samples were made in a grid approach, the $V$ for being made at Valspar, AS for Surfactant-B, B for using the latex Acrylic-B, and 1 for the first sample of the set.

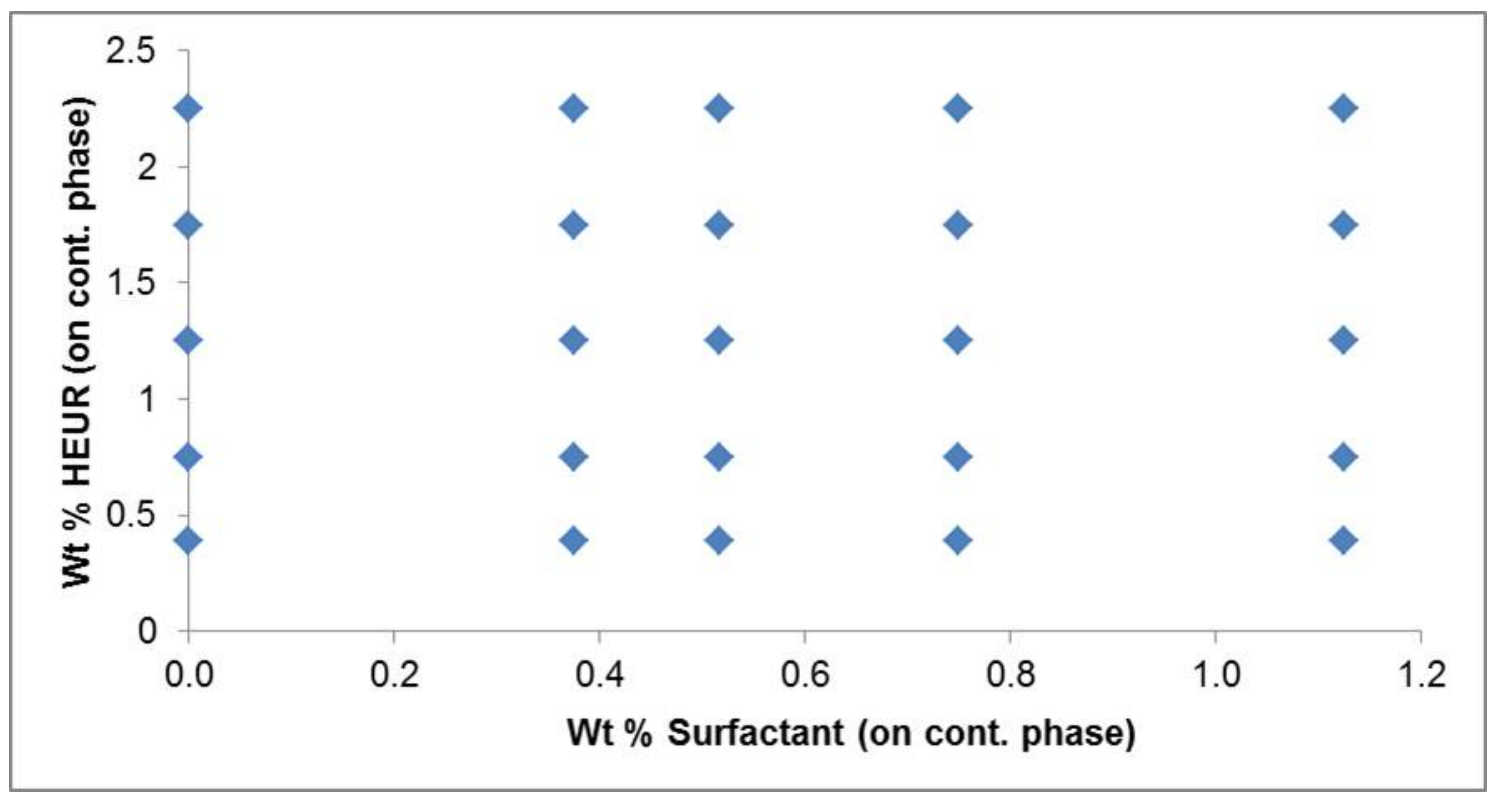

Figure 63. Paint samples for the G-VAS 166B series.

The HEUR levels for the samples are the same as the G-VNS 166B series with the starting $\mathrm{KU}$ builder at $0.39 \%$ instead of $0.26 \%$ for the VSR 1050 grids. The corresponding weight percent of HEUR and surfactant (on the continuous phase) is shown in Appendix A. 
9. Results - Phase 3 at Valspar

\subsection{G-VNS 166B Series}

The results were collected in the same fashion as discussed for the previous G-VNS 166A and G-VAS 166A series.

\subsubsection{Physical Property Data}

The physical properties were collected for the G-VNS 166B series, shown in Appendix B. Conductivity measurements were not made on this sample set.

\subsubsection{Rheology}

The rheology testing was conducted as described previously in which shear-rate ramps are used to plot out the bridging flocculation region. The shear-rate ramps for the samples are shown in Figure 64. 


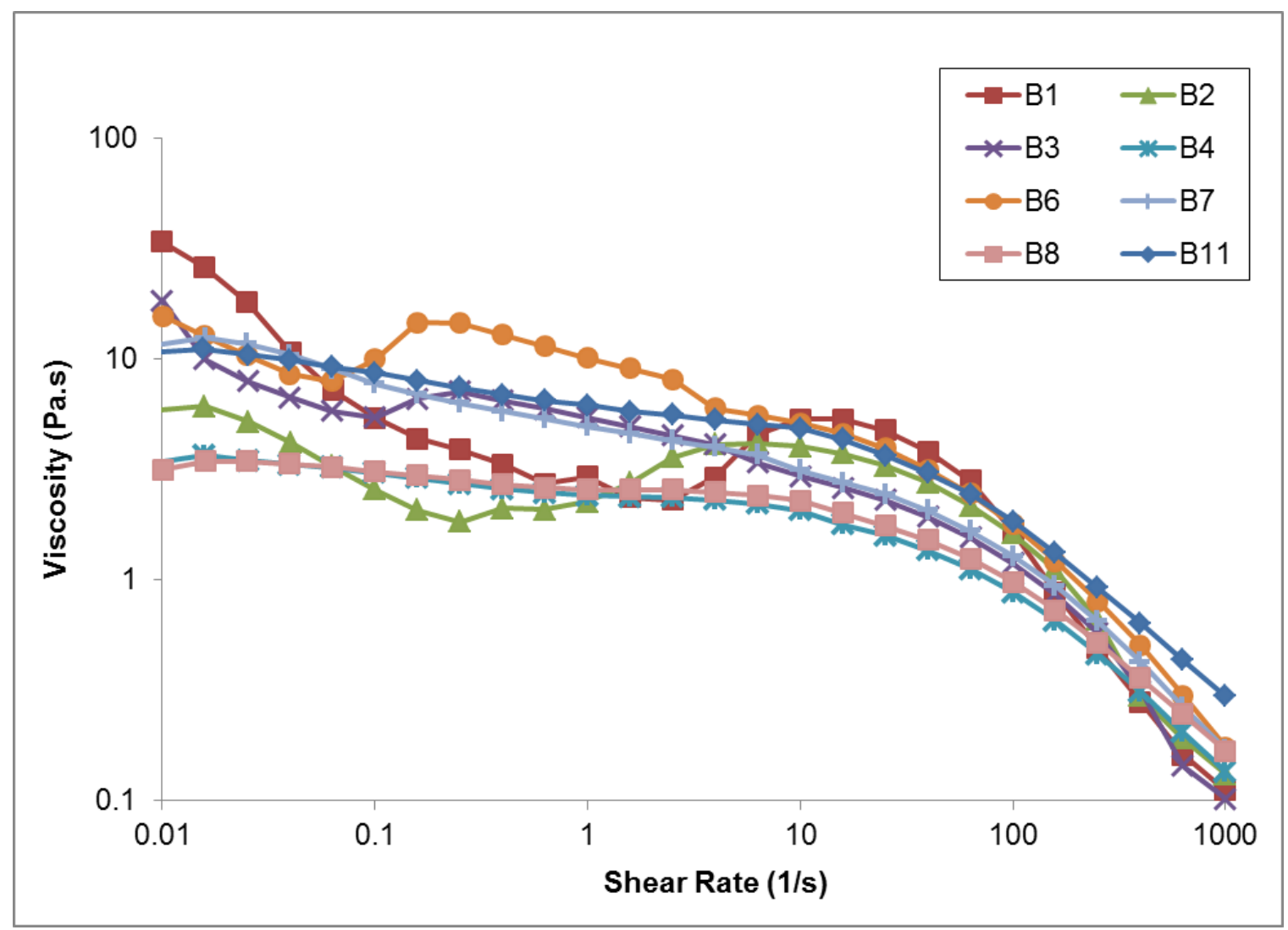

Figure 64. Rheology data for the G-VNS 166B series.

The rheology testing concluded bridging flocculation for samples G-VNS-B1, 2, 3, and 6. Samples G-VNS-B7 and 11 were concluded to be on the boundary of the bridging flocculated region. The boundary regions were confirmed via syneresis and percent solids which will be discussed next.

\subsubsection{Syneresis and Percent Solids}

The syneresis and percent solids data were collected in the same way as the prior grids. The results are shown in Appendix C. The syneresis and percent solids data were analyzed in the same fashion as the prior grids. The samples that were concluded to have bridging flocculation via rheology were G-VNS-B1, 2, 3, and 6 . All four of these samples were confirmed with syneresis and percent solids, showing watery top layers 
with low percent solids values. The sample concluded to be on the boundary of the good dispersion and bridging flocculation region was G-VNS-B11. G-VNS-B11 had a much higher percent solids value of 41.79 ; however, there was clearly a separation present and this observation along with the rheology results puts the sample in the bridging flocculation and good dispersion boundary. For samples at low wt\% HEUR, a transition from bridging flocculation to depletion flocculation was made without observing a good dispersion sample. The data shows a large difference for percent solids of the top layer for this transition with G-VNS-B3 having a percent solids top layer of 3.83, and the next sample G-VNS-B4 with 39.21. Since G-VNS-B4 had a much higher percent solids value, showed no bridging flocculation region in rheology, and had separation present in syneresis, the depletion flocculation conclusion was made. The three highest levels of HEUR showed a transition from non-separated to a separated sample with the addition of surfactant. The conclusion of good dispersion and depletion flocculation samples at the three higher levels were clear.

\subsubsection{Statistical Analysis and Contour Plots}

Multivariate analysis for the G-VNS 166B series was conducted in the same way the prior grids. The results for the G-VNS 166B series multivariate analysis from JMP are shown in Appendix D. The multivariate analysis was used in the same way of the prior two grids. The 24 hour KU viscosity was again correlated with the weight percent surfactant. The amount of surfactant was also correlated with 20 and 60 degree gloss which was explained in the previous results section for the G-VNS 166A series. From the statistical analysis, the flocculation number had a correlation of 0.85 with 24 hour KU which is a higher correlation than flocculation number has had compared to the previous two DPDs. The contour plots will be examined to see if these correlations can be used to explain observable trends for this system. 
The contour plots made for the G-VNS 166B series were 24 hour KU viscosity, 60 degree gloss, and IRBS shown in Figure 65, Figure 66, Figure 67, respectively.

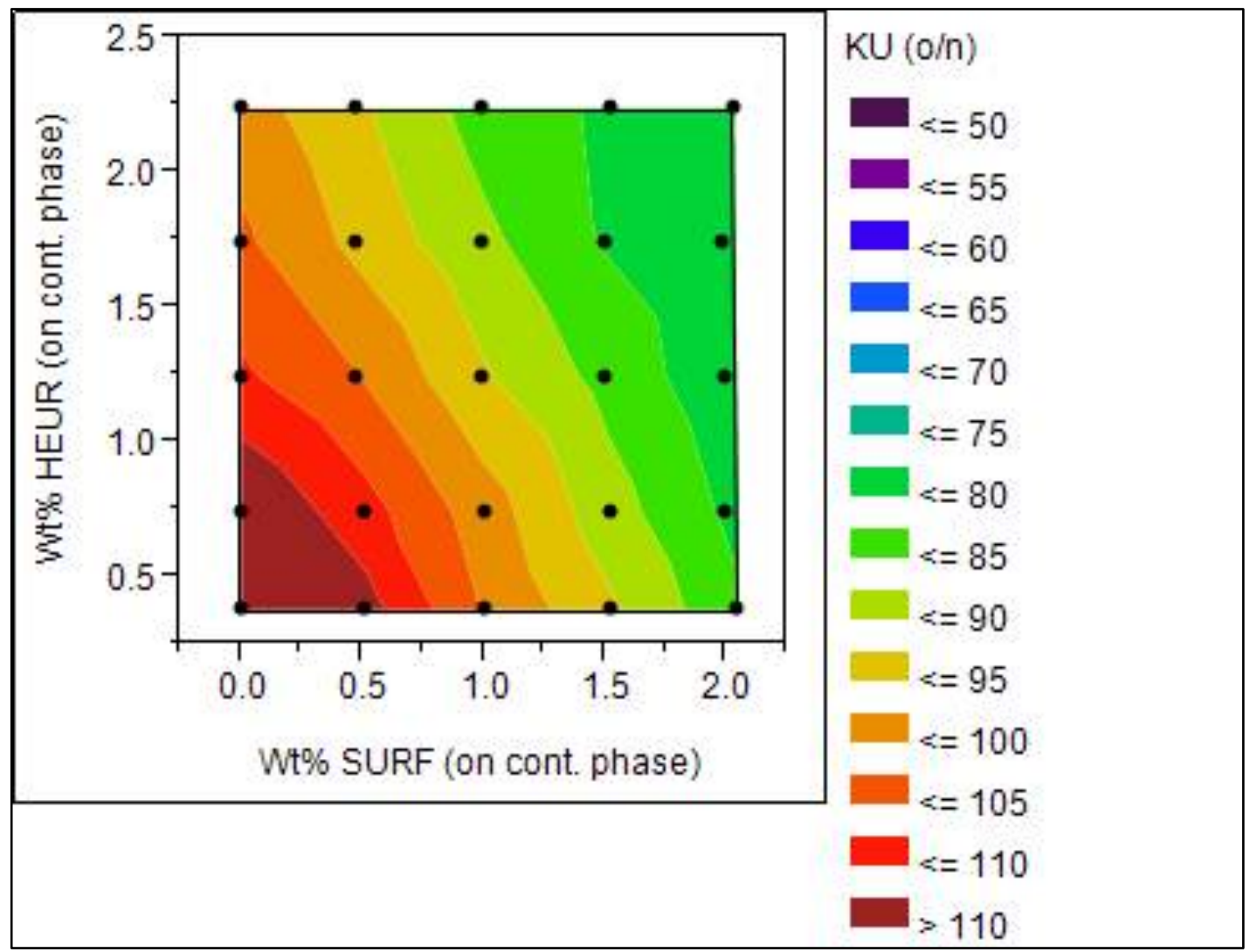

Figure 65. Contour plot for $24 \mathrm{KU}$ viscosities for the G-VNS 166B series.

The 24 hour KU plot for the G-VNS 166B series is similar to the $24 \mathrm{KU}$ plot made for the G-VNS 166A series. Both of the similar plots are for the addition of Surfactant-A and some similar results should be expected even for a different particle size latex. At higher levels of surfactant, the plot becomes more linear and $\mathrm{KU}$ becomes mostly dependent on changes in surfactant. The surfactant additions appear to desorb thickener in the system and cause a drop in viscosity as seen for the G-VNS 166A series. 


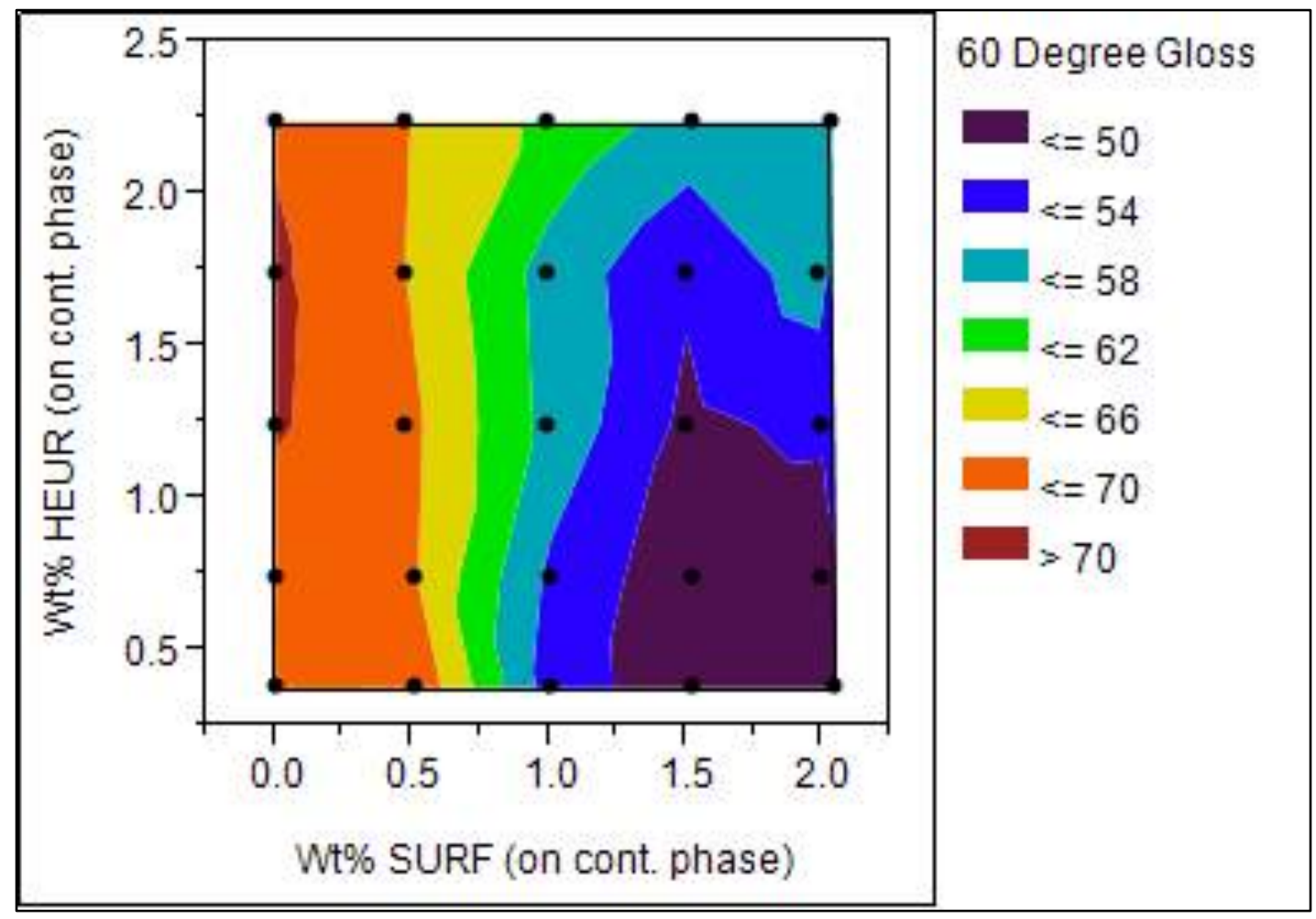

Figure 66. Contour plot for 60 degree gloss for the G-VNS 166B series.

The highest gloss values for the G-VNS 166B series are seen below $0.5 \%$ surfactant and do not appear to be influenced by the \% HEUR. Above $0.5 \%$ surfactant the gloss values drop off to around 50 for the highest levels of surfactant. Here the surfactant is disrupting the network formation of the HEUR for the system. The high gloss values of all samples below $0.5 \%$ surfactant is expected; however, to see high gloss values at low levels of HEUR was not previously observed for this surfactant. The Acrylic-B latex with a particle size of $150 \mathrm{~nm}$ has a high gloss region comparable to the G-VAS $166 \mathrm{~A}$ series. The G-VNS 166A series has a high gloss region above $0.8 \%$ HEUR which is not seen for the G-VNS 166B series. The only major differences between the two systems with the non-ionic surfactant is the latex particle size, and increased KU builder for the ACRLYIC-B system. The changing of the high gloss region must be related to one of those two factors. The range of the gloss values for the G-VNS 166B series is also much 
smaller (67.5 to 50 ) which is most likely as a result of the larger amount of KU builder in the system.

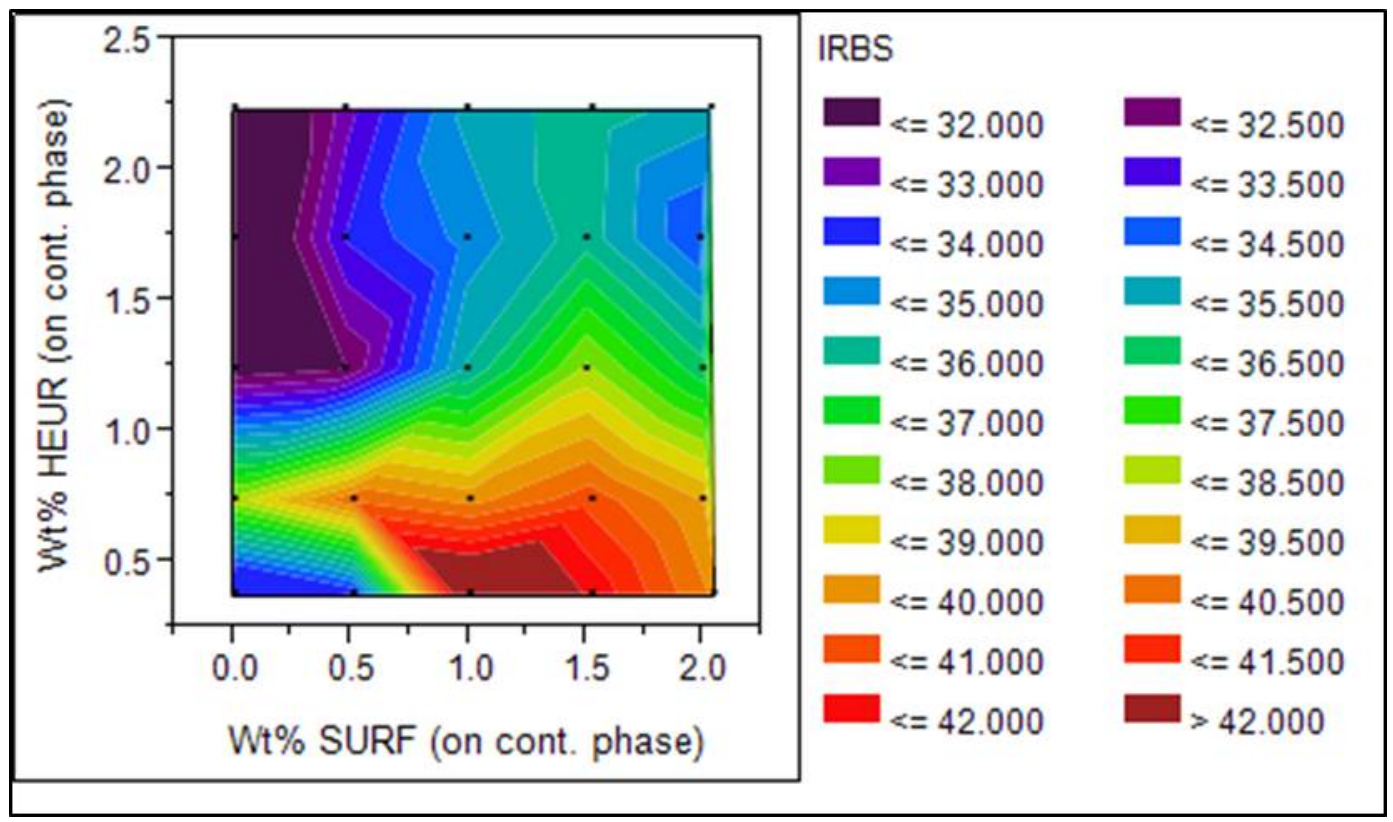

Figure 67. IRBS contour plot for the G-VNS 166B series.

The IRBS shows a smaller region of low values of IRBS. The lowest values for the flocculation gradient are less than 32. The smaller region of good dispersion should be expected for the larger particle size latex because there are less adsorption sites for the associative thickening polymer to adsorb to in the system. The additions of surfactant should enter the depletion flocculation region at lower weight percent as compared to the Acrylic-A systems. The transition from good dispersion to depletion flocculation region at higher HEUR levels shows more gradual changes in the IRBS as compared to the other DPDs. The results will be compared to the finalized DPD to see if the IRBS results remain a viable testing method for this system. 


\subsubsection{G-VNS 166B Series DPD}

The DPD for Acrylic-B (particle size $=150 \mathrm{~nm}$ ), with the addition of the non-ionic Surfactant-A, and the two part HEUR thickening system described in the Phase 2 Valspar experimental section is shown in Figure 68.

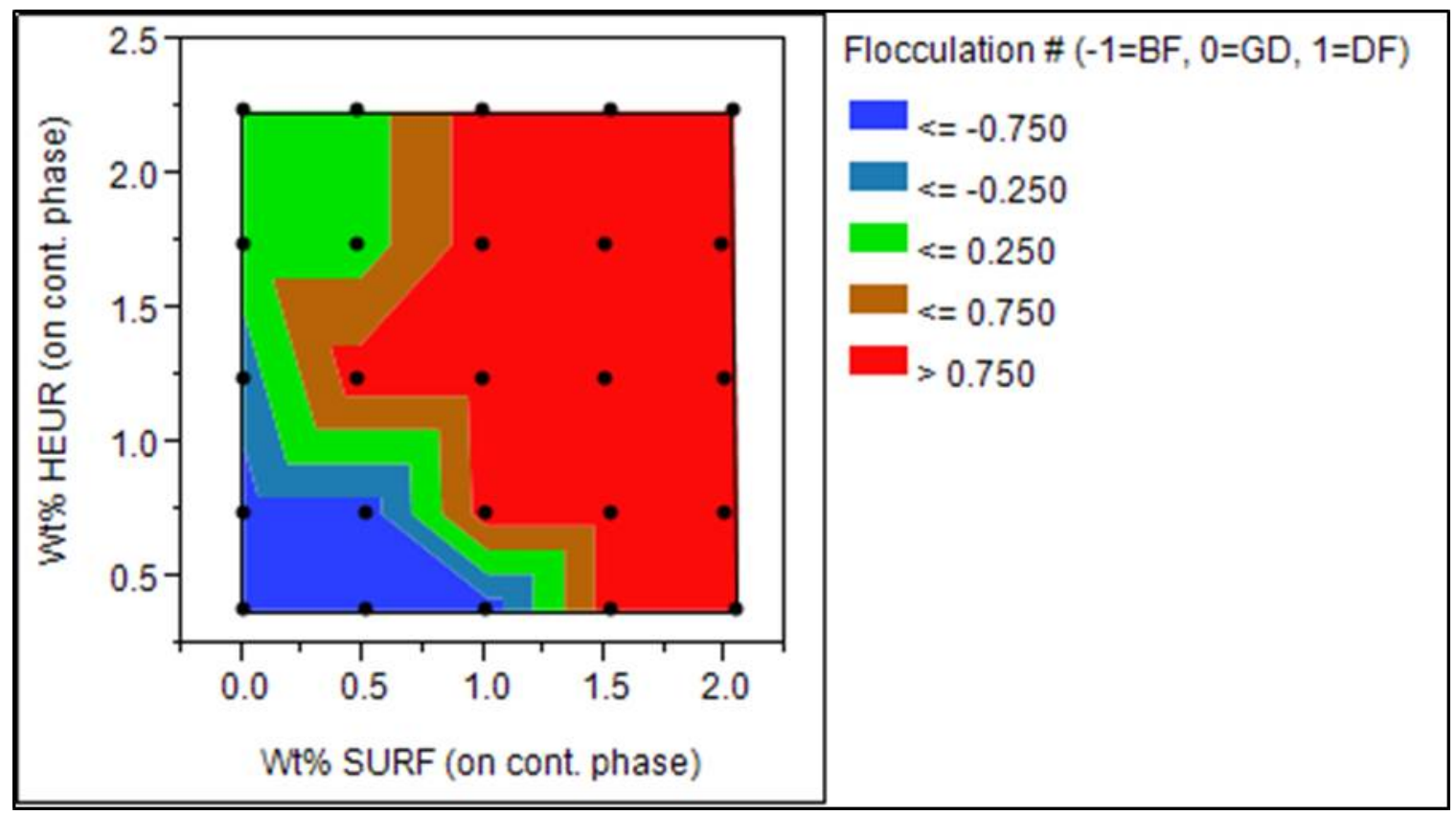

Figure 68. G-VNS 166B series DPD.

The G-VNS 166B series DPD constructed showed some irregularity that was not observed for the previous two systems. The good dispersion region is much smaller as a result of the depletion flocculation region being larger. The shrinking of the good dispersion region is as expected for the larger particle size latex. The surface area for the larger particle size latex is much smaller, and as a result there are less adsorption sites for the thickening polymers of the system. The addition of surfactant will desorb the thickening molecules, and the depletion flocculation region should be entered at much lower levels of surfactant. 


\subsection{G-VAS 166B Series}

\subsubsection{Physical Data}

The physical property data was collected as described in the methods. The results are shown in Appendix B. The analysis for the physical property data will be conducted via contour plot and statistical modeling.

\subsubsection{Rheology}

Rheology was conducted using the new rheology procedure used for the other grids. The rheology results for the G-VAS 166B series are shown in Figure 69.

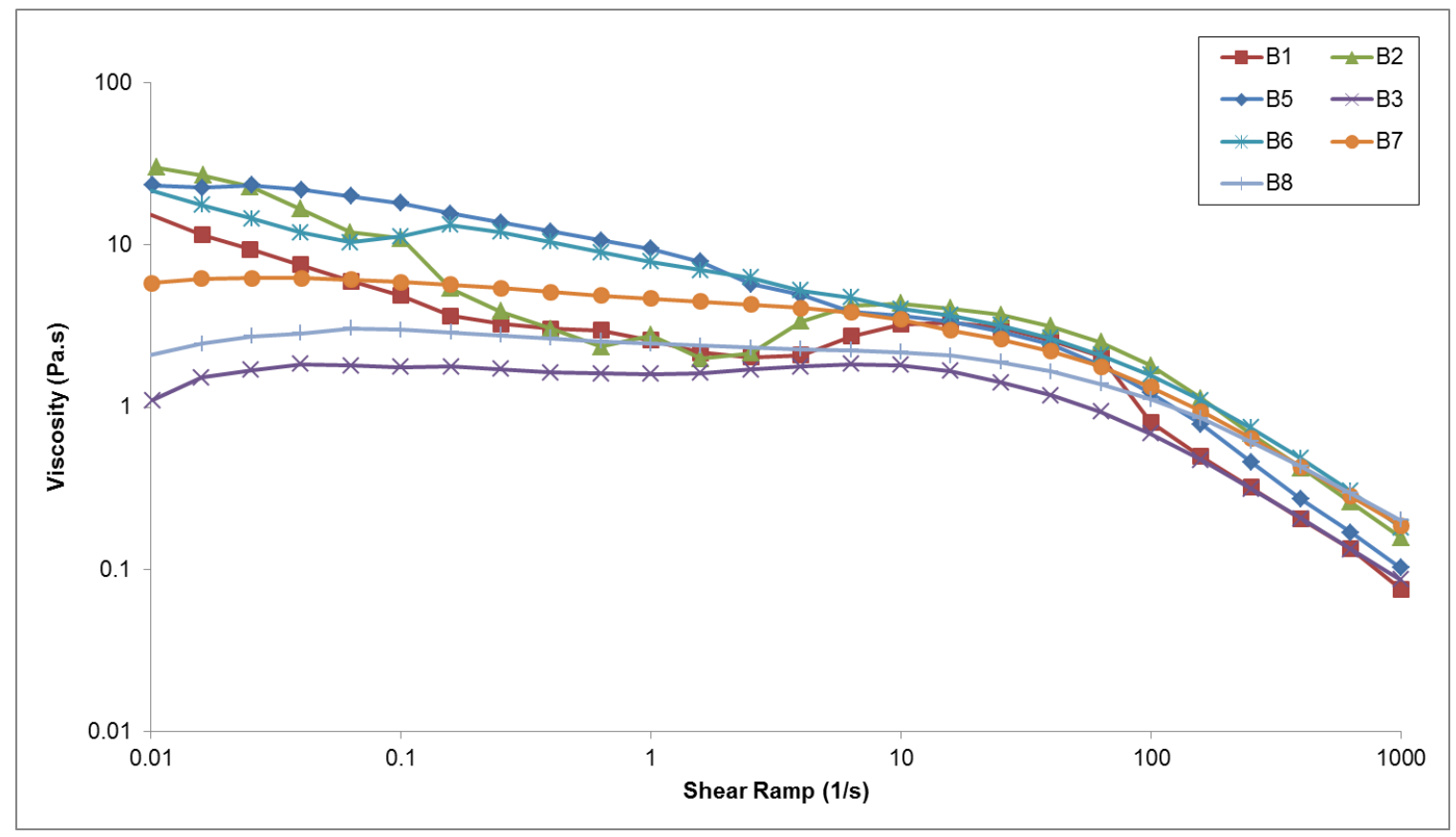

Figure 69. Rheology results for the G-VAS 166B series.

The rheology testing results for the shear-rate ramps concluded bridging flocculation characteristics for the paint samples G-VAS-B1, 2, 5, and 6. G-VAS-B7 may be on the boundary, but will need to be confirmed with the syneresis and percent solids data. The 
rheology results that must be noted are the results for G-VAS-B11 and G-VAS-B11, shown in Figure 70.

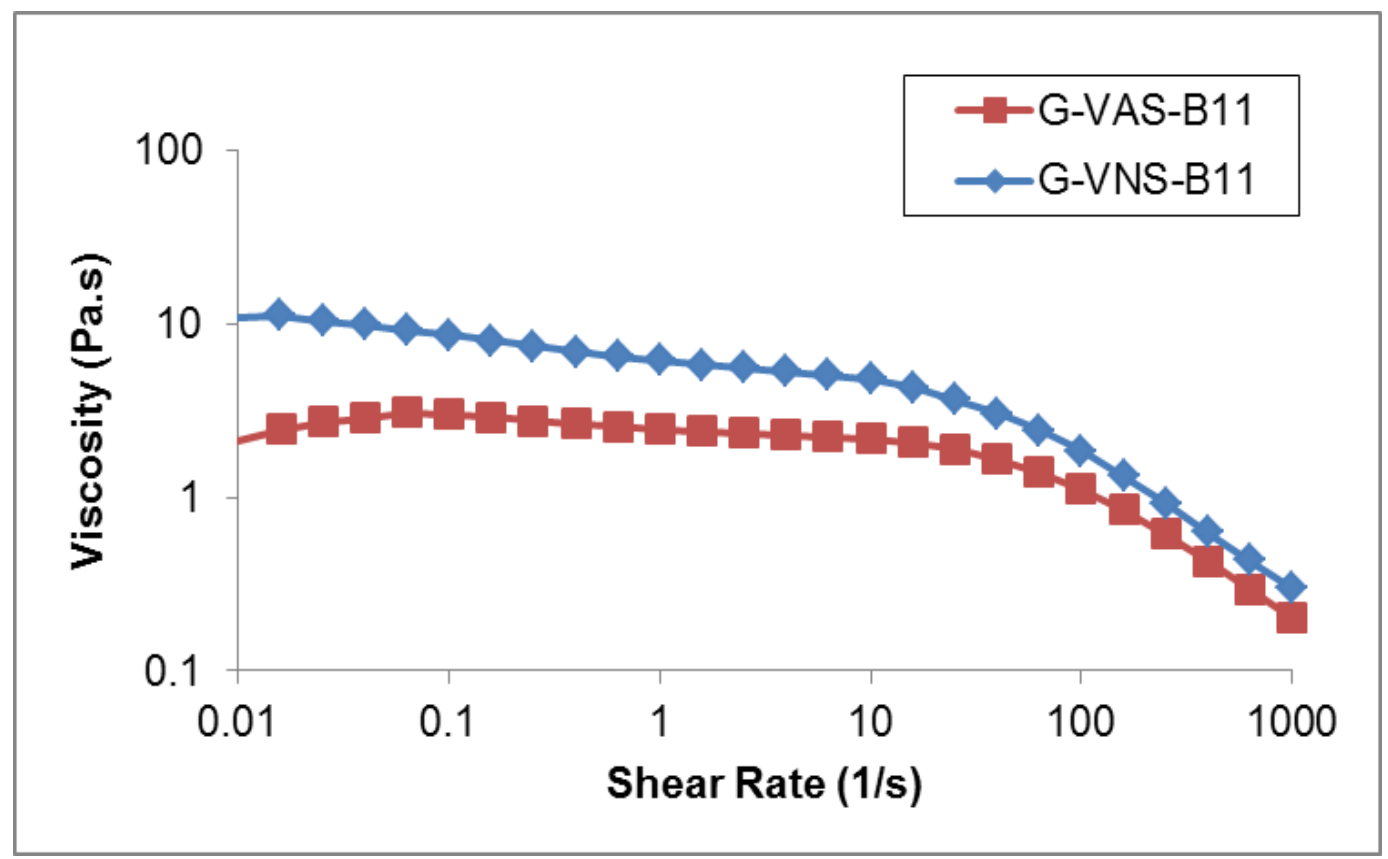

Figure 70. Shear ramp results for samples G-VAS-B11 and G-VNS-B11.

Hypothetically, the two samples shown have the same amount of HEUR and surfactant but were prepared at separate times, and the rheology results are notably different. GVNS-B11 was concluded to be on the boundary of the bridging flocculation and good dispersion region, but G-VAS-B11 appears to be a good dispersion or depletion flocculation sample. This shows that each system is very dependent on the preparation of the paints. Any slight variations in the synthesis of the paint can affect the flocculation determination. The way the DPDs are constructed shows a degree of error, which is reflected in the results. The systems that are being analyzed are a result of many different interactions that are sensitive to any changes in the system, and the nature of 
these systems must be accounted for when attempting to explain trends and observations.

\subsubsection{Syneresis and Percent Solids}

The syneresis and percent solids data for the G-VAS 166B series was collected the same as the prior three grids, shown in Appendix C. The syneresis and percent solids data for the G-VAS 166B series was analyzed using the same parameters as the prior grids. The bridging flocculation samples from rheology, G-VAS-B1, 2, 5, and 6 were verified. All four bridging flocculation samples showed clear-colored separations for the top layer, and very low percent solids values of $<5 \%$ solids. The top layers for these samples are mostly water, which indicates there is bridging flocculation in the sample

\subsubsection{Statistical Analysis and Contour Plots}

Statistical analysis of the G-VAS $166 \mathrm{~B}$ series was conducted in the same fashion as the prior 3 grids. The multivariate analysis for the G-VAS 166B series is shown in Appendix D. The same trends were seen as for the G-VNS 166A series and the same conclusions were made.

The contour plots constructed for the G-VAS 166B series were 24 hour KU, 60 degree gloss, conductivity, and IRBS shown in Figure 71, Figure 72, Figure 73, and Figure 74, respectively. Each plot was scaled on the x-axis to $2.25 \mathrm{wt} \%$ surfactant for ease of comparison for the other systems. 


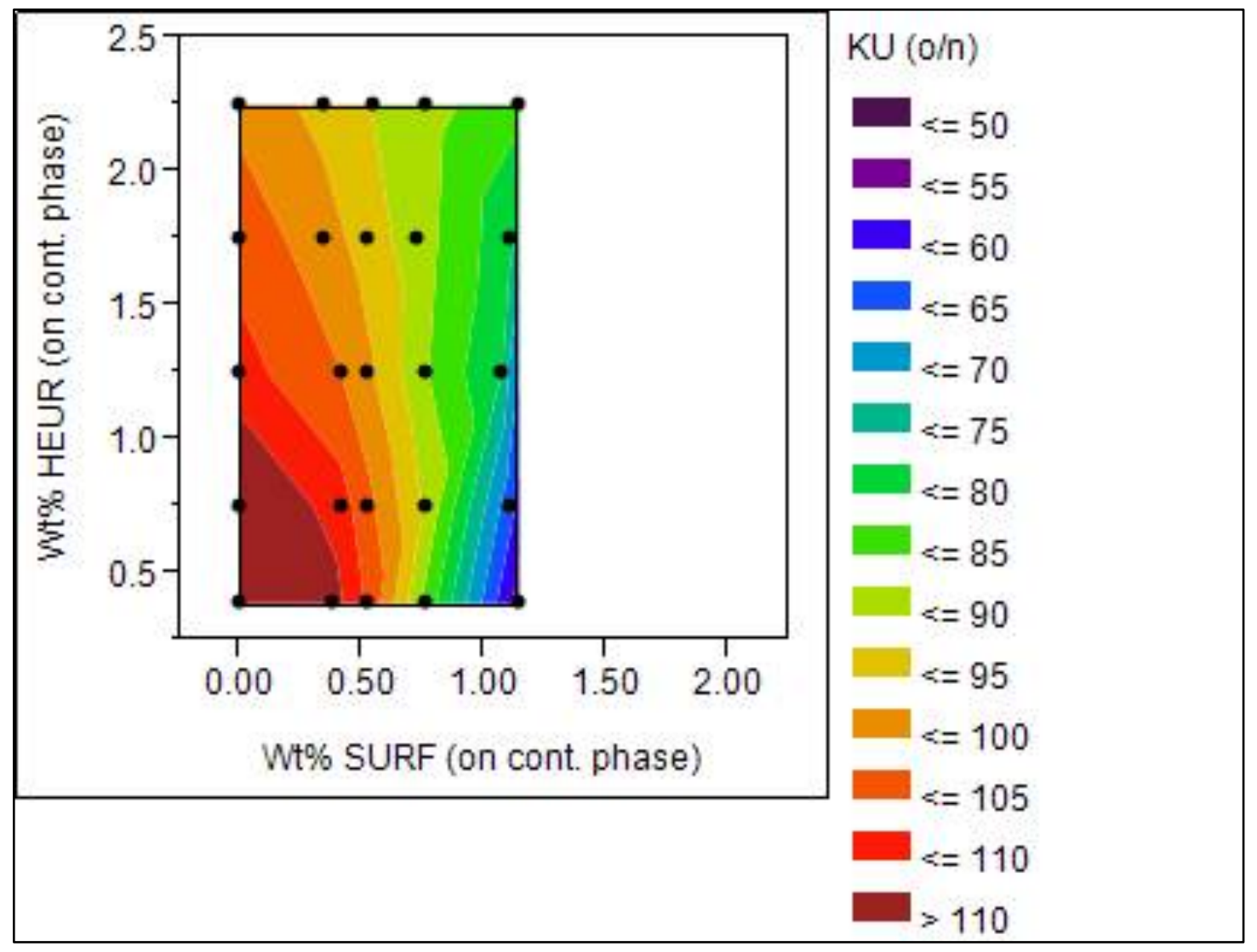

Figure 71. 24 hour KU contour plot for the G-VAS 166B series.

The 24 hour KU plot showed a huge drop in viscosity above $1 \%$ surfactant. The additions of surfactant were kept at lower wt $\%$ because the formulations of paints below $60 \mathrm{KU}$ have no commercial application. Paints are simply not formulated in this region, and more accurate results could be produced by decreasing the maximum amount of surfactant added. The anionic surfactant disrupted the thickening system much more efficiently than the non-ionic surfactant similar to that for the Acrylic-A systems. 


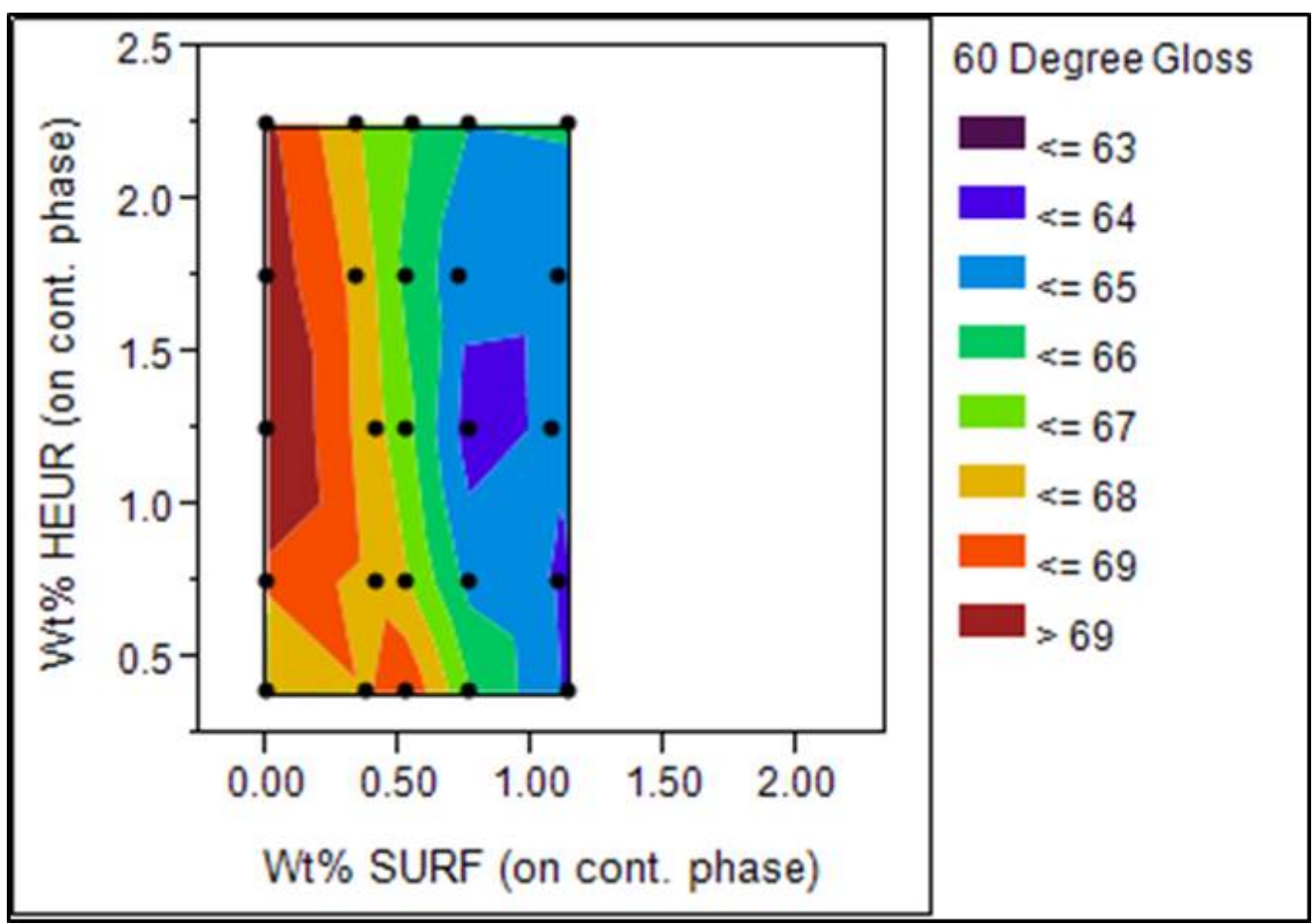

Figure 72. 60 degree contour plot for the G-VAS 166B series.

The gloss values for the G-VAS 166B series showed a much lower spread, which can be accounted for the additions of surfactant are lower than the other systems. The highest gloss values are located below 0.25 wt $\%$ surfactant, and this region matches up with the good dispersion region for the DPD, which will be analyzed in the DPD section for the GVAS $166 \mathrm{~B}$ series. This system showed a high gloss region for the whole DPD space, which was also present for the G-VAS 166A DPD. The depletion flocculation regions show high gloss values, which means the anionic surfactant is providing a better stabilizing of the paints even in the depletion flocculation region when performing drawdowns. 


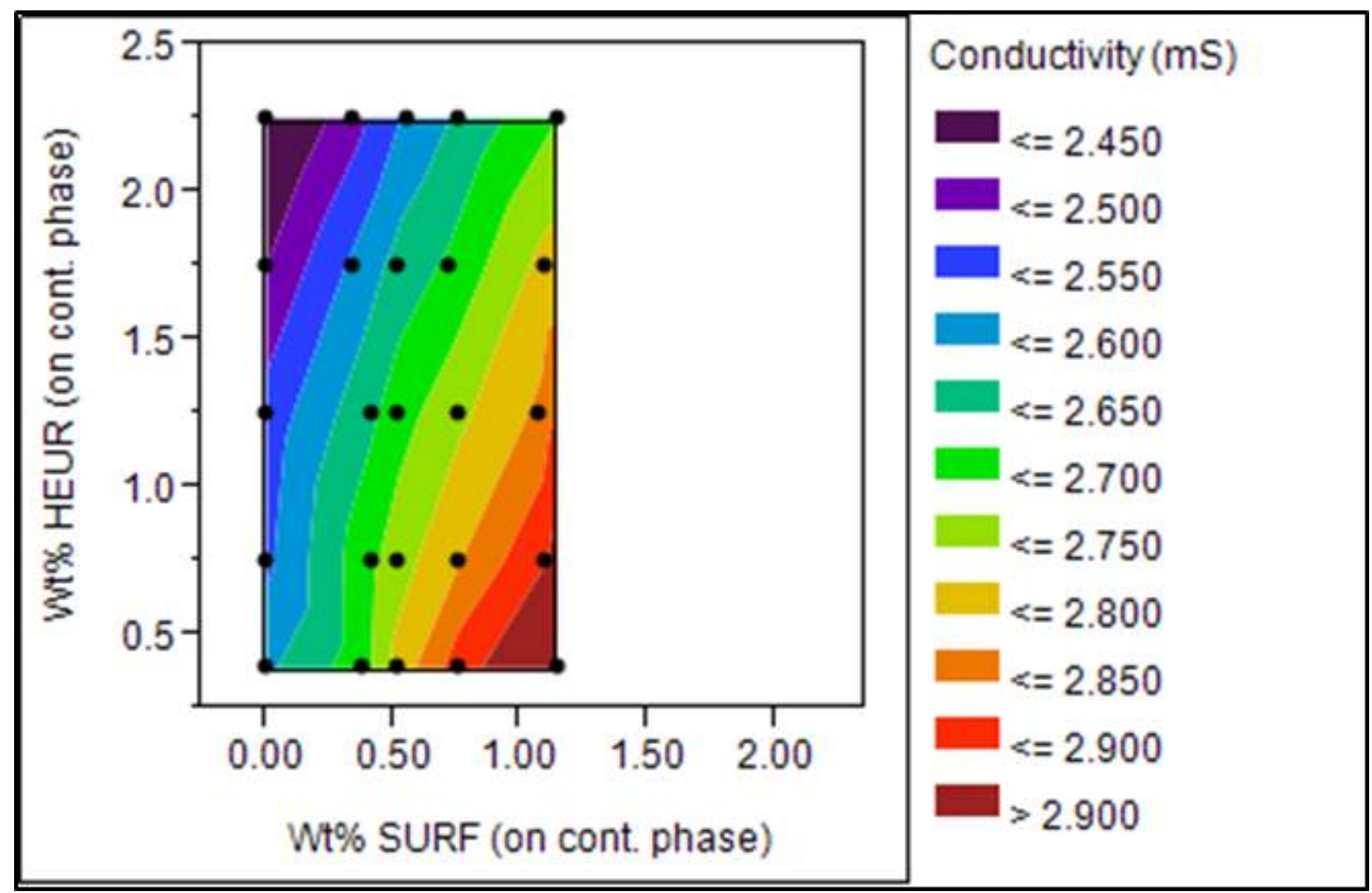

Figure 73. Conductivity contour plot for the G-VAS 166B series.

The conductivity results for the G-VAS 166A series were the same for the G-VAS $166 \mathrm{~B}$ series. There is a positive linear relationship between the addition of anionic surfactant and the conductivity of the sample. 


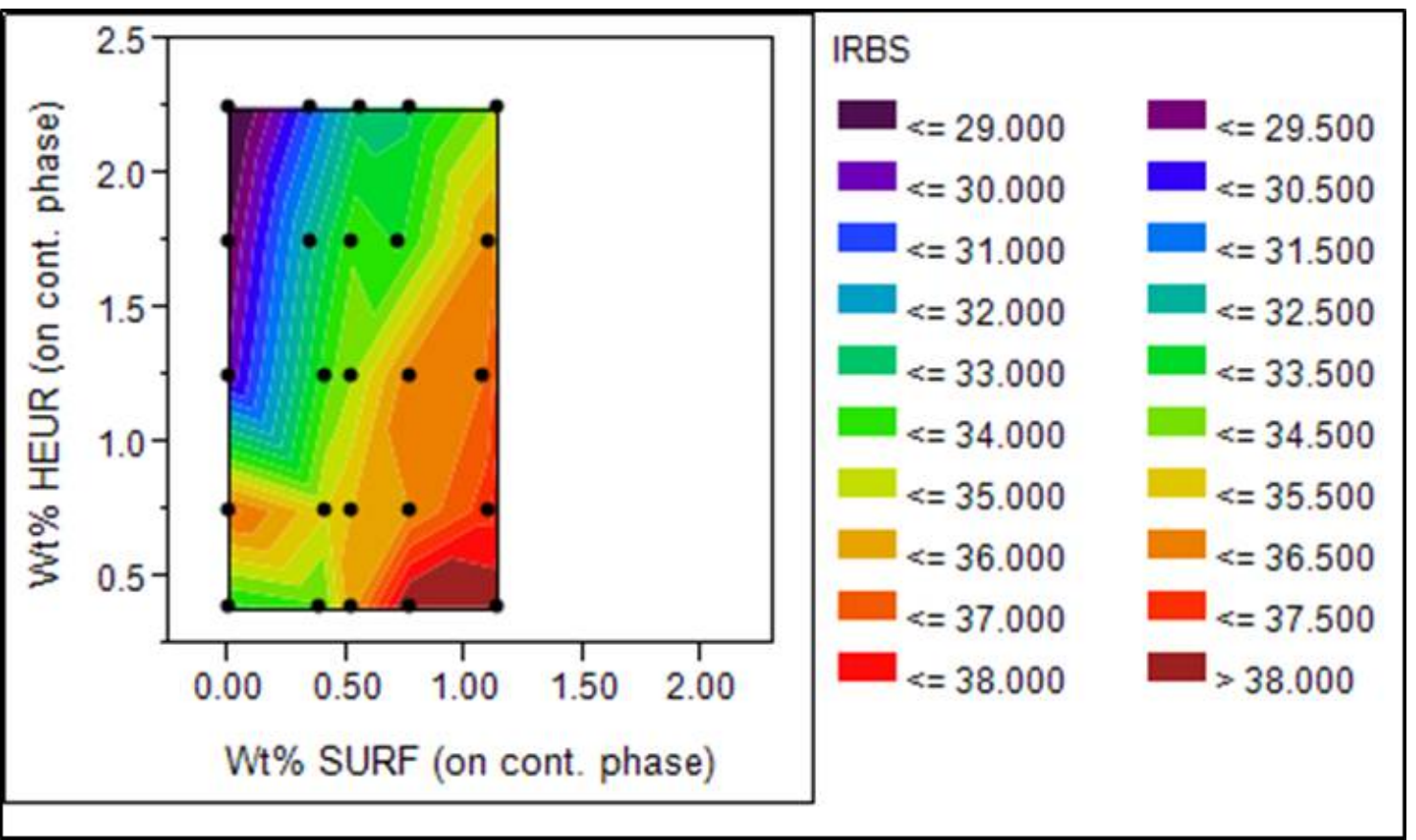

Figure 74. IRBS contour plot for the G-VAS 166B series.

The IRBS results showed the lowest flocculation gradient values at very low levels of surfactant, and above $1.25 \%$ HEUR. This region matches up with the good dispersion region produced from the DPD, and also the 60 degree gloss region with the highest gloss values. All three of these results produce the same region of good dispersion, which provides even more credibility to the test. The IRBS test has been representative of the good dispersion region for 4 different paint systems, and may be able to be used for different systems as well.

\subsubsection{G-VAS 166B Series DPD}

The dispersion phase diagram for the G-VAS 166B series was constructed using the same methods as the previous DPDs. The DPD for the G-VAS 166B containing Acrylic$B$, Surfactant-B, and the described HEUR thickening package, is shown in Figure 75. 


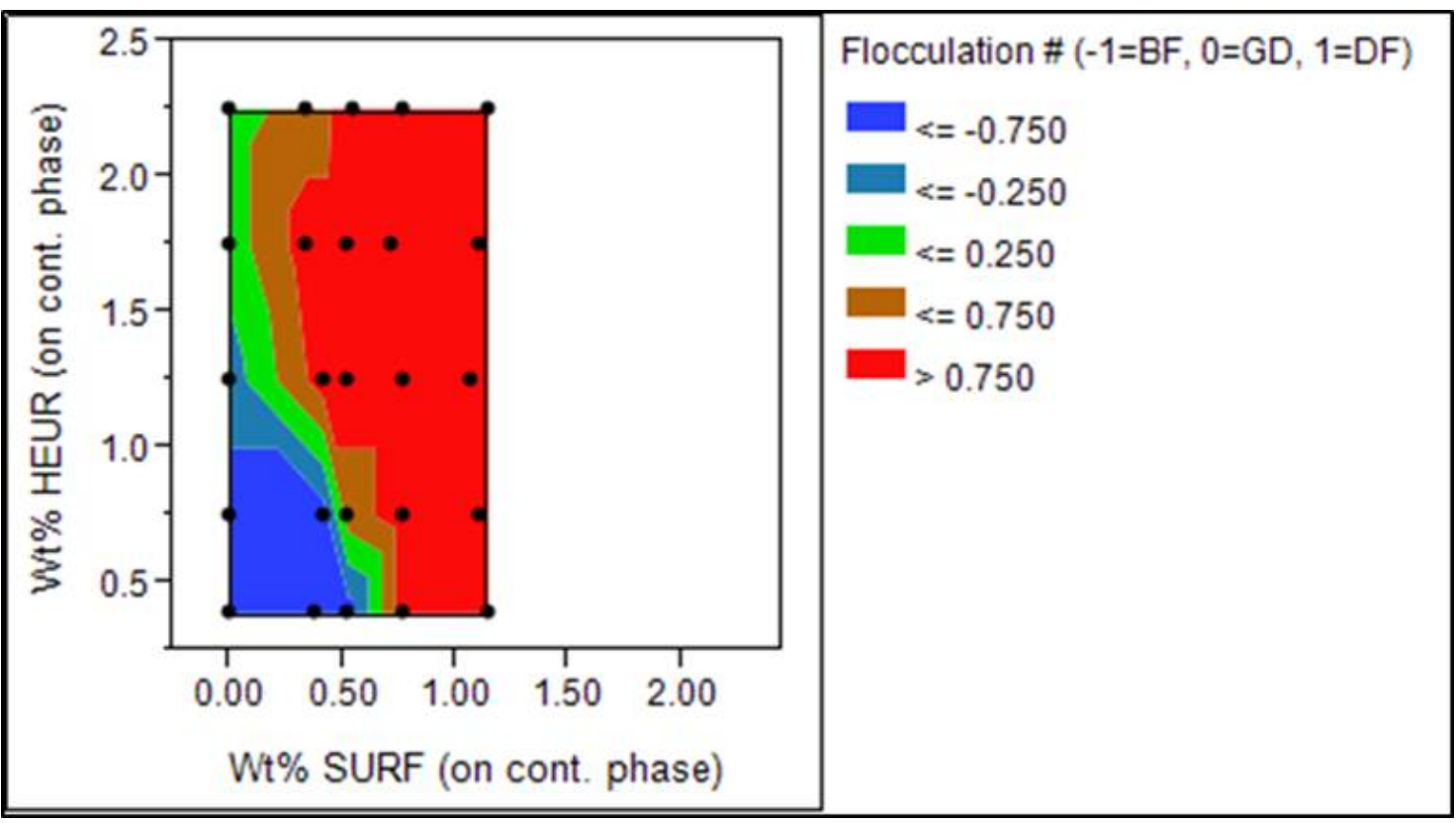

Figure 75. DPD for the G-VAS 166B series.

The G-VAS 166B series DPD shows a much smaller good dispersion region than seen for the other DPDs. The comparison of this DPD with all other DPDs will be conducted in a later section. Some clear observations to mention are that the good dispersion region matches almost identically with the 60 degree gloss, and IRBS contour plots. The ability to match these plots with the DPD is very strong evidence that the experimental testing techniques are achieving the goal of producing high resolution representations of the three regions of the DPD. This was the ultimate goal of the project, and the testing methods and analysis have been shown to be efficient and accurate at producing DPDs for four different systems.

\subsection{Conclusions for Acrylic-B}

The larger particle size Acrylic-B $(150 \mathrm{~nm})$ was studied with Surfactant-A, and Surfactant-B. First, the latex had some formulation compatibility issues that had to be 
corrected. Once the issue was resolved, the testing methods of the DPD making process were scrutinized to see if the methods could be proved useful for a different particle sized latex. The testing methods for making DPDs held up with a new latex which gives credibility to both the testing methods, and the theories behind DPDs. The ability to create DPDs for a different system is a novel part of the project. There will be systems that are not testable via these methods; however, the success of these two different latexes supports the hypothesis that other DPDs can be made to define the flocculation regions for a given system.

Second, the main observation that can be made for the G-VAS $166 \mathrm{~B}$ series is that the good dispersion region is much smaller than the other DPDs. The larger particle size latex has much less surface area for adsorption of polymers in the system, and this system should enter a depletion flocculation region at lower weight percent surfactant than the Acrylic-A. The anionic surfactant which had been observed in the G-VAS 166A series to enter a depletion flocculation region at lower weight percent of surfactant was also observed for this system. The combination of both the larger particle size latex and anionic surfactant translated to a very small region of good dispersion. 
10. DPD Interpretations

The use of DPDs for fully-formulated paint systems has not yet been reported. The construction and implementation of DPDs, including new experimental techniques and procedures have been described. After these four DPDs have been successfully made, some conclusions and analysis of the process and overall findings can be made. The conclusions made in this section analyze all the DPDs and contour plots for the four different systems.

\subsection{KU Contour Comparison}

The 24 hour KU viscosity contour plot for each system is shown in Figure 76. 


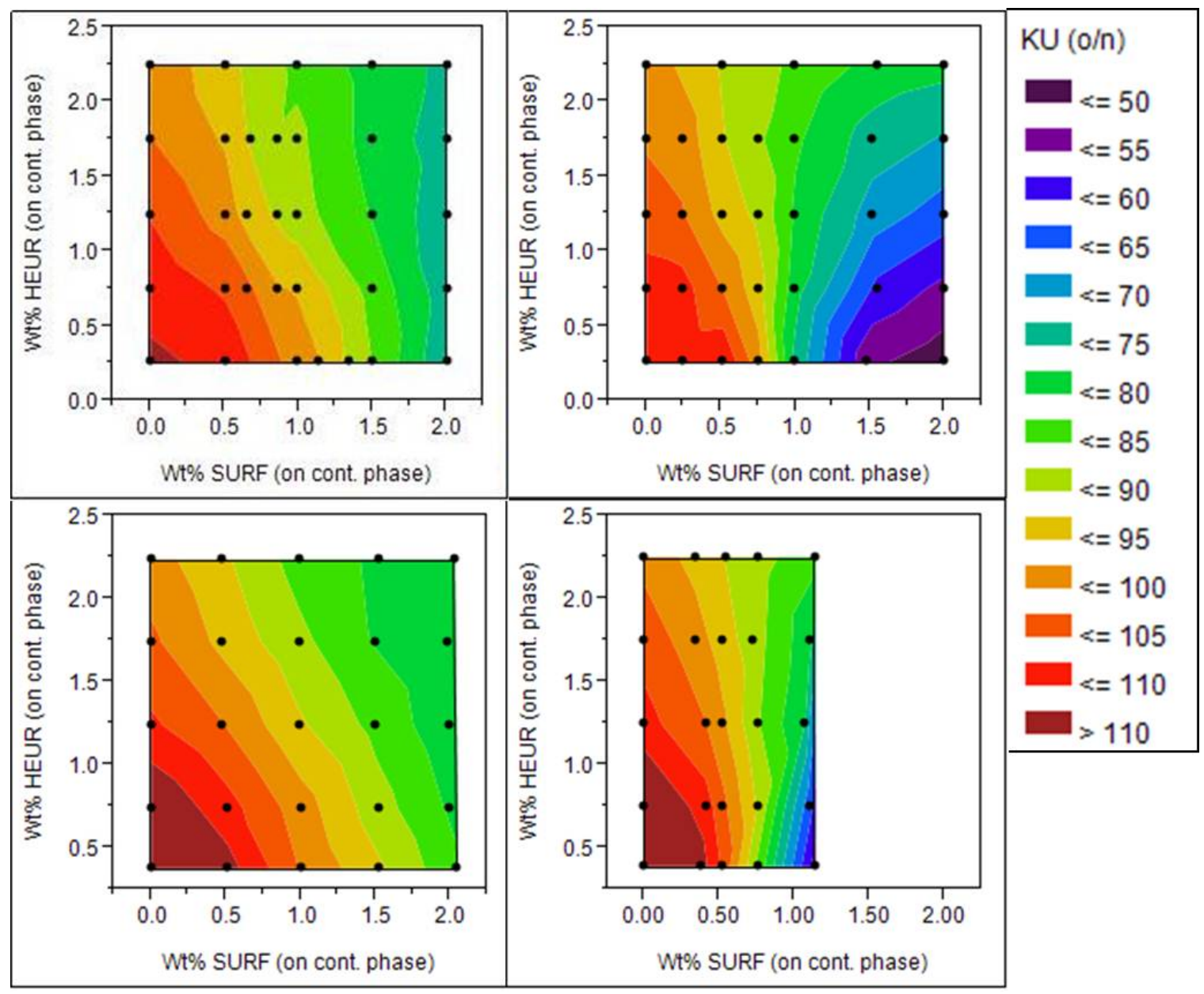

Figure 76. 24 hour KU contour plots for G-VNS 166A series (top left), G-VAS 166A series (top right), G-VNS 166B series (bottom left), and G-VAS 166B series (bottom right).

The KU contours were plotted to have the same range of $\mathrm{KU}$ values. The reasoning for this was to easily compare each system's contour to one another. Each individual KU plot has been previously analyzed; however, some observations can be made for the KU plots in general. The non-ionic and anionic surfactant additions had very similar plots for both latexes. This means that the KU viscosity response to surfactant addition is not dictated entirely by particle size. The viscosifying mechanisms would be expected to be 
noticeably different for the different particle sizes; however, this was not observed for the 4 systems made.

\subsection{Degree Gloss Contour Comparison}

The 60 degree contour plots for the 4 different systems are shown in Figure 77.

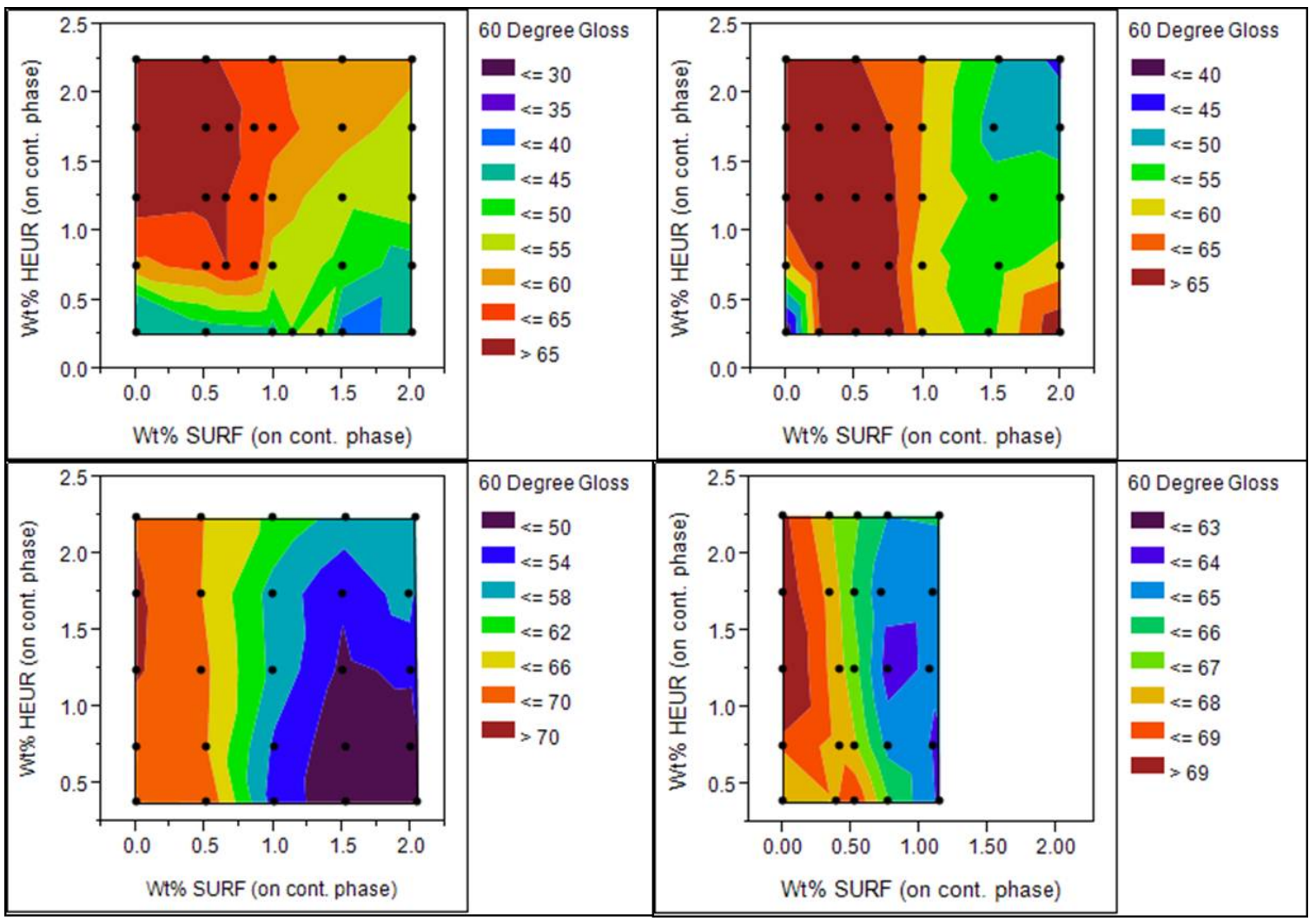

Figure 77. 60 degree gloss contour plots for G-VNS 166A series (top left), G-VAS 166A series (top right), G-VNS 166B series (bottom left), and G-VAS 166B series (bottom right).

Each individual gloss contour plot has been previously analyzed, so observations of general trends and differences will be made for the 4 plots. The 60 degree contours were not plotted with the same range of values because the range was too large to assign values that would be suitable for all four plots. The 60 degree gloss plot for the G- 
VNS $166 \mathrm{~A}$ series is the only system that has the high gloss region matching up with the good dispersion region. All the other systems show a high gloss region below a certain amount of surfactant that is not dependent on the weight percent HEUR. The gloss values must be paired with another type of test to produce regions of good dispersion.

\subsection{IRBS Contour Comparison}

The IRBS contour plots for each system is shown in Figure 78.
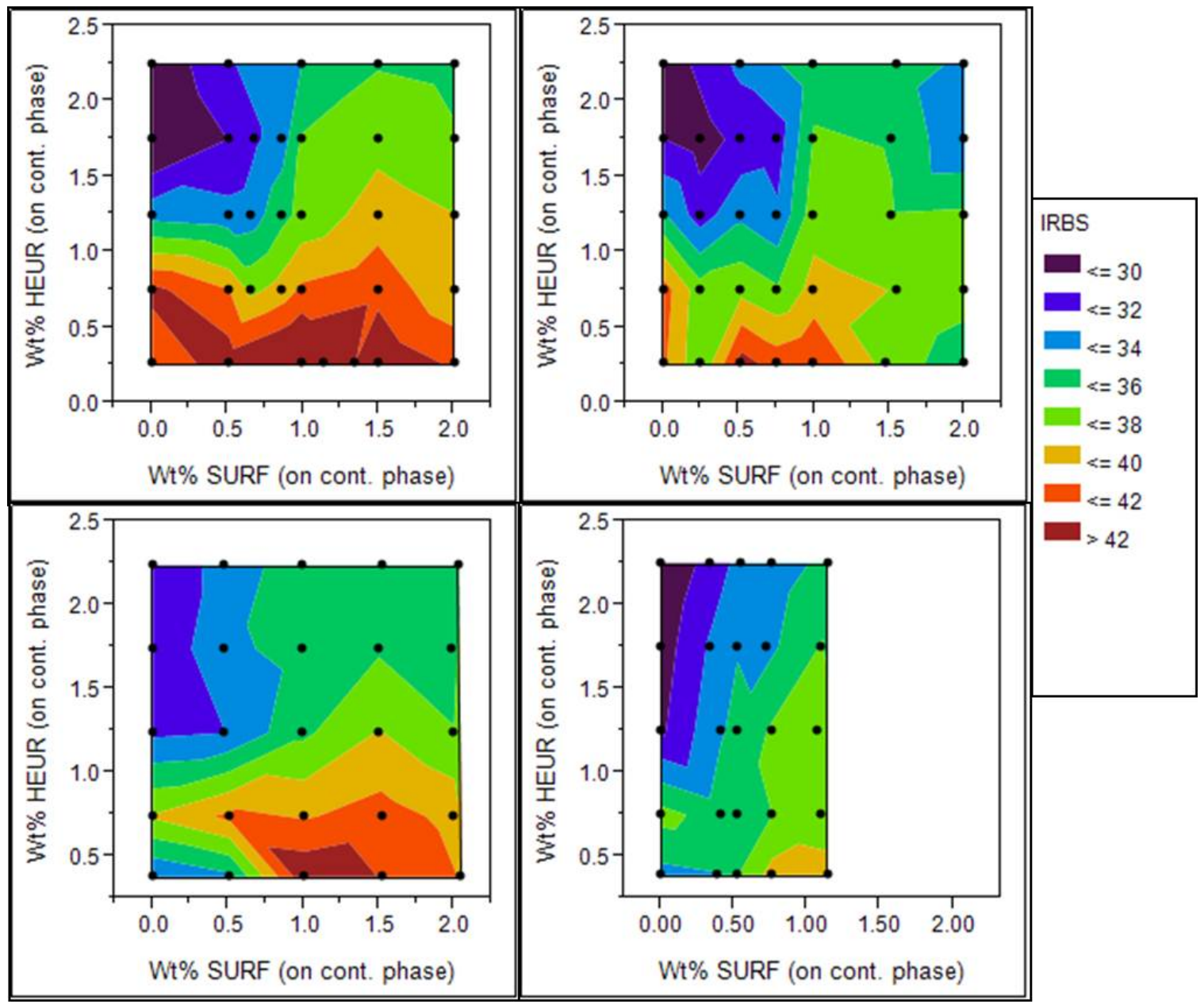

Figure 78. IRBS contour plots for the G-VNS 166A series (top left), G-VAS 166A series (top right), G-VNS 166B series (bottom left), and G-VAS 166B series (bottom right). The values of IRBS are shown on the right with all contours using the same numbering scheme. 
The IRBS contours are presented in lower resolution in order to plot each contour with the same range of IRBS values because the range was small enough to capture all the trends present for all four systems. The presenting of the contours in this form shows the contours for each system with the same values and colors for ease of analyzing trends. The most noticeable difference between the four contour plots is for the G-VAS 166B series. The purple region for the least flocculated $\mathrm{TiO}_{2}$ is much smaller, and shows a transition to higher values at lower weight percent surfactant than the other systems. For the G-VAS 166B series, the addition of an anionic surfactant would be expected to enter a depletion flocculation region quickly, but also stabilize some of the $\mathrm{TiO}_{2}$ in the system. This stabilization was seen for the 60 degree gloss contours for the two anionic systems, but was not reflected in the IRBS. The exact reason for why there is a difference for these two systems is not known. The IRBS has been shown to correlate with the good dispersion region more than the 60 degree gloss. IRBS shows sensitivity for the amount of HEUR for the good dispersion region, in which the 60 degree gloss values only showed the good dispersion region below a certain wt\% surfactant. The IRBS test can be used as a stand-alone test for determining a good dispersion region, where the gloss values must be used with other testing methods to produce a DPD.

\subsection{DPD Comparison}

The contour plots constructed for each DPD system are shown in Figure 79. 

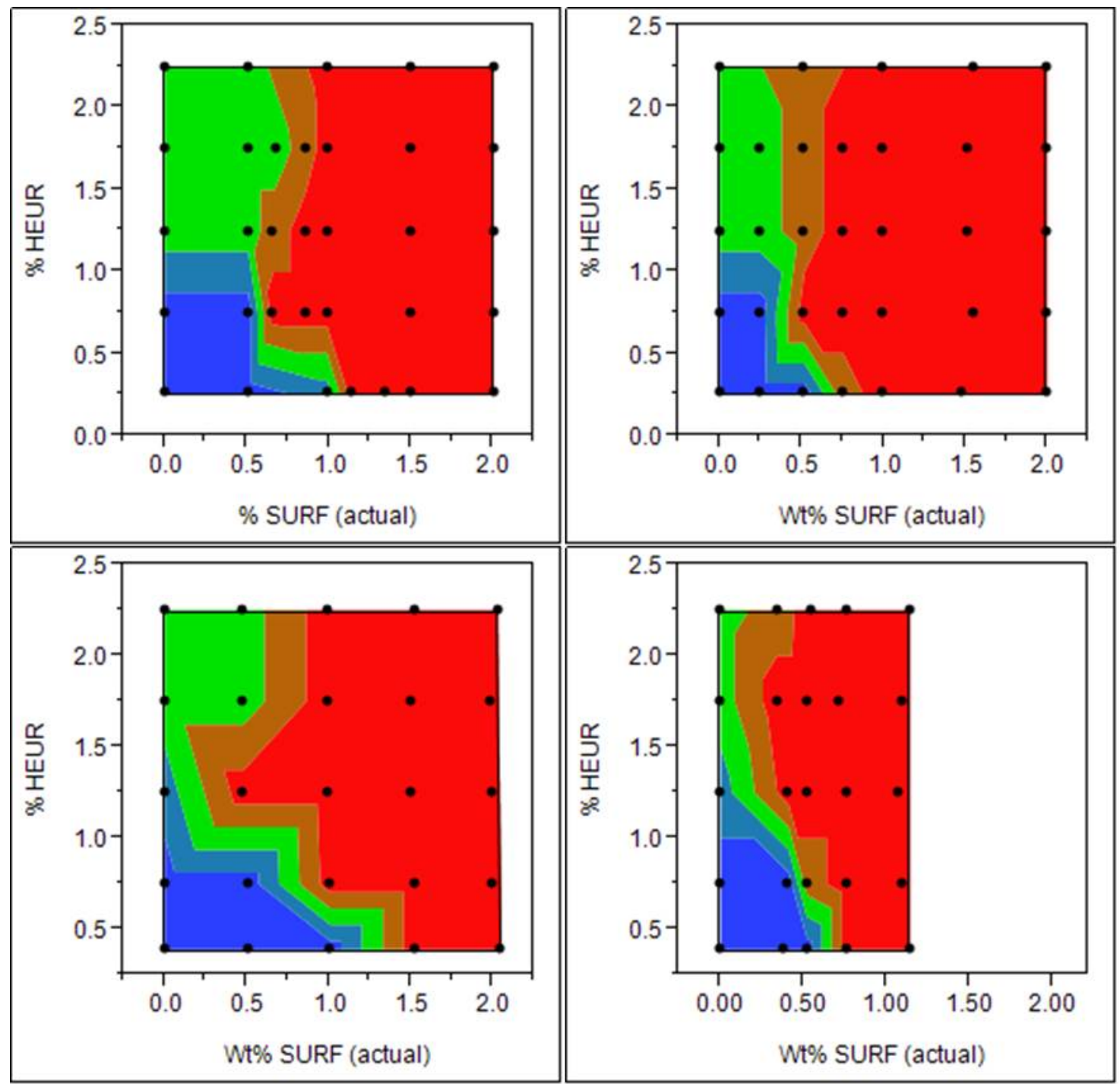

Figure 79. DPD contour plots for the G-VNS 166A series (top left), G-VAS 166A series (top right), G-VNS 166B series (bottom left), and G-VAS 166B series (bottom right).

The comparison of all the DPDs made allows for some hypotheses to be made about the interactions present. The influence of the type of surfactant (non-ionic or anionic) can be easily analyzed. The non-ionic surfactant systems showed good dispersion regions at higher surfactant levels than the anionic. The anionic surfactant yielded smaller good dispersion regions, with the G-VAS 166A DPD showing a good dispersion region from 0 to $0.4 \%$ surfactant and above $1.25 \%$ HEUR. The anionic surfactant has been shown to cause depletion flocculation at lower levels than the non-ionic surfactant. The bridging 
flocculation region is also smaller for both the anionic DPDs, which again is a result of the anionic surfactant removing bridges more efficiently, and stabilizing the bridging flocculation region at lower levels of surfactant.

The latex particle size influence can also be interpreted from the DPDs. From Figure 79, the two top DPDs are for the smaller particle size latex Acrylic-A which has a particle size of $105 \mathrm{~nm}$, and the bottom two DPDs are for Acrylic-B which has a latex size of 150 $\mathrm{nm}$. Acrylic-A has more surface area per volume for adsorption of the thickener and surfactant onto the latex surface. When comparing the G-VNS $166 \mathrm{~A}$ and G-VNS $166 \mathrm{~B}$ series DPDs the good dispersion region is clearly smaller. For the G-VAS 166A and GVAS 166B series DPDs, the decrease in the size of the good dispersion region is significant. The theories behind the formations of DPDs were confirmed, which gives credibility for the use of DPDs for many different systems. The simple representation of these DPDs create strong conclusions about the interactions in the system, as well as providing other useful information such as the physical properties of the systems in the different regions.

\subsection{Extrapolation of DPDs}

All interpretations in this section are strictly hypothesized and must be tested for confirmation. The hypotheses are for formulations similar to that used in this study, and the focus will be on the variation of associative thickener, surfactant, latex, and pigment.

\subsubsection{Change Hydrophobicity of Thickener}

The hydrophobicity of the HEUR thickener should dictate the regions of flocculation. When increasing the hydrophobicity of the thickener, the bridging flocculation region should increase, and the depletion flocculation region should decrease. The idea behind this is that the thickener will have a higher affinity for particles in the system, and as a 
result the bridges should be stronger and resist desorption from surfactant additions better. The contrary to this, the thickener polymers will stay adsorbed to the particles at higher amount of surfactant, and the system require more added surfactant before depletion flocculation is reached.

\subsubsection{Adjust Surfactant for the Latex}

The synthesis of acrylic latex typically includes the addition of surfactant during the emulsion polymerization process. The structure of the surfactant dictates surface characteristics of the polymer and different surfactants lead to different interactions between the latex and thickener and surfactant. The two latex surfactants used in this study were very similar, so it's assumed that the surface characteristics are almost identical. Most surfactants used in formulations are proprietary information which would make this analysis more difficult; however, if the information of surfactant was available more in depth analysis could be conducted.

\subsubsection{Change Hydrophobicity of Surfactant}

The hydrophobicity of surfactant should have the same implications as changing the hydrophobicity of the thickener. Increasing the hydrophobicity should create a stronger surfactant for competition for adsorption onto the particles, and the depletion flocculation region should increase and the bridging flocculation should decrease. The opposite approach of decreasing the hydrophobicity should have the opposite effects on the system.

\subsubsection{Use Different Surface Treated $\mathrm{TiO}_{2}$}

The surface treatment of $\mathrm{TiO}_{2}$ dictates the strength of interactions of $\mathrm{TiO}_{2}$ with thickener and surfactant in a given system. The surface treatment is used to provide good stabilization to the $\mathrm{TiO}_{2}$ particles for a dispersion and provide the system with desirable 
properties. Using different sources of $\mathrm{TiO}_{2}$ and studying them with the DPD approach will help define how much of a role the $\mathrm{TiO}_{2}$ plays in the flocculation mechanisms. Theoretically, the changing of surface treatment of the $\mathrm{TiO}_{2}$ should have a large influence on the flocculation regions for a given system. If the $\mathrm{TiO}_{2}$ outer shell is not completely covering, flocculation of $\mathrm{TiO}_{2}$ with other pigment and latex should occur much more readily.

\subsubsection{Adjust PVC of Formulation}

The theoretical PVC of the formulation used in this study was 21.77. Adjusting the PVC should have an effect on the flocculation regions for a given system. Increasing the pigment concentration of particles by volume in the system should increase the amount of adsorption sites, and the shifting of the flocculation regions would be similar to that of changes the particle size of latex in the system; however, this is considering that the particles added to raise the PVC will interact with the thickener and surfactants of the system. If the particles added had a surface treatment that prevented them from interacting with the thickener and surfactant some different responses may occur. The PVC of the formulation would be a good study to see how the flocculation regions shift as well as using different particles to raise the PVC. 


\section{Future Work}

The future work mentioned is focused around the actual DPDs and how they could be used.

\subsection{Implementation of DPDs}

The DPDs are essentially a roadmap to create new paints, troubleshoot problematic formulations, and understand interactions from a simple standpoint for a complex system. The understanding of the interactions of a complex system is novel information. The simplicity of the DPDs allow interpretations of the main interactions of the system without the need for new and expensive testing. The representation of DPDs in a grid fashion also allows statistical analysis and construction of contour plots. The DPDs are made with common paint making techniques and testing methods that are applicable, and do not require specialized equipment other than the rheometer. The extrapolation of the ideas of DPDs is a key part of this project, and some cautions must be noted. The understanding of the 4 different all-acrylic paint systems studied in this project was supported with the testing methods. The ability to use these testing methods for different systems was not always easy, and other unknown factors could produce problems for the construction of DPDs.

\subsection{Extension to New Systems}

The extension of DPD work into new systems should be a very useful project. Constructing DPDs for many different systems will provide a broad understanding of the various mechanisms related to phase-stability present in the paints. As more testing is conducted, the experimental techniques should be improved and refined to DPDs with 
higher resolution. The resolution of DPDs has been sufficient to create flocculation regions; however, improvement can be made in decreasing testing time to make tests more efficient and cost effective. 
12. Bibliography

Balfour, J. G., \& Hird, M. J. (1975). Flocculation - its Measurement and Effect on Opacity in Systems Containing Titanium Dioxide Pigments. Journal of Oil Colloid Chemical Association , 58, 331-344.

Beshah, K., Izmitli, A., Van Dyk, A. K., Rabasco, J. J., \& Bohling, J. (2013). DiffusionWeighted PFGNMR Study of Molecular Level Interactions of Loops and Direct Bridges of HEURs on Latex Particles. Macromolecules , 46, 2216-2227.

Chen, M., Wetzel, W. H., Ma, Z., \& Glass, J. (1997). Unifying Model for Understanding HEUR Associative Thickener Influences on Waterborne Coatings: I. HEUR Interactions with a Small Particle Latex. Journal of Coatings Technology , 69, 73-80.

Dewalt, L. E., Gao, Z., \& Ou-Yang, H. D. (1996, January). Transient Polymer-Bridging Dynamics of Colloids. 395-405.

Dragnevski, K. I., Routh, A. F., Murray, M. W., \& Donald, A. M. (2010). Cracking of Drying Latex Films: An ESEM Experiment. Langmuir , 26, 7747-7751.

Eley, R. R. (2005). Applied Rheology in the Protective and Decorative Coatings Industry. The British Society of Rheology: Rheology Reviews , 173-240.

Glass, J. E. (2001). A Perspective on the History of and Current Research in SurfactantModified Water-Soluble Polymers. Journal of Coatings Technology , 73, 79-98.

Hall, J. E., Bordeleau, R., \& Rowland, R. (1988). Quantifying Pigment Dispersion. Journal of Coatings Technology, 60, 49-61.

Hansen, C. M., \& Pierce, P. E. (1974). Surface Effects in Coatings Processes. Industrial and Engineering Chemistry Product Research and Development , 13, 218-225.

Herrick, D. J., \& Fernando, R. H. (2013). The Effect of Color Concentrates on the Rheology of Tint Bases. CoatingsTech, 36-42.

Horigome, M., \& Otsubo, Y. (2002). Long-Time Relaxation of Suspensions Flocculated by Associating Polymers. Langmuir, 18, 1968-1973.

JMP 10 Modeling and Multivariate Methods. (2012). Cary: SAS Institute Inc.

Kostansek, E. (2006). Associative Polymer/Particle Dispersion Phase Diagrams III:

Pigments. Journal of Coatings Technology and Research , 3. 
Kostansek, E. (2007). Controlling Particle Dispersion in Latex Paints Containing Associative Thickeners. Journal of Coatings Technology and Research , 4, 375-388.

Kostansek, E. (2003). Using Dispersion/Flocculation Phase Diagrams to Visualize Interactions of Associative Polymers, Latexes, and Surfactants. Journal of Coatings Technology , 75, 1-8.

Kusumgar, Nerlfi, \& Growney. (2013). Global Paint and Coatings 2013-2018. Retrieved January 2, 2014, from http://kusumgar-nerlfi-growney.com/files/KNG_August_22_2012

Lin, I. J. (1972). Hydrophile-Lipophile Balance (HLB) of Flouorocarbon Surfactants and its Relation to the Critical Micelle Concentration (CMC). Journal of Physical Chemistry, 76, 2019-2020.

Münzenberg, C. (2011). Painting the Future. European Coatings Journal , 4, 1-7.

MacFarlane, N., Wagner, N., Kaler, E., \& Lynch, M. (2010). Poly(ethylene oxide) (PEO) and Poly(vinylpyrolidone) (PVP) Induce Different Changes in the Colloid Stability of Nanoparticles. Langmuir , 26, 13823-13830.

Macosko, C. W. (1994). Rheology Principles, Measurements, and Application. Wiley$\mathrm{VCH}$, Inc.

Mahli, D. M., Steffenhagen, L., Xing, L., \& Glass, J. (2003). Surfactant Behavior and its Influence on the Viscosity of Associative Thickeners Solutions, Thickened Latex Dispersions, and Waterborne Latex Coatings. Journal of Coatings Technology , 75, 3951.

Olsson, M., Joabsson, F., \& Piculell, L. (2005). Particle-Induced Phase Separation in Mixed Polymer Solutions. Langmuir, 21, 1560-1567.

Otsubo, Y. (1999). A Nonlinear Elastic Model for Shear Thickening of Suspensions Flocculated by Reversible Bridging. Langmuir , 15, 1960-1965.

Otsubo, Y. (1995). Rheology Control of Suspensions of Soluble Polymers. Langmuir , 11, 1893-1898.

Reck, E., \& Seymour, S. (2003). The Effect of Surface-Coated TiO2 on the Performance of Paratoluene Sulphonic Acid-Catalysed Paint Systems. Surface Coatings International Part B: Coatings Transactions , 86, 253-258.

Rutherford, D. J., \& Simpson, L. A. (1985). Use of a Flocculation Gradient Monitor for Quantifying Titanium Dioxide Pigment Dispersion in Dry and Wet Paint Films. Journal of Coatings Technology and Research , 57, 75-83.

Saucy, D. (2008, August). Avoiding Viscosity Loss on Tinting. Paint and Coatings Industry Magazine , 35-38. 
Wicks, Z. J., Jones, F. N., Pappas, P. S., \& Wicks, D. A. (2007). Organic Coatings Science and Technology Third Edition. New Jersey: John Wiley and Sons. 
13. Appendix A: Sample, Call Names, and Wt\% HEUR and Surfactant for Each Paint Series.

VNS 166A series sample names, call names, and wt\% HEUR and wt $\%$ surfactant.

\begin{tabular}{|c|c|c|c|}
\hline Sample Name & Call Name & Wt\% HEUR & Wt\% Surfactant \\
\hline $\begin{array}{c}\text { V166A-0260-0000- } \\
405\end{array}$ & VNS-A1 & 0.260 & 0.000 \\
\hline $\begin{array}{l}\text { V166A-0260-0123- } \\
405\end{array}$ & VNS-A2 & 0.260 & 0.123 \\
\hline $\begin{array}{c}\text { V166A-0260-0246- } \\
405\end{array}$ & VNS-A3 & 0.260 & 0.246 \\
\hline $\begin{array}{c}\text { V166A-0260-0370- } \\
405\end{array}$ & VNS-A4 & 0.260 & 0.370 \\
\hline $\begin{array}{c}\text { V166A-0260-0493- } \\
405 \\
\end{array}$ & VNS-A5 & 0.260 & 0.493 \\
\hline $\begin{array}{c}\text { V166A-0260-0616- } \\
405\end{array}$ & VNS-A6 & 0.260 & 0.616 \\
\hline $\begin{array}{l}\text { V166A-0260-0739- } \\
405\end{array}$ & VNS-A7 & 0.260 & 0.739 \\
\hline $\begin{array}{c}\text { V166A-0260-0862- } \\
405 \\
\end{array}$ & VNS-A8 & 0.260 & 0.862 \\
\hline $\begin{array}{l}\text { V166A-0260-0985- } \\
405\end{array}$ & VNS-A9 & 0.260 & 0.985 \\
\hline $\begin{array}{l}\text { V166A-0260-1109- } \\
405\end{array}$ & VNS-A10 & 0.260 & 1.109 \\
\hline $\begin{array}{c}\text { V166A-0260-1232- } \\
405\end{array}$ & VNS-A11 & 0.260 & 1.232 \\
\hline $\begin{array}{l}\text { V166A-0260-1355- } \\
405\end{array}$ & VNS-A12 & 0.260 & 1.355 \\
\hline $\begin{array}{c}\text { V166A-0260-1478- } \\
405\end{array}$ & VNS-A13 & 0.260 & 1.478 \\
\hline $\begin{array}{c}\text { V166A-0260-1601- } \\
405\end{array}$ & VNS-A14 & 0.260 & 1.601 \\
\hline $\begin{array}{c}\text { V166A-0260-1724- } \\
405 \\
\end{array}$ & VNS-A15 & 0.260 & 1.724 \\
\hline $\begin{array}{l}\text { V166A-0260-0000- } \\
405\end{array}$ & VNS-A16 & 0.260 & 0.000 \\
\hline $\begin{array}{c}\text { V166A-0260-1724- } \\
405\end{array}$ & VNS-A17 & 0.260 & 1.724 \\
\hline V166A-0260-1971- & VNS-A18 & 0.260 & 1.971 \\
\hline
\end{tabular}




\begin{tabular}{|c|c|c|c|}
\hline 405 & & & \\
\hline $\begin{array}{l}\text { V166A-0260-2463- } \\
405\end{array}$ & VNS-A19 & 0.260 & 2.463 \\
\hline $\begin{array}{l}\text { V166A-0260-2956- } \\
405\end{array}$ & VNS-A20 & 0.260 & 2.956 \\
\hline $\begin{array}{l}\text { V166A-0260-3449- } \\
405 \\
\end{array}$ & VNS-A21 & 0.260 & 3.449 \\
\hline $\begin{array}{c}\text { V166A-260-3941- } \\
405\end{array}$ & VNS-A22 & 0.260 & 3.941 \\
\hline $\begin{array}{c}\text { V166A-0260-0000- } \\
405 \\
\end{array}$ & VNS-A23 & 0.260 & 0.000 \\
\hline $\begin{array}{l}\text { V166A-0612-0000- } \\
405\end{array}$ & VNS-A24 & 0.612 & 0.000 \\
\hline $\begin{array}{l}\text { V166A-0964-0000- } \\
405\end{array}$ & VNS-A25 & 0.964 & 0.000 \\
\hline $\begin{array}{l}\text { V166A-1316-0000- } \\
405\end{array}$ & VNS-A26 & 1.316 & 0.000 \\
\hline $\begin{array}{l}\text { V166A-1668-0000- } \\
405\end{array}$ & VNS-A27 & 1.668 & 0.000 \\
\hline $\begin{array}{l}\text { V166A-2020-0000- } \\
405\end{array}$ & VNS-A28 & 2.020 & 0.000 \\
\hline $\begin{array}{l}\text { V166A-2371-0000- } \\
405\end{array}$ & VNS-A29 & 2.371 & 0.000 \\
\hline $\begin{array}{l}\text { V166A-0260-0000- } \\
405\end{array}$ & VNS-A30 & 0.260 & 0.000 \\
\hline $\begin{array}{l}\text { V166A-0612-0246- } \\
405\end{array}$ & VNS-A31 & 0.612 & 0.246 \\
\hline $\begin{array}{c}\text { V166A-0964-0493- } \\
405 \\
\end{array}$ & VNS-A32 & 0.964 & 0.493 \\
\hline $\begin{array}{l}\text { V166A-1316-0739- } \\
405\end{array}$ & VNS-A33 & 1.316 & 0.739 \\
\hline $\begin{array}{l}\text { V166A-1668-0985- } \\
405\end{array}$ & VNS-A34 & 1.668 & 0.985 \\
\hline $\begin{array}{l}\text { V166A-2020-1232- } \\
405\end{array}$ & VNS-A35 & 2.020 & 1.232 \\
\hline $\begin{array}{c}\text { V166A-2371-1478- } \\
405 \\
\end{array}$ & VNS-A36 & 2.371 & 1.478 \\
\hline $\begin{array}{l}\text { V166A-0260-0000- } \\
405\end{array}$ & VNS-A37 & 0.260 & 0.000 \\
\hline $\begin{array}{l}\text { V166A-0600-1000- } \\
405\end{array}$ & VNS-A38 & 0.600 & 1.000 \\
\hline $\begin{array}{l}\text { V166A-1000-1000- } \\
405\end{array}$ & VNS-A39 & 1.000 & 1.000 \\
\hline $\begin{array}{l}\text { V166A-1400-1000- } \\
405\end{array}$ & VNS-A40 & 1.400 & 1.000 \\
\hline $\begin{array}{l}\text { V166A-0600-0500- } \\
405\end{array}$ & VNS-A41 & 0.600 & 0.500 \\
\hline $\begin{array}{l}\text { V166A-0600-0750- } \\
405\end{array}$ & VNS-A42 & 0.600 & 0.750 \\
\hline
\end{tabular}




\begin{tabular}{|c|c|c|c|}
\hline $\begin{array}{c}\text { V166A-0600-1300- } \\
405\end{array}$ & VNS-A43 & 0.600 & 1.300 \\
\hline $\begin{array}{c}\text { V166A-2000-0750- } \\
405\end{array}$ & VNS-A44 & 2.000 & 0.750 \\
\hline $\begin{array}{c}\text { V166A-2000-1000- } \\
405\end{array}$ & VNS-A45 & 2.000 & 1.000 \\
\hline $\begin{array}{c}\text { V166A-2400-0750- } \\
405\end{array}$ & VNS-A46 & 2.400 & 0.750 \\
\hline $\begin{array}{c}\text { V166A-0260-0000- } \\
405\end{array}$ & VNS-A47 & 0.260 & 0.000 \\
\hline
\end{tabular}

Sample and call name and wt\% HEUR and surfactant on the continuous phase for samples in the VAS 166A Series.

\begin{tabular}{|c|c|c|c|}
\hline Sample Name & Call Name & Wt\% HEUR & Wt\% Surfactant \\
\hline $\begin{array}{l}\text { V166A-0260-0000- } \\
411\end{array}$ & VAS-A1 & 0.260 & 0.00 \\
\hline $\begin{array}{l}\text { V166A-0612-0000- } \\
411\end{array}$ & VAS-A2 & 0.612 & 0.00 \\
\hline $\begin{array}{l}\text { V166A-0964-0000- } \\
411\end{array}$ & VAS-A3 & 0.964 & 0.00 \\
\hline $\begin{array}{c}\text { V166A-1316-0000- } \\
411\end{array}$ & VAS-A4 & 1.316 & 0.00 \\
\hline $\begin{array}{l}\text { V166A-1668-0000- } \\
411\end{array}$ & VAS-A5 & 1.668 & 0.00 \\
\hline $\begin{array}{l}\text { V166A-2020-0000- } \\
411\end{array}$ & VAS-A6 & 2.020 & 0.00 \\
\hline $\begin{array}{l}\text { V166A-2371-0000- } \\
411\end{array}$ & VAS-A7 & 2.371 & 0.00 \\
\hline $\begin{array}{l}\text { V166A-0260-0000- } \\
411\end{array}$ & VAS-A8 & 0.26 & 0.000 \\
\hline $\begin{array}{l}\text { V166A-0260-0412- } \\
411\end{array}$ & VAS-A9 & 0.26 & 0.412 \\
\hline $\begin{array}{l}\text { V166A-0260-0825- } \\
411\end{array}$ & VAS-A10 & 0.26 & 0.825 \\
\hline $\begin{array}{l}\text { V166A-0260-1237- } \\
411\end{array}$ & VAS-A11 & 0.26 & 1.237 \\
\hline $\begin{array}{l}\text { V166A-0260-1650- } \\
411\end{array}$ & VAS-A12 & 0.26 & 1.650 \\
\hline $\begin{array}{l}\text { V166A-0260-0206- } \\
411\end{array}$ & VAS-A13 & 0.26 & 0.206 \\
\hline $\begin{array}{c}\text { V166A-0260-0619- } \\
411\end{array}$ & VAS-A14 & 0.26 & 0.619 \\
\hline $\begin{array}{l}\text { V166A-0260-1031- } \\
411\end{array}$ & VAS-A15 & 0.26 & 1.031 \\
\hline $\begin{array}{l}\text { V166A-0260-0000- } \\
411\end{array}$ & VAS-A16 & 0.260 & 0.000 \\
\hline
\end{tabular}




\begin{tabular}{|c|c|c|c|}
\hline $\begin{array}{c}\text { V166A-0612-0251- } \\
411\end{array}$ & VAS-A17 & 0.612 & 0.251 \\
\hline $\begin{array}{l}\text { V166A-0964-0501- } \\
411\end{array}$ & VAS-A18 & 0.964 & 0.501 \\
\hline $\begin{array}{c}\text { V166A-1316-0752- } \\
411\end{array}$ & VAS-A19 & 1.316 & 0.752 \\
\hline $\begin{array}{l}\text { V166A-1668-1003- } \\
411\end{array}$ & VAS-A20 & 1.668 & 1.003 \\
\hline $\begin{array}{l}\text { V166A-0612-0501- } \\
411\end{array}$ & VAS-A21 & 0.612 & 0.501 \\
\hline $\begin{array}{c}\text { V166A-0964-0752- } \\
411\end{array}$ & VAS-A22 & 0.964 & 0.752 \\
\hline $\begin{array}{c}\text { V166A-1316-1003- } \\
411\end{array}$ & VAS-A23 & 1.316 & 1.003 \\
\hline $\begin{array}{l}\text { V166A-0260-0000- } \\
411\end{array}$ & VAS-A24 & 0.26 & 0.000 \\
\hline $\begin{array}{l}\text { V166A-0600-0700- } \\
411\end{array}$ & VAS-A25 & 0.6 & 0.700 \\
\hline $\begin{array}{c}\text { V166A-0600-0900- } \\
411\end{array}$ & VAS-A26 & 0.6 & 0.900 \\
\hline $\begin{array}{l}\text { V166A-0600-1100- } \\
411\end{array}$ & VAS-A27 & 0.6 & 1.100 \\
\hline $\begin{array}{l}\text { V166A-1316-0500- } \\
411\end{array}$ & VAS-A28 & 1.316 & 0.500 \\
\hline $\begin{array}{l}\text { V166A-1668-0500- } \\
411\end{array}$ & VAS-A29 & 1.668 & 0.500 \\
\hline $\begin{array}{c}\text { V166A-1668-0750- } \\
411\end{array}$ & VAS-A30 & 1.668 & 0.750 \\
\hline $\begin{array}{l}\text { V166A-0964-0250- } \\
411\end{array}$ & VAS-A31 & 0.964 & 0.250 \\
\hline
\end{tabular}

Wt\% HEUR and surfactant on the continuous phase for samples in the VNS2 166A Series.

\begin{tabular}{|c|c|c|c|}
\hline Sample Name & Call Name & Wt\% HEUR & Wt\% Surfactant \\
\hline $\begin{array}{c}\text { V166A-0260-0000- } \\
100\end{array}$ & VNS2-A1 & 0.26 & 0.000 \\
\hline $\begin{array}{c}\text { V166A-0260-0352- } \\
100\end{array}$ & VNS2-A2 & 0.26 & 0.352 \\
\hline $\begin{array}{c}\text { V166A-0260-0704- } \\
100\end{array}$ & VNS2-A3 & 0.26 & 0.704 \\
\hline $\begin{array}{c}\text { V166A-0260-1056- } \\
100\end{array}$ & VNS2-A4 & 0.26 & 1.056 \\
\hline $\begin{array}{c}\text { V166A-0260-1408- } \\
100\end{array}$ & VNS2-A5 & 0.26 & 1.408 \\
\hline $\begin{array}{c}\text { V166A-0260-1760- } \\
100\end{array}$ & VNS2-A6 & 0.26 & 1.760 \\
\hline
\end{tabular}




\begin{tabular}{|c|c|c|c|}
\hline $\begin{array}{c}\text { V166A-0260-2111- } \\
100\end{array}$ & VNS2-A7 & 0.26 & 2.111 \\
\hline $\begin{array}{c}\text { V166A-0260-2463- } \\
100\end{array}$ & VNS2-A8 & 0.26 & 2.463 \\
\hline $\begin{array}{c}\text { V166A-0260-0000- } \\
100\end{array}$ & VNS2-A9 & 0.260 & 0.000 \\
\hline $\begin{array}{c}\text { V166A-0612-0352- } \\
100\end{array}$ & VNS2-A10 & 0.612 & 0.352 \\
\hline $\begin{array}{c}\text { V166A-0964-0704- } \\
100\end{array}$ & VNS2-A11 & 0.964 & 0.704 \\
\hline $\begin{array}{c}\text { V166A-1316-0352- } \\
100\end{array}$ & VNS2-A12 & 1.316 & 1.056 \\
\hline $\begin{array}{c}\text { V166A-1668-0352- } \\
100\end{array}$ & VNS2-A13 & 1.668 & 1.408 \\
\hline $\begin{array}{c}\text { V166A-0612-0352- } \\
100\end{array}$ & VNS2-A14 & 0.612 & 0.704 \\
\hline $\begin{array}{c}\text { V166A-0964-0352- } \\
100\end{array}$ & VNS2-A15 & 0.964 & 1.056 \\
\hline $\begin{array}{c}\text { V166A-1316-0352- } \\
100\end{array}$ & VNS2-A16 & 1.316 & 1.408 \\
\hline
\end{tabular}

Theoretical and actual weight percent HEUR and surfactant for all 25 samples made for the grid synthesis approach for the G-VNS 166A series.

\begin{tabular}{|c|l|l|l|l|}
\hline Sample & Call Name & \multicolumn{1}{|c|}{$\%$ HEUR } & $\begin{array}{c}\% \text { Surfactant } \\
\text { (theoretical) }\end{array}$ & $\begin{array}{c}\% \text { Surfactant } \\
\text { (actual) }\end{array}$ \\
\hline $\begin{array}{c}\text { G-V166A-0260- } \\
0000-405\end{array}$ & G-VNS-A1 & 0.26 & 0 & 0.000 \\
\hline $\begin{array}{c}\text { G-V166A-0260- } \\
0500-405\end{array}$ & G-VNS-A2 & 0.26 & 0.5 & 0.507 \\
\hline $\begin{array}{c}\text { G-V166A-0260- } \\
1000-405\end{array}$ & G-VNS-A3 & 0.26 & 1 & 0.989 \\
\hline $\begin{array}{c}\text { G-V166A-0260- } \\
1500-405\end{array}$ & G-VNS-A4 & 0.26 & 1.5 & 1.496 \\
\hline $\begin{array}{c}\text { G-V166A-0260- } \\
2000-405\end{array}$ & G-VNS-A5 & 0.26 & 2 & 2.003 \\
\hline $\begin{array}{c}\text { G-V166A-0750- } \\
0000-405\end{array}$ & G-VNS-A6 & 0.75 & 0 & 0.000 \\
\hline $\begin{array}{c}\text { G-V166A-0750- } \\
0500-405\end{array}$ & G-VNS-A7 & 0.75 & 0.5 & 0.507 \\
\hline $\begin{array}{c}\text { G-V166A-0750- } \\
1000-405\end{array}$ & G-VNS-A8 & 0.75 & 1 & 0.989 \\
\hline $\begin{array}{c}\text { G-V166A-0750- } \\
1500-405\end{array}$ & G-VNS-A9 & 0.75 & 1.5 & 1.496 \\
\hline $\begin{array}{c}\text { G-V166A-0750- } \\
2000-405\end{array}$ & G-VNS-A10 & 0.75 & 2 & 2.003 \\
\hline $\begin{array}{c}\text { G-V166A-1250- } \\
0000-405\end{array}$ & G-VNS-A11 & 1.25 & 0 & 0.000 \\
\hline $\begin{array}{c}\text { G-V166A-1250- } \\
\text { G-VNS-A12 }\end{array} 11.25$ & 0.5 & 0.507 \\
\hline
\end{tabular}




\begin{tabular}{|c|l|l|l|l|}
\hline $\begin{array}{c}0500-405 \\
\begin{array}{c}\text { G-V166A-1250- } \\
1000-405\end{array}\end{array}$ & G-VNS-A13 & 1.25 & 1 & \\
\hline $\begin{array}{c}\text { G-V166A-1250- } \\
1500-405\end{array}$ & G-VNS-A14 & 1.25 & 1.5 & 0.989 \\
\hline $\begin{array}{c}\text { G-V166A-1250- } \\
2000-405\end{array}$ & G-VNS-A15 & 1.25 & 2 & 1.496 \\
\hline $\begin{array}{c}\text { G-V166A-1750- } \\
0000-405\end{array}$ & G-VNS-A16 & 1.75 & 0 & 2.003 \\
\hline $\begin{array}{c}\text { G-V166A-1750- } \\
0500-405\end{array}$ & G-VNS-A17 & 1.75 & 0.5 & 0.000 \\
\hline $\begin{array}{c}\text { G-V166A-1750- } \\
1000-405\end{array}$ & G-VNS-A18 & 1.75 & 1 & 0.507 \\
\hline $\begin{array}{c}\text { G-V166A-1750- } \\
1500-405\end{array}$ & G-VNS-A19 & 1.75 & 1.5 & 1.496 \\
\hline $\begin{array}{c}\text { G-V166A-1750- } \\
2000-405\end{array}$ & G-VNS-A20 & 1.75 & 2 & 2.003 \\
\hline $\begin{array}{c}\text { G-V166A-2250- } \\
0000-405\end{array}$ & G-VNS-A21 & 2.25 & 0 & 0.000 \\
\hline $\begin{array}{c}\text { G-V166A-2250- } \\
0500-405\end{array}$ & G-VNS-A22 & 2.25 & 0.5 & 0.507 \\
\hline $\begin{array}{c}\text { G-V166A-2250- } \\
1000-405\end{array}$ & G-VNS-A23 & 2.25 & 1.496 \\
\hline $\begin{array}{c}\text { G-V166A-2250- } \\
1500-405\end{array}$ & G-VNS-A24 & 2.25 & 1.5 & 2.003 \\
\hline $\begin{array}{c}\text { G-V166A-2250- } \\
2000-405\end{array}$ & G-VNS-A25 & 2.25 & 0.989 \\
\hline
\end{tabular}

Weight percent HEUR and surfactant (on the continuous phase) for all 25 samples made for the G-VAS 166A series.

\begin{tabular}{|c|c|c|c|c|}
\hline Sample & Call Name & \% HEUR & $\begin{array}{c}\% \text { Surfactant } \\
\text { (theoretical) }\end{array}$ & $\begin{array}{c}\% \text { Surfactant } \\
\text { (actual) }\end{array}$ \\
\hline $\begin{array}{c}\text { G-V166A-0260- } \\
\text { 0000-411 }\end{array}$ & G-VAS-A1 & 0.26 & 0 & 0.000 \\
\hline $\begin{array}{c}\text { G-V166A-0260- } \\
0500-411\end{array}$ & G-VAS-A2 & 0.26 & 0.5 & 0.516 \\
\hline $\begin{array}{c}\text { G-V166A-0260- } \\
1000-411\end{array}$ & G-VAS-A3 & 0.26 & 1 & 0.998 \\
\hline $\begin{array}{c}\text { G-V166A-0260- } \\
1500-411\end{array}$ & G-VAS-A4 & 0.26 & 1.5 & 1.479 \\
\hline $\begin{array}{c}\text { G-V166A-0260- } \\
2000-411\end{array}$ & G-VAS-A5 & 0.26 & 2 & 1.995 \\
\hline $\begin{array}{c}\text { G-V166A-0750- } \\
0000-411\end{array}$ & G-VAS-A6 & 0.75 & 0 & 0.000 \\
\hline G-V166A-0750- & G-VAS-A7 & 0.75 & 0.5 & 0.516 \\
\hline
\end{tabular}




\begin{tabular}{|c|c|c|c|c|}
\hline $0500-411$ & & & & \\
\hline $\begin{array}{c}\text { G-V166A-0750- } \\
1000-411\end{array}$ & G-VAS-A8 & 0.75 & 1 & 0.998 \\
\hline $\begin{array}{c}\text { G-V166A-0750- } \\
1500-411\end{array}$ & G-VAS-A9 & 0.75 & 1.5 & 1.548 \\
\hline $\begin{array}{c}\text { G-V166A-0750- } \\
2000-411\end{array}$ & G-VAS-A10 & 0.75 & 2 & 1.995 \\
\hline $\begin{array}{c}\text { G-V166A-1250- } \\
0000-411\end{array}$ & G-VAS-A11 & 1.25 & 0 & 0.000 \\
\hline $\begin{array}{c}\text { G-V166A-1250- } \\
0500-411\end{array}$ & G-VAS-A12 & 1.25 & 0.5 & 0.516 \\
\hline $\begin{array}{c}\text { G-V166A-1250- } \\
1000-411\end{array}$ & G-VAS-A13 & 1.25 & 1 & 0.998 \\
\hline $\begin{array}{c}\text { G-V166A-1250- } \\
1500-411\end{array}$ & G-VAS-A14 & 1.25 & 1.5 & 1.514 \\
\hline $\begin{array}{c}\text { G-V166A-1250- } \\
2000-411\end{array}$ & G-VAS-A15 & 1.25 & 2 & 1.995 \\
\hline $\begin{array}{c}\text { G-V166A-1750- } \\
0000-411\end{array}$ & G-VAS-A16 & 1.75 & 0 & 0.000 \\
\hline $\begin{array}{c}\text { G-V166A-1750- } \\
0500-411\end{array}$ & G-VAS-A17 & 1.75 & 0.5 & 0.516 \\
\hline $\begin{array}{c}\text { G-V166A-1750- } \\
1000-411 \\
\end{array}$ & G-VAS-A18 & 1.75 & 1 & 0.998 \\
\hline $\begin{array}{c}\text { G-V166A-1750- } \\
1500-411\end{array}$ & G-VAS-A19 & 1.75 & 1.5 & 1.514 \\
\hline $\begin{array}{c}\text { G-V166A-1750- } \\
2000-411\end{array}$ & G-VAS-A20 & 1.75 & 2 & 1.995 \\
\hline $\begin{array}{c}\text { G-V166A-2250- } \\
0000-411\end{array}$ & G-VAS-A21 & 2.25 & 0 & 0.000 \\
\hline $\begin{array}{c}\text { G-V166A-2250- } \\
0500-411\end{array}$ & G-VAS-A22 & 2.25 & 0.5 & 0.516 \\
\hline $\begin{array}{c}\text { G-V166A-2250- } \\
1000-411\end{array}$ & G-VAS-A23 & 2.25 & 1 & 0.998 \\
\hline $\begin{array}{c}\text { G-V166A-2250- } \\
1500-411\end{array}$ & G-VAS-A24 & 2.25 & 1.5 & 1.548 \\
\hline $\begin{array}{c}\text { G-V166A-2250- } \\
2000-411\end{array}$ & G-VAS-A25 & 2.25 & 2 & 1.995 \\
\hline
\end{tabular}

Weight percent HEUR and surfactant for the G-VNS 166B paint samples.

\begin{tabular}{|c|c|c|c|c|}
\hline Sample & $\begin{array}{c}\text { Call } \\
\text { Name }\end{array}$ & $\begin{array}{c}\text { Wt\% } \\
\text { HEUR }\end{array}$ & $\begin{array}{c}\text { Wt\% Surfactant } \\
\text { (theoretical) }\end{array}$ & $\begin{array}{c}\text { Wt\% Surfactant } \\
\text { (actual) }\end{array}$ \\
\hline $\begin{array}{c}\text { G-V166B-0380- } \\
0000-405\end{array}$ & $\begin{array}{c}\text { G- } \\
\text { VNS- } \\
\text { B1 }\end{array}$ & 0.38 & 0 & 0.00 \\
\hline $\begin{array}{c}\text { G-V166B-0380- } \\
\text { 0500-405 }\end{array}$ & $\begin{array}{c}\text { G- } \\
\text { VNS- } \\
\text { B2 }\end{array}$ & 0.38 & 0.5 & 0.51 \\
\hline $\begin{array}{c}\text { G-V166B-0380- } \\
\text { 1000-405 }\end{array}$ & $\begin{array}{c}\text { G- } \\
\text { VNS- }\end{array}$ & 0.38 & 1 & 1.01 \\
\hline
\end{tabular}




\begin{tabular}{|c|c|c|c|c|}
\hline & B3 & & & \\
\hline $\begin{array}{c}\text { G-V166B-0380- } \\
1500-405\end{array}$ & $\begin{array}{c}\text { G- } \\
\text { VNS- } \\
\text { B4 } \\
\end{array}$ & 0.38 & 1.5 & 1.52 \\
\hline $\begin{array}{c}\text { G-V166B-0380- } \\
\text { 2000-405 }\end{array}$ & $\begin{array}{c}\text { G- } \\
\text { VNS- } \\
\text { B5 }\end{array}$ & 0.38 & 2 & 2.05 \\
\hline $\begin{array}{c}\text { G-V166B-0740- } \\
\text { 0000-405 }\end{array}$ & $\begin{array}{c}\text { G- } \\
\text { VNS- } \\
\text { B6 }\end{array}$ & 0.74 & 0 & 0.00 \\
\hline $\begin{array}{c}\text { G-V166B-0740- } \\
\text { 0500-405 }\end{array}$ & $\begin{array}{c}\text { G- } \\
\text { VNS- } \\
\text { B7 }\end{array}$ & 0.74 & 0.5 & 0.51 \\
\hline $\begin{array}{c}\text { G-V166B-0740- } \\
\text { 1000-405 }\end{array}$ & $\begin{array}{c}\text { G- } \\
\text { VNS- } \\
\text { B8 }\end{array}$ & 0.74 & 1 & 1.01 \\
\hline $\begin{array}{c}\text { G-V166B-0740- } \\
1500-405\end{array}$ & $\begin{array}{c}\text { G- } \\
\text { VNS- } \\
\text { B9 }\end{array}$ & 0.74 & 1.5 & 1.52 \\
\hline $\begin{array}{c}\text { G-V166B-0740- } \\
\text { 2000-405 }\end{array}$ & $\begin{array}{c}\text { G- } \\
\text { VNS- } \\
\text { B10 }\end{array}$ & 0.74 & 2 & 2.00 \\
\hline $\begin{array}{l}\text { G-V166B-1240- } \\
\text { 0000-405 }\end{array}$ & $\begin{array}{c}\text { G- } \\
\text { VNS- } \\
\text { B11 }\end{array}$ & 1.24 & 0 & 0.00 \\
\hline $\begin{array}{c}\text { G-V166B-1240- } \\
\text { 0500-405 }\end{array}$ & $\begin{array}{c}\text { G- } \\
\text { VNS- } \\
\text { B12 }\end{array}$ & 1.24 & 0.5 & 0.48 \\
\hline $\begin{array}{c}\text { G-V166B-1240- } \\
\text { 1000-405 }\end{array}$ & $\begin{array}{c}\text { G- } \\
\text { VNS- } \\
\text { B13 }\end{array}$ & 1.24 & 1 & 0.99 \\
\hline $\begin{array}{c}\text { G-V166B-1240- } \\
\text { 1500-405 }\end{array}$ & $\begin{array}{c}\text { G- } \\
\text { VNS- } \\
\text { B14 }\end{array}$ & 1.24 & 1.5 & 1.50 \\
\hline $\begin{array}{c}\text { G-V166B-1240- } \\
\text { 2000-405 }\end{array}$ & $\begin{array}{c}\text { G- } \\
\text { VNS- } \\
\text { B15 }\end{array}$ & 1.24 & 2 & 2.00 \\
\hline $\begin{array}{c}\text { G-V166B-1740- } \\
0000-405\end{array}$ & $\begin{array}{c}\text { G- } \\
\text { VNS- } \\
\text { B16 }\end{array}$ & 1.74 & 0 & 0.00 \\
\hline $\begin{array}{c}\text { G-V166B-1740- } \\
\text { 0500-405 }\end{array}$ & $\begin{array}{c}\text { G- } \\
\text { VNS- } \\
\text { B17 }\end{array}$ & 1.74 & 0.5 & 0.48 \\
\hline $\begin{array}{c}\text { G-V166B-1740- } \\
1000-405\end{array}$ & $\begin{array}{c}\text { G- } \\
\text { VNS- } \\
\text { B18 }\end{array}$ & 1.74 & 1 & 0.99 \\
\hline $\begin{array}{c}\text { G-V166B-1740- } \\
1500-405\end{array}$ & $\begin{array}{c}\text { G- } \\
\text { VNS- } \\
\text { B19 }\end{array}$ & 1.74 & 1.5 & 1.50 \\
\hline G-V166B-1740- & G- & 1.74 & 2 & 1.98 \\
\hline
\end{tabular}




\begin{tabular}{|c|c|c|c|c|}
\hline $2000-405$ & $\begin{array}{l}\text { VNS- } \\
\text { B20 }\end{array}$ & & & \\
\hline $\begin{array}{c}\text { G-V166B-2240- } \\
0000-405\end{array}$ & $\begin{array}{c}\text { G- } \\
\text { VNS- } \\
\text { B21 }\end{array}$ & 2.24 & 0 & 0.00 \\
\hline $\begin{array}{c}\text { G-V166B-2240- } \\
0500-405\end{array}$ & $\begin{array}{c}\text { G- } \\
\text { VNS- } \\
\text { B22 } \\
\end{array}$ & 2.24 & 0.5 & 0.48 \\
\hline $\begin{array}{c}\text { G-V166B-2240- } \\
\text { 1000-405 }\end{array}$ & $\begin{array}{c}\text { G- } \\
\text { VNS- } \\
\text { B23 }\end{array}$ & 2.24 & 1 & 0.99 \\
\hline $\begin{array}{c}\text { G-V166B-2240- } \\
1500-405\end{array}$ & $\begin{array}{c}\text { G- } \\
\text { VNS- } \\
\text { B24 }\end{array}$ & 2.24 & 1.5 & 1.52 \\
\hline $\begin{array}{c}\text { G-V166B-2240- } \\
\text { 2000-405 }\end{array}$ & $\begin{array}{c}\text { G- } \\
\text { VNS- } \\
\text { B25 } \\
\end{array}$ & 2.24 & 2 & 2.03 \\
\hline
\end{tabular}

Surfactant and HEUR wt\% for the G-VAS 166B series.

\begin{tabular}{|c|c|c|c|c|}
\hline Sample & Call Name & $\begin{array}{l}\text { Wt\% HEUR } \\
\text { (Theoretical) }\end{array}$ & $\begin{array}{c}\text { Wt\% } \\
\text { Surfactant } \\
\text { (Theoretical) }\end{array}$ & $\begin{array}{c}\text { Wt\% } \\
\text { Surfactant } \\
\text { (actual) }\end{array}$ \\
\hline $\begin{array}{c}\text { G-V166B-0390-0000- } \\
411\end{array}$ & G-VAS-B1 & 0.39 & 0 & 0.00 \\
\hline $\begin{array}{c}\text { G-V166B-0390-0375- } \\
411\end{array}$ & G-VAS-B2 & 0.39 & 0.375 & 0.38 \\
\hline $\begin{array}{l}\text { G-V166B-0390-0750- } \\
411\end{array}$ & G-VAS-B3 & 0.39 & 0.75 & 0.76 \\
\hline $\begin{array}{l}\text { G-V166B-0390-1125- } \\
411\end{array}$ & G-VAS-B4 & 0.39 & 1.125 & 1.14 \\
\hline $\begin{array}{c}\text { G-V166B-0390-0516- } \\
411\end{array}$ & G-VAS-B5 & 0.39 & 0.516 & 0.52 \\
\hline $\begin{array}{l}\text { G-V166B-0750-0000- } \\
411\end{array}$ & G-VAS-B6 & 0.75 & 0 & 0.00 \\
\hline $\begin{array}{l}\text { G-V166B-0750-0375- } \\
411\end{array}$ & G-VAS-B7 & 0.75 & 0.375 & 0.41 \\
\hline $\begin{array}{c}\text { G-V166B-0750-0750- } \\
411\end{array}$ & G-VAS-B8 & 0.75 & 0.75 & 0.76 \\
\hline $\begin{array}{c}\text { G-V166B-0750-1125- } \\
411\end{array}$ & G-VAS-B9 & 0.75 & 1.125 & 1.10 \\
\hline $\begin{array}{c}\text { G-V166B-0750-0516- } \\
411\end{array}$ & G-VAS-B10 & 0.75 & 0.516 & 0.52 \\
\hline $\begin{array}{c}\text { G-V166B-1250-0000- } \\
411\end{array}$ & G-VAS-B11 & 1.25 & 0 & 0.00 \\
\hline $\begin{array}{c}\text { G-V166B-1250-0375- } \\
411\end{array}$ & G-VAS-B12 & 1.25 & 0.375 & 0.41 \\
\hline $\begin{array}{c}\text { G-V166B-1250-0750- } \\
411\end{array}$ & G-VAS-B13 & 1.25 & 0.75 & 0.76 \\
\hline
\end{tabular}




\begin{tabular}{|c|c|c|c|c|}
\cline { 2 - 4 } $\begin{array}{c}\text { G-V166B-1250-1125- } \\
411\end{array}$ & G-VAS-B14 & 1.25 & 1.125 & 1.07 \\
\hline $\begin{array}{c}\text { G-V166B-1250-0516- } \\
411\end{array}$ & G-VAS-B15 & 1.25 & 0.516 & 0.52 \\
\hline $\begin{array}{c}\text { G-V166B-1750-0000- } \\
411\end{array}$ & G-VAS-B16 & 1.75 & 0 & 0.00 \\
\hline $\begin{array}{c}\text { G-V166B-1750-0375- } \\
411\end{array}$ & G-VAS-B17 & 1.75 & 0.375 & 0.34 \\
\hline $\begin{array}{c}\text { G-V166B-1750-1125- } \\
411\end{array}$ & G-VAS-B18 & 1.75 & 0.75 & 0.72 \\
\hline $\begin{array}{c}\text { G-V166B-1750-0516- } \\
411\end{array}$ & G-VAS-B19 & 1.75 & 1.125 & 1.10 \\
\hline $\begin{array}{c}\text { G-V166B-2250-0000- } \\
411\end{array}$ & G-VAS-B21 & 2.25 & 0.516 & 0.52 \\
\hline $\begin{array}{c}\text { G-V166B-2250-0375- } \\
411\end{array}$ & G-VAS-B22 & 2.25 & 0.375 & 0.00 \\
\hline $\begin{array}{c}\text { G-V166B-2250-0750- } \\
411\end{array}$ & G-VAS-B23 & 2.25 & 0.75 & 0.76 \\
\hline $\begin{array}{c}\text { G-V166B-2250-1125- } \\
411\end{array}$ & G-VAS-B24 & 2.25 & 1.125 & 1.14 \\
\hline $\begin{array}{c}\text { G-V166B-2250-0516- } \\
411\end{array}$ & G-VAS-B25 & 2.25 & 0.516 & 0.55 \\
\hline
\end{tabular}


14. Appendix B: Physical Property Data.

VNS 166A Series physical property data.

\begin{tabular}{|c|c|c|c|c|c|c|c|c|c|c|c|}
\hline \multirow{2}{*}{ Sample } & \multirow{2}{*}{$\begin{array}{c}\text { Call } \\
\text { Name }\end{array}$} & \multirow{2}{*}{$\begin{array}{c}\% \\
\text { HEU } \\
\text { R }\end{array}$} & \multirow{2}{*}{$\begin{array}{c}\% \\
\text { Surf }\end{array}$} & \multicolumn{2}{|c|}{$\mathrm{KU}$} & \multicolumn{3}{|c|}{ Gloss } & \multirow{2}{*}{ CR } & \multirow{2}{*}{$\begin{array}{c}\text { Sa } \\
g\end{array}$} & \multirow{2}{*}{$\begin{array}{c}\text { IRB } \\
\mathrm{S}\end{array}$} \\
\hline & & & & $\begin{array}{c}\text { initia } \\
1\end{array}$ & $24 \mathrm{hr}$ & $20^{\prime}$ & $60^{\prime}$ & $85^{\prime}$ & & & \\
\hline $\begin{array}{c}\text { V166A- } \\
0260- \\
0000-405\end{array}$ & $\begin{array}{l}\text { VNS- } \\
\text { A1 }\end{array}$ & $\begin{array}{c}0.26 \\
0\end{array}$ & $\begin{array}{c}0.00 \\
0\end{array}$ & $\begin{array}{c}106 . \\
2\end{array}$ & $\begin{array}{c}106 . \\
7\end{array}$ & 3 & $\begin{array}{c}20 . \\
6\end{array}$ & 67 & $\begin{array}{l}97 . \\
87\end{array}$ & 6 & $\begin{array}{c}38.9 \\
1\end{array}$ \\
\hline $\begin{array}{c}\text { V166A- } \\
0260- \\
0123-405\end{array}$ & $\begin{array}{l}\text { VNS- } \\
\text { A2 }\end{array}$ & $\begin{array}{c}0.26 \\
0 \\
\end{array}$ & $\begin{array}{c}0.12 \\
3 \\
\end{array}$ & $\begin{array}{c}105 . \\
8 \\
\end{array}$ & $\begin{array}{c}107 . \\
4\end{array}$ & 3 & $\begin{array}{c}19 . \\
3\end{array}$ & $\begin{array}{c}67 . \\
2 \\
\end{array}$ & $\begin{array}{l}97 . \\
91\end{array}$ & 6 & $\begin{array}{c}40.4 \\
3 \\
\end{array}$ \\
\hline $\begin{array}{c}\text { V166A- } \\
0260- \\
0246-405\end{array}$ & $\begin{array}{c}\text { VNS- } \\
\text { A3 }\end{array}$ & $\begin{array}{c}0.26 \\
0\end{array}$ & $\begin{array}{c}0.24 \\
6 \\
\end{array}$ & 105 & $\begin{array}{c}107 . \\
8\end{array}$ & 4.3 & $\begin{array}{c}26 . \\
8\end{array}$ & $\begin{array}{c}74 . \\
8\end{array}$ & $\begin{array}{l}97 . \\
85\end{array}$ & 6 & $\begin{array}{c}41.1 \\
6\end{array}$ \\
\hline $\begin{array}{c}\text { V166A- } \\
0260- \\
0370-405\end{array}$ & $\begin{array}{l}\text { VNS- } \\
\text { A4 }\end{array}$ & $\begin{array}{c}0.26 \\
0\end{array}$ & $\begin{array}{c}0.37 \\
0\end{array}$ & $\begin{array}{c}105 . \\
5\end{array}$ & $\begin{array}{c}107 . \\
8\end{array}$ & 4 & $\begin{array}{c}26 . \\
5\end{array}$ & $\begin{array}{c}77 . \\
1\end{array}$ & $\begin{array}{c}98 . \\
38\end{array}$ & 6 & $\begin{array}{c}41.1 \\
9\end{array}$ \\
\hline $\begin{array}{c}\text { V166A- } \\
0260- \\
0493-405\end{array}$ & $\begin{array}{l}\text { VNS- } \\
\text { A5 }\end{array}$ & $\begin{array}{c}0.26 \\
0\end{array}$ & $\begin{array}{c}0.49 \\
3 \\
\end{array}$ & 105 & $\begin{array}{c}106 . \\
5\end{array}$ & 4.4 & 30 & $\begin{array}{c}79 . \\
2\end{array}$ & $\begin{array}{l}98 . \\
55\end{array}$ & 4 & $\begin{array}{c}43.7 \\
8\end{array}$ \\
\hline $\begin{array}{c}\text { V166A- } \\
0260- \\
0616-405\end{array}$ & $\begin{array}{l}\text { VNS- } \\
\text { A6 }\end{array}$ & $\begin{array}{c}0.26 \\
0\end{array}$ & $\begin{array}{c}0.61 \\
6\end{array}$ & $\begin{array}{c}102 . \\
2\end{array}$ & $\begin{array}{c}104 . \\
9\end{array}$ & 4.6 & 32 & $\begin{array}{c}79 . \\
9\end{array}$ & $\begin{array}{l}97 . \\
76\end{array}$ & 4 & $\begin{array}{c}44.3 \\
2\end{array}$ \\
\hline $\begin{array}{c}\text { V166A- } \\
0260- \\
0739-405\end{array}$ & $\begin{array}{c}\text { VNS- } \\
\text { A7 }\end{array}$ & $\begin{array}{c}0.26 \\
0\end{array}$ & $\begin{array}{c}0.73 \\
9\end{array}$ & $\begin{array}{c}102 . \\
1\end{array}$ & $\begin{array}{c}102 . \\
6\end{array}$ & 5.3 & $\begin{array}{c}36 . \\
1\end{array}$ & $\begin{array}{c}78 . \\
3\end{array}$ & $\begin{array}{c}96 . \\
31\end{array}$ & 4 & $\begin{array}{c}44.9 \\
3\end{array}$ \\
\hline $\begin{array}{c}\text { V166A- } \\
0260- \\
0862-405\end{array}$ & $\begin{array}{c}\text { VNS- } \\
\text { A8 }\end{array}$ & $\begin{array}{c}0.26 \\
0\end{array}$ & $\begin{array}{c}0.86 \\
2 \\
\end{array}$ & $\begin{array}{c}101 . \\
8\end{array}$ & $\begin{array}{c}103 . \\
8\end{array}$ & 4.9 & $\begin{array}{c}35 . \\
6\end{array}$ & $\begin{array}{c}79 . \\
8\end{array}$ & $\begin{array}{l}95 . \\
58\end{array}$ & 4 & $\begin{array}{c}46.0 \\
3 \\
\end{array}$ \\
\hline $\begin{array}{c}\text { V166A- } \\
0260- \\
0985-405\end{array}$ & $\begin{array}{l}\text { VNS- } \\
\text { A9 }\end{array}$ & $\begin{array}{c}0.26 \\
0 \\
\end{array}$ & $\begin{array}{c}0.98 \\
5 \\
\end{array}$ & 92.5 & 95.8 & 5.7 & $\begin{array}{c}38 . \\
6 \\
\end{array}$ & $\begin{array}{c}78 . \\
8 \\
\end{array}$ & $\begin{array}{l}96 . \\
50 \\
\end{array}$ & 4 & $\begin{array}{c}46.5 \\
2 \\
\end{array}$ \\
\hline $\begin{array}{c}\text { V166A- } \\
0260- \\
1109-405\end{array}$ & $\begin{array}{l}\text { VNS- } \\
\text { A10 }\end{array}$ & $\begin{array}{c}0.26 \\
0\end{array}$ & $\begin{array}{c}1.10 \\
9 \\
\end{array}$ & 89.2 & 91.3 & 5.7 & $\begin{array}{c}38 . \\
9\end{array}$ & 82 & $\begin{array}{l}94 . \\
79\end{array}$ & 4 & $\begin{array}{c}44.1 \\
0 \\
\end{array}$ \\
\hline $\begin{array}{c}\text { V166A- } \\
0260- \\
1232-405\end{array}$ & $\begin{array}{l}\text { VNS- } \\
\text { A11 }\end{array}$ & $\begin{array}{c}0.26 \\
0\end{array}$ & $\begin{array}{c}1.23 \\
2\end{array}$ & 86.1 & 87.8 & 5.8 & $\begin{array}{c}38 . \\
7\end{array}$ & $\begin{array}{c}82 . \\
2\end{array}$ & $\begin{array}{l}95 . \\
48\end{array}$ & 4 & $\begin{array}{c}44.6 \\
6\end{array}$ \\
\hline $\begin{array}{c}\text { V166A- } \\
0260- \\
1355-405\end{array}$ & $\begin{array}{l}\text { VNS- } \\
\text { A12 }\end{array}$ & $\begin{array}{c}0.26 \\
0\end{array}$ & $\begin{array}{c}1.35 \\
5\end{array}$ & 81.5 & 83.8 & 5.3 & $\begin{array}{c}36 . \\
8\end{array}$ & $\begin{array}{c}82 . \\
7\end{array}$ & $\begin{array}{l}95 . \\
51\end{array}$ & 0 & $\begin{array}{c}43.6 \\
0\end{array}$ \\
\hline $\begin{array}{c}\text { V166A- } \\
\text { 0260- }\end{array}$ & $\begin{array}{l}\text { VNS- } \\
\text { A13 }\end{array}$ & $\begin{array}{c}0.26 \\
0\end{array}$ & $\begin{array}{c}1.47 \\
8\end{array}$ & 78.2 & 80.1 & 6.1 & $\begin{array}{c}38 . \\
9\end{array}$ & $\begin{array}{c}82 . \\
8\end{array}$ & $\begin{array}{l}95 . \\
38\end{array}$ & 0 & $\begin{array}{c}44.5 \\
0\end{array}$ \\
\hline
\end{tabular}




\begin{tabular}{|c|c|c|c|c|c|c|c|c|c|c|c|}
\hline $1478-405$ & & & & & & & & & & & \\
\hline $\begin{array}{c}\text { V166A- } \\
0260- \\
1601-405\end{array}$ & $\begin{array}{c}\text { VNS- } \\
\text { A14 }\end{array}$ & $\begin{array}{c}0.26 \\
0 \\
\end{array}$ & $\begin{array}{c}1.60 \\
1 \\
\end{array}$ & 73.8 & 76.2 & 4.4 & $\begin{array}{c}32 . \\
8 \\
\end{array}$ & $\begin{array}{c}81 . \\
4 \\
\end{array}$ & $\begin{array}{c}95 . \\
44 \\
\end{array}$ & 0 & $\begin{array}{c}45.7 \\
4 \\
\end{array}$ \\
\hline $\begin{array}{c}\text { V166A- } \\
\text { 0260- } \\
1724-405\end{array}$ & $\begin{array}{l}\text { VNS- } \\
\text { A15 }\end{array}$ & $\begin{array}{c}0.26 \\
0\end{array}$ & $\begin{array}{c}1.72 \\
4\end{array}$ & 71.2 & 73.8 & 4.8 & $\begin{array}{c}34 . \\
6\end{array}$ & $\begin{array}{c}82 . \\
9\end{array}$ & $\begin{array}{l}95 . \\
67\end{array}$ & 0 & $\begin{array}{c}41.5 \\
8\end{array}$ \\
\hline $\begin{array}{c}\text { V166A- } \\
\text { 0260- } \\
0000-405\end{array}$ & $\begin{array}{c}\text { VNS- } \\
\text { A16 }\end{array}$ & $\begin{array}{c}0.26 \\
0\end{array}$ & $\begin{array}{c}0.00 \\
0\end{array}$ & $\begin{array}{c}106 . \\
2\end{array}$ & $\begin{array}{c}106 . \\
9\end{array}$ & 2.6 & 21 & $\begin{array}{c}67 . \\
5\end{array}$ & $\begin{array}{l}97 . \\
30\end{array}$ & 6 & $\begin{array}{c}38.3 \\
4\end{array}$ \\
\hline $\begin{array}{c}\text { V166A- } \\
\text { 0260- } \\
1724-405\end{array}$ & $\begin{array}{c}\text { VNS- } \\
\text { A17 }\end{array}$ & $\begin{array}{c}0.26 \\
0\end{array}$ & $\begin{array}{c}1.72 \\
4\end{array}$ & 73.2 & 73 & $\begin{array}{c}13 . \\
2\end{array}$ & $\begin{array}{c}54 . \\
3\end{array}$ & 91 & $\begin{array}{l}96 . \\
23\end{array}$ & 0 & $\begin{array}{c}41.1 \\
2\end{array}$ \\
\hline $\begin{array}{c}\text { V166A- } \\
\text { 0260- } \\
1971-405\end{array}$ & $\begin{array}{c}\text { VNS- } \\
\text { A18 }\end{array}$ & $\begin{array}{c}0.26 \\
0\end{array}$ & $\begin{array}{c}1.97 \\
1\end{array}$ & 68.1 & 67.9 & 8.8 & $\begin{array}{c}48 . \\
6\end{array}$ & $\begin{array}{c}84 . \\
1\end{array}$ & $\begin{array}{l}94 . \\
98\end{array}$ & 0 & $\begin{array}{c}39.7 \\
2\end{array}$ \\
\hline $\begin{array}{c}\text { V166A- } \\
\text { 0260- } \\
2463-405\end{array}$ & $\begin{array}{c}\text { VNS- } \\
\text { A19 }\end{array}$ & $\begin{array}{c}0.26 \\
0\end{array}$ & $\begin{array}{c}2.46 \\
3\end{array}$ & 61.4 & 61.1 & $\begin{array}{c}15 . \\
6\end{array}$ & $\begin{array}{c}56 . \\
2\end{array}$ & $\begin{array}{c}91 . \\
8\end{array}$ & $\begin{array}{l}96 . \\
54\end{array}$ & 0 & $\begin{array}{c}39.8 \\
0\end{array}$ \\
\hline $\begin{array}{c}\text { V166A- } \\
\text { 0260- } \\
2956-405\end{array}$ & $\begin{array}{c}\text { VNS- } \\
\text { A20 }\end{array}$ & $\begin{array}{c}0.26 \\
0 \\
\end{array}$ & $\begin{array}{c}2.95 \\
6 \\
\end{array}$ & 57.8 & 57.3 & $\begin{array}{c}11 . \\
1 \\
\end{array}$ & $\begin{array}{c}49 . \\
7 \\
\end{array}$ & 88 & $\begin{array}{c}95 . \\
47 \\
\end{array}$ & 0 & $\begin{array}{c}36.2 \\
3 \\
\end{array}$ \\
\hline $\begin{array}{c}\text { V166A- } \\
\text { 0260- } \\
3449-405\end{array}$ & $\begin{array}{l}\text { VNS- } \\
\text { A21 }\end{array}$ & $\begin{array}{c}0.26 \\
0 \\
\end{array}$ & $\begin{array}{c}3.44 \\
9 \\
\end{array}$ & 55.9 & 55.8 & $\begin{array}{c}13 . \\
7 \\
\end{array}$ & $\begin{array}{c}53 . \\
7 \\
\end{array}$ & $\begin{array}{c}90 . \\
7 \\
\end{array}$ & $\begin{array}{c}95 . \\
50\end{array}$ & 0 & $\begin{array}{c}36.9 \\
5\end{array}$ \\
\hline $\begin{array}{c}\text { V166A- } \\
\text { 260-3941- } \\
405\end{array}$ & $\begin{array}{c}\text { VNS- } \\
\text { A22 }\end{array}$ & $\begin{array}{c}0.26 \\
0\end{array}$ & $\begin{array}{c}3.94 \\
1\end{array}$ & 55 & 57.8 & $\begin{array}{c}17 . \\
3\end{array}$ & 58 & 92 & $\begin{array}{l}95 . \\
99\end{array}$ & 0 & $\begin{array}{c}36.4 \\
2\end{array}$ \\
\hline $\begin{array}{c}\text { V166A- } \\
\text { 0260- } \\
0000-405\end{array}$ & $\begin{array}{c}\text { VNS- } \\
\text { A23 }\end{array}$ & $\begin{array}{c}0.26 \\
0\end{array}$ & $\begin{array}{c}0.00 \\
0\end{array}$ & $\begin{array}{c}107 . \\
8\end{array}$ & $\begin{array}{c}110 . \\
8\end{array}$ & 3.5 & $\begin{array}{c}22 . \\
3\end{array}$ & 69 & $\begin{array}{l}97 . \\
77\end{array}$ & 6 & $\begin{array}{c}41.0 \\
5\end{array}$ \\
\hline $\begin{array}{c}\text { V166A- } \\
\text { 0612- } \\
0000-405\end{array}$ & $\begin{array}{l}\text { VNS- } \\
\text { A24 }\end{array}$ & $\begin{array}{c}0.61 \\
2 \\
\end{array}$ & $\begin{array}{c}0.00 \\
0 \\
\end{array}$ & $\begin{array}{c}106 . \\
3\end{array}$ & 117 & 6.1 & $\begin{array}{c}41 . \\
6\end{array}$ & $\begin{array}{c}84 . \\
6\end{array}$ & $\begin{array}{c}95 . \\
80\end{array}$ & 6 & $\begin{array}{c}42.2 \\
7\end{array}$ \\
\hline $\begin{array}{c}\text { V166A- } \\
\text { 0964- } \\
0000-405\end{array}$ & $\begin{array}{c}\text { VNS- } \\
\text { A25 }\end{array}$ & $\begin{array}{c}0.96 \\
4\end{array}$ & $\begin{array}{c}0.00 \\
0\end{array}$ & $\begin{array}{c}101 . \\
8\end{array}$ & $\begin{array}{c}106 . \\
2\end{array}$ & $\begin{array}{c}22 . \\
1\end{array}$ & $\begin{array}{c}65 . \\
7 \\
\end{array}$ & $\begin{array}{c}92 . \\
7\end{array}$ & $\begin{array}{l}97 . \\
71 \\
\end{array}$ & 6 & $\begin{array}{c}42.2 \\
2 \\
\end{array}$ \\
\hline $\begin{array}{c}\text { V166A- } \\
1316- \\
0000-405\end{array}$ & $\begin{array}{l}\text { VNS- } \\
\text { A26 }\end{array}$ & $\begin{array}{c}1.31 \\
6 \\
\end{array}$ & $\begin{array}{c}0.00 \\
0 \\
\end{array}$ & 98.5 & $\begin{array}{c}103 . \\
8\end{array}$ & $\begin{array}{c}29 . \\
1\end{array}$ & $\begin{array}{c}70 . \\
5 \\
\end{array}$ & $\begin{array}{c}93 . \\
7 \\
\end{array}$ & $\begin{array}{c}98 . \\
08 \\
\end{array}$ & 8 & $\begin{array}{c}35.7 \\
3 \\
\end{array}$ \\
\hline $\begin{array}{c}\text { V166A- } \\
1668- \\
0000-405\end{array}$ & $\begin{array}{l}\text { VNS- } \\
\text { A27 }\end{array}$ & $\begin{array}{c}1.66 \\
8 \\
\end{array}$ & $\begin{array}{c}0.00 \\
0 \\
\end{array}$ & 95.6 & $\begin{array}{c}102 . \\
2\end{array}$ & $\begin{array}{c}30 . \\
9\end{array}$ & $\begin{array}{c}70 . \\
6 \\
\end{array}$ & $\begin{array}{c}93 . \\
3\end{array}$ & $\begin{array}{l}97 . \\
89\end{array}$ & 8 & $\begin{array}{c}30.6 \\
0\end{array}$ \\
\hline $\begin{array}{c}\text { V166A- } \\
2020- \\
0000-405\end{array}$ & $\begin{array}{c}\text { VNS- } \\
\text { A28 }\end{array}$ & $\begin{array}{c}2.02 \\
0\end{array}$ & $\begin{array}{c}0.00 \\
0\end{array}$ & 94 & 101 & $\begin{array}{c}31 . \\
4\end{array}$ & $\begin{array}{c}70 . \\
9\end{array}$ & $\begin{array}{c}93 . \\
6\end{array}$ & $\begin{array}{l}97 . \\
67\end{array}$ & 8 & $\begin{array}{c}28.5 \\
6\end{array}$ \\
\hline $\begin{array}{c}\text { V166A- } \\
2371- \\
0000-405\end{array}$ & $\begin{array}{c}\text { VNS- } \\
\text { A29 }\end{array}$ & $\begin{array}{c}2.37 \\
1\end{array}$ & $\begin{array}{c}0.00 \\
0\end{array}$ & 91 & $\begin{array}{c}100 . \\
2\end{array}$ & $\begin{array}{c}29 . \\
4\end{array}$ & $\begin{array}{c}69 . \\
8\end{array}$ & $\begin{array}{c}91 . \\
8\end{array}$ & $\begin{array}{l}97 . \\
65 \\
\end{array}$ & 8 & $\begin{array}{c}27.4 \\
1\end{array}$ \\
\hline V166A- & VNS- & 0.26 & 0.00 & 116. & 119. & 4.5 & 30. & 81. & 98. & 6 & 40.3 \\
\hline
\end{tabular}




\begin{tabular}{|c|c|c|c|c|c|c|c|c|c|c|c|}
\hline $\begin{array}{c}0260- \\
0000-405\end{array}$ & A30 & 0 & 0 & 1 & 8 & & 6 & 2 & 64 & & 1 \\
\hline $\begin{array}{c}\text { V166A- } \\
\text { 0612- } \\
0246-405\end{array}$ & $\begin{array}{l}\text { VNS- } \\
\text { A31 }\end{array}$ & $\begin{array}{c}0.61 \\
2 \\
\end{array}$ & $\begin{array}{c}0.24 \\
6 \\
\end{array}$ & $\begin{array}{c}110 . \\
7\end{array}$ & $\begin{array}{c}121 . \\
8\end{array}$ & 8.6 & $\begin{array}{c}48 . \\
5\end{array}$ & $\begin{array}{c}87 . \\
4 \\
\end{array}$ & $\begin{array}{l}98 . \\
21\end{array}$ & 6 & $\begin{array}{c}47.3 \\
8 \\
\end{array}$ \\
\hline $\begin{array}{c}\text { V166A- } \\
\text { 0964- } \\
0493-405\end{array}$ & $\begin{array}{l}\text { VNS- } \\
\text { A32 }\end{array}$ & $\begin{array}{c}0.96 \\
4 \\
\end{array}$ & $\begin{array}{c}0.49 \\
3 \\
\end{array}$ & 97.9 & $\begin{array}{c}107 . \\
9 \\
\end{array}$ & $\begin{array}{c}25 . \\
3\end{array}$ & $\begin{array}{c}67 . \\
7 \\
\end{array}$ & $\begin{array}{c}94 . \\
3\end{array}$ & $\begin{array}{c}99 . \\
10 \\
\end{array}$ & 6 & $\begin{array}{c}43.1 \\
3 \\
\end{array}$ \\
\hline $\begin{array}{c}\text { V166A- } \\
1316- \\
0739-405\end{array}$ & $\begin{array}{l}\text { VNS- } \\
\text { A33 }\end{array}$ & $\begin{array}{c}1.31 \\
6 \\
\end{array}$ & $\begin{array}{c}0.73 \\
9 \\
\end{array}$ & 90.9 & 99.2 & $\begin{array}{c}25 . \\
7\end{array}$ & $\begin{array}{c}66 . \\
5\end{array}$ & $\begin{array}{c}93 . \\
4\end{array}$ & $\begin{array}{l}98 . \\
51\end{array}$ & 4 & $\begin{array}{c}36.0 \\
8\end{array}$ \\
\hline $\begin{array}{c}\text { V166A- } \\
1668- \\
0985-405\end{array}$ & $\begin{array}{l}\text { VNS- } \\
\text { A34 }\end{array}$ & $\begin{array}{c}1.66 \\
8 \\
\end{array}$ & $\begin{array}{c}0.98 \\
5 \\
\end{array}$ & 82.2 & 91.8 & 22 & $\begin{array}{c}62 . \\
6 \\
\end{array}$ & 94 & $\begin{array}{c}98 . \\
12 \\
\end{array}$ & 4 & $\begin{array}{c}35.8 \\
6 \\
\end{array}$ \\
\hline $\begin{array}{c}\text { V166A- } \\
2020- \\
1232-405\end{array}$ & $\begin{array}{l}\text { VNS- } \\
\text { A35 }\end{array}$ & $\begin{array}{c}2.02 \\
0 \\
\end{array}$ & $\begin{array}{c}1.23 \\
2 \\
\end{array}$ & 77.2 & 88 & $\begin{array}{c}20 . \\
3\end{array}$ & $\begin{array}{c}60 . \\
6 \\
\end{array}$ & 94 & $\begin{array}{l}97 . \\
73 \\
\end{array}$ & 4 & $\begin{array}{c}36.5 \\
8 \\
\end{array}$ \\
\hline $\begin{array}{c}\text { V166A- } \\
2371- \\
1478-405\end{array}$ & $\begin{array}{l}\text { VNS- } \\
\text { A36 }\end{array}$ & $\begin{array}{c}2.37 \\
1\end{array}$ & $\begin{array}{c}1.47 \\
8\end{array}$ & 77.4 & 85 & $\begin{array}{c}16 . \\
9\end{array}$ & $\begin{array}{c}56 . \\
6\end{array}$ & $\begin{array}{c}93 . \\
5\end{array}$ & $\begin{array}{l}97 . \\
55\end{array}$ & 4 & $\begin{array}{c}35.1 \\
7\end{array}$ \\
\hline $\begin{array}{c}\text { V166A- } \\
\text { 0260- } \\
0000-405\end{array}$ & $\begin{array}{l}\text { VNS- } \\
\text { A37 }\end{array}$ & $\begin{array}{c}0.26 \\
0 \\
\end{array}$ & $\begin{array}{c}0.00 \\
0 \\
\end{array}$ & $\begin{array}{c}108 . \\
2\end{array}$ & $\begin{array}{c}108 . \\
6\end{array}$ & 2.8 & $\begin{array}{c}17 . \\
2 \\
\end{array}$ & $\begin{array}{c}59 . \\
2\end{array}$ & $\begin{array}{l}97 . \\
92\end{array}$ & - & $\begin{array}{c}40.6 \\
3 \\
\end{array}$ \\
\hline $\begin{array}{c}\text { V166A- } \\
0600- \\
1000-405\end{array}$ & $\begin{array}{l}\text { VNS- } \\
\text { A38 }\end{array}$ & $\begin{array}{c}0.60 \\
0 \\
\end{array}$ & $\begin{array}{c}1.00 \\
0 \\
\end{array}$ & 87.2 & 89.4 & 5 & $\begin{array}{c}36 . \\
7\end{array}$ & $\begin{array}{c}83 . \\
6 \\
\end{array}$ & $\begin{array}{l}94 . \\
93\end{array}$ & - & $\begin{array}{c}42.3 \\
2\end{array}$ \\
\hline $\begin{array}{c}\text { V166A- } \\
1000- \\
1000-405\end{array}$ & $\begin{array}{l}\text { VNS- } \\
\text { A39 }\end{array}$ & $\begin{array}{c}1.00 \\
0\end{array}$ & $\begin{array}{c}1.00 \\
0\end{array}$ & 81.8 & 84.8 & 9.2 & $\begin{array}{c}50 . \\
3\end{array}$ & $\begin{array}{c}85 . \\
2\end{array}$ & $\begin{array}{l}97 . \\
98\end{array}$ & - & $\begin{array}{c}41.4 \\
9 \\
\end{array}$ \\
\hline $\begin{array}{c}\text { V166A- } \\
1400- \\
1000-405\end{array}$ & $\begin{array}{l}\text { VNS- } \\
\text { A40 }\end{array}$ & $\begin{array}{c}1.40 \\
0\end{array}$ & $\begin{array}{c}1.00 \\
0\end{array}$ & 77.6 & 80.8 & $\begin{array}{c}17 . \\
3\end{array}$ & $\begin{array}{c}57 . \\
8\end{array}$ & $\begin{array}{c}91 . \\
6\end{array}$ & $\begin{array}{l}96 . \\
94\end{array}$ & - & $\begin{array}{c}38.0 \\
3\end{array}$ \\
\hline $\begin{array}{c}\text { V166A- } \\
\text { 0600- } \\
0500-405\end{array}$ & $\begin{array}{l}\text { VNS- } \\
\text { A41 }\end{array}$ & $\begin{array}{c}0.60 \\
0\end{array}$ & $\begin{array}{c}0.50 \\
0 \\
\end{array}$ & $\begin{array}{c}100 . \\
5\end{array}$ & $\begin{array}{c}108 . \\
7\end{array}$ & 9.1 & $\begin{array}{c}49 . \\
7\end{array}$ & $\begin{array}{c}87 . \\
4\end{array}$ & $\begin{array}{l}94 . \\
20\end{array}$ & - & $\begin{array}{c}43.8 \\
8\end{array}$ \\
\hline $\begin{array}{c}\text { V166A- } \\
\text { 0600- } \\
0750-405\end{array}$ & $\begin{array}{l}\text { VNS- } \\
\text { A42 }\end{array}$ & $\begin{array}{c}0.60 \\
0\end{array}$ & $\begin{array}{c}0.75 \\
0\end{array}$ & 93.7 & 96.4 & 7.7 & $\begin{array}{c}46 . \\
3\end{array}$ & $\begin{array}{c}86 . \\
1\end{array}$ & $\begin{array}{l}96 . \\
29\end{array}$ & - & $\begin{array}{c}46.8 \\
9\end{array}$ \\
\hline $\begin{array}{c}\text { V166A- } \\
0600- \\
1300-405\end{array}$ & $\begin{array}{l}\text { VNS- } \\
\text { A43 }\end{array}$ & $\begin{array}{c}0.60 \\
0\end{array}$ & $\begin{array}{c}1.30 \\
0\end{array}$ & 77.6 & 82 & 6.1 & $\begin{array}{c}40 . \\
4\end{array}$ & $\begin{array}{c}86 . \\
1\end{array}$ & $\begin{array}{l}95 . \\
40\end{array}$ & - & $\begin{array}{c}40.1 \\
9 \\
\end{array}$ \\
\hline $\begin{array}{c}\text { V166A- } \\
2000- \\
0750-405\end{array}$ & $\begin{array}{l}\text { VNS- } \\
\text { A44 }\end{array}$ & $\begin{array}{c}2.00 \\
0\end{array}$ & $\begin{array}{c}0.75 \\
0\end{array}$ & 81 & 85.1 & $\begin{array}{c}24 . \\
6\end{array}$ & $\begin{array}{c}65 . \\
2\end{array}$ & $\begin{array}{c}93 . \\
9\end{array}$ & $\begin{array}{c}98 . \\
34\end{array}$ & - & $\begin{array}{c}38.8 \\
2\end{array}$ \\
\hline $\begin{array}{c}\text { V166A- } \\
2000- \\
1000-405\end{array}$ & $\begin{array}{l}\text { VNS- } \\
\text { A45 }\end{array}$ & $\begin{array}{c}2.00 \\
0 \\
\end{array}$ & $\begin{array}{c}1.00 \\
0\end{array}$ & 74 & 81 & 20 & $\begin{array}{c}61 . \\
3\end{array}$ & $\begin{array}{c}93 . \\
3\end{array}$ & $\begin{array}{l}97 . \\
88\end{array}$ & - & $\begin{array}{c}39.6 \\
2\end{array}$ \\
\hline $\begin{array}{c}\text { V166A- } \\
2400- \\
0750-405\end{array}$ & $\begin{array}{l}\text { VNS- } \\
\text { A46 }\end{array}$ & $\begin{array}{c}2.40 \\
0\end{array}$ & $\begin{array}{c}0.75 \\
0\end{array}$ & 78.4 & 83.8 & $\begin{array}{c}24 . \\
5\end{array}$ & $\begin{array}{c}65 . \\
7 \\
\end{array}$ & $\begin{array}{c}93 . \\
7\end{array}$ & $\begin{array}{c}96 . \\
59\end{array}$ & - & $\begin{array}{c}33.2 \\
8\end{array}$ \\
\hline
\end{tabular}




\begin{tabular}{|c|c|c|c|c|c|c|c|c|c|c|c|} 
V166A- & VNS- & 0.26 & 0.00 & 109. & & & 15. & 58. & 97. & & 38.6 \\
$0260-$ & A47 & 0 & 0 & 3 & 111 & 2.6 & 9 & 3 & 01 & - & 7 \\
$0000-405$ & & 0
\end{tabular}

VAS 166 A series physical property data.

\begin{tabular}{|c|c|c|c|c|c|c|c|c|c|c|}
\hline \multirow[t]{2}{*}{ Sample } & \multirow{2}{*}{$\begin{array}{c}\text { Call } \\
\text { Name }\end{array}$} & \multirow{2}{*}{$\begin{array}{c}\% \\
\text { HEUR }\end{array}$} & \multirow{2}{*}{$\begin{array}{l}\% \\
\text { Surf }\end{array}$} & \multicolumn{2}{|c|}{$\mathrm{KU}$} & \multicolumn{3}{|c|}{ Gloss } & \multirow[t]{2}{*}{ CR } & \multirow[t]{2}{*}{ IRBS } \\
\hline & & & & initial & $24 \mathrm{hr}$ & $20^{\prime}$ & $60^{\prime}$ & $85^{\prime}$ & & \\
\hline $\begin{array}{c}\text { V166A- } \\
0260-0000- \\
411\end{array}$ & $\begin{array}{c}\text { VAS- } \\
\text { A1 }\end{array}$ & 0.260 & 0.00 & 107.8 & 110.8 & 3.5 & 22.3 & 69 & 97.77 & 41.05 \\
\hline $\begin{array}{c}\text { V166A- } \\
0612-0000- \\
411\end{array}$ & $\begin{array}{c}\text { VAS- } \\
\text { A2 }\end{array}$ & 0.612 & 0.00 & 106.3 & 117 & 6.1 & 41.6 & 84.6 & 95.80 & 42.27 \\
\hline $\begin{array}{c}\text { V166A- } \\
0964-0000- \\
411\end{array}$ & $\begin{array}{c}\text { VAS- } \\
\text { A3 }\end{array}$ & 0.964 & 0.00 & 101.8 & 106.2 & 22.1 & 65.7 & 92.7 & 97.71 & 42.22 \\
\hline $\begin{array}{c}\text { V166A- } \\
1316-0000- \\
411\end{array}$ & $\begin{array}{c}\text { VAS- } \\
\text { A4 }\end{array}$ & 1.316 & 0.00 & 98.5 & 103.8 & 29.1 & 70.5 & 93.7 & 98.08 & 35.73 \\
\hline $\begin{array}{c}\text { V166A- } \\
1668-0000- \\
411\end{array}$ & $\begin{array}{c}\text { VAS- } \\
\text { A5 }\end{array}$ & 1.668 & 0.00 & 95.6 & 102.2 & 30.9 & 70.6 & 93.3 & 97.89 & 30.60 \\
\hline $\begin{array}{c}\text { V166A- } \\
2020-0000- \\
411\end{array}$ & $\begin{array}{c}\text { VAS- } \\
\text { A6 }\end{array}$ & 2.020 & 0.00 & 94 & 101 & 31.4 & 70.9 & 93.6 & 97.67 & 28.56 \\
\hline $\begin{array}{c}\text { V166A- } \\
2371-0000- \\
411\end{array}$ & $\begin{array}{c}\text { VAS- } \\
\text { A7 }\end{array}$ & 371 & 00 & 91 & 100.2 & 29.4 & 69.8 & 91.8 & 97.65 & 27.41 \\
\hline $\begin{array}{c}\text { V166A- } \\
0260-0000- \\
411\end{array}$ & $\begin{array}{c}\text { VAS- } \\
\text { A8 }\end{array}$ & 0.26 & $\begin{array}{c}0.00 \\
0\end{array}$ & 104.4 & 108 & 2.9 & 18.6 & 65.7 & 4.52 & 40.56 \\
\hline $\begin{array}{c}\text { V166A- } \\
0260-0412- \\
411\end{array}$ & $\begin{array}{c}\text { VAS- } \\
\text { A9 }\end{array}$ & 0.26 & $\begin{array}{c}0.41 \\
2 \\
\end{array}$ & 108.6 & 112.8 & 10.9 & 51.9 & 86.9 & 96.77 & 43.76 \\
\hline $\begin{array}{c}\text { V166A- } \\
0260-0825- \\
411\end{array}$ & $\begin{array}{l}\text { VAS- } \\
\text { A10 }\end{array}$ & 26 & $\begin{array}{c}0.82 \\
5\end{array}$ & 86.6 & 95.5 & 18 & 62.1 & 88.7 & 94.44 & 49.58 \\
\hline $\begin{array}{c}\text { V166A- } \\
0260-1237- \\
411\end{array}$ & VAS- & 0.26 & $\begin{array}{c}1.23 \\
7\end{array}$ & 57.8 & 66.1 & 14.1 & 53.4 & 85.5 & 95.63 & 45.81 \\
\hline $\begin{array}{c}\text { V166A- } \\
0260-1650- \\
411\end{array}$ & $\begin{array}{l}\text { VAS- } \\
\text { A12 }\end{array}$ & 0.26 & $\begin{array}{c}1.65 \\
0\end{array}$ & 55 & 53.6 & 9.8 & 46.3 & 82.5 & 93.07 & 38.66 \\
\hline $\begin{array}{c}\text { V166A- } \\
0260-0206- \\
411\end{array}$ & $\begin{array}{l}\text { VAS- } \\
\text { A13 }\end{array}$ & 0.26 & $\begin{array}{c}0.20 \\
6 \\
\end{array}$ & 109.7 & 112.2 & 7.7 & 40.8 & 84.6 & 94.11 & 39.65 \\
\hline V166A- & VAS- & 0.26 & 0.61 & 97.1 & 106.2 & 13.9 & 58.4 & 80.5 & 90.75 & 46.39 \\
\hline
\end{tabular}




\begin{tabular}{|c|c|c|c|c|c|c|c|c|c|c|}
\hline $\begin{array}{c}0260-0619- \\
411\end{array}$ & A14 & & 9 & & & & & & & \\
\hline $\begin{array}{c}\text { V166A- } \\
\text { 0260-1031- } \\
411\end{array}$ & $\begin{array}{l}\text { VAS- } \\
\text { A15 }\end{array}$ & 0.26 & $\begin{array}{c}1.03 \\
1 \\
\end{array}$ & 69.9 & 82.3 & 12.6 & 51.7 & 84.1 & 94.51 & 47.33 \\
\hline $\begin{array}{c}\text { V166A- } \\
0260-0000- \\
411 \\
\end{array}$ & $\begin{array}{l}\text { VAS- } \\
\text { A16 }\end{array}$ & 0.260 & $\begin{array}{c}0.00 \\
0\end{array}$ & 106 & 107.1 & 2.3 & 14.4 & 58.2 & 98.29 & 42.36 \\
\hline $\begin{array}{c}\text { V166A- } \\
0612-0251- \\
411\end{array}$ & $\begin{array}{l}\text { VAS- } \\
\text { A17 }\end{array}$ & 0.612 & $\begin{array}{c}0.25 \\
1\end{array}$ & 103.4 & 114.6 & 6.9 & 44.5 & 85 & 94.14 & 44.33 \\
\hline $\begin{array}{c}\text { V166A- } \\
\text { 0964-0501- } \\
411\end{array}$ & $\begin{array}{l}\text { VAS- } \\
\text { A18 }\end{array}$ & 0.964 & $\begin{array}{c}0.50 \\
1\end{array}$ & 97.1 & 94.4 & 16.4 & 58.8 & 88.7 & 96.69 & 37.82 \\
\hline $\begin{array}{c}\text { V166A- } \\
\text { 0964-0501- } \\
411\end{array}$ & $\begin{array}{l}\text { VAS- } \\
\text { A19 }\end{array}$ & 1.316 & $\begin{array}{c}0.75 \\
2\end{array}$ & 73.8 & 83.8 & 16.6 & 57.2 & 89.6 & 97.43 & 39.35 \\
\hline $\begin{array}{c}\text { V166A- } \\
\text { 1668-1003- } \\
411\end{array}$ & $\begin{array}{l}\text { VAS- } \\
\text { A20 }\end{array}$ & 1.668 & $\begin{array}{c}1.00 \\
3\end{array}$ & 66.8 & 76.4 & 13.5 & 52.3 & 89.8 & 97.14 & 39.99 \\
\hline $\begin{array}{c}\text { V166A- } \\
0612-0501- \\
411\end{array}$ & $\begin{array}{l}\text { VAS- } \\
\text { A21 }\end{array}$ & 0.612 & $\begin{array}{c}0.50 \\
1\end{array}$ & 94.1 & 100.4 & 8.2 & 47 & 85.7 & 94.68 & 43.14 \\
\hline $\begin{array}{c}\text { V166A- } \\
0964-0752- \\
411\end{array}$ & $\begin{array}{l}\text { VAS- } \\
\text { A22 }\end{array}$ & 0.964 & $\begin{array}{c}0.75 \\
2\end{array}$ & 74.4 & 83.8 & 10.4 & 49 & 87.1 & 97.56 & 41.22 \\
\hline $\begin{array}{c}\text { V166A- } \\
\text { 1316-1003- } \\
411\end{array}$ & $\begin{array}{l}\text { VAS- } \\
\text { A23 }\end{array}$ & 1.316 & $\begin{array}{c}1.00 \\
3\end{array}$ & 66.6 & 75.4 & 11.5 & 49.6 & 87.7 & 95.37 & 37.10 \\
\hline $\begin{array}{c}\text { V166A- } \\
\text { 0260-0000- } \\
411\end{array}$ & $\begin{array}{l}\text { VAS- } \\
\text { A24 }\end{array}$ & 0.26 & $\begin{array}{c}0.00 \\
0\end{array}$ & 102 & 108.3 & 15.1 & 54.2 & 92.3 & 97.79 & 37.59 \\
\hline $\begin{array}{c}\text { V166A- } \\
0600-0700- \\
411\end{array}$ & $\begin{array}{l}\text { VAS- } \\
\text { A25 }\end{array}$ & 0.6 & $\begin{array}{c}0.70 \\
0\end{array}$ & 78 & 86.1 & 2.2 & 14.5 & 64.2 & 94.33 & 43.43 \\
\hline $\begin{array}{c}\text { V166A- } \\
0600-0900- \\
411\end{array}$ & $\begin{array}{l}\text { VAS- } \\
\text { A26 }\end{array}$ & 0.6 & $\begin{array}{c}0.90 \\
0\end{array}$ & 64.5 & 73.6 & 2.5 & 16.2 & 65.8 & 94.81 & 41.89 \\
\hline $\begin{array}{c}\text { V166A- } \\
\text { 0600-1100- } \\
411\end{array}$ & $\begin{array}{l}\text { VAS- } \\
\text { A27 }\end{array}$ & 0.6 & $\begin{array}{c}1.10 \\
0\end{array}$ & 55 & 60.4 & 5.2 & 33.7 & 81.2 & 94.15 & 36.85 \\
\hline $\begin{array}{c}\text { V166A- } \\
1316-0500- \\
411\end{array}$ & $\begin{array}{l}\text { VAS- } \\
\text { A28 }\end{array}$ & 1.316 & $\begin{array}{c}0.50 \\
0\end{array}$ & 80.1 & 87 & 12.7 & 51.3 & 92.9 & 98.21 & 37.78 \\
\hline $\begin{array}{c}\text { V166A- } \\
1668-0500- \\
411\end{array}$ & $\begin{array}{l}\text { VAS- } \\
\text { A29 }\end{array}$ & 1.668 & $\begin{array}{c}0.50 \\
0\end{array}$ & 76.8 & 84.4 & 19.7 & 60.1 & 94.1 & 97.23 & 33.13 \\
\hline $\begin{array}{c}\text { V166A- } \\
\text { 1668-0750- } \\
411\end{array}$ & $\begin{array}{l}\text { VAS- } \\
\text { A30 }\end{array}$ & 1.668 & $\begin{array}{c}0.75 \\
0\end{array}$ & 71.4 & 79 & 17.2 & 57.1 & 93.5 & 98.67 & 38.65 \\
\hline
\end{tabular}


\begin{tabular}{|c|c|c|c|c|c|c|c|c|c|c|} 
V166A- & & & & & & & & & & \\
0964-0250- & VAS- & & 0.25 & & & & & & & \\
411 & A31 & 0.964 & 0 & 92.6 & 97.3 & 10.9 & 52 & 92.8 & 98.37 & 43.98 \\
\hline
\end{tabular} VNS2 166A series physical property data.

\begin{tabular}{|c|c|c|c|c|c|c|c|c|c|c|}
\hline \multirow{2}{*}{ Sample } & \multirow{2}{*}{$\begin{array}{c}\text { Call } \\
\text { Name }\end{array}$} & \multirow{2}{*}{$\begin{array}{c}\% \\
\text { HEU } \\
\text { R }\end{array}$} & \multirow{2}{*}{$\begin{array}{l}\% \\
\text { Surf }\end{array}$} & \multicolumn{2}{|c|}{$\mathrm{KU}$} & \multicolumn{3}{|c|}{ Gloss } & \multirow{2}{*}{ CR } & \multirow{2}{*}{ IRBS } \\
\hline & & & & initial & $24 \mathrm{hr}$ & $20^{\prime}$ & $60^{\prime}$ & $85^{\prime}$ & & \\
\hline $\begin{array}{c}\text { V166A- } \\
0260- \\
0000-100\end{array}$ & $\begin{array}{c}\text { VNS2- } \\
\text { A1 }\end{array}$ & 0.26 & $\begin{array}{c}0.00 \\
0 \\
\end{array}$ & $\begin{array}{c}106 . \\
2\end{array}$ & $\begin{array}{c}109 . \\
5\end{array}$ & 3.4 & $\begin{array}{c}22 . \\
2\end{array}$ & $\begin{array}{c}67 . \\
7\end{array}$ & $\begin{array}{c}98.9 \\
2 \\
\end{array}$ & 43.44 \\
\hline $\begin{array}{c}\text { V166A- } \\
0260- \\
0352-100\end{array}$ & $\begin{array}{c}\text { VNS2- } \\
\text { A2 }\end{array}$ & 0.26 & $\begin{array}{c}0.35 \\
2\end{array}$ & 99.4 & $\begin{array}{c}102 . \\
7\end{array}$ & 3.8 & $\begin{array}{c}23 . \\
9\end{array}$ & $\begin{array}{c}72 . \\
1\end{array}$ & $\begin{array}{c}99.1 \\
9 \\
\end{array}$ & 46.86 \\
\hline $\begin{array}{c}\text { V166A- } \\
\text { 0260- } \\
0704-100\end{array}$ & $\begin{array}{c}\text { VNS2- } \\
\text { A3 }\end{array}$ & 0.26 & $\begin{array}{c}0.70 \\
4\end{array}$ & 97.3 & 100 & 6.1 & $\begin{array}{c}34 . \\
7\end{array}$ & 80 & $\begin{array}{c}99.0 \\
6\end{array}$ & 46.86 \\
\hline $\begin{array}{c}\text { V166A- } \\
0260- \\
1056-100\end{array}$ & $\begin{array}{c}\text { VNS2- } \\
\text { A4 }\end{array}$ & 0.26 & $\begin{array}{c}1.05 \\
6\end{array}$ & 87.8 & 94.6 & 5.7 & $\begin{array}{c}39 . \\
4\end{array}$ & $\begin{array}{c}79 . \\
3\end{array}$ & $\begin{array}{c}96.5 \\
9\end{array}$ & 46.59 \\
\hline $\begin{array}{c}\text { V166A- } \\
0260- \\
1408-100\end{array}$ & $\begin{array}{c}\text { VNS2- } \\
\text { A5 }\end{array}$ & 0.26 & $\begin{array}{c}1.40 \\
8 \\
\end{array}$ & 79 & 87.1 & 7.8 & $\begin{array}{c}45 . \\
3\end{array}$ & $\begin{array}{c}83 . \\
1\end{array}$ & $\begin{array}{c}97.2 \\
9 \\
\end{array}$ & 46.45 \\
\hline $\begin{array}{c}\text { V166A- } \\
0260- \\
1760-100\end{array}$ & $\begin{array}{c}\text { VNS2- } \\
\text { A6 }\end{array}$ & 0.26 & $\begin{array}{c}1.76 \\
0\end{array}$ & 71.2 & 79.3 & 8.7 & $\begin{array}{c}48 . \\
1\end{array}$ & $\begin{array}{c}76 . \\
3\end{array}$ & $\begin{array}{c}96.9 \\
5\end{array}$ & 42.85 \\
\hline $\begin{array}{c}\text { V166A- } \\
0260- \\
2111-100\end{array}$ & $\begin{array}{c}\text { VNS2- } \\
\text { A7 }\end{array}$ & 0.26 & $\begin{array}{c}2.11 \\
1\end{array}$ & 64 & 71.4 & $\begin{array}{c}10 . \\
7\end{array}$ & $\begin{array}{c}49 . \\
3\end{array}$ & $\begin{array}{c}88 . \\
2\end{array}$ & $\begin{array}{c}97.4 \\
2\end{array}$ & 42.17 \\
\hline $\begin{array}{c}\text { V166A- } \\
0260- \\
2463-100\end{array}$ & $\begin{array}{c}\text { VNS2- } \\
\text { A8 }\end{array}$ & 0.26 & $\begin{array}{c}2.46 \\
3\end{array}$ & 59.1 & 67 & $\begin{array}{c}13 . \\
9\end{array}$ & $\begin{array}{c}53 . \\
2\end{array}$ & $\begin{array}{c}88 . \\
7\end{array}$ & $\begin{array}{c}98.0 \\
2\end{array}$ & 42.17 \\
\hline $\begin{array}{c}\text { V166A- } \\
\text { 0260- } \\
0000-100\end{array}$ & $\begin{array}{c}\text { VNS2- } \\
\text { A9 }\end{array}$ & 0.260 & $\begin{array}{c}0.00 \\
0\end{array}$ & 112 & $\begin{array}{c}110 . \\
2\end{array}$ & 3.6 & $\begin{array}{c}22 . \\
8\end{array}$ & $\begin{array}{c}68 . \\
4\end{array}$ & $\begin{array}{c}98.3 \\
3\end{array}$ & $\begin{array}{c}43.88 \\
2\end{array}$ \\
\hline $\begin{array}{c}\text { V166A- } \\
\text { 0612- } \\
0352-100\end{array}$ & $\begin{array}{l}\text { VNS2- } \\
\text { A10 }\end{array}$ & 0.612 & $\begin{array}{c}0.35 \\
2\end{array}$ & $\begin{array}{c}102 . \\
7\end{array}$ & $\begin{array}{c}105 . \\
5\end{array}$ & 5.4 & $\begin{array}{c}38 . \\
5\end{array}$ & 81 & $\begin{array}{c}92.5 \\
0\end{array}$ & $\begin{array}{c}46.01 \\
8\end{array}$ \\
\hline $\begin{array}{c}\text { V166A- } \\
\text { 0964- } \\
0704-100\end{array}$ & $\begin{array}{c}\text { VNS2- } \\
\text { A11 }\end{array}$ & 0.964 & $\begin{array}{c}0.70 \\
4\end{array}$ & 88.9 & 88.2 & $\begin{array}{c}19 . \\
5\end{array}$ & $\begin{array}{c}60 . \\
9\end{array}$ & $\begin{array}{c}90 . \\
2\end{array}$ & $\begin{array}{c}95.5 \\
9\end{array}$ & $\begin{array}{c}37.66 \\
4\end{array}$ \\
\hline $\begin{array}{c}\text { V166A- } \\
1316- \\
0352-100\end{array}$ & $\begin{array}{l}\text { VNS2- } \\
\text { A12 }\end{array}$ & 1.316 & $\begin{array}{c}1.05 \\
6 \\
\end{array}$ & 79.3 & 79.3 & $\begin{array}{c}18 . \\
1\end{array}$ & $\begin{array}{c}57 . \\
7\end{array}$ & 89 & $\begin{array}{c}96.9 \\
8 \\
\end{array}$ & $\begin{array}{c}39.86 \\
1 \\
\end{array}$ \\
\hline $\begin{array}{c}\text { V166A- } \\
1668- \\
0352-100\end{array}$ & $\begin{array}{l}\text { VNS2- } \\
\text { A13 }\end{array}$ & 1.668 & $\begin{array}{c}1.40 \\
8\end{array}$ & 73.6 & 2.6 & $\begin{array}{c}18 . \\
4\end{array}$ & $\begin{array}{c}58 . \\
9\end{array}$ & $\begin{array}{c}86 . \\
9\end{array}$ & $\begin{array}{c}96.4 \\
9\end{array}$ & $\begin{array}{c}39.15 \\
4\end{array}$ \\
\hline $\begin{array}{c}\text { V166A- } \\
\text { 0612- } \\
0352-100\end{array}$ & $\begin{array}{l}\text { VNS2- } \\
\text { A14 }\end{array}$ & 0.612 & $\begin{array}{c}0.70 \\
4\end{array}$ & 95.2 & 94.5 & 5.9 & $\begin{array}{c}40 . \\
7\end{array}$ & $\begin{array}{c}83 . \\
5\end{array}$ & $\begin{array}{c}91.9 \\
6\end{array}$ & $\begin{array}{c}45.13 \\
8\end{array}$ \\
\hline
\end{tabular}




\begin{tabular}{|c|c|c|c|c|c|c|c|c|c|c|}
\hline $\begin{array}{c}\text { V166A- } \\
\text { 0964- } \\
0352-100\end{array}$ & $\begin{array}{c}\text { VNS2- } \\
\text { A15 }\end{array}$ & 0.964 & $\begin{array}{c}1.05 \\
6\end{array}$ & 79.9 & 79.9 & $\begin{array}{c}16 . \\
1\end{array}$ & $\begin{array}{c}56 . \\
8\end{array}$ & $\begin{array}{c}86 . \\
8\end{array}$ & $\begin{array}{c}96.5 \\
8\end{array}$ & $\begin{array}{c}39.00 \\
0\end{array}$ \\
\hline $\begin{array}{c}\text { V166A- } \\
1316- \\
0352-100\end{array}$ & $\begin{array}{c}\text { VNS2- } \\
\text { A16 }\end{array}$ & 1.316 & $\begin{array}{c}1.40 \\
8\end{array}$ & 73.4 & 73.4 & $\begin{array}{c}19 . \\
7\end{array}$ & $\begin{array}{c}59 . \\
6\end{array}$ & $\begin{array}{c}91 . \\
4\end{array}$ & $\begin{array}{c}96.1 \\
6\end{array}$ & $\begin{array}{c}40.49 \\
8\end{array}$ \\
\hline
\end{tabular}

Physical Property data for samples in the G-VNS 166A series.

\begin{tabular}{|c|c|c|c|c|c|c|c|c|c|}
\hline \multirow[b]{2}{*}{ Sample } & \multirow{2}{*}{$\begin{array}{l}\text { Call } \\
\text { Name }\end{array}$} & \multirow{2}{*}{$\begin{array}{c}\% \\
\text { HEU } \\
\mathrm{R}\end{array}$} & \multirow{2}{*}{$\begin{array}{l}\% \\
\text { SUR } \\
F\end{array}$} & \multicolumn{2}{|c|}{$\mathrm{KU}$} & \multicolumn{3}{|c|}{ Gloss } & \multirow[b]{2}{*}{ IRBS } \\
\hline & & & & initial & $24 \mathrm{hr}$ & $20^{\prime}$ & $60^{\prime}$ & $85^{\prime}$ & \\
\hline $\begin{array}{c}\text { G-V166A- } \\
0260-0000- \\
405\end{array}$ & $\begin{array}{c}\text { G- } \\
\text { VNS- } \\
\text { A1 }\end{array}$ & 0.26 & 0 & 109.1 & 110.6 & 3.8 & 25.4 & 75.2 & 40.36 \\
\hline $\begin{array}{c}\text { G-V166A- } \\
0260-0500- \\
405\end{array}$ & $\begin{array}{c}\text { G- } \\
\text { VNS- } \\
\text { A2 } \\
\end{array}$ & 0.26 & 0.5 & 107.9 & 109.2 & 7.1 & 41.3 & 84.4 & 43.17 \\
\hline $\begin{array}{c}\text { G-V166A- } \\
0260-1000- \\
405\end{array}$ & $\begin{array}{c}\text { G- } \\
\text { VNS- } \\
\text { A3 } \\
\end{array}$ & 0.26 & 1 & 96.8 & 97.6 & 7.1 & 42.8 & 78.1 & 45.76 \\
\hline $\begin{array}{c}\text { G-V166A- } \\
0260-1500- \\
405\end{array}$ & $\begin{array}{c}\text { G- } \\
\text { VNS- } \\
\text { A4 }\end{array}$ & 0.26 & 1.5 & 81.8 & 85 & 5.7 & 37.2 & 79.4 & 43.53 \\
\hline $\begin{array}{c}\text { G-V166A- } \\
0260-2000- \\
405\end{array}$ & $\begin{array}{c}\text { G- } \\
\text { VNS- } \\
\text { A5 }\end{array}$ & 0.26 & 2 & 67.7 & 70.5 & 7.7 & 42.2 & 85 & 41.72 \\
\hline $\begin{array}{c}\text { G-V166A- } \\
0750-0000- \\
405\end{array}$ & $\begin{array}{c}\text { G- } \\
\text { VNS- } \\
\text { A6 }\end{array}$ & 0.75 & 0 & 106.3 & 108.9 & 15.8 & 58.9 & 90.3 & 42.55 \\
\hline $\begin{array}{c}\text { G-V166A- } \\
0750-0500- \\
405\end{array}$ & $\begin{array}{c}\text { G- } \\
\text { VNS- } \\
\text { A7 }\end{array}$ & 0.75 & 0.5 & 101.2 & 104.2 & 19.1 & 61.6 & 90.7 & 40.06 \\
\hline $\begin{array}{c}\text { G-V166A- } \\
0750-1000- \\
405\end{array}$ & $\begin{array}{c}\text { G- } \\
\text { VNS- } \\
\text { A8 }\end{array}$ & 0.75 & 1 & 90.2 & 94.7 & 13 & 53.1 & 88.7 & 40.37 \\
\hline $\begin{array}{c}\text { G-V166A- } \\
0750-1500- \\
405\end{array}$ & $\begin{array}{c}\text { G- } \\
\text { VNS- } \\
\text { A9 }\end{array}$ & 0.75 & 1.5 & 78.6 & 83.2 & 10.3 & 48.7 & 87.2 & 41.45 \\
\hline $\begin{array}{c}\text { G-V166A- } \\
0750-2000- \\
405\end{array}$ & $\begin{array}{c}\text { G- } \\
\text { VNS- } \\
\text { A10 }\end{array}$ & 0.75 & 2 & 68.6 & 72.2 & 7.6 & 42.1 & 86.7 & 38.28 \\
\hline $\begin{array}{c}\text { G-V166A- } \\
1250-0000- \\
405\end{array}$ & $\begin{array}{c}\text { G- } \\
\text { VNS- } \\
\text { A11 }\end{array}$ & 1.25 & 0 & 103.6 & 104.7 & 26.6 & 67.6 & 92.8 & 33.24 \\
\hline $\begin{array}{c}\text { G-V166A- } \\
1250-0500- \\
405\end{array}$ & $\begin{array}{c}\text { G- } \\
\text { VNS- } \\
\text { A12 } \\
\end{array}$ & 1.25 & 0.5 & 99.4 & 97.8 & 26 & 66.6 & 92.1 & 32.65 \\
\hline $\begin{array}{c}\text { G-V166A- } \\
1250-1000- \\
405\end{array}$ & $\begin{array}{c}\text { G- } \\
\text { VNS- } \\
\text { A13 }\end{array}$ & 1.25 & 1 & 88.2 & 87.1 & 17.9 & 57.9 & 91.2 & 36.52 \\
\hline
\end{tabular}




\begin{tabular}{|c|c|c|c|c|c|c|c|c|c|}
\hline $\begin{array}{c}\text { G-V166A- } \\
1250-1500- \\
405\end{array}$ & $\begin{array}{l}\text { G- } \\
\text { VNS- } \\
\text { A14 }\end{array}$ & 1.25 & 1.5 & 79.3 & 79.7 & 12.7 & 51.5 & 90.3 & 39.03 \\
\hline $\begin{array}{c}\text { G-V166A- } \\
1250-2000- \\
405\end{array}$ & $\begin{array}{c}\text { G- } \\
\text { VNS- } \\
\text { A15 }\end{array}$ & 1.25 & 2 & 72 & 71.6 & 15.3 & 54.9 & 90.9 & 38.03 \\
\hline $\begin{array}{c}\text { G-V166A- } \\
1750-0000- \\
405\end{array}$ & $\begin{array}{c}\text { G- } \\
\text { VNS- } \\
\text { A16 } \\
\end{array}$ & 1.75 & 0 & 99.8 & 100.2 & 26.8 & 67.4 & 92.4 & 27.29 \\
\hline $\begin{array}{c}\text { G-V166A- } \\
1750-0500- \\
405\end{array}$ & $\begin{array}{c}\text { G- } \\
\text { VNS- } \\
\text { A17 }\end{array}$ & 1.75 & 0.5 & 95.2 & 94.4 & 26.7 & 67.2 & 92.2 & 30.05 \\
\hline $\begin{array}{c}\text { G-V166A- } \\
1750-1000- \\
405\end{array}$ & $\begin{array}{c}\text { G- } \\
\text { VNS- } \\
\text { A18 }\end{array}$ & 1.75 & 1 & 86.1 & 86.1 & 21.7 & 61.9 & 91.8 & 36.16 \\
\hline $\begin{array}{c}\text { G-V166A- } \\
1750-1500- \\
405\end{array}$ & $\begin{array}{c}\text { G- } \\
\text { VNS- } \\
\text { A19 }\end{array}$ & 1.75 & 1.5 & 78.4 & 78 & 17.4 & 57.2 & 91.1 & 37.32 \\
\hline $\begin{array}{c}\text { G-V166A- } \\
1750-2000- \\
405\end{array}$ & $\begin{array}{c}\text { G- } \\
\text { VNS- } \\
\text { A20 }\end{array}$ & 1.75 & 2 & 72.4 & 72.6 & 13.6 & 52.7 & 91.3 & 36.17 \\
\hline $\begin{array}{c}\text { G-V166A- } \\
2250-0000- \\
405\end{array}$ & $\begin{array}{c}\text { G- } \\
\text { VNS- } \\
\text { A21 }\end{array}$ & 2.25 & 0 & 98.1 & 99.1 & 27.9 & 68.2 & 93.1 & 28.23 \\
\hline $\begin{array}{c}\text { G-V166A- } \\
2250-0500- \\
405\end{array}$ & $\begin{array}{c}\text { G- } \\
\text { VNS- } \\
\text { A22 }\end{array}$ & 2.25 & 0.5 & 92.3 & 91.6 & 26.3 & 66 & 92.5 & 31.79 \\
\hline $\begin{array}{c}\text { G-V166A- } \\
2250-1000- \\
405\end{array}$ & $\begin{array}{c}\text { G- } \\
\text { VNS- } \\
\text { A23 }\end{array}$ & 2.25 & 1 & 84.7 & 83.8 & 20.7 & 60.8 & 91.9 & 33.94 \\
\hline $\begin{array}{c}\text { G-V166A- } \\
2250-1500- \\
405\end{array}$ & $\begin{array}{c}\text { G- } \\
\text { VNS- } \\
\text { A24 }\end{array}$ & 2.25 & 1.5 & 79 & 78 & 16 & 55.1 & 91.6 & 35.87 \\
\hline $\begin{array}{c}\text { G-V166A- } \\
2250-2000- \\
405\end{array}$ & $\begin{array}{c}\text { G- } \\
\text { VNS- } \\
\text { A25 }\end{array}$ & 2.25 & 2 & 73.2 & 73.8 & 16 & 56.5 & 91.8 & 35.51 \\
\hline $\begin{array}{c}\text { G-V166A- } \\
0260-1150- \\
405\end{array}$ & $\begin{array}{c}\text { G- } \\
\text { VNS- } \\
\text { A34 }\end{array}$ & 0.26 & 1.15 & 90.7 & 95.2 & 10.5 & 49.7 & 84.7 & 44.43 \\
\hline $\begin{array}{c}\text { G-V166A- } \\
0260-1350- \\
405\end{array}$ & $\begin{array}{c}\text { G- } \\
\text { VNS- } \\
\text { A35 }\end{array}$ & 0.26 & 1.35 & 84.8 & 89.1 & 12.2 & 53.1 & 89.1 & 42.04 \\
\hline $\begin{array}{c}\text { G-V166A- } \\
0750-0650- \\
405\end{array}$ & $\begin{array}{c}\text { G- } \\
\text { VNS- } \\
\text { A36 }\end{array}$ & 0.75 & 0.65 & 99.9 & 101.1 & 23.7 & 65 & 90.6 & 37.48 \\
\hline $\begin{array}{c}\text { G-V166A- } \\
0750-0850- \\
405\end{array}$ & $\begin{array}{c}\text { G- } \\
\text { VNS- } \\
\text { A37 }\end{array}$ & 0.75 & 0.85 & 86.4 & 95.4 & 20.8 & 62.6 & 91.8 & 38.87 \\
\hline $\begin{array}{l}\text { G-V166A- } \\
1250-0650-\end{array}$ & $\begin{array}{c}\text { G- } \\
\text { VNS- }\end{array}$ & 1.25 & 0.65 & 86.7 & 92.7 & 25.7 & 65 & 91.7 & 32.99 \\
\hline
\end{tabular}




\begin{tabular}{|c|c|c|c|c|c|c|c|c|c|}
\hline 405 & A38 & & & & & & & & \\
\hline $\begin{array}{c}\text { G-V166A- } \\
1250-0850- \\
405\end{array}$ & $\begin{array}{c}\text { G- } \\
\text { VNS- } \\
\text { A39 }\end{array}$ & 1.25 & 0.85 & 82.3 & 89.2 & 23.1 & 62.8 & 91.7 & 35.42 \\
\hline $\begin{array}{c}\text { G-V166A- } \\
1750-0650- \\
405\end{array}$ & $\begin{array}{c}\text { G- } \\
\text { VNS- } \\
\text { A40 }\end{array}$ & 1.75 & 0.65 & 83 & 89.6 & 28.3 & 66.8 & 92.5 & 31.62 \\
\hline $\begin{array}{c}\text { G-V166A- } \\
1750-0850- \\
405\end{array}$ & $\begin{array}{c}\text { G- } \\
\text { VNS- } \\
\text { A41 }\end{array}$ & 1.75 & 0.85 & 74.8 & 85.4 & 23.3 & 62.3 & 92.7 & 33.05 \\
\hline
\end{tabular}

Physical property data for the G-VAS 166A series.

\begin{tabular}{|c|c|c|c|c|c|c|c|c|c|}
\hline \multirow[t]{2}{*}{ Sample } & \multirow{2}{*}{$\begin{array}{c}\text { Call } \\
\text { Name }\end{array}$} & \multirow{2}{*}{$\begin{array}{c}\% \\
\text { HEU } \\
\text { R }\end{array}$} & \multirow{2}{*}{$\begin{array}{c}\% \\
\text { Surf }\end{array}$} & \multicolumn{2}{|c|}{$\mathrm{KU}$} & \multicolumn{3}{|c|}{ Gloss } & \multirow[t]{2}{*}{ IRBS } \\
\hline & & & & initial & $24 \mathrm{hr}$ & $20^{\prime}$ & $60^{\prime}$ & $85^{\prime}$ & \\
\hline $\begin{array}{c}\text { G-V166A- } \\
0260-0000- \\
411\end{array}$ & $\begin{array}{c}\text { G- } \\
\text { VAS- } \\
\text { A1 }\end{array}$ & 0.26 & 0 & 109.6 & 109.8 & 6.3 & 36.1 & 83.5 & $\begin{array}{c}40.31 \\
8\end{array}$ \\
\hline $\begin{array}{c}\text { G-V166A- } \\
0260-0500- \\
411\end{array}$ & $\begin{array}{c}\text { G- } \\
\text { VAS- } \\
\text { A2 }\end{array}$ & 0.26 & 0.5 & 108.9 & 109.5 & 21.2 & 65.2 & 91.9 & $\begin{array}{c}42.89 \\
3\end{array}$ \\
\hline $\begin{array}{c}\text { G-V166A- } \\
0260-1000- \\
411\end{array}$ & $\begin{array}{c}\text { G- } \\
\text { VAS- } \\
\text { A3 }\end{array}$ & 0.26 & 1 & 69.2 & 73.4 & 18.6 & 57.6 & 87.8 & $\begin{array}{c}42.12 \\
7\end{array}$ \\
\hline $\begin{array}{c}\text { G-V166A- } \\
0260-1500- \\
411\end{array}$ & $\begin{array}{c}\text { G- } \\
\text { VAS- } \\
\text { A4 }\end{array}$ & 0.26 & 1.5 & 50.6 & 51.2 & 15.2 & 53.4 & 88.6 & $\begin{array}{c}37.20 \\
3\end{array}$ \\
\hline $\begin{array}{c}\text { G-V166A- } \\
0260-2000- \\
411\end{array}$ & $\begin{array}{c}\text { G- } \\
\text { VAS- } \\
\text { A5 } \\
\end{array}$ & 0.26 & 2 & 47 & 47 & 33.6 & 69.6 & 89.5 & $\begin{array}{c}34.71 \\
8\end{array}$ \\
\hline $\begin{array}{c}\text { G-V166A- } \\
0750-0000- \\
411\end{array}$ & $\begin{array}{c}\text { G- } \\
\text { VAS- } \\
\text { A6 }\end{array}$ & 0.75 & 0 & 105 & 107.8 & 15.7 & 58.3 & 91.9 & $\begin{array}{c}40.91 \\
8\end{array}$ \\
\hline $\begin{array}{c}\text { G-V166A- } \\
0750-0500- \\
411\end{array}$ & $\begin{array}{c}\text { G- } \\
\text { VAS- } \\
\text { A7 }\end{array}$ & 0.75 & 0.5 & 98.5 & 99.8 & 25.9 & 66.7 & 92.7 & $\begin{array}{c}37.46 \\
0\end{array}$ \\
\hline $\begin{array}{c}\text { G-V166A- } \\
0750-1000- \\
411\end{array}$ & $\begin{array}{c}\text { G- } \\
\text { VAS- } \\
\text { A8 } \\
\end{array}$ & 0.75 & 1 & 74 & 76.8 & 17.2 & 55.8 & 89.3 & $\begin{array}{c}38.75 \\
0\end{array}$ \\
\hline $\begin{array}{c}\text { G-V166A- } \\
0750-1500- \\
411\end{array}$ & $\begin{array}{c}\text { G- } \\
\text { VAS- } \\
\text { A9 }\end{array}$ & 0.75 & 1.5 & 56.2 & 58.6 & 15.6 & 53.5 & 85.6 & $\begin{array}{c}37.91 \\
2\end{array}$ \\
\hline $\begin{array}{c}\text { G-V166A- } \\
0750-2000- \\
411\end{array}$ & $\begin{array}{c}\text { G- } \\
\text { VAS- } \\
\text { A10 } \\
\end{array}$ & 0.75 & 2 & 52.1 & 53.6 & 18.1 & 57.5 & 87 & $\begin{array}{c}36.89 \\
4 \\
\end{array}$ \\
\hline $\begin{array}{c}\text { G-V166A- } \\
1250-0000- \\
411\end{array}$ & $\begin{array}{c}\text { G- } \\
\text { VAS- } \\
\text { A11 }\end{array}$ & 1.25 & 0 & 98.6 & 102 & 28.6 & 69.1 & 94.3 & $\begin{array}{c}34.22 \\
0\end{array}$ \\
\hline $\begin{array}{l}\text { G-V166A- } \\
1250-0500-\end{array}$ & $\begin{array}{c}\text { G- } \\
\text { VAS- }\end{array}$ & 1.25 & 0.5 & 90.7 & 93.2 & 27.7 & 66.2 & 92.9 & $\begin{array}{c}33.58 \\
5\end{array}$ \\
\hline
\end{tabular}




\begin{tabular}{|c|c|c|c|c|c|c|c|c|c|}
\hline 411 & A12 & & & & & & & & \\
\hline $\begin{array}{c}\text { G-V166A- } \\
1250-1000- \\
411\end{array}$ & $\begin{array}{c}\text { G- } \\
\text { VAS- } \\
\text { A13 }\end{array}$ & 1.25 & 1 & 76.4 & 79 & 20.5 & 59.4 & 91.1 & $\begin{array}{c}37.13 \\
6\end{array}$ \\
\hline $\begin{array}{c}\text { G-V166A- } \\
1250-1500- \\
411\end{array}$ & $\begin{array}{c}\text { G- } \\
\text { VAS- } \\
\text { A14 } \\
\end{array}$ & 1.25 & 1.5 & 65 & 67.7 & 14.3 & 52.3 & 85.9 & $\begin{array}{c}36.12 \\
4\end{array}$ \\
\hline $\begin{array}{c}\text { G-V166A- } \\
1250-2000- \\
411\end{array}$ & $\begin{array}{c}\text { G- } \\
\text { VAS- } \\
\text { A15 }\end{array}$ & 1.25 & 2 & 59.1 & 62.4 & 13.5 & 51.2 & 78.5 & $\begin{array}{c}36.32 \\
0\end{array}$ \\
\hline $\begin{array}{c}\text { G-V166A- } \\
1750-0000- \\
411\end{array}$ & $\begin{array}{c}\text { G- } \\
\text { VAS- } \\
\text { A16 } \\
\end{array}$ & 1.75 & 0 & 96.2 & 99.5 & 31 & 70.4 & 94.7 & $\begin{array}{c}30.03 \\
6\end{array}$ \\
\hline $\begin{array}{c}\text { G-V166A- } \\
1750-0500- \\
411\end{array}$ & $\begin{array}{l}\text { G- } \\
\text { VAS- } \\
\text { A17 } \\
\end{array}$ & 1.75 & 0.5 & 86.1 & 90.3 & 27.5 & 66.4 & 93.7 & $\begin{array}{c}30.58 \\
5 \\
\end{array}$ \\
\hline $\begin{array}{c}\text { G-V166A- } \\
1750-1000- \\
411\end{array}$ & $\begin{array}{c}\text { G- } \\
\text { VAS- } \\
\text { A18 } \\
\end{array}$ & 1.75 & 1 & 79 & 80.8 & 21 & 59.7 & 91.2 & $\begin{array}{c}36.17 \\
7 \\
\end{array}$ \\
\hline $\begin{array}{c}\text { G-V166A- } \\
1750-1500- \\
411\end{array}$ & $\begin{array}{l}\text { G- } \\
\text { VAS- } \\
\text { A19 } \\
\end{array}$ & 1.75 & 1.5 & 70.1 & 72.6 & 11.8 & 47.8 & 78.1 & $\begin{array}{c}35.86 \\
2 \\
\end{array}$ \\
\hline $\begin{array}{c}\text { G-V166A- } \\
1750-2000- \\
411 \\
\end{array}$ & $\begin{array}{l}\text { G- } \\
\text { VAS- } \\
\text { A20 } \\
\end{array}$ & 1.75 & 2 & 66.8 & 69.5 & 12.4 & 48.9 & 82.1 & $\begin{array}{c}32.22 \\
1 \\
\end{array}$ \\
\hline $\begin{array}{c}\text { G-V166A- } \\
2250-0000- \\
411\end{array}$ & $\begin{array}{c}\text { G- } \\
\text { VAS- } \\
\text { A21 }\end{array}$ & 2.25 & 0 & 94 & 98.3 & 31.2 & 70.2 & 94.9 & $\begin{array}{c}28.69 \\
8\end{array}$ \\
\hline $\begin{array}{c}\text { G-V166A- } \\
2250-0500- \\
411 \\
\end{array}$ & $\begin{array}{c}\text { G- } \\
\text { VAS- } \\
\text { A22 } \\
\end{array}$ & 2.25 & 0.5 & 88.7 & 89.1 & 27.1 & 65.3 & 93.8 & $\begin{array}{c}32.50 \\
4 \\
\end{array}$ \\
\hline $\begin{array}{c}\text { G-V166A- } \\
2250-1000- \\
411\end{array}$ & $\begin{array}{c}\text { G- } \\
\text { VAS- } \\
\text { A23 }\end{array}$ & 2.25 & 1 & 81.8 & 84 & 22 & 60.2 & 92.5 & $\begin{array}{c}35.27 \\
1\end{array}$ \\
\hline $\begin{array}{c}\text { G-V166A- } \\
2250-1500- \\
411 \\
\end{array}$ & $\begin{array}{l}\text { G- } \\
\text { VAS- } \\
\text { A24 } \\
\end{array}$ & 2.25 & 1.5 & 75.8 & 78.2 & 12.9 & 49.8 & 84.1 & $\begin{array}{c}34.77 \\
9 \\
\end{array}$ \\
\hline $\begin{array}{c}\text { G-V166A- } \\
2250-2000- \\
411\end{array}$ & $\begin{array}{c}\text { G- } \\
\text { VAS- } \\
\text { A25 } \\
\end{array}$ & 2.25 & 2 & 72.8 & 76.6 & 9.4 & 43.4 & 78 & $\begin{array}{c}33.67 \\
8 \\
\end{array}$ \\
\hline $\begin{array}{c}\text { G-V166A- } \\
0260-0250- \\
411\end{array}$ & $\begin{array}{c}\text { G- } \\
\text { VAS- } \\
\text { A26 }\end{array}$ & 0.26 & 0.25 & 111.4 & 108.8 & 20.9 & 65.5 & 92.1 & $\begin{array}{c}36.30 \\
8\end{array}$ \\
\hline $\begin{array}{c}\text { G-V166A- } \\
0260-0750- \\
411\end{array}$ & $\begin{array}{c}\text { G- } \\
\text { VAS- } \\
\text { A27 } \\
\end{array}$ & 0.26 & 0.75 & 93.5 & 97.2 & 31.5 & 71.4 & 92.7 & $\begin{array}{c}41.17 \\
8\end{array}$ \\
\hline $\begin{array}{c}\text { G-V166A- } \\
0750-0250- \\
411\end{array}$ & $\begin{array}{c}\text { G- } \\
\text { VAS- } \\
\text { A28 } \\
\end{array}$ & 0.75 & 0.25 & 105 & 107 & 27.2 & 68.2 & 92.9 & $\begin{array}{c}36.83 \\
3 \\
\end{array}$ \\
\hline G-V166A- & G- & 0.75 & 0.75 & 89.8 & 91.8 & 27.8 & 67.2 & 92.4 & 36.27 \\
\hline
\end{tabular}




\begin{tabular}{|c|c|c|c|c|c|c|c|c|c|}
\hline $\begin{array}{c}0750-0750- \\
411\end{array}$ & $\begin{array}{l}\text { VAS- } \\
\text { A29 }\end{array}$ & & & & & & & & 0 \\
\hline $\begin{array}{c}\text { G-V166A- } \\
\text { 1250-0250- } \\
411\end{array}$ & $\begin{array}{c}\text { G- } \\
\text { VAS- } \\
\text { A30 }\end{array}$ & 1.25 & 0.25 & 96.4 & 100.4 & 29.8 & 68.7 & 93.7 & $\begin{array}{c}30.98 \\
3 \\
\end{array}$ \\
\hline $\begin{array}{c}\text { G-V166A- } \\
1250-0750- \\
411\end{array}$ & $\begin{array}{c}\text { G- } \\
\text { VAS- } \\
\text { A31 }\end{array}$ & 1.25 & 0.75 & 83.8 & 88.6 & 28.2 & 66.2 & 93 & $\begin{array}{c}32.29 \\
5\end{array}$ \\
\hline $\begin{array}{c}\text { G-V166A- } \\
1750-0250- \\
411\end{array}$ & $\begin{array}{l}\text { G- } \\
\text { VAS- } \\
\text { A32 }\end{array}$ & 1.75 & 0.25 & 96.5 & 98 & 29.7 & 68.2 & 93.1 & $\begin{array}{c}29.10 \\
6\end{array}$ \\
\hline $\begin{array}{c}\text { G-V166A- } \\
1750-0750- \\
411\end{array}$ & $\begin{array}{c}\text { G- } \\
\text { VAS- } \\
\text { A33 } \\
\end{array}$ & 1.75 & 0.75 & 83.2 & 85.6 & 26.9 & 65 & 92.7 & $\begin{array}{c}31.03 \\
7 \\
\end{array}$ \\
\hline
\end{tabular}

Physical property data set for the G-VNS 166B series.

\begin{tabular}{|c|c|c|c|c|c|c|c|c|c|}
\hline \multirow[b]{2}{*}{ Sample } & \multirow{2}{*}{$\begin{array}{c}\text { Call } \\
\text { Name }\end{array}$} & \multirow{2}{*}{$\begin{array}{c}\% \\
\text { HEU } \\
\text { R }\end{array}$} & \multirow{2}{*}{$\begin{array}{c}\% \\
\text { SUR } \\
F\end{array}$} & \multicolumn{2}{|c|}{$\mathrm{KU}$} & \multicolumn{3}{|c|}{ Gloss } & \multirow{2}{*}{$\begin{array}{c}\text { IRB } \\
\text { S }\end{array}$} \\
\hline & & & & $\begin{array}{c}\text { initia } \\
\text { l }\end{array}$ & $24 \mathrm{hr}$ & 20' & $60^{\prime}$ & $85^{\prime}$ & \\
\hline $\begin{array}{c}\text { G-V166B- } \\
0380-0000- \\
405\end{array}$ & $\begin{array}{c}\text { G- } \\
\text { VNS- } \\
\text { B1 }\end{array}$ & 0.38 & 0.00 & $\begin{array}{c}113 . \\
8\end{array}$ & $\begin{array}{c}120 . \\
1\end{array}$ & 17.7 & 60.8 & 91.5 & $\begin{array}{c}32.0 \\
3\end{array}$ \\
\hline $\begin{array}{c}\text { G-V166B- } \\
0380-0500- \\
405\end{array}$ & $\begin{array}{c}\text { G- } \\
\text { VNS- } \\
\text { B2 }\end{array}$ & 0.38 & 0.51 & $\begin{array}{c}106 . \\
8\end{array}$ & 112 & 27.2 & 69.2 & 93.5 & $\begin{array}{c}33.6 \\
0\end{array}$ \\
\hline $\begin{array}{c}\text { G-V166B- } \\
0380-1000- \\
405\end{array}$ & $\begin{array}{c}\text { G- } \\
\text { VNS- } \\
\text { B3 } \\
\end{array}$ & 0.38 & 1.01 & 98 & 99.5 & 11.4 & 52 & 91.4 & $\begin{array}{c}43.5 \\
6\end{array}$ \\
\hline $\begin{array}{c}\text { G-V166B- } \\
0380-1500- \\
405\end{array}$ & $\begin{array}{c}\text { G- } \\
\text { VNS- } \\
\text { B4 }\end{array}$ & 0.38 & 1.52 & 85 & 90.8 & 9.4 & 47.4 & 90.7 & $\begin{array}{c}41.9 \\
0\end{array}$ \\
\hline $\begin{array}{c}\text { G-V166B- } \\
0380-2000- \\
405\end{array}$ & $\begin{array}{c}\text { G- } \\
\text { VNS- } \\
\text { B5 } \\
\end{array}$ & 0.38 & 2.05 & 74.4 & 80.8 & 9.9 & 47.7 & 91.4 & $\begin{array}{c}39.8 \\
8\end{array}$ \\
\hline $\begin{array}{c}\text { G-V166B- } \\
0740-0000- \\
405\end{array}$ & $\begin{array}{c}\text { G- } \\
\text { VNS- } \\
\text { B6 } \\
\end{array}$ & 0.74 & 0.00 & $\begin{array}{c}110 . \\
4\end{array}$ & 115 & 25.7 & 67.8 & 94.4 & $\begin{array}{c}38.2 \\
3\end{array}$ \\
\hline $\begin{array}{c}\text { G-V166B- } \\
0740-0500- \\
405\end{array}$ & $\begin{array}{c}\text { G- } \\
\text { VNS- } \\
\text { B7 }\end{array}$ & 0.74 & 0.51 & 101 & 107 & 23.9 & 66.2 & 93.6 & $\begin{array}{c}40.4 \\
4\end{array}$ \\
\hline $\begin{array}{c}\text { G-V166B- } \\
0740-1000- \\
405\end{array}$ & $\begin{array}{c}\text { G- } \\
\text { VNS- } \\
\text { B8 }\end{array}$ & 0.74 & 1.01 & 90.6 & 97.3 & 13 & 53 & 92.1 & $\begin{array}{c}39.8 \\
4\end{array}$ \\
\hline $\begin{array}{c}\text { G-V166B- } \\
0740-1500- \\
405\end{array}$ & $\begin{array}{c}\text { G- } \\
\text { VNS- } \\
\text { B9 } \\
\end{array}$ & 0.74 & 1.52 & 80.8 & 87.1 & 9.6 & 47.2 & 91.5 & $\begin{array}{c}40.8 \\
2\end{array}$ \\
\hline G-V166B- & G- & 0.74 & 2.00 & 72 & 79.3 & 9.7 & 46.8 & 91.9 & 39.4 \\
\hline
\end{tabular}




\begin{tabular}{|c|c|c|c|c|c|c|c|c|c|}
$\begin{array}{c}0740-2000- \\
405\end{array}$ & $\begin{array}{c}\text { VNS- } \\
\text { B10 }\end{array}$ & & & & & & & & 7 \\
\hline $\begin{array}{c}\text { G-V166B- } \\
1240-0000- \\
405\end{array}$ & $\begin{array}{c}\text { G- } \\
\text { VNS- } \\
\text { B11 }\end{array}$ & 1.24 & 0.00 & $\begin{array}{c}100 . \\
4\end{array}$ & $\begin{array}{c}105 . \\
9\end{array}$ & 29.4 & 70.4 & 94.5 & $\begin{array}{c}31.6 \\
1\end{array}$ \\
\hline $\begin{array}{c}\text { G-V166B- } \\
1240-0500- \\
405\end{array}$ & $\begin{array}{c}\text { G- } \\
\text { VNS- } \\
\text { B12 }\end{array}$ & 1.24 & 0.48 & 95.7 & 100. & 27.3 & 67.1 & 94.3 & $\begin{array}{c}31.9 \\
9\end{array}$ \\
\hline $\begin{array}{c}\text { G-V166B- } \\
1240-1000- \\
405\end{array}$ & $\begin{array}{c}\text { G- } \\
\text { VNS- } \\
\text { B13 }\end{array}$ & 1.24 & 0.99 & 85 & 90.8 & 17.3 & 57 & 93.4 & $\begin{array}{c}35.5 \\
6\end{array}$ \\
\hline $\begin{array}{c}\text { G-V166B- } \\
1240-1500- \\
405\end{array}$ & $\begin{array}{c}\text { G- } \\
\text { VNS- } \\
\text { B14 }\end{array}$ & 1.24 & 1.50 & 77.4 & 83.5 & 10.9 & 49.1 & 91.9 & $\begin{array}{c}38.1 \\
2\end{array}$ \\
\hline $\begin{array}{c}\text { G-V166B- } \\
1240-2000- \\
405\end{array}$ & $\begin{array}{c}\text { G- } \\
\text { VNS- } \\
\text { B15 }\end{array}$ & 1.24 & 2.00 & 71 & 76.6 & 12.2 & 50.9 & 92.2 & $\begin{array}{c}36.1 \\
9\end{array}$ \\
\hline $\begin{array}{c}\text { G-V166B- } \\
1740-0000- \\
405\end{array}$ & $\begin{array}{c}\text { G- } \\
\text { VNS- } \\
\text { B16 }\end{array}$ & 1.74 & 0.00 & 95.5 & 101 & 31.1 & 70.6 & 94.8 & $\begin{array}{c}30.2 \\
4\end{array}$ \\
\hline $\begin{array}{c}\text { G-V166B- } \\
1740-0500- \\
405\end{array}$ & $\begin{array}{c}\text { G- } \\
\text { VNS- } \\
\text { B17 }\end{array}$ & 1.74 & 0.48 & 90.8 & 93.7 & 26.7 & 65.9 & 94.9 & 33.5 \\
\hline $\begin{array}{c}\text { G-V166B- } \\
1740-1000- \\
405\end{array}$ & $\begin{array}{c}\text { G- } \\
\text { VNS- } \\
\text { B18 }\end{array}$ & 1.74 & 0.99 & 81 & 86.3 & 16.8 & 56.5 & 92.8 & $\begin{array}{c}34.6 \\
8\end{array}$ \\
\hline $\begin{array}{c}\text { G-V166B- } \\
1740-1500- \\
405\end{array}$ & $\begin{array}{c}\text { G- } \\
\text { VNS- } \\
\text { B19 }\end{array}$ & 1.74 & 1.50 & 72.4 & 79.7 & 11.8 & 50.6 & 92.4 & $\begin{array}{c}35.7 \\
6\end{array}$ \\
\hline $\begin{array}{c}\text { G-V166B- } \\
1740-2000- \\
405\end{array}$ & $\begin{array}{c}\text { G- } \\
\text { VNS- } \\
\text { B20 }\end{array}$ & 1.74 & 1.98 & 69.2 & 75.6 & 16 & 55.8 & 93 & $\begin{array}{c}33.9 \\
6\end{array}$ \\
\hline $\begin{array}{c}\text { G-V166B- } \\
2240-0000- \\
405\end{array}$ & $\begin{array}{c}\text { G- } \\
\text { VNS- } \\
\text { B21 }\end{array}$ & 2.24 & 0.00 & 92 & 97.3 & 30.3 & 69.6 & 95.4 & $\begin{array}{c}30.3 \\
7\end{array}$ \\
\hline $\begin{array}{c}\text { G-V166B- } \\
2240-0500- \\
405\end{array}$ & $\begin{array}{c}\text { G- } \\
\text { VNS- } \\
\text { B22 }\end{array}$ & 2.24 & 0.48 & 84.4 & 90.9 & 27 & 66.1 & 94.5 & $\begin{array}{c}32.7 \\
9\end{array}$ \\
\hline $\begin{array}{c}\text { G-V166B- } \\
2240-1000- \\
405\end{array}$ & $\begin{array}{c}\text { G- } \\
\text { VNS- } \\
\text { B23 }\end{array}$ & 2.24 & 0.99 & 77 & 83 & 21.6 & 61.1 & 93.9 & $\begin{array}{c}35.1 \\
4\end{array}$ \\
\hline $\begin{array}{c}\text { G-V166B- } \\
2240-1500- \\
405\end{array}$ & $\begin{array}{c}\text { G- } \\
\text { VNS- } \\
\text { B24 }\end{array}$ & 2.24 & 1.52 & 71.2 & 79.1 & 15.9 & 56.3 & 93.8 & $\begin{array}{c}35.8 \\
1\end{array}$ \\
\hline $\begin{array}{c}\text { G-V166B- } \\
2240-2000- \\
405\end{array}$ & $\begin{array}{c}\text { G- } \\
\text { VNS- } \\
\text { B25 }\end{array}$ & 2.24 & 2.03 & 68.4 & 75 & 16.3 & 56.8 & 93.5 & $\begin{array}{c}35.2 \\
4\end{array}$ \\
\hline
\end{tabular}


Physical property data for the G-VAS 166B series.

\begin{tabular}{|c|c|c|c|c|c|c|c|c|c|}
\hline \multirow[t]{2}{*}{ Sample } & \multirow{2}{*}{$\begin{array}{c}\text { Call } \\
\text { Name }\end{array}$} & \multirow{2}{*}{$\begin{array}{c}\% \\
\text { HEU } \\
\text { R }\end{array}$} & \multirow{2}{*}{$\begin{array}{c}\% \\
\text { SUR } \\
\mathrm{F}\end{array}$} & \multicolumn{2}{|c|}{$\mathrm{KU}$} & \multicolumn{3}{|c|}{ Gloss } & \multirow{2}{*}{$\begin{array}{c}\text { IRB } \\
\text { S }\end{array}$} \\
\hline & & & & $\begin{array}{c}\text { initi } \\
\text { al }\end{array}$ & $\begin{array}{l}24 \\
\mathrm{hr}\end{array}$ & $20^{\prime}$ & $60^{\prime}$ & $85^{\prime}$ & \\
\hline $\begin{array}{c}\text { G-V166B- } \\
0390-0000- \\
411\end{array}$ & $\begin{array}{c}\text { G- } \\
\text { VAS- } \\
\text { B1 }\end{array}$ & 0.39 & 0.00 & 119 & 120 & 19.4 & 62.4 & 91.7 & $\begin{array}{c}33.3 \\
3\end{array}$ \\
\hline $\begin{array}{c}\text { G-V166B- } \\
0390-0375- \\
411\end{array}$ & $\begin{array}{c}\text { G- } \\
\text { VAS- } \\
\text { B2 } \\
\end{array}$ & 0.39 & 0.38 & $\begin{array}{c}113 \\
.3\end{array}$ & $\begin{array}{c}112 . \\
2\end{array}$ & 25.1 & 67.9 & 91.6 & $\begin{array}{c}33.8 \\
6\end{array}$ \\
\hline $\begin{array}{c}\text { G-V166B- } \\
0390-0750- \\
411\end{array}$ & $\begin{array}{c}\text { G- } \\
\text { VAS- } \\
\text { B3 }\end{array}$ & 0.39 & 0.76 & $\begin{array}{c}76 . \\
4\end{array}$ & 83.3 & 25.5 & 66.1 & 93.3 & $\begin{array}{c}38.7 \\
4\end{array}$ \\
\hline $\begin{array}{c}\text { G-V166B- } \\
\text { 0390-1125- } \\
411\end{array}$ & $\begin{array}{c}\text { G- } \\
\text { VAS- } \\
\text { B4 } \\
\end{array}$ & 0.39 & 1.14 & 50 & 52.4 & 24.6 & 63.8 & 94.1 & $\begin{array}{c}38.4 \\
7\end{array}$ \\
\hline $\begin{array}{c}\text { G-V166B- } \\
0390-0516- \\
411\end{array}$ & $\begin{array}{c}\text { G- } \\
\text { VAS- } \\
\text { B5 }\end{array}$ & 0.39 & 0.52 & 100 & $\begin{array}{c}104 . \\
3\end{array}$ & 27 & 68.9 & 93.8 & $\begin{array}{c}35.9 \\
0\end{array}$ \\
\hline $\begin{array}{c}\text { G-V166B- } \\
0750-0000- \\
411\end{array}$ & $\begin{array}{c}\text { G- } \\
\text { VAS- } \\
\text { B6 }\end{array}$ & 0.75 & 0.00 & 112 & 117 & 26.9 & 68.7 & 94.3 & $\begin{array}{c}36.6 \\
9\end{array}$ \\
\hline $\begin{array}{c}\text { G-V166B- } \\
0750-0375- \\
411\end{array}$ & $\begin{array}{c}\text { G- } \\
\text { VAS- } \\
\text { B7 }\end{array}$ & 0.75 & 0.41 & $\begin{array}{c}104 \\
.1\end{array}$ & $\begin{array}{c}107 . \\
4\end{array}$ & 25.8 & 67.6 & 93.7 & $\begin{array}{c}35.0 \\
4\end{array}$ \\
\hline $\begin{array}{c}\text { G-V166B- } \\
0750-0750- \\
411\end{array}$ & $\begin{array}{c}\text { G- } \\
\text { VAS- } \\
\text { B8 }\end{array}$ & 0.75 & 0.76 & $\begin{array}{c}82 . \\
2\end{array}$ & 89.1 & 24.2 & 64.7 & 94 & $\begin{array}{c}36.0 \\
0\end{array}$ \\
\hline $\begin{array}{c}\text { G-V166B- } \\
0750-1125- \\
411\end{array}$ & $\begin{array}{c}\text { G- } \\
\text { VAS- } \\
\text { B9 }\end{array}$ & 0.75 & 1.10 & 57 & 61.9 & 24.1 & 63.9 & 93.5 & $\begin{array}{c}37.3 \\
1\end{array}$ \\
\hline $\begin{array}{c}\text { G-V166B- } \\
0750-0516- \\
411\end{array}$ & $\begin{array}{c}\text { G- } \\
\text { VAS- } \\
\text { B10 }\end{array}$ & 0.75 & 0.52 & $\begin{array}{c}95 . \\
8\end{array}$ & $\begin{array}{c}101 . \\
6\end{array}$ & 25.6 & 67.1 & 94 & $\begin{array}{c}35.5 \\
5\end{array}$ \\
\hline $\begin{array}{c}\text { G-V166B- } \\
1250-0000- \\
411\end{array}$ & $\begin{array}{l}\text { G- } \\
\text { VAS- } \\
\text { B11 }\end{array}$ & 1.25 & 0.00 & 105 & $\begin{array}{c}106 . \\
9\end{array}$ & 28.6 & 70.3 & 94.5 & $\begin{array}{c}29.6 \\
8\end{array}$ \\
\hline $\begin{array}{c}\text { G-V166B- } \\
1250-0375- \\
411\end{array}$ & $\begin{array}{c}\text { G- } \\
\text { VAS- } \\
\text { B12 }\end{array}$ & 1.25 & 0.41 & 96 & $\begin{array}{c}100 . \\
1\end{array}$ & 27.6 & 67.3 & 93.9 & $\begin{array}{c}33.8 \\
4\end{array}$ \\
\hline $\begin{array}{c}\text { G-V166B- } \\
1250-0750- \\
411\end{array}$ & $\begin{array}{c}\text { G- } \\
\text { VAS- } \\
\text { B13 }\end{array}$ & 1.25 & 0.76 & $\begin{array}{c}77 . \\
8\end{array}$ & 85.3 & 23.7 & 63.5 & 94.1 & $\begin{array}{c}36.2 \\
9\end{array}$ \\
\hline $\begin{array}{c}\text { G-V166B- } \\
1250-1125- \\
411\end{array}$ & $\begin{array}{l}\text { G- } \\
\text { VAS- } \\
\text { B14 }\end{array}$ & 1.25 & 1.07 & $\begin{array}{c}69 . \\
7\end{array}$ & 74.8 & 24.5 & 64.2 & 94.1 & $\begin{array}{c}36.4 \\
7\end{array}$ \\
\hline
\end{tabular}




\begin{tabular}{|c|c|c|c|c|c|c|c|c|c|}
\hline $\begin{array}{c}\text { G-V166B- } \\
\text { 1250-0516- } \\
411\end{array}$ & $\begin{array}{l}\text { G- } \\
\text { VAS- } \\
\text { B15 }\end{array}$ & 1.25 & 0.52 & $\begin{array}{c}92 . \\
8\end{array}$ & 96.1 & 26.4 & 66.3 & 94.3 & $\begin{array}{c}34.4 \\
8\end{array}$ \\
\hline $\begin{array}{c}\text { G-V166B- } \\
1750-0000- \\
411\end{array}$ & $\begin{array}{l}\text { G- } \\
\text { VAS- } \\
\text { B16 }\end{array}$ & 1.75 & 0.00 & $\begin{array}{c}99 . \\
4 \\
\end{array}$ & $\begin{array}{c}102 . \\
9\end{array}$ & 28.2 & 69.6 & 94.5 & $\begin{array}{c}29.0 \\
0\end{array}$ \\
\hline $\begin{array}{c}\text { G-V166B- } \\
1750-0375- \\
411\end{array}$ & $\begin{array}{l}\text { G- } \\
\text { VAS- } \\
\text { B17 }\end{array}$ & 1.75 & 0.34 & $\begin{array}{c}94 . \\
5 \\
\end{array}$ & 97.5 & 28.2 & 67.7 & 94.6 & $\begin{array}{c}32.3 \\
3\end{array}$ \\
\hline $\begin{array}{c}\text { G-V166B- } \\
1750-0750- \\
411\end{array}$ & $\begin{array}{l}\text { G- } \\
\text { VAS- } \\
\text { B18 }\end{array}$ & 1.75 & 0.72 & 84 & 87.5 & 24.1 & 64.4 & 94 & $\begin{array}{c}33.4 \\
2\end{array}$ \\
\hline $\begin{array}{c}\text { G-V166B- } \\
1750-1125- \\
411\end{array}$ & $\begin{array}{c}\text { G- } \\
\text { VAS- } \\
\text { B19 }\end{array}$ & 1.75 & 1.10 & 72 & 76.6 & 24.2 & 64.3 & 93.8 & $\begin{array}{c}36.1 \\
5\end{array}$ \\
\hline $\begin{array}{c}\text { G-V166B- } \\
1750-0516- \\
411\end{array}$ & $\begin{array}{l}\text { G- } \\
\text { VAS- } \\
\text { B20 }\end{array}$ & 1.75 & 0.52 & 88 & 92.6 & 26.1 & 65.8 & 94 & $\begin{array}{c}33.9 \\
0\end{array}$ \\
\hline $\begin{array}{c}\text { G-V166B- } \\
\text { 2250-0000- } \\
411\end{array}$ & $\begin{array}{l}\text { G- } \\
\text { VAS- } \\
\text { B21 }\end{array}$ & 2.25 & 0.00 & $\begin{array}{c}95 . \\
2\end{array}$ & 98.6 & 28.2 & 69.2 & 94 & $\begin{array}{c}28.0 \\
5\end{array}$ \\
\hline $\begin{array}{c}\text { G-V166B- } \\
2250-0375- \\
411\end{array}$ & $\begin{array}{l}\text { G- } \\
\text { VAS- } \\
\text { B22 }\end{array}$ & 2.25 & 0.34 & $\begin{array}{c}89 . \\
1\end{array}$ & 93.3 & 27.2 & 67.1 & 94.8 & $\begin{array}{c}30.8 \\
3\end{array}$ \\
\hline $\begin{array}{c}\text { G-V166B- } \\
2250-0750- \\
411\end{array}$ & $\begin{array}{c}\text { G- } \\
\text { VAS- } \\
\text { B23 }\end{array}$ & 2.25 & 0.76 & 83 & 87.1 & 25.1 & 65 & 94 & $\begin{array}{c}32.8 \\
9\end{array}$ \\
\hline $\begin{array}{c}\text { G-V166B- } \\
\text { 2250-1125- } \\
411\end{array}$ & $\begin{array}{l}\text { G- } \\
\text { VAS- } \\
\text { B24 }\end{array}$ & 2.25 & 1.14 & $\begin{array}{c}75 . \\
1\end{array}$ & 80.9 & 25.2 & 65.1 & 94.2 & $\begin{array}{c}34.5 \\
9\end{array}$ \\
\hline $\begin{array}{c}\text { G-V166B- } \\
2250-0516- \\
411\end{array}$ & $\begin{array}{l}\text { G- } \\
\text { VAS- } \\
\text { B25 }\end{array}$ & 2.25 & 0.55 & 85 & 89.6 & 26.2 & 66 & 94 & $\begin{array}{c}32.7 \\
6\end{array}$ \\
\hline
\end{tabular}


15. Appendix C: Syneresis and Percent Solids Data

Syneresis and percent solids data for the VNS 166A series.

\begin{tabular}{|c|c|c|c|c|c|c|c|}
\hline \multirow{2}{*}{ Sample } & \multirow{2}{*}{$\begin{array}{l}\text { Call } \\
\text { Name }\end{array}$} & \multirow{2}{*}{$\begin{array}{c}\% \\
\text { HEU } \\
\text { R }\end{array}$} & \multirow{2}{*}{$\begin{array}{l}\% \\
\text { Surf }\end{array}$} & \multicolumn{2}{|c|}{ Syneresis } & \multirow{2}{*}{$\begin{array}{c}\% \\
\text { Solids } \\
\text { Top } \\
\text { Layer }\end{array}$} & \multirow{2}{*}{$\begin{array}{c}\% \\
\text { Solid } \\
\text { s Bot } \\
\text { Layer }\end{array}$} \\
\hline & & & & 1 week $(\mathrm{mm})$ & $\begin{array}{l}\text { Appearance } \\
\text { of Top Layer }\end{array}$ & & \\
\hline $\begin{array}{l}\text { V166A-0260- } \\
0000-405\end{array}$ & $\begin{array}{l}\text { VNS- } \\
\text { A1 }\end{array}$ & 0.260 & $\begin{array}{c}0.00 \\
0\end{array}$ & 9 & Clear & 0.8 & 49.65 \\
\hline $\begin{array}{l}\text { V166A-0260- } \\
0123-405\end{array}$ & $\begin{array}{l}\text { VNS- } \\
\text { A2 }\end{array}$ & 0.260 & $\begin{array}{c}0.12 \\
3\end{array}$ & 9 & Clear & 0.73 & 49.41 \\
\hline $\begin{array}{l}\text { V166A-0260- } \\
0246-405\end{array}$ & $\begin{array}{c}\text { VNS- } \\
\text { A3 }\end{array}$ & 0.260 & $\begin{array}{c}0.24 \\
6\end{array}$ & 8 & Clear & 1.16 & 49.51 \\
\hline $\begin{array}{l}\text { V166A-0260- } \\
0370-405\end{array}$ & $\begin{array}{l}\text { VNS- } \\
\text { A4 }\end{array}$ & 0.260 & $\begin{array}{c}0.37 \\
0\end{array}$ & 12 & Clear & 1.27 & 50.67 \\
\hline $\begin{array}{l}\text { V166A-0260- } \\
0493-405\end{array}$ & $\begin{array}{l}\text { VNS- } \\
\text { A5 }\end{array}$ & 0.260 & $\begin{array}{c}0.49 \\
3\end{array}$ & 13 & Clear & 1.53 & 52.37 \\
\hline $\begin{array}{l}\text { V166A-0260- } \\
0616-405\end{array}$ & $\begin{array}{l}\text { VNS- } \\
\text { A6 }\end{array}$ & 0.260 & $\begin{array}{l}0.61 \\
6\end{array}$ & 19 & Clear & 1.54 & 58.31 \\
\hline $\begin{array}{l}\text { V166A-0260- } \\
0739-405\end{array}$ & $\begin{array}{l}\text { VNS- } \\
\text { A7 }\end{array}$ & 0.260 & $\begin{array}{c}0.73 \\
9\end{array}$ & 12 & Clear/Opaque & 1.59 & 64.73 \\
\hline $\begin{array}{l}\text { V166A-0260- } \\
0862-405\end{array}$ & $\begin{array}{l}\text { VNS- } \\
\text { A8 }\end{array}$ & 0.260 & $\begin{array}{c}0.86 \\
2\end{array}$ & 8 & Clear/Opaque & 3.81 & 58.93 \\
\hline $\begin{array}{l}\text { V166A-0260- } \\
0985-405\end{array}$ & $\begin{array}{l}\text { VNS- } \\
\text { A9 }\end{array}$ & 0.260 & $\begin{array}{l}0.98 \\
5\end{array}$ & 1 & Opaque & 34.45 & 54.97 \\
\hline $\begin{array}{l}\text { V166A-0260- } \\
1109-405\end{array}$ & $\begin{array}{l}\text { VNS- } \\
\text { A10 }\end{array}$ & 0.260 & $\begin{array}{c}1.10 \\
9\end{array}$ & 0 & $\begin{array}{c}\text { No } \\
\text { Separation }\end{array}$ & 38.41 & 47.38 \\
\hline $\begin{array}{c}\text { V166A-0260- } \\
1232-405 \\
\end{array}$ & $\begin{array}{l}\text { VNS- } \\
\text { A11 } \\
\end{array}$ & 0.260 & $\begin{array}{c}1.23 \\
2\end{array}$ & 0 & $\begin{array}{c}\text { No } \\
\text { Separation }\end{array}$ & 41.44 & 46.62 \\
\hline $\begin{array}{c}\text { V166A-0260- } \\
1355-405\end{array}$ & $\begin{array}{l}\text { VNS- } \\
\text { A12 }\end{array}$ & 0.260 & $\begin{array}{c}1.35 \\
5\end{array}$ & 0 & $\begin{array}{c}\text { No } \\
\text { Separation }\end{array}$ & 43.42 & 46.22 \\
\hline $\begin{array}{l}\text { V166A-0260- } \\
1478-405\end{array}$ & $\begin{array}{l}\text { VNS- } \\
\text { A13 }\end{array}$ & 0.260 & $\begin{array}{c}1.47 \\
8\end{array}$ & 4 & Opaque & 42.96 & 46.3 \\
\hline $\begin{array}{l}\text { V166A-0260- } \\
1601-405\end{array}$ & $\begin{array}{l}\text { VNS- } \\
\text { A14 }\end{array}$ & 0.260 & $\begin{array}{c}1.60 \\
1\end{array}$ & 7 & Opaque & 37.87 & 46.51 \\
\hline $\begin{array}{l}\text { V166A-0260- } \\
1724-405\end{array}$ & $\begin{array}{l}\text { VNS- } \\
\text { A15 }\end{array}$ & 0.260 & $\begin{array}{c}1.72 \\
4\end{array}$ & 10 & e & 36.91 & 49.35 \\
\hline $\begin{array}{l}\text { V166A-0260- } \\
0000-405\end{array}$ & $\begin{array}{l}\text { VNS- } \\
\text { A16 }\end{array}$ & 0.260 & $\begin{array}{c}0.00 \\
0\end{array}$ & 9 & Clear & 0.85 & 49.62 \\
\hline $\begin{array}{l}\text { V166A-0260- } \\
1724-405\end{array}$ & $\begin{array}{l}\text { VNS- } \\
\text { A17 }\end{array}$ & 0.260 & $\begin{array}{c}1.72 \\
4\end{array}$ & 11.5 & Opaque & 32.75 & 49.94 \\
\hline $\begin{array}{l}\text { V166A-0260- } \\
1971-405\end{array}$ & $\begin{array}{l}\text { VNS- } \\
\text { A18 }\end{array}$ & 0.260 & $\begin{array}{c}1.97 \\
1\end{array}$ & 14 & Opaque & 31.24 & 47.29 \\
\hline $\begin{array}{l}\text { V166A-0260- } \\
2463-405\end{array}$ & $\begin{array}{l}\text { VNS- } \\
\text { A19 }\end{array}$ & 0.260 & $\begin{array}{c}2.46 \\
3\end{array}$ & 19 & Opaque & 31.27 & 47.57 \\
\hline
\end{tabular}




\begin{tabular}{|c|c|c|c|c|c|c|c|}
\hline $\begin{array}{c}\text { V166A-0260- } \\
2956-405\end{array}$ & $\begin{array}{l}\text { VNS- } \\
\text { A20 }\end{array}$ & 0.260 & $\begin{array}{c}2.95 \\
6 \\
\end{array}$ & 24 & Opaque & 31.86 & 50.55 \\
\hline $\begin{array}{c}\text { V166A-0260- } \\
3449-405\end{array}$ & $\begin{array}{l}\text { VNS- } \\
\text { A21 }\end{array}$ & 0.260 & $\begin{array}{c}3.44 \\
9 \\
\end{array}$ & 32 & Opaque & 31.87 & 52.06 \\
\hline $\begin{array}{c}\text { V166A-260- } \\
3941-405 \\
\end{array}$ & $\begin{array}{l}\text { VNS- } \\
\text { A22 }\end{array}$ & 0.260 & $\begin{array}{c}3.94 \\
1\end{array}$ & 35 & Opaque & 31.93 & 52.82 \\
\hline $\begin{array}{c}\text { V166A-0260- } \\
0000-405\end{array}$ & $\begin{array}{l}\text { VNS- } \\
\text { A23 }\end{array}$ & 0.260 & $\begin{array}{c}0.00 \\
0\end{array}$ & 9 & Clear & 0.74 & 49.6 \\
\hline $\begin{array}{c}\text { V166A-0612- } \\
0000-405\end{array}$ & $\begin{array}{l}\text { VNS- } \\
\text { A24 }\end{array}$ & 0.612 & $\begin{array}{c}0.00 \\
0\end{array}$ & 3 & Opaque & 36.39 & 45.66 \\
\hline $\begin{array}{c}\text { V166A-0964- } \\
0000-405\end{array}$ & $\begin{array}{l}\text { VNS- } \\
\text { A25 }\end{array}$ & 0.964 & $\begin{array}{c}0.00 \\
0\end{array}$ & 0 & $\begin{array}{c}\text { No } \\
\text { Separation }\end{array}$ & 43.57 & 44.29 \\
\hline $\begin{array}{c}\text { V166A-1316- } \\
0000-405\end{array}$ & $\begin{array}{l}\text { VNS- } \\
\text { A26 }\end{array}$ & 1.316 & $\begin{array}{c}0.00 \\
0\end{array}$ & 0 & $\begin{array}{c}\text { No } \\
\text { Separation }\end{array}$ & 43.87 & 44.57 \\
\hline $\begin{array}{c}\text { V166A-1668- } \\
0000-405\end{array}$ & $\begin{array}{l}\text { VNS- } \\
\text { A27 }\end{array}$ & 1.668 & $\begin{array}{c}0.00 \\
0\end{array}$ & 0 & $\begin{array}{c}\text { No } \\
\text { Separation }\end{array}$ & 43.73 & 44.6 \\
\hline $\begin{array}{c}\text { V166A-2020- } \\
0000-405\end{array}$ & $\begin{array}{l}\text { VNS- } \\
\text { A28 }\end{array}$ & 2.020 & $\begin{array}{c}0.00 \\
0\end{array}$ & 0 & $\begin{array}{c}\text { No } \\
\text { Separation }\end{array}$ & 44.31 & 44.72 \\
\hline $\begin{array}{c}\text { V166A-2371- } \\
0000-405\end{array}$ & $\begin{array}{l}\text { VNS- } \\
\text { A29 }\end{array}$ & 2.371 & $\begin{array}{c}0.00 \\
0\end{array}$ & 0 & $\begin{array}{c}\text { No } \\
\text { Separation }\end{array}$ & 43 & 44.33 \\
\hline $\begin{array}{c}\text { V166A-0260- } \\
0000-405\end{array}$ & $\begin{array}{l}\text { VNS- } \\
\text { A30 }\end{array}$ & 0.260 & $\begin{array}{c}0.00 \\
0\end{array}$ & 10 & Clear & 0.4 & 50.68 \\
\hline $\begin{array}{c}\text { V166A-0612- } \\
0246-405\end{array}$ & $\begin{array}{l}\text { VNS- } \\
\text { A31 }\end{array}$ & 0.612 & $\begin{array}{c}0.24 \\
6\end{array}$ & 2 & Opaque/Clear & 36.22 & 59.88 \\
\hline $\begin{array}{c}\text { V166A-0964- } \\
0493-405\end{array}$ & $\begin{array}{l}\text { VNS- } \\
\text { A32 }\end{array}$ & 0.964 & $\begin{array}{c}0.49 \\
3\end{array}$ & 0 & $\begin{array}{c}\text { No } \\
\text { Separation }\end{array}$ & 43.8 & 47 \\
\hline $\begin{array}{c}\text { V166A-1316- } \\
0739-405\end{array}$ & $\begin{array}{l}\text { VNS- } \\
\text { A33 }\end{array}$ & 1.316 & $\begin{array}{c}0.73 \\
9\end{array}$ & 0 & $\begin{array}{c}\text { No } \\
\text { Separation }\end{array}$ & 44.25 & 45.55 \\
\hline $\begin{array}{c}\text { V166A-1668- } \\
0985-405 \\
\end{array}$ & $\begin{array}{l}\text { VNS- } \\
\text { A34 }\end{array}$ & 1.668 & $\begin{array}{c}0.98 \\
5 \\
\end{array}$ & 5 & Opaque & 42.42 & 45.45 \\
\hline $\begin{array}{c}\text { V166A-2020- } \\
1232-405\end{array}$ & $\begin{array}{l}\text { VNS- } \\
\text { A35 }\end{array}$ & 2.020 & $\begin{array}{c}1.23 \\
2 \\
\end{array}$ & 5 & Opaque & 42.5 & 46.06 \\
\hline $\begin{array}{c}\text { V166A-2371- } \\
1478-405 \\
\end{array}$ & $\begin{array}{l}\text { VNS- } \\
\text { A36 }\end{array}$ & 2.371 & $\begin{array}{c}1.47 \\
8 \\
\end{array}$ & 5 & Opaque & 42.92 & 46.21 \\
\hline $\begin{array}{c}\text { V166A-0260- } \\
0000-405\end{array}$ & $\begin{array}{l}\text { VNS- } \\
\text { A37 }\end{array}$ & 0.260 & $\begin{array}{c}0.00 \\
0\end{array}$ & 11 & Clear & 0.82 & 50.06 \\
\hline $\begin{array}{c}\text { V166A-0600- } \\
1000-405\end{array}$ & $\begin{array}{l}\text { VNS- } \\
\text { A38 }\end{array}$ & 0.600 & $\begin{array}{c}1.00 \\
0 \\
\end{array}$ & 8 & Opaque & 36.64 & 45.51 \\
\hline $\begin{array}{c}\text { V166A-1000- } \\
1000-405 \\
\end{array}$ & $\begin{array}{l}\text { VNS- } \\
\text { A39 }\end{array}$ & 1.000 & $\begin{array}{c}1.00 \\
0 \\
\end{array}$ & 7 & Opaque & 40.58 & 43.29 \\
\hline $\begin{array}{c}\text { V166A-1400- } \\
1000-405\end{array}$ & $\begin{array}{l}\text { VNS- } \\
\text { A40 }\end{array}$ & 1.400 & $\begin{array}{c}1.00 \\
0\end{array}$ & 6 & Opaque & 36.44 & 44.7 \\
\hline $\begin{array}{c}\text { V166A-0600- } \\
0500-405\end{array}$ & $\begin{array}{l}\text { VNS- } \\
\text { A41 }\end{array}$ & 0.600 & $\begin{array}{c}0.50 \\
0\end{array}$ & 2 & Opaque Film & 33.44 & 61.83 \\
\hline $\begin{array}{c}\text { V166A-0600- } \\
0750-405\end{array}$ & $\begin{array}{l}\text { VNS- } \\
\text { A42 }\end{array}$ & 0.600 & $\begin{array}{c}0.75 \\
0\end{array}$ & 1 & Opaque Film & 33.76 & 50.88 \\
\hline $\begin{array}{c}\text { V166A-0600- } \\
1300-405\end{array}$ & $\begin{array}{l}\text { VNS- } \\
\text { A43 }\end{array}$ & 0.600 & $\begin{array}{c}1.30 \\
0\end{array}$ & 9 & Opaque & 37.63 & 46.64 \\
\hline $\begin{array}{c}\text { V166A-2000- } \\
0750-405\end{array}$ & $\begin{array}{l}\text { VNS- } \\
\text { A44 }\end{array}$ & 2.000 & $\begin{array}{c}0.75 \\
0\end{array}$ & 0 & $\begin{array}{c}\text { No } \\
\text { Separation }\end{array}$ & 39.21 & 44.92 \\
\hline
\end{tabular}




\begin{tabular}{|c|c|c|c|c|c|c|c|}
\hline $\begin{array}{c}\text { V166A-2000- } \\
1000-405 \\
\end{array}$ & $\begin{array}{l}\text { VNS- } \\
\text { A45 }\end{array}$ & 2.000 & $\begin{array}{c}1.00 \\
0 \\
\end{array}$ & 0 & $\begin{array}{c}\text { No } \\
\text { Separation }\end{array}$ & 40.88 & 44.93 \\
\hline $\begin{array}{c}\text { V166A-2400- } \\
0750-405\end{array}$ & $\begin{array}{l}\text { VNS- } \\
\text { A46 }\end{array}$ & 2.400 & $\begin{array}{c}0.75 \\
0\end{array}$ & 0 & $\begin{array}{c}\text { No } \\
\text { Separation }\end{array}$ & 40.68 & 44.13 \\
\hline $\begin{array}{c}\text { V166A-0260- } \\
0000-405\end{array}$ & $\begin{array}{l}\text { VNS- } \\
\text { A47 }\end{array}$ & 0.260 & $\begin{array}{c}0.00 \\
0\end{array}$ & 13 & Clear & 1.19 & 50.41 \\
\hline
\end{tabular}

VAS 166A series syneresis and percent solids data.

\begin{tabular}{|c|c|c|c|c|c|c|c|c|}
\hline \multirow[t]{2}{*}{ Sample } & \multirow{2}{*}{$\begin{array}{l}\text { Call } \\
\text { Name }\end{array}$} & \multirow{2}{*}{$\begin{array}{c}\% \\
\text { HEU } \\
\text { R }\end{array}$} & \multirow{2}{*}{$\begin{array}{l}\% \\
\text { Surf }\end{array}$} & \multicolumn{2}{|c|}{ Syneresis (mm) } & \multirow{2}{*}{$\begin{array}{c}\% \\
\text { Solids } \\
\text { Top } \\
\text { Layer }\end{array}$} & \multirow{2}{*}{$\begin{array}{c}\% \\
\text { Solids } \\
\text { Bot } \\
\text { Layer }\end{array}$} & \multirow[t]{2}{*}{ IRBS } \\
\hline & & & & 1 week & $\begin{array}{l}\text { Appearance } \\
\text { of Top Layer }\end{array}$ & & & \\
\hline $\begin{array}{c}\text { V166-0260- } \\
0000-411\end{array}$ & $\begin{array}{l}\text { VAS- } \\
\text { A1 }\end{array}$ & $\begin{array}{c}0.26 \\
0\end{array}$ & 0.00 & 9 & Clear & 0.74 & 49.6 & $\begin{array}{c}41.0 \\
5\end{array}$ \\
\hline $\begin{array}{c}\text { V166-0612- } \\
0000-411\end{array}$ & $\begin{array}{c}\text { VAS- } \\
\text { A2 }\end{array}$ & $\begin{array}{c}0.61 \\
2 \\
\end{array}$ & 0.00 & 3 & Opaque & 36.39 & 45.66 & $\begin{array}{c}42.2 \\
7\end{array}$ \\
\hline $\begin{array}{c}\text { V166-0964- } \\
0000-411 \\
\end{array}$ & $\begin{array}{l}\text { VAS- } \\
\text { A3 }\end{array}$ & $\begin{array}{c}0.96 \\
4\end{array}$ & 0.00 & 0 & $\begin{array}{c}\text { No } \\
\text { Separation }\end{array}$ & 43.57 & 44.29 & $\begin{array}{c}42.2 \\
2 \\
\end{array}$ \\
\hline $\begin{array}{c}\text { V166-1316- } \\
0000-411 \\
\end{array}$ & $\begin{array}{l}\text { VAS- } \\
\text { A4 }\end{array}$ & $\begin{array}{c}1.31 \\
6 \\
\end{array}$ & 0.00 & 0 & $\begin{array}{c}\text { No } \\
\text { Separation }\end{array}$ & 43.87 & 44.57 & $\begin{array}{c}35.7 \\
3\end{array}$ \\
\hline $\begin{array}{c}\text { V166-1668- } \\
0000-411\end{array}$ & $\begin{array}{l}\text { VAS- } \\
\text { A5 }\end{array}$ & $\begin{array}{c}1.66 \\
8\end{array}$ & 0.00 & 0 & $\begin{array}{c}\text { No } \\
\text { Separation }\end{array}$ & 43.73 & 44.6 & $\begin{array}{c}30.6 \\
0\end{array}$ \\
\hline $\begin{array}{c}\text { V166-2020- } \\
0000-411\end{array}$ & $\begin{array}{l}\text { VAS- } \\
\text { A6 }\end{array}$ & $\begin{array}{c}2.02 \\
0\end{array}$ & 0.00 & 0 & $\begin{array}{c}\text { No } \\
\text { Separation }\end{array}$ & 44.31 & 44.72 & $\begin{array}{c}28.5 \\
6\end{array}$ \\
\hline $\begin{array}{c}\text { V166-2371- } \\
0000-411\end{array}$ & $\begin{array}{l}\text { VAS- } \\
\text { A7 }\end{array}$ & $\begin{array}{c}2.37 \\
1\end{array}$ & 0.00 & 0 & $\begin{array}{c}\text { No } \\
\text { Separation }\end{array}$ & 43 & 44.33 & $\begin{array}{c}27.4 \\
1\end{array}$ \\
\hline $\begin{array}{c}\text { V166-0260- } \\
0000-411\end{array}$ & $\begin{array}{c}\text { VAS- } \\
\text { A8 }\end{array}$ & 0.26 & $\begin{array}{c}0.00 \\
0\end{array}$ & 10 & Clear & 0.75 & 49.46 & $\begin{array}{c}40.5 \\
6\end{array}$ \\
\hline $\begin{array}{c}\text { V166-0260- } \\
0412-411\end{array}$ & $\begin{array}{l}\text { VAS- } \\
\text { A9 }\end{array}$ & 0.26 & $\begin{array}{c}0.41 \\
2\end{array}$ & 19 & Clear & 1.12 & 54.66 & $\begin{array}{c}43.7 \\
6\end{array}$ \\
\hline $\begin{array}{c}\text { V166-0260- } \\
0825-411\end{array}$ & $\begin{array}{l}\text { VAS- } \\
\text { A10 }\end{array}$ & 0.26 & $\begin{array}{c}0.82 \\
5\end{array}$ & 0 & $\begin{array}{c}\text { No } \\
\text { Separation }\end{array}$ & 44.32 & 46 & $\begin{array}{c}49.5 \\
8\end{array}$ \\
\hline $\begin{array}{c}\text { V166-0260- } \\
1237-411\end{array}$ & $\begin{array}{l}\text { VAS- } \\
\text { A11 }\end{array}$ & 0.26 & $\begin{array}{c}1.23 \\
7\end{array}$ & 0 & $\begin{array}{c}\text { No } \\
\text { Separation }\end{array}$ & 40.4 & 46.14 & $\begin{array}{c}45.8 \\
1\end{array}$ \\
\hline $\begin{array}{c}\text { V166-0260- } \\
1650-411\end{array}$ & $\begin{array}{l}\text { VAS- } \\
\text { A12 }\end{array}$ & 0.26 & $\begin{array}{c}1.65 \\
0\end{array}$ & 5 & Opaque & 31.6 & 53.58 & $\begin{array}{c}38.6 \\
6\end{array}$ \\
\hline $\begin{array}{c}\text { V166-0260- } \\
0206-411 \\
\end{array}$ & $\begin{array}{l}\text { VAS- } \\
\text { A13 }\end{array}$ & 0.26 & $\begin{array}{c}0.20 \\
6 \\
\end{array}$ & 17 & Clear/Opaque & 1.07 & 52.81 & $\begin{array}{c}39.6 \\
5 \\
\end{array}$ \\
\hline $\begin{array}{c}\text { V166-0260- } \\
0619-411\end{array}$ & $\begin{array}{l}\text { VAS- } \\
\text { A14 }\end{array}$ & 0.26 & $\begin{array}{c}0.61 \\
9\end{array}$ & 14 & Opaque & 4.47 & 57.95 & $\begin{array}{c}46.3 \\
9\end{array}$ \\
\hline $\begin{array}{c}\text { V166-0260- } \\
1031-411 \\
\end{array}$ & $\begin{array}{l}\text { VAS- } \\
\text { A15 }\end{array}$ & 0.26 & $\begin{array}{c}1.03 \\
1\end{array}$ & 0 & $\begin{array}{c}\text { No } \\
\text { Separation }\end{array}$ & 42.27 & 45.83 & $\begin{array}{c}47.3 \\
3\end{array}$ \\
\hline $\begin{array}{c}\text { V166-0260- } \\
0000-411\end{array}$ & $\begin{array}{l}\text { VAS- } \\
\text { A16 }\end{array}$ & $\begin{array}{c}0.26 \\
0\end{array}$ & $\begin{array}{c}0.00 \\
0\end{array}$ & 14 & Clear & 0.95 & 50.72 & $\begin{array}{c}42.3 \\
6\end{array}$ \\
\hline $\begin{array}{c}\text { V166-0612- } \\
0251-411 \\
\end{array}$ & $\begin{array}{l}\text { VAS- } \\
\text { A17 }\end{array}$ & $\begin{array}{c}0.61 \\
2\end{array}$ & $\begin{array}{c}0.25 \\
1\end{array}$ & 5 & Clear & 19.21 & 63.54 & $\begin{array}{c}44.3 \\
3\end{array}$ \\
\hline $\begin{array}{c}\text { V166-0964- } \\
0501-411\end{array}$ & $\begin{array}{l}\text { VAS- } \\
\text { A18 }\end{array}$ & $\begin{array}{c}0.96 \\
4\end{array}$ & $\begin{array}{c}0.50 \\
1\end{array}$ & 0 & - & 41.12 & 45.94 & $\begin{array}{c}37.8 \\
2\end{array}$ \\
\hline $\begin{array}{c}\text { V166-1316- } \\
0752-411\end{array}$ & $\begin{array}{l}\text { VAS- } \\
\text { A19 }\end{array}$ & $\begin{array}{c}1.31 \\
6\end{array}$ & $\begin{array}{c}0.75 \\
2\end{array}$ & 7 & Opaque & 39.21 & 45.19 & $\begin{array}{c}39.3 \\
5\end{array}$ \\
\hline
\end{tabular}




\begin{tabular}{|c|c|c|c|c|c|c|c|c|}
\hline $\begin{array}{c}\text { V166-1668- } \\
1003-411\end{array}$ & $\begin{array}{l}\text { VAS- } \\
\text { A20 }\end{array}$ & $\begin{array}{c}1.66 \\
8\end{array}$ & $\begin{array}{c}1.00 \\
3\end{array}$ & 7 & Opaque & 39.55 & 45.13 & $\begin{array}{c}39.9 \\
9\end{array}$ \\
\hline $\begin{array}{c}\text { V166-0612- } \\
0501-411 \\
\end{array}$ & $\begin{array}{l}\text { VAS- } \\
\text { A21 }\end{array}$ & $\begin{array}{c}0.61 \\
2 \\
\end{array}$ & $\begin{array}{c}0.50 \\
1\end{array}$ & 1 & Opaque Film & 38.08 & 45.46 & $\begin{array}{c}43.1 \\
4 \\
\end{array}$ \\
\hline $\begin{array}{c}\text { V166-0964- } \\
0752-411 \\
\end{array}$ & $\begin{array}{l}\text { VAS- } \\
\text { A22 }\end{array}$ & $\begin{array}{c}0.96 \\
4\end{array}$ & $\begin{array}{c}0.75 \\
2 \\
\end{array}$ & 7 & Opaque & 39.45 & 45.63 & $\begin{array}{c}41.2 \\
2 \\
\end{array}$ \\
\hline $\begin{array}{c}\text { V166-1316- } \\
1003-411 \\
\end{array}$ & $\begin{array}{l}\text { VAS- } \\
\text { A23 }\end{array}$ & $\begin{array}{c}1.31 \\
6 \\
\end{array}$ & $\begin{array}{c}1.00 \\
3 \\
\end{array}$ & 7 & Opaque & 41.69 & 45.01 & $\begin{array}{c}37.1 \\
0\end{array}$ \\
\hline $\begin{array}{c}\text { V166-0260- } \\
0000-411\end{array}$ & $\begin{array}{l}\text { VAS- } \\
\text { A24 }\end{array}$ & 0.26 & $\begin{array}{c}0.00 \\
0\end{array}$ & 12 & clear & 0.72 & 50.56 & $\begin{array}{c}37.5 \\
9\end{array}$ \\
\hline $\begin{array}{c}\text { V166-0600- } \\
0700-411 \\
\end{array}$ & $\begin{array}{l}\text { VAS- } \\
\text { A25 }\end{array}$ & 0.6 & $\begin{array}{c}0.70 \\
0 \\
\end{array}$ & 0 & no separation & 36.68 & 47.035 & $\begin{array}{c}43.4 \\
3 \\
\end{array}$ \\
\hline $\begin{array}{c}\text { V166-0600- } \\
0900-411\end{array}$ & $\begin{array}{l}\text { VAS- } \\
\text { A26 }\end{array}$ & 0.6 & $\begin{array}{c}0.90 \\
0\end{array}$ & 10 & opaque & 36.55 & 46.26 & $\begin{array}{c}41.8 \\
9\end{array}$ \\
\hline $\begin{array}{c}\text { V166-0600- } \\
1100-411\end{array}$ & $\begin{array}{l}\text { VAS- } \\
\text { A27 }\end{array}$ & 0.6 & $\begin{array}{c}1.10 \\
0\end{array}$ & 15 & opaque & 35.875 & 48.4 & $\begin{array}{c}36.8 \\
5\end{array}$ \\
\hline $\begin{array}{c}\text { V166-1316- } \\
0500-411\end{array}$ & $\begin{array}{l}\text { VAS- } \\
\text { A28 }\end{array}$ & $\begin{array}{c}1.31 \\
6\end{array}$ & $\begin{array}{c}0.50 \\
0\end{array}$ & 0 & no separation & 41.85 & 43.76 & $\begin{array}{c}37.7 \\
8\end{array}$ \\
\hline $\begin{array}{c}\text { V166-1668- } \\
0500-411 \\
\end{array}$ & $\begin{array}{l}\text { VAS- } \\
\text { A29 }\end{array}$ & $\begin{array}{c}1.66 \\
8\end{array}$ & $\begin{array}{c}0.50 \\
0 \\
\end{array}$ & 6 & opaque & 41.955 & 44.125 & $\begin{array}{c}33.1 \\
3\end{array}$ \\
\hline $\begin{array}{c}\text { V166-1668- } \\
0750-411 \\
\end{array}$ & $\begin{array}{l}\text { VAS- } \\
\text { A30 }\end{array}$ & $\begin{array}{c}1.66 \\
8\end{array}$ & $\begin{array}{c}0.75 \\
0\end{array}$ & 7 & opaque & 41.585 & 43.16 & $\begin{array}{c}38.6 \\
5\end{array}$ \\
\hline $\begin{array}{c}\text { V166-0964- } \\
0250-411 \\
\end{array}$ & $\begin{array}{l}\text { VAS- } \\
\text { A31 }\end{array}$ & $\begin{array}{c}0.96 \\
4 \\
\end{array}$ & $\begin{array}{c}0.25 \\
0 \\
\end{array}$ & 0 & no separation & 41.665 & 44.375 & $\begin{array}{c}43.9 \\
8 \\
\end{array}$ \\
\hline
\end{tabular}

VNS2 166A series syneresis and percent solids data.

\begin{tabular}{|c|c|c|c|c|c|c|c|}
\hline \multirow{2}{*}{ Sample } & \multirow{2}{*}{$\begin{array}{l}\text { Call } \\
\text { Name }\end{array}$} & \multirow{2}{*}{$\begin{array}{c}\% \\
\text { HEU } \\
\text { R }\end{array}$} & \multirow[t]{2}{*}{$\begin{array}{l}\% \\
\text { Surf }\end{array}$} & \multicolumn{2}{|c|}{ Syneresis } & \multirow{2}{*}{$\begin{array}{c}\% \\
\text { Solid } \\
\text { s Top } \\
\text { Layer }\end{array}$} & \multirow{2}{*}{$\begin{array}{c}\% \\
\text { Solid } \\
\text { s Bot } \\
\text { Layer }\end{array}$} \\
\hline & & & & $\begin{array}{c}1 \text { week } \\
(\mathrm{mm})\end{array}$ & $\begin{array}{l}\text { Appearance } \\
\text { of Top Layer }\end{array}$ & & \\
\hline $\begin{array}{c}\text { V166A-0260- } \\
0000-100\end{array}$ & $\begin{array}{c}\text { VNS2- } \\
\text { A1 }\end{array}$ & 0.26 & 0.000 & 12 & Clear & 0.8 & 47.48 \\
\hline $\begin{array}{c}\text { V166A-0260- } \\
0352-100\end{array}$ & $\begin{array}{l}\text { VNS2- } \\
\text { A2 }\end{array}$ & 0.26 & 0.352 & 7 & Clear & 0.91 & 50.06 \\
\hline $\begin{array}{c}\text { V166A-0260- } \\
0704-100 \\
\end{array}$ & $\begin{array}{l}\text { VNS2- } \\
\text { A3 }\end{array}$ & 0.26 & 0.704 & 14 & Clear/opaque & 1.64 & 53.43 \\
\hline $\begin{array}{c}\text { V166A-0260- } \\
1056-100\end{array}$ & $\begin{array}{l}\text { VNS2- } \\
\text { A4 }\end{array}$ & 0.26 & 1.056 & 6 & Clear/opaque & 9.27 & 59.17 \\
\hline $\begin{array}{c}\text { V166A-0260- } \\
1408-100\end{array}$ & $\begin{array}{l}\text { VNS2- } \\
\text { A5 }\end{array}$ & 0.26 & 1.408 & 6 & Opaque & 37.93 & 42.44 \\
\hline $\begin{array}{c}\text { V166A-0260- } \\
1760-100\end{array}$ & $\begin{array}{c}\text { VNS2- } \\
\text { A6 }\end{array}$ & 0.26 & 1.760 & 6 & Opaque & 40 & 42.67 \\
\hline $\begin{array}{c}\text { V166A-0260- } \\
2111-100\end{array}$ & $\begin{array}{l}\text { VNS2- } \\
\text { A7 }\end{array}$ & 0.26 & 2.111 & 7 & Opaque & 32.64 & 46.3 \\
\hline $\begin{array}{c}\text { V166A-0260- } \\
2463-100\end{array}$ & $\begin{array}{l}\text { VNS2- } \\
\text { A8 }\end{array}$ & 0.26 & 2.463 & 7 & Opaque & 31.73 & 46.34 \\
\hline $\begin{array}{c}\text { V166A-0260- } \\
0000-100\end{array}$ & $\begin{array}{l}\text { VNS2- } \\
\text { A9 }\end{array}$ & 0.260 & 0.000 & 6 & Clear & 1.08 & 46.22 \\
\hline $\begin{array}{c}\text { V166A-0612- } \\
\text { 0352-100 }\end{array}$ & $\begin{array}{l}\text { VNS2- } \\
\text { A10 }\end{array}$ & 0.612 & 0.352 & 4 & $\begin{array}{c}\text { Clear/Opaqu } \\
\mathrm{e}\end{array}$ & 3.94 & 64.06 \\
\hline
\end{tabular}




\begin{tabular}{|c|c|c|c|c|c|c|c|}
\hline $\begin{array}{c}\text { V166A-0964- } \\
0704-100\end{array}$ & $\begin{array}{l}\text { VNS2- } \\
\text { A11 }\end{array}$ & 0.964 & 0.704 & 0 & $\begin{array}{c}\text { No } \\
\text { Separation }\end{array}$ & 41.33 & 43.44 \\
\hline $\begin{array}{c}\text { V166A-1316- } \\
0352-100\end{array}$ & $\begin{array}{l}\text { VNS2- } \\
\text { A12 }\end{array}$ & 1.316 & 1.056 & 0 & $\begin{array}{c}\text { No } \\
\text { Separation }\end{array}$ & 39.64 & 43.03 \\
\hline $\begin{array}{c}\text { V166A-1668- } \\
0352-100\end{array}$ & $\begin{array}{c}\text { VNS2- } \\
\text { A13 }\end{array}$ & 1.668 & 1.408 & 0 & $\begin{array}{c}\text { No } \\
\text { Separation }\end{array}$ & 38.04 & 43.11 \\
\hline $\begin{array}{c}\text { V166A-0612- } \\
0352-100 \\
\end{array}$ & $\begin{array}{c}\text { VNS2- } \\
\text { A14 }\end{array}$ & 0.612 & 0.704 & 0 & $\begin{array}{c}\text { No } \\
\text { Separation }\end{array}$ & 33.92 & 49.42 \\
\hline $\begin{array}{c}\text { V166A-0964- } \\
0352-100 \\
\end{array}$ & $\begin{array}{l}\text { VNS2- } \\
\text { A15 }\end{array}$ & 0.964 & 1.056 & 0 & $\begin{array}{c}\text { No } \\
\text { Separation }\end{array}$ & 41.3 & 45.12 \\
\hline $\begin{array}{c}\text { V166A-1316- } \\
0352-100\end{array}$ & $\begin{array}{c}\text { VNS2- } \\
\text { A16 }\end{array}$ & 1.316 & 1.408 & 0 & $\begin{array}{c}\text { No } \\
\text { Separation }\end{array}$ & 42.46 & 44.89 \\
\hline
\end{tabular}

Syneresis and percent solids data for G-VNS 166A series.

\begin{tabular}{|c|c|c|c|c|c|c|c|}
\hline \multirow[b]{2}{*}{ Sample } & \multirow[b]{2}{*}{$\begin{array}{l}\text { Call } \\
\text { Name }\end{array}$} & \multirow[b]{2}{*}{$\begin{array}{c}\% \\
\text { HEU } \\
\text { R }\end{array}$} & \multirow[b]{2}{*}{$\begin{array}{c}\% \\
\text { SUR } \\
F\end{array}$} & \multicolumn{2}{|c|}{ Syneresis } & \multirow[b]{2}{*}{$\begin{array}{l}\% \text { Solids } \\
\text { Top Layer }\end{array}$} & \multirow[b]{2}{*}{$\begin{array}{c}\% \\
\text { Solids } \\
\text { Bot } \\
\text { Layer }\end{array}$} \\
\hline & & & & $\begin{array}{c}1 \\
\text { wee } \\
\text { k } \\
(\mathrm{m} \\
\mathrm{m})\end{array}$ & $\begin{array}{c}\text { Appearanc } \\
\text { e of Top } \\
\text { Layer }\end{array}$ & & \\
\hline $\begin{array}{c}\text { G-V166A-0260- } \\
0000-405\end{array}$ & $\begin{array}{c}\text { G-VNS- } \\
\text { A1 }\end{array}$ & 0.26 & 0 & 8 & clear & 0.62 & 53.22 \\
\hline $\begin{array}{c}\text { G-V166A-0260- } \\
0500-405\end{array}$ & $\begin{array}{c}\text { G-VNS- } \\
\text { A2 }\end{array}$ & 0.26 & 0.5 & 15 & $\begin{array}{c}\text { clear/opaq } \\
\text { ue }\end{array}$ & 1.41 & 54.91 \\
\hline $\begin{array}{c}\text { G-V166A-0260- } \\
1000-405\end{array}$ & $\begin{array}{c}\text { G-VNS- } \\
\text { A3 }\end{array}$ & 0.26 & 1 & 3 & opaque & 36.33 & 52.46 \\
\hline $\begin{array}{c}\text { G-V166A-0260- } \\
1500-405\end{array}$ & $\begin{array}{l}\text { G-VNS- } \\
\text { A4 }\end{array}$ & 0.26 & 1.5 & 7 & opaque & 41.74 & 45.97 \\
\hline $\begin{array}{c}\text { G-V166A-0260- } \\
2000-405\end{array}$ & $\begin{array}{c}\text { G-VNS- } \\
\text { A5 }\end{array}$ & 0.26 & 2 & 10 & opaque & 34.01 & 48.27 \\
\hline $\begin{array}{c}\text { G-V166A-0750- } \\
0000-405\end{array}$ & $\begin{array}{c}\text { G-VNS- } \\
\text { A6 }\end{array}$ & 0.75 & 0 & 4 & clear & 43.68 & 44.05 \\
\hline $\begin{array}{c}\text { G-V166A-0750- } \\
0500-405\end{array}$ & $\begin{array}{l}\text { G-VNS- } \\
\text { A7 }\end{array}$ & 0.75 & 0.5 & 8 & opaque & 40.7 & 44.16 \\
\hline $\begin{array}{c}\text { G-V166A-0750- } \\
1000-405\end{array}$ & $\begin{array}{c}\text { G-VNS- } \\
\text { A8 }\end{array}$ & 0.75 & 1 & 6 & opaque & 40.04 & 43.15 \\
\hline $\begin{array}{c}\text { G-V166A-0750- } \\
1500-405\end{array}$ & $\begin{array}{c}\text { G-VNS- } \\
\text { A9 }\end{array}$ & 0.75 & 1.5 & 4 & opaque & 41.41 & 47.65 \\
\hline $\begin{array}{c}\text { G-V166A-0750- } \\
2000-405\end{array}$ & $\begin{array}{l}\text { G-VNS- } \\
\text { A10 }\end{array}$ & 0.75 & 2 & 9 & opaque & 36.32 & 48.73 \\
\hline $\begin{array}{c}\text { G-V166A-1250- } \\
0000-405\end{array}$ & $\begin{array}{l}\text { G-VNS- } \\
\text { A11 }\end{array}$ & 1.25 & 0 & 0 & $\begin{array}{c}\text { no } \\
\text { separation }\end{array}$ & 42.99 & 44.14 \\
\hline $\begin{array}{c}\text { G-V166A-1250- } \\
0500-405\end{array}$ & $\begin{array}{l}\text { G-VNS- } \\
\text { A12 }\end{array}$ & 1.25 & 0.5 & 0 & $\begin{array}{c}\text { no } \\
\text { separation }\end{array}$ & 39.29 & 44.21 \\
\hline $\begin{array}{c}\text { G-V166A-1250- } \\
1000-405\end{array}$ & $\begin{array}{c}\text { G-VNS- } \\
\text { A13 }\end{array}$ & 1.25 & 1 & 8 & opaque & 36.2 & 43.69 \\
\hline $\begin{array}{c}\text { G-V166A-1250- } \\
1500-405\end{array}$ & $\begin{array}{c}\text { G-VNS- } \\
\text { A14 }\end{array}$ & 1.25 & 1.5 & 9 & opaque & 37.05 & 42.71 \\
\hline $\begin{array}{c}\text { G-V166A-1250- } \\
2000-405 \\
\end{array}$ & $\begin{array}{c}\text { G-VNS- } \\
\text { A15 }\end{array}$ & 1.25 & 2 & 9.5 & opaque & 35.74 & 45.39 \\
\hline
\end{tabular}




\begin{tabular}{|c|c|c|c|c|c|c|c|}
\hline $\begin{array}{c}\text { G-V166A-1750- } \\
0000-405\end{array}$ & $\begin{array}{l}\text { G-VNS- } \\
\text { A16 }\end{array}$ & 1.75 & 0 & 0 & $\begin{array}{c}\text { no } \\
\text { separation }\end{array}$ & 42.94 & 43.83 \\
\hline $\begin{array}{c}\text { G-V166A-1750- } \\
0500-405\end{array}$ & $\begin{array}{l}\text { G-VNS- } \\
\text { A17 }\end{array}$ & 1.75 & 0.5 & 0 & $\begin{array}{c}\text { no } \\
\text { separation }\end{array}$ & 44.45 & 44.79 \\
\hline $\begin{array}{c}\text { G-V166A-1750- } \\
1000-405\end{array}$ & $\begin{array}{c}\text { G-VNS- } \\
\text { A18 }\end{array}$ & 1.75 & 1 & 6 & opaque & 38.93 & 42.66 \\
\hline $\begin{array}{c}\text { G-V166A-1750- } \\
1500-405\end{array}$ & $\begin{array}{l}\text { G-VNS- } \\
\text { A19 }\end{array}$ & 1.75 & 1.5 & 7.5 & opaque & 38.4 & 44.25 \\
\hline $\begin{array}{c}\text { G-V166A-1750- } \\
2000-405\end{array}$ & $\begin{array}{l}\text { G-VNS- } \\
\text { A20 }\end{array}$ & 1.75 & 2 & 8.5 & opaque & 33.96 & 44.04 \\
\hline $\begin{array}{c}\text { G-V166A-2250- } \\
0000-405\end{array}$ & $\begin{array}{c}\text { G-VNS- } \\
\text { A21 }\end{array}$ & 2.25 & 0 & 0 & $\begin{array}{c}\text { no } \\
\text { separation }\end{array}$ & 43.47 & 43.31 \\
\hline $\begin{array}{c}\text { G-V166A-2250- } \\
0500-405\end{array}$ & $\begin{array}{l}\text { G-VNS- } \\
\text { A22 }\end{array}$ & 2.25 & 0.5 & 0 & $\begin{array}{c}\text { no } \\
\text { separation }\end{array}$ & 40.81 & 43.18 \\
\hline $\begin{array}{c}\text { G-V166A-2250- } \\
1000-405\end{array}$ & $\begin{array}{c}\text { G-VNS- } \\
\text { A23 }\end{array}$ & 2.25 & 1 & 7 & opaque & 38.5 & 44.08 \\
\hline $\begin{array}{c}\text { G-V166A-2250- } \\
1500-405\end{array}$ & $\begin{array}{l}\text { G-VNS- } \\
\text { A24 }\end{array}$ & 2.25 & 1.5 & 8 & opaque & 36.76 & 41.98 \\
\hline $\begin{array}{c}\text { G-V166A-2250- } \\
2000-405 \\
\end{array}$ & $\begin{array}{c}\text { G-VNS- } \\
\text { A25 }\end{array}$ & 2.25 & 2 & 8 & opaque & 36.86 & 44.58 \\
\hline $\begin{array}{c}\text { G-V166A-0260- } \\
1150-405\end{array}$ & $\begin{array}{c}\text { G-VNS- } \\
\text { A34 }\end{array}$ & 0.26 & 1.15 & 6 & opaque & 35.86 & 43.18 \\
\hline $\begin{array}{c}\text { G-V166A-0260- } \\
1350-405\end{array}$ & $\begin{array}{l}\text { G-VNS- } \\
\text { A35 }\end{array}$ & 0.26 & 1.35 & 6.5 & opaque & 32.91 & 42.09 \\
\hline $\begin{array}{c}\text { G-V166A-0750- } \\
0650-405\end{array}$ & $\begin{array}{c}\text { G-VNS- } \\
\text { A36 }\end{array}$ & 0.75 & 0.65 & 7 & opaque & 32.58 & 41.27 \\
\hline $\begin{array}{c}\text { G-V166A-0750- } \\
0850-405\end{array}$ & $\begin{array}{c}\text { G-VNS- } \\
\text { A37 }\end{array}$ & 0.75 & 0.85 & 8 & opaque & 34.14 & 42.75 \\
\hline $\begin{array}{c}\text { G-V166A-1250- } \\
0650-405\end{array}$ & $\begin{array}{c}\text { G-VNS- } \\
\text { A38 }\end{array}$ & 1.25 & 0.65 & 0 & $\begin{array}{c}\text { no } \\
\text { separation }\end{array}$ & 37.75 & 43 \\
\hline $\begin{array}{c}\text { G-V166A-1250- } \\
0850-405\end{array}$ & $\begin{array}{c}\text { G-VNS- } \\
\text { A39 }\end{array}$ & 1.25 & 0.85 & 7 & opaque & 35.76 & 41.15 \\
\hline $\begin{array}{c}\text { G-V166A-1750- } \\
0650-405\end{array}$ & $\begin{array}{l}\text { G-VNS- } \\
\text { A40 }\end{array}$ & 1.75 & 0.65 & 0 & $\begin{array}{c}\text { no } \\
\text { separation }\end{array}$ & 39.78 & 40.88 \\
\hline $\begin{array}{c}\text { G-V166A-1750- } \\
0850-405\end{array}$ & $\begin{array}{l}\text { G-VNS- } \\
\text { A41 }\end{array}$ & 1.75 & 0.85 & 0 & $\begin{array}{c}\text { no } \\
\text { separation }\end{array}$ & 38.13 & 40.14 \\
\hline
\end{tabular}

Syneresis and percent solids data for G-VAS 166 A series.

\begin{tabular}{|c|c|c|c|c|c|c|c|}
\hline \multirow[b]{2}{*}{ Sample } & \multirow[b]{2}{*}{$\begin{array}{l}\text { Call } \\
\text { Name }\end{array}$} & \multirow{2}{*}{$\begin{array}{c}\% \\
\text { HEU } \\
\text { R }\end{array}$} & \multirow{2}{*}{$\begin{array}{l}\% \\
\mathrm{Su} \\
\mathrm{rf}\end{array}$} & \multicolumn{2}{|c|}{ Syneresis } & \multirow{2}{*}{$\begin{array}{c}\% \\
\text { Solid } \\
\text { s Top } \\
\text { Layer }\end{array}$} & \multirow{2}{*}{$\begin{array}{c}\% \\
\text { Solid } \\
\text { s Bot } \\
\text { Layer }\end{array}$} \\
\hline & & & & $\begin{array}{c}1 \text { week } \\
(\mathrm{mm})\end{array}$ & $\begin{array}{l}\text { Appearance } \\
\text { of Top Layer }\end{array}$ & & \\
\hline $\begin{array}{c}\text { G-V166A-0260- } \\
0000-411\end{array}$ & $\begin{array}{c}\text { G-VAS- } \\
\text { A1 }\end{array}$ & 0.26 & 0 & 8 & clear & - & - \\
\hline $\begin{array}{c}\text { G-V166A-0260- } \\
0500-411\end{array}$ & $\begin{array}{c}\text { G-VAS- } \\
\text { A2 }\end{array}$ & 0.26 & 0.5 & 15 & clear/opaque & 2.63 & - \\
\hline $\begin{array}{c}\text { G-V166A-0260- } \\
1000-411\end{array}$ & $\begin{array}{c}\text { G-VAS- } \\
\text { A3 }\end{array}$ & 0.26 & 1 & 6 & opaque & 39.71 & 44.6 \\
\hline $\begin{array}{c}\text { G-V166A-0260- } \\
1500-411\end{array}$ & $\begin{array}{c}\text { G-VAS- } \\
\text { A4 }\end{array}$ & 0.26 & 1.5 & 30 & opaque & 31.28 & - \\
\hline
\end{tabular}




\begin{tabular}{|c|c|c|c|c|c|c|c|}
\hline $\begin{array}{c}\text { G-V166A-0260- } \\
2000-411\end{array}$ & $\begin{array}{l}\text { G-VAS- } \\
\text { A5 }\end{array}$ & 0.26 & 2 & 39 & opaque & - & - \\
\hline $\begin{array}{c}\text { G-V166A-0750- } \\
0000-411\end{array}$ & $\begin{array}{l}\text { G-VAS- } \\
\text { A6 }\end{array}$ & 0.75 & 0 & 3 & clear & - & - \\
\hline $\begin{array}{c}\text { G-V166A-0750- } \\
0500-411\end{array}$ & $\begin{array}{l}\text { G-VAS- } \\
\text { A7 }\end{array}$ & 0.75 & 0.5 & 5 & opaque & 38.5 & 41.79 \\
\hline $\begin{array}{c}\text { G-V166A-0750- } \\
1000-411\end{array}$ & $\begin{array}{l}\text { G-VAS- } \\
\text { A8 }\end{array}$ & 0.75 & 1 & 5 & opaque & 38.05 & 42.13 \\
\hline $\begin{array}{c}\text { G-V166A-0750- } \\
1500-411\end{array}$ & $\begin{array}{l}\text { G-VAS- } \\
\text { A9 }\end{array}$ & 0.75 & 1.5 & 14 & opaque & 29.22 & - \\
\hline $\begin{array}{c}\text { G-V166A-0750- } \\
2000-411\end{array}$ & $\begin{array}{l}\text { G-VAS- } \\
\text { A10 }\end{array}$ & 0.75 & 2 & 20 & opaque & - & - \\
\hline $\begin{array}{c}\text { G-V166A-1250- } \\
0000-411\end{array}$ & $\begin{array}{l}\text { G-VAS- } \\
\text { A11 }\end{array}$ & 1.25 & 0 & 0 & no separation & 40.48 & 43.33 \\
\hline $\begin{array}{c}\text { G-V166A-1250- } \\
0500-411\end{array}$ & $\begin{array}{l}\text { G-VAS- } \\
\text { A12 }\end{array}$ & 1.25 & 0.5 & 0 & no separation & 36.15 & \\
\hline $\begin{array}{c}\text { G-V166A-1250- } \\
1000-411\end{array}$ & $\begin{array}{l}\text { G-VAS- } \\
\text { A13 }\end{array}$ & 1.25 & 1 & 7 & opaque & 37.05 & \\
\hline $\begin{array}{c}\text { G-V166A-1250- } \\
1500-411\end{array}$ & $\begin{array}{l}\text { G-VAS- } \\
\text { A14 }\end{array}$ & 1.25 & 1.5 & 8.5 & opaque & - & - \\
\hline $\begin{array}{c}\text { G-V166A-1250- } \\
2000-411\end{array}$ & $\begin{array}{l}\text { G-VAS- } \\
\text { A15 }\end{array}$ & 1.25 & 2 & 9 & opaque & - & - \\
\hline $\begin{array}{c}\text { G-V166A-1750- } \\
0000-411\end{array}$ & $\begin{array}{l}\text { G-VAS- } \\
\text { A16 }\end{array}$ & 1.75 & 0 & 0 & no separation & - & - \\
\hline $\begin{array}{c}\text { G-V166A-1750- } \\
0500-411\end{array}$ & $\begin{array}{l}\text { G-VAS- } \\
\text { A17 }\end{array}$ & 1.75 & 0.5 & 0 & no separation & 33.92 & - \\
\hline $\begin{array}{c}\text { G-V166A-1750- } \\
1000-411\end{array}$ & $\begin{array}{l}\text { G-VAS- } \\
\text { A18 }\end{array}$ & 1.75 & 1 & 6 & opaque & 34.85 & - \\
\hline $\begin{array}{c}\text { G-V166A-1750- } \\
1500-411\end{array}$ & $\begin{array}{l}\text { G-VAS- } \\
\text { A19 }\end{array}$ & 1.75 & 1.5 & 6.5 & opaque & - & - \\
\hline $\begin{array}{c}\text { G-V166A-1750- } \\
2000-411\end{array}$ & $\begin{array}{l}\text { G-VAS- } \\
\text { A20 }\end{array}$ & 1.75 & 2 & 7 & opaque & - & - \\
\hline $\begin{array}{c}\text { G-V166A-2250- } \\
0000-411\end{array}$ & $\begin{array}{l}\text { G-VAS- } \\
\text { A21 }\end{array}$ & 2.25 & 0 & 0 & no separation & & \\
\hline $\begin{array}{c}\text { G-V166A-2250- } \\
0500-411\end{array}$ & $\begin{array}{l}\text { G-VAS- } \\
\text { A22 }\end{array}$ & 2.25 & 0.5 & 0 & no separation & 33.33 & - \\
\hline $\begin{array}{c}\text { G-V166A-2250- } \\
1000-411\end{array}$ & $\begin{array}{l}\text { G-VAS- } \\
\text { A23 }\end{array}$ & 2.25 & 1 & 6 & opaque & 30.26 & - \\
\hline $\begin{array}{c}\text { G-V166A-2250- } \\
1500-411\end{array}$ & $\begin{array}{l}\text { G-VAS- } \\
\text { A24 }\end{array}$ & 2.25 & 1.5 & 6 & opaque & - & - \\
\hline $\begin{array}{c}\text { G-V166A-2250- } \\
2000-411\end{array}$ & $\begin{array}{l}\text { G-VAS- } \\
\text { A25 }\end{array}$ & 2.25 & 2 & 6 & opaque & - & - \\
\hline $\begin{array}{c}\text { G-V166A-0260- } \\
0250-411\end{array}$ & $\begin{array}{l}\text { G-VAS- } \\
\text { A26 }\end{array}$ & 0.26 & $\begin{array}{c}0.2 \\
5\end{array}$ & 10 & clear & 0.63 & - \\
\hline $\begin{array}{c}\text { G-V166A-0260- } \\
0750-411\end{array}$ & $\begin{array}{l}\text { G-VAS- } \\
\text { A27 }\end{array}$ & 0.26 & $\begin{array}{c}0.7 \\
5\end{array}$ & 0 & no separation & 39.23 & 43.97 \\
\hline $\begin{array}{c}\text { G-V166A-0750- } \\
0250-411\end{array}$ & $\begin{array}{l}\text { G-VAS- } \\
\text { A28 }\end{array}$ & 0.75 & $\begin{array}{c}0.2 \\
5\end{array}$ & 3 & opaque & 39.8 & 42.35 \\
\hline $\begin{array}{c}\text { G-V166A-0750- } \\
0750-411\end{array}$ & $\begin{array}{c}\text { G-VAS- } \\
\text { A29 }\end{array}$ & 0.75 & $\begin{array}{c}0.7 \\
5\end{array}$ & 4 & opaque & 41.32 & 43.37 \\
\hline
\end{tabular}




\begin{tabular}{|c|c|c|c|c|c|c|c|}
$\begin{array}{c}\text { G-V166A-1250- } \\
0250-411\end{array}$ & $\begin{array}{c}\text { G-VAS- } \\
\text { A30 }\end{array}$ & 1.25 & $\begin{array}{c}0.2 \\
5\end{array}$ & 0 & no separation & 41.28 & 42.08 \\
\hline $\begin{array}{c}\text { G-V166A-1250- } \\
0750-411\end{array}$ & $\begin{array}{c}\text { G-VAS- } \\
\text { A31 }\end{array}$ & 1.25 & $\begin{array}{c}0.7 \\
5\end{array}$ & 3 & opaque & 40.77 & 43.5 \\
\hline $\begin{array}{c}\text { G-V166A-1750- } \\
0250-411\end{array}$ & $\begin{array}{c}\text { G-VAS- } \\
\text { A32 }\end{array}$ & 1.75 & $\begin{array}{c}0.2 \\
5\end{array}$ & 0 & no separation & 43.92 & 42.95 \\
\hline $\begin{array}{c}\text { G-V166A-1750- } \\
0750-411\end{array}$ & $\begin{array}{c}\text { G-VAS- } \\
\text { A33 }\end{array}$ & 1.75 & $\begin{array}{c}0.7 \\
5\end{array}$ & 3 & opaque & 39.44 & 42.41 \\
\hline
\end{tabular}

Syneresis and percent solids data for G-VNS 166B series.

\begin{tabular}{|c|c|c|c|c|c|c|c|}
\hline \multirow[b]{2}{*}{ Sample } & \multirow[b]{2}{*}{$\begin{array}{l}\text { Call } \\
\text { Name }\end{array}$} & \multirow{2}{*}{$\begin{array}{c}\% \\
\text { HEU } \\
\text { R }\end{array}$} & \multirow[b]{2}{*}{$\begin{array}{c}\% \\
\text { SURF }\end{array}$} & \multicolumn{2}{|c|}{ Syneresis } & \multirow{2}{*}{$\begin{array}{c}\% \\
\text { Solids } \\
\text { Top } \\
\text { Layer* }\end{array}$} & \multirow{2}{*}{$\begin{array}{c}\% \\
\text { Solids } \\
\text { Bot } \\
\text { Layer }\end{array}$} \\
\hline & & & & $\begin{array}{c}1 \text { week } \\
(\mathrm{mm})\end{array}$ & $\begin{array}{c}\text { Appearance of } \\
\text { Top Layer }\end{array}$ & & \\
\hline $\begin{array}{c}\text { G-V166B- } \\
\text { 0380-0000-405 }\end{array}$ & $\begin{array}{c}\text { G- } \\
\text { VNS- } \\
\text { B1 }\end{array}$ & 0.38 & 0.00 & 7 & clear & 0.72 & - \\
\hline $\begin{array}{c}\text { G-V166B- } \\
0380-0500-405\end{array}$ & $\begin{array}{c}\text { G- } \\
\text { VNS- } \\
\text { B2 }\end{array}$ & 0.38 & 0.51 & 6 & clear & 1.12 & - \\
\hline $\begin{array}{c}\text { G-V166B- } \\
0380-1000-405\end{array}$ & $\begin{array}{c}\text { G- } \\
\text { VNS- } \\
\text { B3 }\end{array}$ & 0.38 & 1.01 & 14 & $\begin{array}{l}\text { op/clear } \\
\text { (watery) }\end{array}$ & 3.83 & 54.89 \\
\hline $\begin{array}{c}\text { G-V166B- } \\
0380-1500-405\end{array}$ & $\begin{array}{c}\text { G- } \\
\text { VNS- } \\
\text { B4 }\end{array}$ & 0.38 & 1.52 & 4 & opaque & 39.21 & 44.69 \\
\hline $\begin{array}{c}\text { G-V166B- } \\
0380-2000-405\end{array}$ & $\begin{array}{c}\text { G- } \\
\text { VNS- } \\
\text { B5 }\end{array}$ & 0.38 & 2.05 & 6 & opaque & 39.15 & 45.27 \\
\hline $\begin{array}{c}\text { G-V166B- } \\
0740-0000-405\end{array}$ & $\begin{array}{c}\text { G- } \\
\text { VNS- } \\
\text { B6 }\end{array}$ & 0.74 & 0.00 & 13 & $\begin{array}{l}\text { op/clear } \\
\text { (watery) }\end{array}$ & 1.71 & - \\
\hline $\begin{array}{c}\text { G-V166B- } \\
\text { 0740-0500-405 }\end{array}$ & $\begin{array}{c}\text { G- } \\
\text { VNS- } \\
\text { B7 }\end{array}$ & 0.74 & 0.51 & 8 & $\begin{array}{l}\text { op/clear } \\
\text { (watery) }\end{array}$ & 4 & - \\
\hline $\begin{array}{c}\text { G-V166B- } \\
\text { 0740-1000-405 }\end{array}$ & $\begin{array}{c}\text { G- } \\
\text { VNS- } \\
\text { B8 }\end{array}$ & 0.74 & 1.01 & 6 & opaque & 39.29 & 44.68 \\
\hline $\begin{array}{c}\text { G-V166B- } \\
\text { 0740-1500-405 }\end{array}$ & $\begin{array}{c}\text { G- } \\
\text { VNS- } \\
\text { B9 }\end{array}$ & 0.74 & 1.52 & 4 & opaque & 38.23 & - \\
\hline $\begin{array}{c}\text { G-V166B- } \\
\text { 0740-2000-405 }\end{array}$ & $\begin{array}{c}\text { G- } \\
\text { VNS- } \\
\text { B10 }\end{array}$ & 0.74 & 2.00 & 5 & opaque & 35.71 & - \\
\hline $\begin{array}{c}\text { G-V166B- } \\
1240-0000-405\end{array}$ & $\begin{array}{c}\text { G- } \\
\text { VNS- } \\
\text { B11 }\end{array}$ & 1.24 & 0.00 & 3 & opaque & 41.79 & 44.04 \\
\hline G-V166B- & G- & 1.24 & 0.48 & 5 & opaque & 35.75 & 44.14 \\
\hline
\end{tabular}




\begin{tabular}{|c|c|c|c|c|c|c|c|}
\hline $1240-0500-405$ & $\begin{array}{l}\text { VNS- } \\
\text { B12 }\end{array}$ & & & & & & \\
\hline $\begin{array}{c}\text { G-V166B- } \\
1240-1000-405\end{array}$ & $\begin{array}{c}\text { G- } \\
\text { VNS- } \\
\text { B13 }\end{array}$ & 1.24 & 0.99 & 6 & opaque & 34.84 & - \\
\hline $\begin{array}{c}\text { G-V166B- } \\
1240-1500-405\end{array}$ & $\begin{array}{c}\text { G- } \\
\text { VNS- } \\
\text { B14 }\end{array}$ & 1.24 & 1.50 & 6 & opaque & - & - \\
\hline $\begin{array}{c}\text { G-V166B- } \\
1240-2000-405\end{array}$ & $\begin{array}{c}\text { G- } \\
\text { VNS- } \\
\text { B15 }\end{array}$ & 1.24 & 2.00 & 6 & opaque & - & - \\
\hline $\begin{array}{c}\text { G-V166B- } \\
1740-0000-405\end{array}$ & $\begin{array}{c}\text { G- } \\
\text { VNS- } \\
\text { B16 } \\
\end{array}$ & 1.74 & 0.00 & 0 & no separation & 41.13 & 42.31 \\
\hline $\begin{array}{c}\text { G-V166B- } \\
1740-0500-405\end{array}$ & $\begin{array}{c}\text { G- } \\
\text { VNS- } \\
\text { B17 } \\
\end{array}$ & 1.74 & 0.48 & 0 & no separation & 37.15 & 41.93 \\
\hline $\begin{array}{c}\text { G-V166B- } \\
1740-1000-405\end{array}$ & $\begin{array}{c}\text { G- } \\
\text { VNS- } \\
\text { B18 }\end{array}$ & 1.74 & 0.99 & 6 & opaque & 35.11 & 45.22 \\
\hline $\begin{array}{c}\text { G-V166B- } \\
1740-1500-405\end{array}$ & $\begin{array}{c}\text { G- } \\
\text { VNS- } \\
\text { B19 } \\
\end{array}$ & 1.74 & 1.50 & 8 & opaque & - & - \\
\hline $\begin{array}{c}\text { G-V166B- } \\
\text { 1740-2000-405 }\end{array}$ & $\begin{array}{c}\text { G- } \\
\text { VNS- } \\
\text { B20 }\end{array}$ & 1.74 & 1.98 & 9 & opaque & - & - \\
\hline $\begin{array}{c}\text { G-V166B- } \\
2240-0000-405\end{array}$ & $\begin{array}{c}\text { G- } \\
\text { VNS- } \\
\text { B21 }\end{array}$ & 2.24 & 0.00 & 0 & no separation & 41.2 & 41.97 \\
\hline $\begin{array}{c}\text { G-V166B- } \\
2240-0500-405\end{array}$ & $\begin{array}{c}\text { G- } \\
\text { VNS- } \\
\text { B22 } \\
\end{array}$ & 2.24 & 0.48 & 0 & no separation & 36.33 & 43.85 \\
\hline $\begin{array}{c}\text { G-V166B- } \\
2240-1000-405\end{array}$ & $\begin{array}{c}\text { G- } \\
\text { VNS- } \\
\text { B23 }\end{array}$ & 2.24 & 0.99 & 6 & opaque & 38.28 & - \\
\hline $\begin{array}{c}\text { G-V166B- } \\
2240-1500-405\end{array}$ & $\begin{array}{c}\text { G- } \\
\text { VNS- } \\
\text { B24 } \\
\end{array}$ & 2.24 & 1.52 & 7 & opaque & - & - \\
\hline $\begin{array}{c}\text { G-V166B- } \\
2240-2000-405\end{array}$ & $\begin{array}{c}\text { G- } \\
\text { VNS- } \\
\text { B25 }\end{array}$ & 2.24 & 2.03 & 8 & opaque & - & - \\
\hline
\end{tabular}

Syneresis and percent solids data for the G-VAS 166B series.

\begin{tabular}{|c|c|c|c|c|c|c|c|}
\hline \multirow[b]{2}{*}{ Sample } & \multirow[b]{2}{*}{$\begin{array}{l}\text { Call } \\
\text { Name }\end{array}$} & \multirow[b]{2}{*}{$\begin{array}{c}\% \\
\text { HEUR }\end{array}$} & \multirow[b]{2}{*}{$\begin{array}{c}\% \\
\text { SURF }\end{array}$} & \multicolumn{2}{|c|}{ Syneresis } & \multirow{2}{*}{$\begin{array}{c}\% \\
\text { Solids } \\
\text { Top } \\
\text { Layer* }\end{array}$} & \multirow{2}{*}{$\begin{array}{c}\% \\
\text { Solids } \\
\text { Bot } \\
\text { Layer }\end{array}$} \\
\hline & & & & $\begin{array}{c}1 \text { week } \\
(\mathrm{mm})\end{array}$ & $\begin{array}{l}\text { Appearance } \\
\text { of Top Layer }\end{array}$ & & \\
\hline $\begin{array}{c}\text { G-V166B- } \\
0390-0000- \\
411\end{array}$ & $\begin{array}{c}\text { G-VAS- } \\
\text { B1 }\end{array}$ & 0.39 & 0.00 & 7 & clear & 0.8 & - \\
\hline
\end{tabular}




\begin{tabular}{|c|c|c|c|c|c|c|c|}
\hline $\begin{array}{c}\text { G-V166B- } \\
0390-0375- \\
411\end{array}$ & $\begin{array}{c}\text { G-VAS- } \\
\text { B2 }\end{array}$ & 0.39 & 0.38 & 8 & clear & 1.07 & - \\
\hline $\begin{array}{c}\text { G-V166B- } \\
0390-0750- \\
411\end{array}$ & $\begin{array}{c}\text { G-VAS- } \\
\text { B3 }\end{array}$ & 0.39 & 0.76 & 4 & opaque & 33.47 & - \\
\hline $\begin{array}{c}\text { G-V166B- } \\
0390-1125- \\
411\end{array}$ & $\begin{array}{c}\text { G-VAS- } \\
\text { B4 }\end{array}$ & 0.39 & 1.14 & 9 & opaque & 31.12 & 50.62 \\
\hline $\begin{array}{c}\text { G-V166B- } \\
0390-0516- \\
411\end{array}$ & $\begin{array}{c}\text { G-VAS- } \\
\text { B5 }\end{array}$ & 0.39 & 0.52 & 16 & clear/opaque & 2.58 & - \\
\hline $\begin{array}{c}\text { G-V166B- } \\
0750-0000- \\
411\end{array}$ & $\begin{array}{c}\text { G-VAS- } \\
\text { B6 }\end{array}$ & 0.75 & 0.00 & 11 & clear & 0.94 & - \\
\hline $\begin{array}{c}\text { G-V166B- } \\
0750-0375- \\
411\end{array}$ & $\begin{array}{c}\text { G-VAS- } \\
\text { B7 }\end{array}$ & 0.75 & 0.41 & 3 & clear/opaque & 20.22 & 47.1 \\
\hline $\begin{array}{c}\text { G-V166B- } \\
0750-0750- \\
411\end{array}$ & $\begin{array}{c}\text { G-VAS- } \\
\text { B8 }\end{array}$ & 0.75 & 0.76 & 4 & opaque & 41.87 & 43.09 \\
\hline $\begin{array}{c}\text { G-V166B- } \\
0750-1125- \\
411\end{array}$ & $\begin{array}{c}\text { G-VAS- } \\
\text { B9 }\end{array}$ & 0.75 & 1.10 & 6 & opaque & 39.61 & - \\
\hline $\begin{array}{c}\text { G-V166B- } \\
0750-0516- \\
411\end{array}$ & $\begin{array}{l}\text { G-VAS- } \\
\text { B10 }\end{array}$ & 0.75 & 0.52 & 4 & opaque & 43.81 & - \\
\hline $\begin{array}{c}\text { G-V166B- } \\
\text { 1250-0000- } \\
411\end{array}$ & $\begin{array}{c}\text { G-VAS- } \\
\text { B11 }\end{array}$ & 1.25 & 0.00 & 4 & opaque & 41.25 & - \\
\hline $\begin{array}{c}\text { G-V166B- } \\
1250-0375- \\
411\end{array}$ & $\begin{array}{c}\text { G-VAS- } \\
\text { B12 }\end{array}$ & 1.25 & 0.41 & 4 & opaque & 40.83 & - \\
\hline $\begin{array}{c}\text { G-V166B- } \\
1250-0750- \\
411\end{array}$ & $\begin{array}{l}\text { G-VAS- } \\
\text { B13 }\end{array}$ & 1.25 & 0.76 & 4 & opaque & - & - \\
\hline $\begin{array}{c}\text { G-V166B- } \\
1250-1125- \\
411\end{array}$ & $\begin{array}{l}\text { G-VAS- } \\
\text { B14 }\end{array}$ & 1.25 & 1.07 & 4 & opaque & - & - \\
\hline $\begin{array}{c}\text { G-V166B- } \\
\text { 1250-0516- } \\
411\end{array}$ & $\begin{array}{l}\text { G-VAS- } \\
\text { B15 }\end{array}$ & 1.25 & 0.52 & 4 & opaque & - & - \\
\hline $\begin{array}{c}\text { G-V166B- } \\
1750-0000- \\
411 \\
\end{array}$ & $\begin{array}{l}\text { G-VAS- } \\
\text { B16 }\end{array}$ & 1.75 & 0.00 & 0 & $\begin{array}{c}\text { no } \\
\text { separation }\end{array}$ & 42.65 & 42.63 \\
\hline $\begin{array}{c}\text { G-V166B- } \\
1750-0375- \\
411\end{array}$ & $\begin{array}{c}\text { G-VAS- } \\
\text { B17 }\end{array}$ & 1.75 & 0.34 & 5 & opaque & 40.24 & - \\
\hline $\begin{array}{c}\text { G-V166B- } \\
\text { 1750-0750- }\end{array}$ & $\begin{array}{c}\text { G-VAS- } \\
\text { B18 }\end{array}$ & 1.75 & 0.72 & 5 & opaque & - & - \\
\hline
\end{tabular}




\begin{tabular}{|c|c|c|c|c|c|c|c|}
\hline 411 & & & & & & & \\
\hline $\begin{array}{c}\text { G-V166B- } \\
\text { 1750-1125- } \\
411\end{array}$ & $\begin{array}{c}\text { G-VAS- } \\
\text { B19 }\end{array}$ & 1.75 & 1.10 & 5 & opaque & - & - \\
\hline $\begin{array}{c}\text { G-V166B- } \\
\text { 1750-0516- } \\
411\end{array}$ & $\begin{array}{c}\text { G-VAS- } \\
\text { B20 }\end{array}$ & 1.75 & 0.52 & 5 & opaque & - & - \\
\hline $\begin{array}{c}\text { G-V166B- } \\
2250-0000- \\
411\end{array}$ & $\begin{array}{c}\text { G-VAS- } \\
\text { B21 }\end{array}$ & 2.25 & 0.00 & 0 & $\begin{array}{c}\text { no } \\
\text { separation }\end{array}$ & 42.84 & 42.89 \\
\hline $\begin{array}{c}\text { G-V166B- } \\
2250-0375- \\
411\end{array}$ & $\begin{array}{c}\text { G-VAS- } \\
\text { B22 }\end{array}$ & 2.25 & 0.34 & 0 & $\begin{array}{c}\text { no } \\
\text { separation }\end{array}$ & 40.23 & 42.44 \\
\hline $\begin{array}{c}\text { G-V166B- } \\
2250-0750- \\
411\end{array}$ & $\begin{array}{c}\text { G-VAS- } \\
\text { B23 }\end{array}$ & 2.25 & 0.76 & 4 & opaque & 39.5 & - \\
\hline $\begin{array}{c}\text { G-V166B- } \\
2250-1125- \\
411\end{array}$ & $\begin{array}{c}\text { G-VAS- } \\
\text { B24 }\end{array}$ & 2.25 & 1.14 & 4 & opaque & - & - \\
\hline $\begin{array}{c}\text { G-V166B- } \\
2250-0516- \\
411\end{array}$ & $\begin{array}{c}\text { G-VAS- } \\
\text { B25 }\end{array}$ & 2.25 & 0.55 & 5 & opaque & - & - \\
\hline
\end{tabular}


16. Appendix D: Multivariate Analysis

G-VNS 166A series multivariate analysis.

\begin{tabular}{|c|c|c|c|c|c|c|c|c|c|c|}
\hline & $\begin{array}{l}\% \\
\text { HEUR }\end{array}$ & $\begin{array}{l}\% \\
\text { SURF }\end{array}$ & $\begin{array}{l}\mathrm{KU} \\
(\mathrm{o} / \mathrm{n})\end{array}$ & $\begin{array}{l}20 \\
\text { Gloss }\end{array}$ & $\begin{array}{l}60 \\
\text { Gloss }\end{array}$ & $\begin{array}{l}85 \\
\text { Gloss }\end{array}$ & $\begin{array}{l}\% \\
\text { Solids } \\
\text { Top }\end{array}$ & IRBS & $\begin{array}{l}\text { Cond. } \\
\text { Mixed }\end{array}$ & $\begin{array}{l}\text { Floc } \\
\#\end{array}$ \\
\hline $\begin{array}{l}\% \\
\text { HEUR }\end{array}$ & 1.000 & $\begin{array}{l}- \\
0.039\end{array}$ & $\begin{array}{l}- \\
0.303\end{array}$ & 0.673 & 0.643 & 0.728 & 0.419 & $\begin{array}{l}- \\
0.814\end{array}$ & $\begin{array}{l}- \\
0.649\end{array}$ & 0.169 \\
\hline $\begin{array}{l}\% \\
\text { SURF }\end{array}$ & -0.039 & 1.000 & $\begin{array}{l}- \\
0.907\end{array}$ & $\begin{array}{l}- \\
0.500\end{array}$ & $\begin{array}{l}- \\
0.378\end{array}$ & $\begin{array}{l}- \\
0.094\end{array}$ & 0.080 & 0.358 & $\begin{array}{l}- \\
0.565\end{array}$ & 0.721 \\
\hline $\begin{array}{l}\mathrm{KU} \\
(\mathrm{o} / \mathrm{n})\end{array}$ & -0.303 & $\begin{array}{l}- \\
0.907\end{array}$ & 1.000 & 0.194 & 0.119 & $\begin{array}{l}- \\
0.173\end{array}$ & $\begin{array}{l}- \\
0.278\end{array}$ & 0.015 & 0.731 & $\begin{array}{l}- \\
0.765\end{array}$ \\
\hline $\begin{array}{l}20 \\
\text { Gloss }\end{array}$ & 0.673 & $\begin{array}{l}- \\
0.500\end{array}$ & 0.194 & 1.000 & 0.956 & 0.819 & 0.506 & $\begin{array}{l}- \\
0.856\end{array}$ & $\begin{array}{l}- \\
0.026\end{array}$ & $\begin{array}{l}- \\
0.057\end{array}$ \\
\hline $\begin{array}{l}60 \\
\text { Gloss }\end{array}$ & 0.643 & $\begin{array}{l}- \\
0.378\end{array}$ & 0.119 & 0.956 & 1.000 & 0.902 & 0.625 & $\begin{array}{l}- \\
0.741\end{array}$ & $\begin{array}{l}- \\
0.086\end{array}$ & 0.042 \\
\hline $\begin{array}{l}85 \\
\text { Gloss }\end{array}$ & 0.728 & $\begin{array}{l}- \\
0.094\end{array}$ & $\begin{array}{l}- \\
0.173\end{array}$ & 0.819 & 0.902 & 1.000 & 0.562 & $\begin{array}{l}- \\
0.710\end{array}$ & $\begin{array}{l}- \\
0.306\end{array}$ & 0.242 \\
\hline $\begin{array}{l}\text { \% } \\
\text { Solids } \\
\text { Top } \\
\text { Layer }\end{array}$ & 0.419 & 0.080 & $\begin{array}{l}- \\
0.278\end{array}$ & 0.506 & 0.625 & 0.562 & 1.000 & $\begin{array}{l}- \\
0.366\end{array}$ & $\begin{array}{l}- \\
0.364\end{array}$ & 0.326 \\
\hline IRBS & -0.814 & 0.358 & 0.015 & $\begin{array}{l}- \\
0.856\end{array}$ & $\begin{array}{l}- \\
0.741\end{array}$ & $\begin{array}{l}- \\
0.710\end{array}$ & $\begin{array}{l}- \\
0.366\end{array}$ & 1.000 & 0.280 & 0.007 \\
\hline $\begin{array}{l}\text { Cond. } \\
\text { Mixed }\end{array}$ & -0.649 & $\begin{array}{l}- \\
0.565\end{array}$ & 0.731 & $\begin{array}{l}- \\
0.026\end{array}$ & $\begin{array}{l}- \\
0.086\end{array}$ & $\begin{array}{l}- \\
0.306\end{array}$ & $\begin{array}{l}- \\
0.364\end{array}$ & 0.280 & 1.000 & $\begin{array}{l}- \\
0.381\end{array}$ \\
\hline
\end{tabular}


\begin{tabular}{|l|l|l|l|l|l|l|l|l|l|l|} 
Floc \# & 0.169 & 0.721 & 0.765 & 0.057 & 0.042 & 0.242 & 0.326 & 0.007 & 0.381 & 1.000 \\
\hline
\end{tabular}

G-VAS $166 \mathrm{~A}$ series multivariate analysis.

\begin{tabular}{|c|c|c|c|c|c|c|c|c|c|c|}
\hline & $\begin{array}{c}\% \\
\text { HEUR }\end{array}$ & $\begin{array}{c}\% \\
\text { SURF }\end{array}$ & $\begin{array}{l}\text { U } 24 \\
\mathrm{hr}\end{array}$ & $\begin{array}{c}\text { Gloss } \\
20 \\
\end{array}$ & $\begin{array}{c}\text { Gloss } \\
60\end{array}$ & $\begin{array}{c}\text { Gloss } \\
85\end{array}$ & $\begin{array}{c}\% \\
\text { Solids } \\
\text { Top }\end{array}$ & IRBS & Floc \# & Cond. \\
\hline $\begin{array}{c}\% \\
\text { HEUR }\end{array}$ & 1 & 508 & 0001 & 0322 & 0483 & .0613 & 4174 & 7181 & 2893 & .5183 \\
\hline $\begin{array}{c}\% \\
\text { SURF }\end{array}$ & 508 & 1 & $8 \overline{8973}$ & 483 & 5154 & 7336 & 0489 & 1107 & 7152 & 7767 \\
\hline $\begin{array}{c}\mathrm{KU} 24 \\
\mathrm{hr}\end{array}$ & & 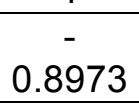 & 1 & 3 & 25 & 09 & 218 & 237 & 65 & 7316 \\
\hline $\begin{array}{c}\text { Gloss } \\
20\end{array}$ & 0322 & .483 & 3273 & 1 & 9631 & 0.832 & 4108 & 4319 & -0.107 & .2692 \\
\hline $\begin{array}{c}\text { Gloss } \\
60\end{array}$ & 0483 & - & 825 & 9631 & 1 & 8702 & 1186 & -0.313 & $-\overline{-}$ & $\begin{array}{c}- \\
0.2717\end{array}$ \\
\hline $\begin{array}{c}\text { Gloss } \\
85\end{array}$ & $-\overline{613}$ & 336 & 409 & 32 & 702 & 1 & 1322 & & $-\overline{3}$. & $\begin{array}{c}- \\
0.4835\end{array}$ \\
\hline $\begin{array}{c}\% \\
\text { Solids } \\
\text { Top }\end{array}$ & 174 & 489 & $-\quad 218$ & 4108 & 1186 & 0.1322 & 1 & 0.3692 & .5775 & 0.1018 \\
\hline IRBS & 181 & 107 & 237 & 1319 & 313 & 2259 & 3692 & 1 & 1564 & .3837 \\
\hline $\begin{array}{c}\text { Floc } \\
\#\end{array}$ & 2893 & 7152 & 7665 & -0.107 & 0.1938 & $\begin{array}{l} \\
0.3329\end{array}$ & 0.5775 & $\begin{array}{l} \\
0.1564\end{array}$ & 1 & 0.4401 \\
\hline Conc & 183 & 0.7767 & 0.7316 & 0.2692 & 0.2717 & 0.4835 & 0.1018 & 0.3837 & 0.4401 & 1 \\
\hline
\end{tabular}

Multivariate analysis for the G-VNS 166B series.

\begin{tabular}{|c|c|c|c|c|c|c|c|c|c|}
\hline & $\begin{array}{c}\% \\
\text { HEUR }\end{array}$ & $\begin{array}{c}\% \\
\text { SURF }\end{array}$ & $\begin{array}{c}\text { KU } 24 \\
\text { hr }\end{array}$ & $\begin{array}{c}\text { Gloss } \\
20\end{array}$ & $\begin{array}{c}\text { Gloss } \\
60\end{array}$ & $\begin{array}{c}\text { Gloss } \\
85\end{array}$ & $\begin{array}{c}\% \\
\text { Solids } \\
\text { TL }\end{array}$ & IRBS & Floc \# \\
\hline $\begin{array}{c}\% \\
\text { HEUR } \\
\%\end{array}$ & 1.0000 & -0.0000 & -0.4569 & 0.3508 & 0.2912 & 0.6366 & 0.2153 & -0.5816 & 0.3368 \\
\hline $\begin{array}{c}\text { SURF } \\
\text { KU } 24 \\
\text { hr }\end{array}$ & -0.0000 & 1.0000 & -0.8655 & -0.8239 & -0.8506 & -0.6030 & 0.0102 & 0.5012 & 0.7280 \\
\hline $\begin{array}{c}\text { Gloss } \\
20\end{array}$ & 0.3508 & -0.8239 & 0.5656 & 1.0000 & 0.9871 & 0.9040 & 0.0170 & -0.7314 & -0.5374 \\
\hline $\begin{array}{c}\text { Gloss } \\
60\end{array}$ & 0.2912 & -0.8506 & 0.6408 & 0.9871 & 1.0000 & 0.8691 & -0.1146 & -0.7042 & -0.6192 \\
\hline
\end{tabular}




\begin{tabular}{|c|c|c|c|c|c|c|c|c|c|}
\hline $\begin{array}{c}\text { Gloss } \\
85\end{array}$ & 0.6366 & -0.6030 & 0.2391 & 0.9040 & 0.8691 & 1.0000 & 0.0805 & -0.7152 & -0.2726 \\
\hline $\begin{array}{c}\text { Solids } \\
\text { TL }\end{array}$ & 0.2153 & 0.0102 & -0.2851 & 0.0170 & -0.1146 & 0.0805 & 1.0000 & -0.1293 & 0.5179 \\
\hline IRBS & -0.5816 & 0.5012 & -0.1843 & -0.7314 & -0.7042 & -0.7152 & -0.1293 & 1.0000 & 0.1130 \\
\hline Floc \# & 0.3368 & 0.7280 & -0.8449 & -0.5374 & -0.6192 & -0.2726 & 0.5179 & 0.1130 & 1.0000 \\
\hline
\end{tabular}

Multivariate analysis for the G-VAS 166B series.

\begin{tabular}{|c|c|c|c|c|c|c|c|c|}
\hline & $\%$ HEUR & $\%$ SURF & KU $24 \mathrm{hr}$ & Gloss 20 & Gloss 60 & Gloss 85 & IRBS & Floc \# \\
\hline \% HEUR & 1.0000 & -0.0097 & -0.1206 & 0.3534 & 0.0824 & 0.5345 & -0.6152 & 0.4303 \\
\hline \% SURF & -0.0097 & 1.0000 & -0.8658 & -0.3928 & -0.6785 & 0.0655 & 0.6740 & 0.6614 \\
\hline KU 24 hr & -0.1206 & -0.8658 & 1.0000 & 0.1972 & 0.5717 & -0.2694 & -0.4602 & -0.7483 \\
\hline Gloss 20 & 0.3534 & -0.3928 & 0.1972 & 1.0000 & 0.8658 & 0.6227 & -0.4806 & -0.0488 \\
\hline Gloss 60 & 0.0824 & -0.6785 & 0.5717 & 0.8658 & 1.0000 & 0.2791 & -0.5410 & -0.5048 \\
\hline Gloss 85 & 0.5345 & 0.0655 & -0.2694 & 0.6227 & 0.2791 & 1.0000 & -0.1967 & 0.4268 \\
\hline IRBS & -0.6152 & 0.6740 & -0.4602 & -0.4806 & -0.5410 & -0.1967 & 1.0000 & 0.2166 \\
\hline Floc \# & 0.4303 & 0.6614 & -0.7483 & -0.0488 & -0.5048 & 0.4268 & 0.2166 & 1.0000 \\
\hline
\end{tabular}

